\title{
Exploring high-end climate change scenarios for flood protection of the Netherlands
}

Pier Vellinga, Caroline Katsman, Andreas Sterl, Jules Beersma, Wilco Hazeleger, John Church, Robert Kopp, Dick Kroon, Michael Oppenheimer, Hans-Peter Plag, Stefan Rahmstorf, Jason Lowe, Jeff Ridley, Hans von Storch, David Vaughan, Roderik van de Wal, Ralf Weisse, Jaap Kwadijk, Rita Lammersen and Natasha Marinova 
KNMI scientific report = wetenschappelijk rapport; WR 2009-05

De Bilt, 2009

PO BOx 201

$3730 \mathrm{AE}$ De Bilt

Wilhelminalaan 10

De Bilt

The Netherlands

http://www.knmi.nl

Telephone +31(0)30-22069 1

Telefax +31 (0) 30-22 1 0407 


\section{Exploring high-end climate}

\section{change scenarios for flood}

\section{protection of the Netherlands}

\section{International Scientific Assessment}

carried out at request of the Delta Committee

The Netherlands, September 2008

Pier Vellinga, Caroline Katsman, Andreas Sterl, Jules Beersma, Wilco Hazeleger, John Church, Robert Kopp, Dick Kroon, Michael Oppenheimer,

Hans-Peter Plag, Stefan Rahmstorf, Jason Lowe, Jeff Ridley, Hans von Storch, David Vaughan, Roderik van de Wal, Ralf Weisse, Jaap Kwadijk, Rita Lammersen, Natasha Marinova

This scientific report is a joint publication by

Wageningen University and Research Centre / Alterra and the Royal Netherlands Meteorological Institute (KNMI) 
$-2-$ 


\section{Author Team}

\section{Convening author/ editor}

Pier Vellinga ${ }^{1}$

\section{Introduction and Main findings}

Pier Vellinga ${ }^{1}$, Natasha Marinova ${ }^{1}$, Wilco Hazeleger ${ }^{2}$, Caroline Katsman $^{2}$, Andreas Sterl $^{2}$, Jules Beersma ${ }^{2}$

\section{Chapter I - High-end projection for local sea level rise along the Dutch} coast in 2100 and 2200

Caroline Katsman ${ }^{2}$, John Church ${ }^{3}$, Robert Kopp ${ }^{4}$, Dick Kroon ${ }^{56}$, Michael

Oppenheimer ${ }^{4}$, Hans-Peter Plag ${ }^{7}$, Stefan Rahmstorf ${ }^{8}$, Jeff Ridley ${ }^{9}$, Hans von Storch $^{10}$, David Vaughan ${ }^{11}$, Roderik van der Wal ${ }^{12}$

Thanks to: Catia Domingues ${ }^{3}$, Sybren Drijfhout2, Wilco Hazeleger ${ }^{2}$, Simon Jung ${ }^{5}$, Simon Tett $^{5}$, Bert Vermeersen ${ }^{13}$, Neil White ${ }^{3}$

\section{Chapter II - Winds and storm surges along the Dutch coast} Andreas Sterl $^{2}$, Ralf Weisse ${ }^{9}$, Jason Lowe ${ }^{8}$, Hans von Storch ${ }^{9}$

Thanks to: Hans de Vries ${ }^{2}$, Henk van den Brink ${ }^{2}$, Reindert Haarsma ${ }^{2}$, Erik van Meijgaard $^{2}$

\section{Chapter III - River Rhine discharge}

Jules Beersma ${ }^{2}$, Jaap Kwadijk ${ }^{14}$ and Rita Lammersen ${ }^{15}$

Thanks to: Adri Buishand ${ }^{2}$, Hendrik Buiteveld ${ }^{14}$, Alexander Bakker ${ }^{2}$, Albert Klein Tank $^{2}$, Nick Raynard ${ }^{16}$

\section{Addendum - Sea level rise in foreign policy documents}

Natasha Marinova ${ }^{1}$

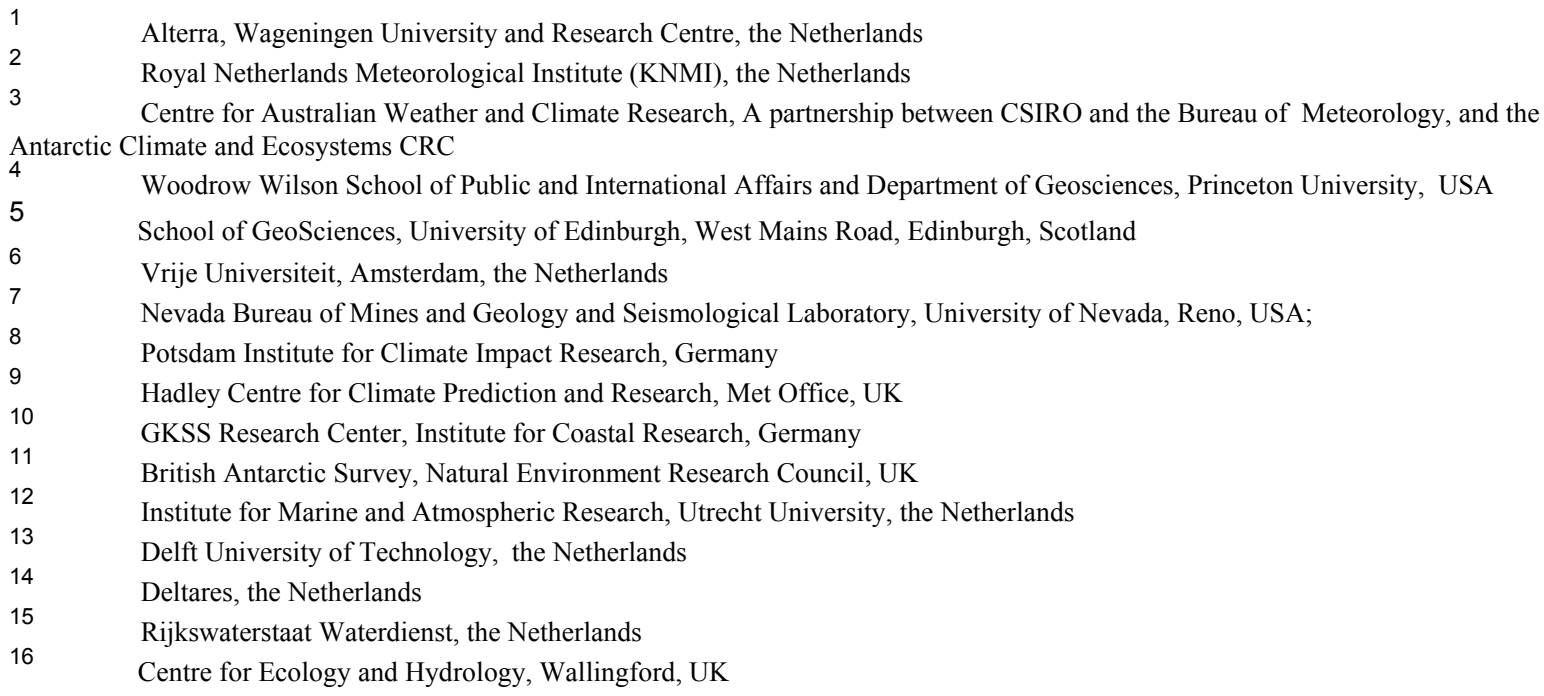


$-4-$ 


\section{Table of Contents}

Synthesis of the main findings ................................................................ 13

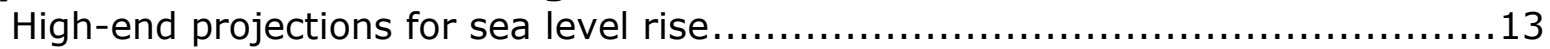

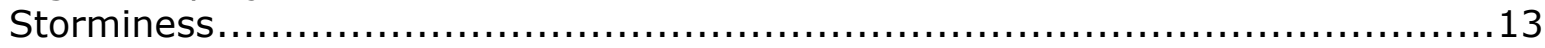

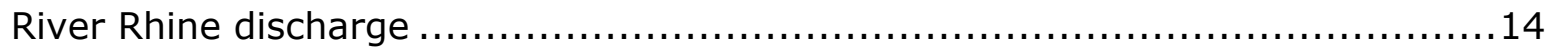

CHAPTER I - High-end projection for local sea level rise along the Dutch

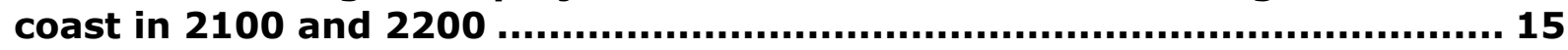

1. Introduction ....................................................................................... 15

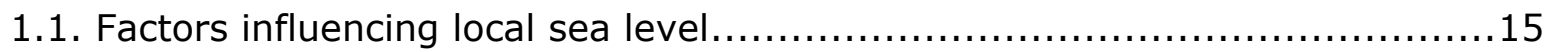

1.2. Uncertainties involved in projecting future local sea level......................16

2. Sea level rise in the twenty-first century ........................................... 17

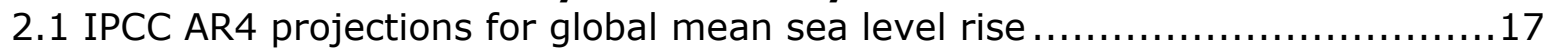

2.2 High-end contributions to global mean sea level rise ..............................18

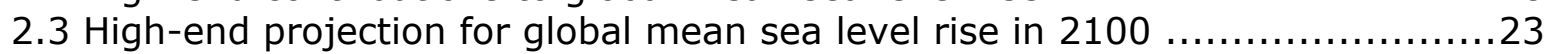

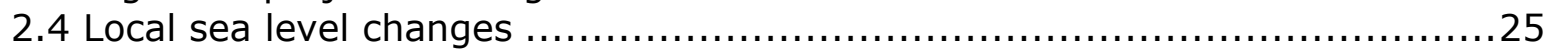

2.5 High-end projection for sea level rise along the Dutch coast in $2100 \ldots \ldots \ldots \ldots .28$

3. Sea level rise in the twenty-second century ....................................... 30

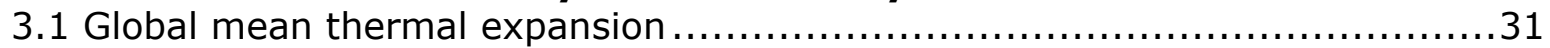

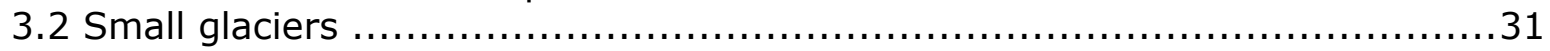

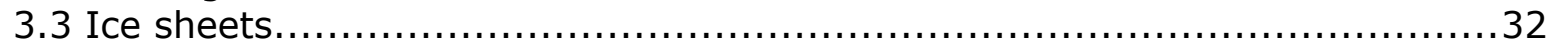

3.4 Plausible high-end scenario for global mean sea level rise for $2200 \ldots \ldots \ldots \ldots . .33$

3.5 Plausible high-end scenario for sea level rise at the Dutch coast for $2200 \ldots .34$

4. Conclusions and recommendations................................................... 35

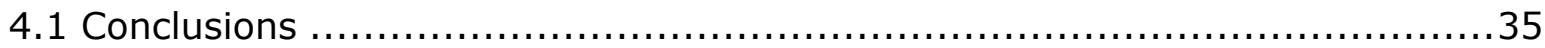

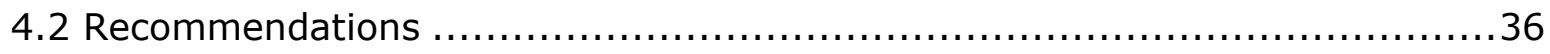

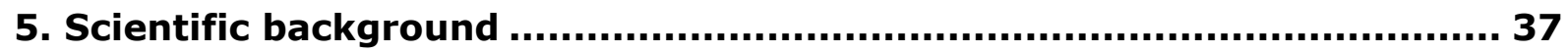

5.1 Observed local sea level changes along the Dutch coast ......................... 37

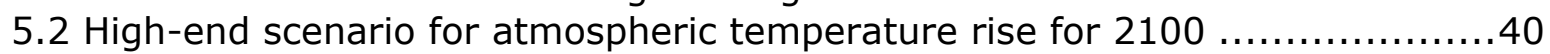

5.3 Global mean thermal expansion ................................................... 40

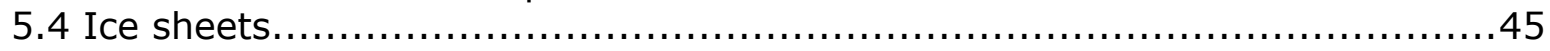

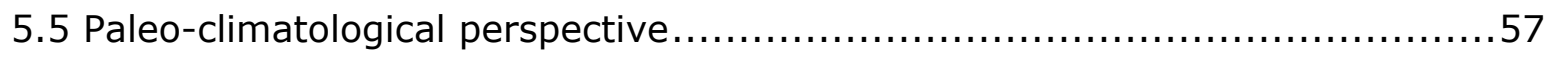

Appendix I-a: Thermosteric sea level sensitivity ........................................65

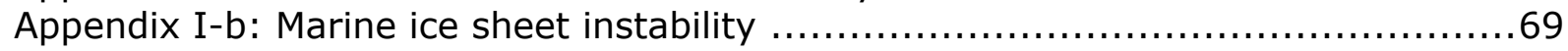

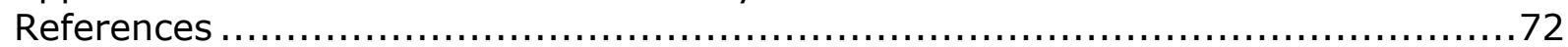

CHAPTER II - Winds and storm surges along the Dutch coast ................... 82

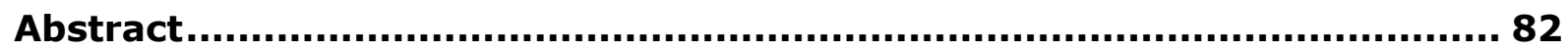

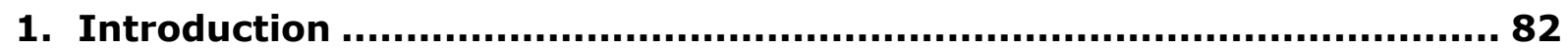

2. Past and future changes of near-surface marine wind fields ................. 83 


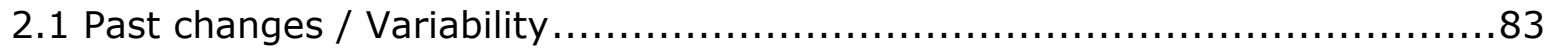

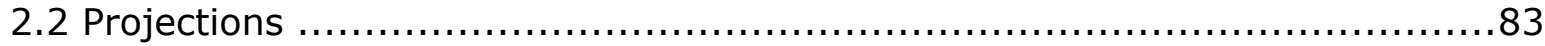

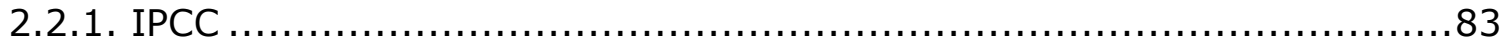

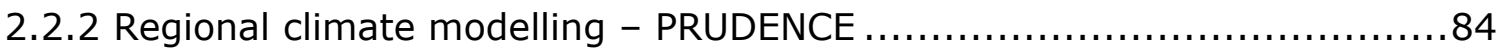

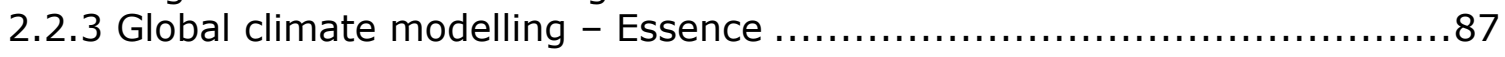

3. Projected changes of local storm surges ............................................ 90

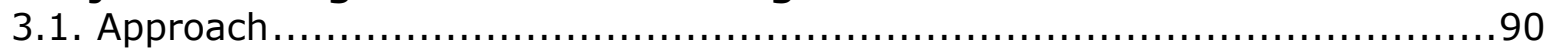

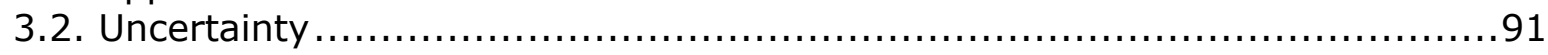

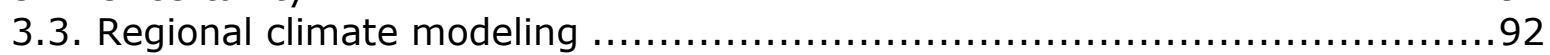

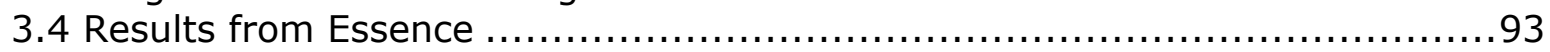

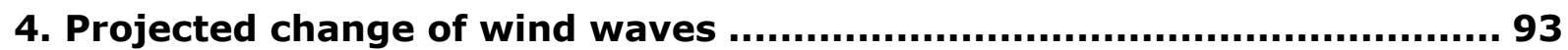

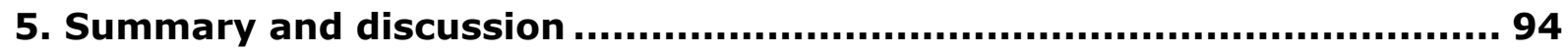

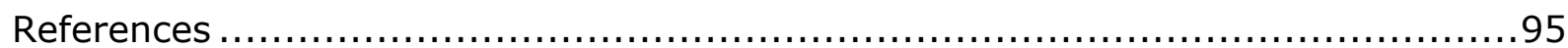

CHAPTER III - Effects of climate change on the Rhine discharges............ 99

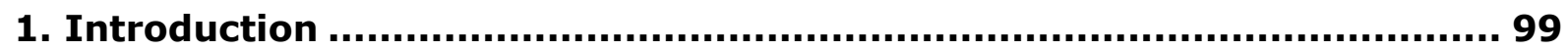

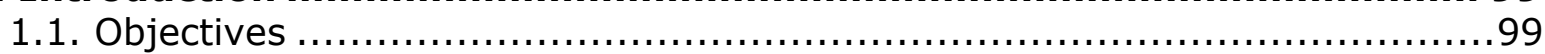

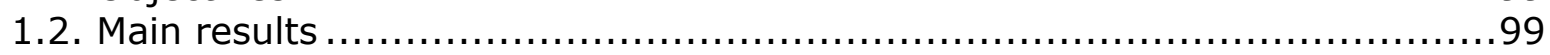

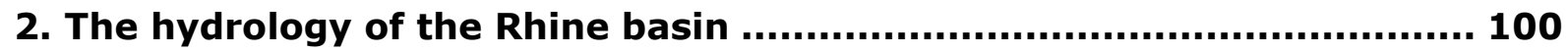

3. Methods used to assess future discharge changes of the River Rhine . 101

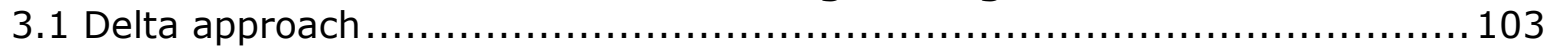

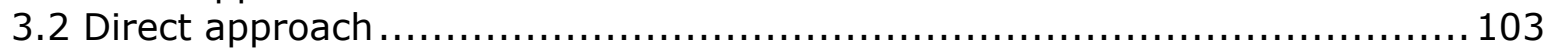

3.3 Approaches specifically applied to assess extreme flood events ................104

4. Estimates of future Rhine discharge ............................................. 104

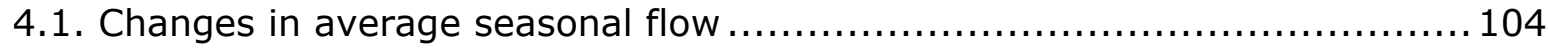

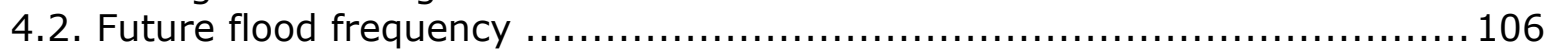

4.3. Changes in the 1250 -year discharge based on KNMI'06 climate scenarios.. 106

4.4. Changes in the 1250-year discharge based on direct approach ...............107

4.5. Estimated range of the future 1250 -year discharge and uncertainty .......... 108

4.6. Assessing the maximum flow arriving at the Netherlands $\ldots \ldots \ldots \ldots \ldots \ldots \ldots \ldots \ldots$

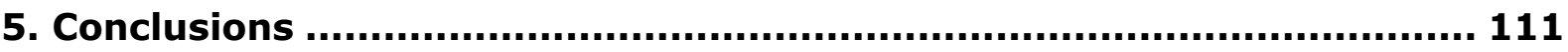

Appendix III-a Future Rhine discharge as a result of climate change $\ldots \ldots \ldots \ldots \ldots \ldots 113$

Appendix III-b: Effects of flooding in Germany upon the peak discharge at Lobith 131

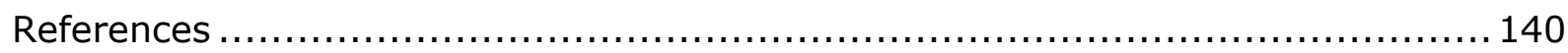

Addendum - Sea level rise in foreign policy documents ....................... 143 


\section{Abstract}

This international scientific assessment has been carried out at the request of the Dutch Delta Committee. The Committee requested that the assessment explore the high-end climate change scenarios for flood protection of the Netherlands. It is a state-of-the art scientific assessment of the upper bound values and longer term projections (for sea level rise up to 2200) of climate induced sea level rise, changing storm surge conditions and peak discharge of river Rhine. It comprises a review of recent studies, model projections and expert opinions of more than 20 leading climate scientists from different countries around the North Sea, Australia and the USA. Although building on the previous IPCC AR4 (2007) and KNMI (2006) assessments, this report deliberately explores low probability/high impact scenarios, which will pose significant threats to the safety of people and infrastructure and capital invested below sea level. According to its high-end estimates global mean sea level may rise in the range of $0.55-1.10 \mathrm{~m}$ in 2100 and $1.5-3.5 \mathrm{~m}$ in 2200, when higher temperature rise scenarios (up to $6{ }^{\circ} \mathrm{C}$ by 2100) and increased ice discharge from Antarctica are considered. This would correspond with local sea levels along the coast of the Netherlands of up to maximally $1.20 \mathrm{~m}$ in 2100 and $4 \mathrm{~m}$ in 2200 . An increase in peak discharge of river Rhine of 3 to $19 \%$ for 2050 and 6 to $38 \%$ for 2100 is foreseen. The storm regime along the Dutch North Sea coast in terms of maximum surge level will probably not change significantly in this extreme climate change frame. 
$-8-$ 


\section{Introduction}

This international scientific assessment has been carried out at the request of the Dutch Delta Committee. The Committee asked that the assessment explore the high-end climate change scenarios for flood protection of the Netherlands. It is a state-of-the-art scientific evaluation of the upper-bound values and longer-term projections (for sea level rise up to 2200) of climate-induced sea level rise, changing storm surge conditions, and peak discharge of the river Rhine. The international scientific assessment was commissioned by the Delta Committee to Alterra/Wageningen University to be conducted in close cooperation with the Royal Netherlands Meteorological Institute (KNMI). It combines a review of recent studies, model projections and expert opinions. The fundamental task of the international team of scientists has been to explore the upper bound of the expected changes and to develop low-probability/high-impact scenarios for the Netherlands for the years 2050, 2100, and 2200.

Sea level rise, changing storm frequency and intensity, and increased river discharge resulting from climate change pose a particular threat to low-lying countries like the Netherlands and create many new challenges for them. The Netherlands is home to about 16.5 million people, 9 million of whom live in the low-lying area, situated between the North Sea and river dikes below current sea level. This area, which comprises sixty percent of the territory of the Netherlands, also hosts intensive economic activity, including one of the biggest ports in the world (Rotterdam) and the international financial and cultural centre around Amsterdam (including Schiphol airport). Approximately $65 \%$ of the Dutch GDP is generated there (Ministerie van Verkeer en Waterstaat, 2006). The country is thus highly vulnerable to a substantial rise of the water heights in the rivers and alongside the North Sea coast.

After the dramatic flooding of 1953 , when 1,835 people lost their lives, the Netherlands introduced the strictest norms for flood defense in the world by law. According to these norms, the dikes have to be able to protect the low-lying Dutch regions from a flood event with a probability of 1 in 10,000 per year. The Intergovernmental Panel on Climate Change (IPCC) in its Climate Change 2007 report (Meehl et al., 2007) expects a global sea level rise between 25 and $59 \mathrm{~cm}$ (without scaled-up ice discharge) for the end of the 21st century; for the same period KNMI (2006) estimates a local sea level rise for the Netherlands in the range of 35 to $85 \mathrm{~cm}$. This projected sea level rise means that the hydraulic boundary-conditions and the coastal-protection concepts which were proposed almost half a century ago have to be re-evaluated.

In order to explore the possibilities of effectively and efficiently dealing with the climate-induced changing physical conditions and their implications for urban planning and water management, in early 2007 the Dutch cabinet established a special committee, called the Delta Committee, and charged it with the development of ideas and effective planning-, management- and adaptationstrategies for climate proofing the Netherlands. Efficient response strategies to the climate-change problem require, however, careful considerations of the average, 'best estimates' and the extremes in sea level rise, storm surges, and river discharge, including those for time frames extending beyond 2100 . There is also evidence that the range of projections for sea level rise up to 2100 does not 
sufficiently cover low-probability/high-impact scenarios and that higher values for sea level rise cannot be ruled out.

The sea level rise projections for 2100 of KNMI, cited above, for instance take into account the 'most probable' range of temperature changes in the interval 2$4^{\circ} \mathrm{C}$ (covering $80 \%$ of the global temperature rise in the IPCC projections for 2100), but, unlike the IPCC projections, include a contribution of increased discharge from Greenland and Antarctica. In the latest IPCC report, contributions to global sea level rise from a potentially rapid dynamical change in the ice sheets were excluded from the 'Summary for Policymakers', because the dynamical response of the large ice sheets to warming is not yet well understood and current models are unable to capture this response properly. In addition, the consensus approach adopted by IPCC makes it difficult to include the newest (for the latest, fourth report newer than mid-2006) studies and observations.

Recent observations from tide gauges and satellite-altimeters suggest that sea level has been rising faster since 1993 than the average model-projection, although there is no discrepancy between the two when error bars are accounted for (Rahmstorf et al., 2007). Yet, our understanding of the processes forcing sea level rise is limited and the data series available are too short to determine whether the observed changes demonstrate long-term trends or natural variability.

Like other climate-change problems, the uncertainties regarding sea level rise, and especially its upper bound, will probably not be resolved to a high degree of confidence in the next decade. For many spatial planning and infrastructure projects with a life span of a century or more, however, low-probability/highimpact projections are needed today, as the cost of preparing for more extreme rises now is in many cases lower than the capital and social costs of making adjustments at a later date. For the low-lying Netherlands low-probability/highimpact sea levels, storm surges and peak river discharge have significant implications for infrastructure like port facilities, new islands and new towns. However, since sea level rise is a slow process, flexible management-policies can be developed, so that any decisions made now can be updated in light of new scientific understanding and the observed rise in sea level.

Extreme sea level rise will threaten the very existence of the Wadden islands, while the combination of high sea levels and low discharge of the river Rhine will significantly enhance salt water intrusion into the estuaries and rivers. The work of the Delta Committee and of this international scientific assessment team is particularly relevant at this point in time as the Dutch government is looking into a range of possibilities for expansion of presently land-based activities such as sea-ports, airports and energy systems into the North Sea. In this process it is important to consider not just most probable scenarios, but also lowprobability/high-impact ones.

In this context, the Delta Committee asked the authors of this assessment to extend the range of IPCC and KNMI projections with their knowledge about and argued views on the low-probability/high-impact scenarios for 2100 and 2200. After conducting a detailed literature study, more than 20 leading climate scientists from different countries around the North Sea, Australia and the USA 
were identified and invited to take part in the expert panel (full list of the experts is presented on page 2 of this report).

As part of the preparation of this assessment, the expert opinions, based on paleoclimatic data, observations and on the current knowledge and understanding of the relevant processes and feedbacks, were extensively discussed and contested. Alternative theories were also analysed and uncertainties were stressed. Special attention was paid to assessing the contribution from accelerated ice sheet melting and from thermal expansion at high-end temperature projections reported by IPCC (Meehl et al., 2007). The assessment of the ice sheet contributions to both global and local sea level rise posed the biggest challenge in this assessment. The outcomes should be considered only as indicative for the high-end future sea level changes at a longer time-scale. These projections, which are based on the insights gained from recent observations and paleo-climatic evidence, allow a depiction of longer-term future sea levels, and they may be useful for physical and mathematical model analyses. However, care should be taken that they are interpreted properly, and they need to be reviewed and revised in the future with further development of scientific knowledge and information from monitoring networks.

As the overall objective of the study was to cover the projections for local sea level rise, storminess and river Rhine discharge, relevant for the Dutch North sea cost, it addressed the following questions:

Based on the current state-of-the-art knowledge, what is the upper bound of global sea level rise for the years 2100 and 2200?

What is the upper bound of sea level rise for the Dutch coast, taking into account local subsidence effects and changes in the Earth's gravitational field due to the melting of the Greenland and Antarctica ice sheets?

What changes in the storm surge frequency and heights can be expected, superposed on sea level rise?

How will the projected change in climate affect peak discharge of the river Rhine?

With the exception of the effect of sea level rise on storm surges, the interaction between the three above mentioned effects - sea level rise, storminess and river Rhine discharge - is not addressed in the current assessment. While the authors of this assessment are aware of the great importance of these interactions on the inundation risks, salt water intrusion, water quality and quantity in general, they are beyond the scope of the current report.

This paper consists of three separate reports. Chapter II comprises the high-end estimates for global and local sea level rise in 2100 and 2200, which were made, using a methodology similar to the one employed in the IPCC's Fourth Assessment Report (Meehl et al., 2007) and KNMI scenarios (KNMI, 2006). Each process contributing to local sea level rise, including thermal expansion, melting of small glaciers and ice sheets and vertical land movement, is addressed separately. Explicit efforts were made to describe the degrees of uncertainty associated with each contribution. This physical-mathematical modeling approach to estimating of future global sea level change is complemented by analysis of paleoclimatic analogues and estimates of the total ice volume that could be susceptible to melting on a multi-century timescale. 
Chapter II addresses the storm climate of the Dutch coast and the expected impact of climate change on it. Chapter III adds to this the expected impact of climate change on river Rhine discharge. The results presented in Chapter II and III are based on model simulations; separate expert opinions were not included there. The time horizon for these two chapters is 2100 , as there are no model results available for 2200 . 


\title{
Synthesis of the main findings
}

\author{
High-end projections for sea level rise
}

- Assuming a scenario for temperature rise of up to $6 \mathrm{C}$ in 2100 and up to $8 \mathrm{C}$ in 2200 , the high-end projection for global sea level is estimated to be 0.55 $1.10 \mathrm{~m}$ in 2100 and $1.5-3.5 \mathrm{~m}$ in 2200 .

- Depending on the adopted gravitational and elastic fingerprints of the two big ice sheets and regional effects of thermal expansion, in that case high-end rising in local sea levels of $0.50-1.15 \mathrm{~m}$ and $0.05-1.25 \mathrm{~m}$ is projected for the Dutch coast for 2100; for 2200 these ranges are $1.5-4.0 \mathrm{~m}$ and 0.5 $4.0 \mathrm{~m}$ respectively, including local land subsidence.

- Depending on the geochronology adopted, paleoclimatic evidence indicates that, during the most recent period analogous to the present and immediate future, the Last Interglacial stage ( $\sim 125$ thousand years ago), global sea level rose at either $1.2 \pm 0.5$ or $1.7 \pm 0.7 \mathrm{~m} /$ century. Based on these ancient data, two alternative high-end scenarios can be formulated:

- a rate of $\sim 1.7 \mathrm{~m} /$ century, yielding a rise in global mean sea level of about $+50 \mathrm{~cm}$ in 2050, $+1.4 \mathrm{~m}$ in 2100 , and $+3.1 \mathrm{~m}$ in 2200 ;

- a rate of $\sim 2.4 \mathrm{~m} /$ century, yielding a rise in global mean sea level of about $+70 \mathrm{~cm}$ in $2050,+1.9 \mathrm{~m}$ in 2100 , and $+4.3 \mathrm{~m}$ in 2200 .

- Unresolved discrepancies in calculation of elastic effects caused by melting ice masses on land increase the uncertainty in the local sea level projections substantially.

\section{Storminess}

- Changes of the 50 or 100-year return time wind speed values in 2100 are much smaller than the internal (year-to-year) variability.

- The models show a tendency to westerly winds becoming more frequent, while no changes are reported for northerly and north-westerly winds, which are most dangerous for the Dutch coast.

- Climate change will not have dramatic consequences on the contribution of storminess to surge heights along the Dutch coast.

- To a first order approximation, mean sea level rise can be added linearly to the storm surge height. Nonlinear effects are in the order of $10 \%$ of the change in mean sea level. 
- All climate model simulations considerably underestimate present-day annual mean and annual 99th percentile significant wave heights

\section{River Rhine discharge}

- Average winter flow will increase but summer flows will be, depending on the scenario, a little to considerably reduced

- Peak discharges that are currently considered being very high will become normal.

- Presuming the recent dike situation will not change dramatically the projected ranges for the River Rhine discharges are $15500-17000$ m3/s in 2050 and $16000-17500 \mathrm{~m} 3 / \mathrm{s}$ in 2100 .

- The current hydraulic properties of the Rhine, in particular the less strict defence guidelines upstream in Germany, limit the potential increase of the design discharge substantially. 


\section{CHAPTER I - High-end projection for local sea level rise along the Dutch coast in 2100 and 2200}

\section{Introduction}

The following report explores the upper end of sea level rise scenarios and longterm projections extending to 2200, using modeling and expert judgment. It contains no implied criticism, dissatisfaction, or disagreement with the methods, reasoning or outcome of the assessments made earlier by the IPCC AR4 (2007) and/or KNMI (2006). In fact, this report strongly builds on these two previous assessments and seeks to achieve a rather different goal: it specifically explores, at the request of the Delta Committee, the upper end of the sea level rise scenarios and longer term projections, using modeling and expert judgment, without the limitation, under which the IPCC was drafted, that the work presented is already published in the scientific literature.

It is in this light, that we consider several plausible scenarios for sea level variations based on our expert opinion. Our lack of knowledge of some of the relevant responses of components of the climate system to greenhouse gas emission leads to a wide range of sea level projections. This range should be taken as indicative of what is - according to our expert judgment and based on the current level of scientific understanding - a plausible high end and longer time frame range of future sea level change scenarios rather than what is most likely. It is by no means guaranteed that these high-end scenarios will remain valid as science progresses, that we bound the possibilities, or that the scenarios are agreed upon by the entire scientific community.

\subsection{Factors influencing local sea level}

When we speak of 'Local Sea Level', we refer to the difference between the sea surface height and the land surface height. Changes in local sea level can result from local changes in the sea surface height, the land surface height, or both. Changes in coastal local sea level determine whether land is inundated or exposed, depending on the sign of the changes and the land surface topography. Global mean sea level change is the spatial average of local sea level changes over the complete ocean area and is directly related to the change in the global volume of the ocean. While most published projections focus on the global mean sea level, the impact of sea level rise on the Netherlands is almost entirely governed by local sea level changes. Local sea level is influenced by a number of processes that act on a wide range of spatial and temporal scales, and it is important to take account of these processes as local sea level rise deviates in many areas substantially from the global average and can even have an opposite sign.

To assess future changes in local sea level for The Netherlands, we consider a range of plausible scenarios for the dominant processes affecting local sea level, 
similar to the approach taken in IPCC AR4 (Meehl et al., 2007). In this chapter, we focus on the dominant processes affecting local sea level on century and longer time scales ${ }^{17}$ : changes in ocean density (mainly caused by thermal expansion), mass changes in small continental glaciers, mass changes in the large ice sheets of Antarctica and Greenland, changes in ocean circulation, and vertical land motion including postglacial rebound. The contributions of the processes involving shrinking of land-based ice masses are first assessed in a global context before focusing on the Dutch coast.

\subsection{Uncertainties involved in projecting future local sea level}

Different types of uncertainties need to be considered when making projections for individual components contributing to local sea level change. The uncertainties can

be classified into five broad areas based on their origin (Manning and Petit, 2003):

- incomplete or imperfect observations;

- incomplete conceptual frameworks

- inaccurate prescriptions of known processes;

- chaotic, or inherently unpredictable responses;

- lack of predictability due to non-physical factors (e.g. policy-decisions).

The contribution from global mean thermal expansion of the ocean is assessed here using an analysis of coupled climate models, which predominantly incurs uncertainties of types 3 and 5 . The estimated ocean thermal expansion depends on the parameterization of small-scale mixing, large scale ocean circulation and heat uptake from the atmosphere (type 3), which differs from model to model. To estimate this uncertainty, we make use of an ensemble of climate models. In addition, the contribution of ocean thermal expansion contains an element of lack of predictability (type 5), because it is affected by the development of future greenhouse gas emissions, which are, in turn, affected by future socio-economic factors and policies. In all IPCC reports, this type of uncertainty is treated by exploring outcomes implied by a representative range of emission scenarios. A comparable approach is applied here by exploring a range of future atmospheric temperature rises. This range is intended to encompass a range of emission scenarios, and the range of temperature rise that these could produce (see Section 2.3).

The contribution from small glaciers is estimated here based on an empirical formula linking global mean temperature to mass loss based on observations, as in IPCC AR4 (2007). Clearly, such a temperature-dependent estimate involves uncertainties of type 5 , which are treated by exploring the same range of future atmospheric temperature rise mentioned above.

The predominant uncertainty affecting the contribution from the large ice sheets is of type 2. This was highlighted in IPCC AR4 (Meehl et al., 2007, Ch 10), in which it was noted that new observations of recent rapid changes in ice flow on the Antarctic Peninsula, West Antarctica and Greenland has raised the possibility of larger dynamical changes in the future than are projected by state-of-the-art 
ice-sheet models, because these models do not incorporate all the processes responsible for the rapid marginal thinning that has been recently observed. This type of uncertainty is the result of shortcomings in our understanding, but also partly due to a lack of observations (type 1), and is the most difficult aspect of uncertainty to characterize accurately (Manning and Petit, 2003).

The assessment of ocean circulation changes under a changing climate and its impacts on local sea level are associated with a degree of non-linear behavior that is hard to predict because of our limited knowledge of the likelihood of relatively fast regime transitions and their possible impacts (type 2 ). To estimate this uncertainty, we once again make use of an ensemble of climate models to analyze local sea level changes associated with changing ocean dynamics.

For the vertical land motion, the most important uncertainties are those related to incomplete or imperfect observations (type 1). In comparison to some of the other uncertainties mentioned above, these are well-known and their contribution to the overall uncertainty of the projections can be quantified. Finally, the uncertainty in the estimate for the contribution of changes in terrestrial water storage is dominated by uncertainties due to incomplete or imperfect observations (type 1 ) and lack of predictability (type 5).

Because of the caveats on our knowledge of current sea level changes (in particular of ice sheet dynamics), and hence our limitations in modeling its future behavior, the projections for sea level rise presented in this report are to be considered high-end scenarios of what - according to our expert judgment and based on the current level of scientific understanding - is plausible. It is by no means guaranteed that these high-end scenarios will remain valid as science progresses, or that they even cap the range of plausible future sea level trajectories, or that they are agreed upon by the entire scientific community.

In light of all these uncertainties involved in projecting future sea level rise, we therefore stress the need for flexible coastal management strategies, so that any decisions made now can be updated in light of new scientific understanding that should arise in coming years and decades. In addition, we should stress that comprehensive monitoring of local and global sea level rise are essential in order to narrow the current uncertainties (in particular those of type 1) and to be able to identify the possible need for further adaptations in coastal management. These observations essentially form an early warning system that could give us years to decades in which to prepare.

\section{Sea level rise in the twenty-first century}

\subsection{IPCC AR4 projections for global mean sea level rise}

IPCC AR4 (2007) contains the most authoritative assessment of global mean sea level rise so far undertaken. The quantitative IPCC AR4 projections are, however, restricted to the 21st century. They are based on detailed assessment of thermal expansion of the oceans from climate models, melting of mountain glaciers from scaling of observations to atmospheric temperature rise, and ice 
sheet mass balance changes and dynamic response from ice sheet models and the extrapolation of recent observations (IPCC AR4, Ch. 10, Meehl et al 2007).

In IPCC AR4, the projections of global average sea level rise for 2090-2099 cover a range of 0.18-0.59 m (see Figure 1.1). However, the IPCC text notes explicitly that this range does not include the full range of possible change, as it does not include potential contributions resulting from rapid dynamical processes in the Greenland and Antarctic Ice Sheets that are not adequately represented in the current generation of ice-sheet models. The IPCC AR4 does include a thorough discussion of the possible contribution of the Antarctic and Greenland Ice Sheets but notes that a greater level of uncertainty surrounds the ice-sheet contribution than others (see also Section 1.2).

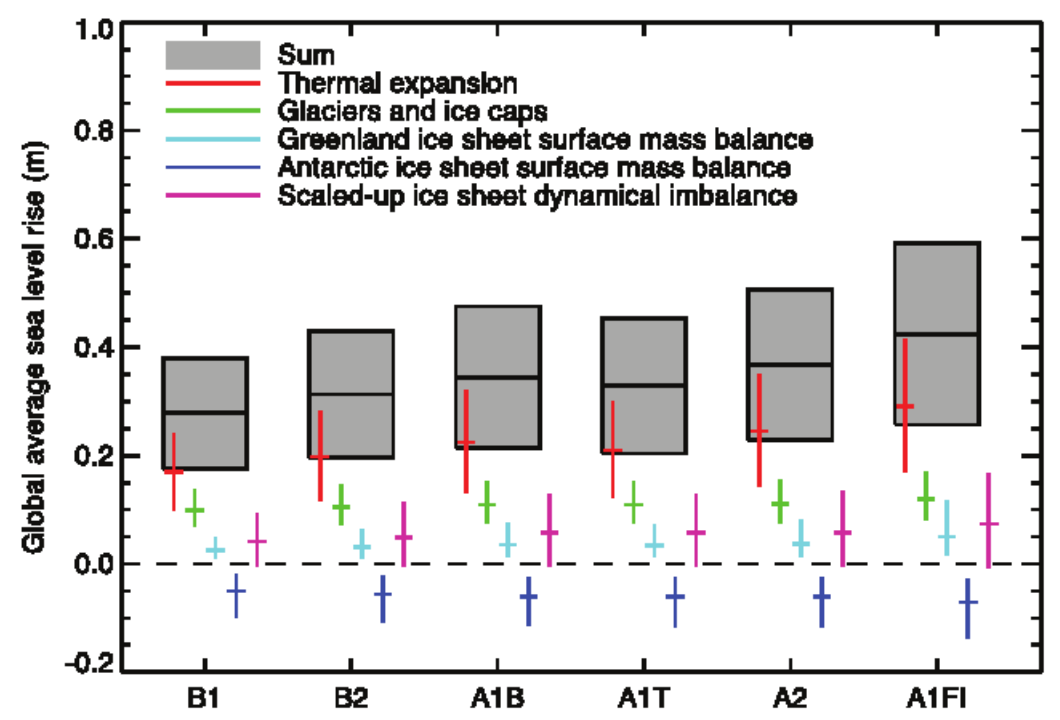

Figure 1.1: Reproduced from IPCC AR4 (2007). Projections and uncertainties (5 to 95\% ranges) of global average sea level rise and its components in 2090 to 2099 (relative to 1980 to 1999) for the six SRES marker scenarios. The projected sea level rise (gray) assumes that the part of the present-day ice sheet mass imbalance that is due to recent ice flow acceleration will persist unchanged. It does not include the contribution shown from scaled-up ice sheet discharge (magenta).

In IPCC AR4, it is stated that an additional, temperature-dependent contribution of up to 0.1-0.2 m (referred to as the 'scaled-up ice sheet discharge') could arise from the ice sheets if the recently observed acceleration in discharge continues (IPCC AR4, Ch. 10.6.5). When this contribution is added, the projected range in global mean sea level rise becomes 0.17-0.76 m. However, the understanding of these effects is too limited to assess their likelihood or provide a justifiable estimate or an upper bound for sea level rise (IPCC AR4).

\subsection{High-end contributions to global mean sea level rise}

In response to the request from the Delta Committee to explore the high end of the sea level rise scenarios (see Introduction), an additional projection method is also presented here. The approach is used to compute sea level rise for the A1FI scenario to explore the upper end of the potential sea level rise scenarios. The outcome is compared with the equivalent IPCC projections. 
Different processes contributing to sea level rise (thermal expansion of the ocean, the shrinking of small glaciers, the Greenland and the Antarctic Ice Sheets, and changes in terrestrial water storage) are considered separately, along with their uncertainties. Except for the contribution of the Antarctic Ice Sheet (the temperature sensitivity of which is very uncertain), all contributions are assumed to depend (at least in part) on the rise in global mean atmospheric temperature rise projected for the course of the twenty-first century. We consider a range spanning from a modest rise of $2{ }^{\circ} \mathrm{C}$ to a rise of $6{ }^{\circ} \mathrm{C}$, which is close to the upper end of the IPCC AR4 projections (see Section 5.2; Ch. 10, Meehl et al. 2007). This range of temperature rise is most comparable to the A1FI scenario. The $6^{\circ} \mathrm{C}$ rise is probably more likely to occur if there are significant climate-carbon cycle feedbacks.

\subsubsection{Global mean thermal expansion}

For 2100 , global mean thermal expansion is estimated using two idealized scaling relations for the expansion and the rise in global mean atmospheric temperature. The first assumes a linear relation between thermal expansion and atmospheric temperature rise for a certain year of interest (Katsman et al., 2008); the second assumes a linear relation between the rate of global mean thermal expansion and atmospheric temperature rise (Rahmstorf, 2007). Both methods assume ongoing upwards trends in atmospheric temperature (see Section 5.3.1 for details on both scaling relations). Both methods have their limitations in particular when applied to the high end of the scenario range (large atmospheric temperature rise).

As such, we can be confident only that these approximations will give reasonable estimates for a limited range of temperature rise. It remains unclear, whether these approximations are valid when applied to scenarios for the large atmospheric temperature rise of $6 \mathrm{C}$ associated with the more extreme scenarios. Because of the uncertainties involved, the estimate for the contribution of global mean thermal expansion is averaged over the two methods. The approach yields a contribution to global mean sea level rise of 0.12-0.49 m in 2100 (see Table 1.1).

\subsubsection{Small glaciers}

The glacier contribution is calculated using the same scaling approach as applied in IPCC AR4 (Appendix 10.A, p.884). The approach assumes a linear relationship between the rate of sea level rise from the world's glaciers and ice caps (excluding those in Antarctica and Greenland) and global mean atmospheric temperature based on observations. It takes into account the decline of the mass balance sensitivity during glacier retreat, as the most sensitive areas are ablated most rapidly. The fact that the glacier area declines as volume is lost is also accounted for. To include contributions from small glaciers surrounding the Greenland and Antarctic Ice Sheets, a scaling factor is introduced. Note that this approach is expected to be less accurate further into the future, as greater area and volume is lost. The calculated contribution from glaciers to global mean sea level rise in 2100 ranges from $0.07 \mathrm{~m}$ to $0.18 \mathrm{~m}$ (see Table 1.1). 


\subsubsection{Ice sheets}

As explained in Section 1.2, the contribution from the ice sheets is the most uncertain component as there are important gaps in our understanding of their dynamic behavior. The mass of ice grounded on land in the Greenland and Antarctic Ice Sheets can change as a result of changes in surface mass balance (SMB, the mean sum of snow and frost accumulation, runoff and evaporation/sublimation) or by the flux of ice leaving the grounded ice sheet and entering the ocean (either as floating ice, or melt water). The former is largely a response to atmospheric climate change, while the latter will be a complex response to atmospheric, oceanographic forcing and internal changes in the ice sheet. Partly because of this complexity and partly due to a lack of long-term observational data, there is little confidence that the present generation of ice sheet models correctly simulates likely change in ice flux; this component is therefore hard to assess with confidence.

The most vulnerable parts of ice sheets are thought to be the so-called marine ice sheets. There has been a longstanding concern that an ice sheet that rests on bed rock that is below sea level and slopes downwards from the margin to the interior is an essentially unstable system (see Appendix II of this document). There is a possibility that positive feedbacks in a marine ice sheet system could lead to a runaway "collapse" of the ice sheet, which would stop only where the retreat encountered a rising bed slope. The timescale over which such a collapse might occur is not well understood but for large sections of an ice sheet would probably not run to completion on less than century scales. Today, there are a few examples of marine ice sheets left on Earth. The largest covers the majority of West Antarctica, although a few glaciers in East Antarctica also have large catchment basins below sea level. The strongest inland bed slope, and probably the strongest tendency to instability, exists in that portion of the West-Antarctic Ice Sheet (WAIS) which drains into the Amundsen Sea - the so-called Amundsen Sea embayment. In Greenland, there is only one glacier basin, that of Jacobshavns Isbrae (glacier), that appears to contain a similar prominent inland slope and could potentially display a sustained retreat (see Appendix II).

Recent observations of rapid flux changes in Antarctic glaciers provide tentative support for the view that the WAIS may lose a significant fraction of its mass on timescales relevant for coastal planning. There are, however, also reasons to believe that the process may not involve the entirety of the WAIS (see Appendix II). Despite improvements in observations, our understanding of marine ice sheet instability is at present inadequate to make realistic projections for several reasons. In particular, models of collapse presented so far indicate only the potential instability in the system. They cannot be used to explore rates at which collapse might be expected to proceed or whether there are features in the system that could halt the retreat long enough for a new equilibrium, or even a re-advance, to be established.

Unlike Antarctica, the Greenland Ice Sheet is subject to extensive surface melting in summer. The amount of melt is non-linearly dependent on surface temperatures and on average accounts for half of the mass loss. There are two main ice dynamical processes that could generate a rapid response to climate change: the lubrication of the ice sheet base by surface runoff, leading to faster ice flow generally (Zwally et al., 2002, Joughin et al., 2008, van de Wal et al. 
2008) and the retreat of the grounding line, leading to acceleration and thinning of tidewater outlet glaciers (e.g., Nick \& Oerlemans, 2006). Despite

improvements in observation, our understanding of the surface melt percolation is at present inadequate to make realistic projections (see also Section 5.4.2). All model studies for the 21st century suggest that Antarctic SMB changes will contribute negatively to sea level rise, owing to increasing accumulation in excess of any ablation increase (IPCC AR4; Ch. 10). According to these model studies, the Antarctic SMB changes tend to reduce global mean sea level in the $21^{\text {st }}$ century by 0.02 to $0.14 \mathrm{~m}$, depending on the emission scenario. In projections for Greenland, ablation increase is important but uncertain, being particularly sensitive to temperature change around the margins. In most studies, Greenland SMB changes represent a net positive contribution to sea level in the 21st century (IPCC AR4; Ch. 10) because the ablation increase is larger than the precipitation increase. The Greenland Ice Sheet is projected to contribute 0.01 to $0.12 \mathrm{~m}$ to global mean sea level rise during that period (see also Fig. 1.1).

However, there are explicit statements within the IPCC AR4 (2007, Ch 10) that retain the possibility that the projections it presents may not fully bound the possible upper rates of sea level rise that could be experienced in the coming century. It is stated that our current understanding of ice sheet behavior is too limited to assess their likelihood or provide a best estimate or an upper bound for sea level rise. Based on the considerations above, we propose here the following additional scenarios for the contribution of the Antarctic Ice Sheet and the Greenland Ice Sheet, as complementary to those in IPCC AR4 (2007), for the purposes of risk management as requested by the Delta Committee.

\section{Antarctic Ice Sheet}

The scenario for the Antarctic Ice Sheet is based on plausible contributions from three areas of Antarctica that are already showing signs of change (see Section 5.4.1 and Appendix II for further discussion):

- The Amundsen Sea Embayment (ASE)

- The three marine glacier basins in East Antarctica that are showing recent thinning (EAIS-g);

- The northern Antarctic Peninsula (n-AP), an area that has suffered recent increases in atmospheric temperature, increased glacier melt, glacier retreat, and glacier acceleration.

A modest scenario can be obtained by assuming continued increase in the glacier velocities in ASE and EAIS-g, and continued melting and glacier flow in the n-AP. A plausible high end of the range can be obtained based on an emerging collapse of ASE and EAIS-g, and accelerating melting and glacier flow in the n-AP (see Section 5.4.1). Collapse of Larsen B ice shelf resulted in a speed up of 2-8 times of the glaciers feeding it. If the loss of ice across ASE increases similarly it will dominate sea level rise over the second half of the century. Including EAIS-g and $\mathrm{n}$-AP the total sea level rise due to dynamical changes is estimated to be $0.49 \mathrm{~m}$. The approach yields a contribution of the Antarctic Ice Sheet to global mean sea level rise in 2100 ranging from $-0.01 \mathrm{~m}$ to $+0.41 \mathrm{~m}$ (see Table 1.1 ). This range includes an adjustment of $-0.08 \mathrm{~m}$ to account for the projected increase in accumulation over Antarctica (IPCC AR4, Meehl et al 2007). 


\section{Greenland Ice Sheet}

Future projections for the ice sheet presented in IPCC AR4 are based on results obtained with models that include only the surface mass balance and slow ice dynamical processes and do not include rapid dynamical processes. However, recent observations have shown that outlet glaciers which end in the ocean might respond rapidly.

To arrive at an additional scenario for the high end of the contribution of the Greenland Ice Sheet, we accept the IPCC AR4 assessment of surface mass balance changes and associated sea level rise for surface ablation and slow dynamics; we reassess only the additional contribution from fast dynamical processes. The surface mass balance component is estimated based on the regressions for temperature sensitivity of ablation and accumulation derived in Gregory and Huybrechts (2006). Temperature profiles to 2100 are scaled versions of SRES A1B to reach 2100 (using a polynomial fit) with a global rise of $+2^{\circ} \mathrm{C}$ and $+6^{\circ} \mathrm{C}$. Amplification of global temperatures over Greenland is assumed to be a factor 1.5 (Gregory \& Huybrechts, 2006).

The additional contribution from fast dynamical processes is estimated based on the following assumptions:

Surface melt increases such that a $3+{ }^{\circ} \mathrm{C}$ local temperature rise by 2100 will result in much of the ice sheet surface experiencing summer runoff. We suggest that, as a consequence of increased bedrock lubrication, this will result in an additional sea level rise of $4 \mathrm{~cm}$ (Parizek and Alley, 2004).

The discharge from tidewater glaciers in the east and south will gradually double from 1996 discharge (Rignot and Kangaratnam, 2006) until 2050, and then rapidly slow to 1996 discharge rates when it is assumed that their termini are above sea level. The discharge from Jakobshavn and the Northern tidewater glaciers is assumed to increase to four times their 1996 discharge rates by 2100 . All changes are assumed linear over the relevant time period.

The analysis yields an additional sea level rise by 2100 due to fast ice dynamics of $\sim 0.1 \mathrm{~m}$ (see Section 5.4.2). The total contribution of the Greenland Ice Sheet to global mean sea level rise is estimated at 0.13 to $0.22 \mathrm{~m}$. This is in line with estimates of the current loss of ice (e.g. Rignot et al. 2006, Luthcke et al. 2007). It is noteworthy to mention that in a slightly warmer climate (2-3 C global mean temperature rise), ablation is estimated to be larger than accumulation leading to a decrease of ice volume independent of dynamical processes. Greenland could enter a phase of retreat that could only be reversed by a substantial increase in snowfall, or a subsequent cooling. Such a retreat might take on the order of 1000 years to complete but is significant because once it is begun represents a very long-term commitment to sea level rise (see also Section 5.4.2).

\subsubsection{Terrestrial water storage}

Besides being stored in ice sheets and glaciers, water is stored on land as snow, surface waters (including manmade reservoirs), and subsurface water (ground water). Changes in this storage may occur due to climate variations and to human interventions in the water cycle, such as changes in land use (Church et al., 2001). Estimates of the various contributions are highly uncertain, and of different signs (Church et al., 2001; Cazenave and Nerem, 2004; Chao et al. 2008). The net trend in sea level appears likely to be negative but the 
uncertainty on the estimates does also contain the possibility of a positive contribution. In IPCC AR4 (2007), the possibility of sea level changes resulting from anthropogenic changes in terrestrial water-storage is mentioned but not quantified. We estimate the terrestrial water storage contributions to be $0.02 \pm$ $0.02 \mathrm{~m}$ in 2100, following Katsman et al. (2008).

\subsection{High-end projection for global mean sea level rise in 2100}

The final high-end projection for global mean sea level rise in 2100 is obtained by adding the estimates for each of the separate contributions (thermal expansion of the ocean, the shrinking of small glaciers, the Antarctic and the Greenland Ice Sheets and terrestrial water storage) discussed in the previous sections ${ }^{18}$. Because of the large uncertainties involved in estimating each of the individual contributions, the final numbers are rounded to $5 \mathrm{~cm}$. The high-end projection for global mean sea level rise in 2100 becomes $0.55-1.10 \mathrm{~m}$ (see Table 1.1 )

\subsubsection{Comparison to IPCC AR4 projection (A1FI emission scenario)}

Figure 1.2 and Table 1.1 compare the individual contributions and the projection for global mean sea level rise developed here (black) and the one presented for the A1FI emission scenario in IPCC AR4 (blue and red). The A1FI scenario is the most relevant emission scenario in this case, since we focus on the high end of the range for sea level rise scenarios.

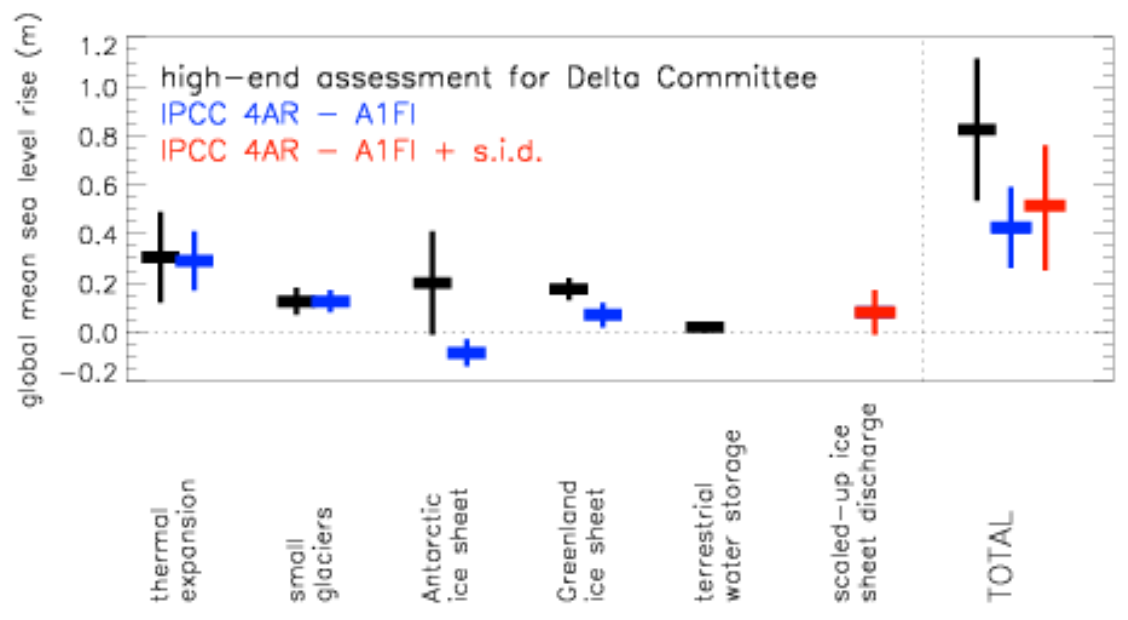

Figure 1.2: Comparison of individual contributions and total projected global mean sea level rise for 2100 as presented in this report (black) and in IPCC AR4 for the A1FI emission scenario, excluding (blue) and including (red) the contribution from 'scaled-up ice sheet discharge' (s.i.d.). To construct this figure, it is assumed that the bandwidths of all individual components presented in IPCC AR4 (Table 10.7) represent a Gaussian distribution.

18 First, a central estimate is calculated by adding the central estimates of the individual components (all ranges are assumed to be Gaussian). Next, the uncertainty is calculated by quadratic summation of the bandwidths of the individual contributions, as in IPCC AR4 (2007), since it can be assumed that the reported uncertainties for the various contributions are independent. The reported total range is the range spanned by this uncertainty band. 
For the A1FI scenario, IPCC AR4 projects a global mean sea level rise of 0.26$0.59 \mathrm{~m}$ in 2090-2099 (blue in Figure 1.2). This range contains contributions from four components: thermal expansion, glaciers and ice caps (excluding the Greenland and Antarctic Ice Sheets), ice sheet surface mass balance, and ice sheet dynamical imbalance. The contribution from the two major ice sheets is split into two parts. The contribution referred to as the surface mass balance refers to snowfall minus surface ablation and is computed from an ice sheet surface mass balance model driven by snowfall amounts and temperatures derived from a high-resolution atmospheric circulation model. The contribution from ice sheet dynamical imbalance that is included is estimated from observations of increased flow rates around the edges of Greenland and Antarctica during the period 1993-2003, under the assumption that this contribution remains constant until the end of this century. The range of 0.26 $0.59 \mathrm{~m}$ does not include the contribution referred to as the scaled-up ice discharge reported by IPCC AR4 (see Section 2.1). When the latter is included, the projected range becomes $0.25-0.76 \mathrm{~m}$ (red in Figure 1.2).

Even with the scaled-up ice discharge included, the upper end of the A1FI scenario reported by IPCC AR4 is substantially lower than the upper end of the projection presented in this assessment for the Delta Committee $(0.76 \mathrm{~m}$ and $1.1 \mathrm{~m}$, respectively). This is a reflection of the fact that we explicitly focus on the high end of the range. In particular the estimate for the contribution from the Antarctic Ice Sheet for the severe scenario based on an emerging collapse of the Amundsen Sea Embayment (this report) yields a relatively large contribution, in contrast to the model-based estimate of a growing ice sheet presented by IPCC AR4 (2007). Since the appearance of the IPCC report, several studies have indicated this retreat in the Amundsen Sea Embayment, justifying the need to explicitly include the dynamical adjustment of the ice sheet, although the duration of this adjustment remains highly uncertain.

Also the contribution from the Greenland Ice Sheet is estimated to be larger than in IPCC AR4 (2007), since we added an estimate for the effects of rapid dynamical processes. Finally, the bandwidth of the estimate for the global mean thermal expansion is slightly larger than reported in IPCC AR4 (2007), because of the larger range in atmospheric temperature rise that is explored here.

Table 1.1: Overview of all estimated contributions and the total high-end projection for global mean sea level rise for 2100 assessed here, and the corresponding contributions reported in IPCC AR4 for the A1FI emission scenario (in m) including the scaled-up ice discharge from table 10.7 in IPCC AR4.

\begin{tabular}{|l|l|l|}
\hline component & $\begin{array}{l}\text { high-end assessment for the } \\
\text { Delta Committee (in m) }\end{array}$ & $\begin{array}{l}\text { IPCC AR4 (2007) - A1FI } \\
\text { emission scenario (in m) }\end{array}$ \\
\hline $\begin{array}{l}\text { global mean thermal } \\
\text { expansion }\end{array}$ & +0.12 to +0.49 & +0.17 to +0.41 \\
\hline small glaciers & +0.07 to +0.18 & +0.08 to +0.17 \\
\hline Antarctic Ice Sheet & -0.01 to +0.41 & -0.14 to -0.03 \\
\hline Greenland Ice Sheet & +0.13 to +0.22 & +0.02 to +0.12 \\
\hline scaled-up ice discharge & - & -0.01 to +0.17 \\
\hline terrestrial water storage & 0.0 to +0.04 & - \\
\hline Total & +0.55 to +1.10 & +0.25 to +0.76 \\
\hline
\end{tabular}




\subsubsection{Comparison to paleoclimatic evidence of global mean sea level rise}

During the Last Interglacial stage, about 125,000 years ago, global temperatures were slightly warmer than today and global sea level was likely 4-6 m higher (Overpeck et al, 2006; Duplessy et al., 2007). Global sea level records derived from oxygen isotopes and the local sea level record of the Red Sea suggest that rates of global sea level rise reached 0.7 to $1.7 \mathrm{~m} /$ century during intervals within the Last Interglacial when ice sheets of the scale of the present Greenland and West Antarctic Ice Sheets were the only major melt water contributors (see Section 5.3). The paleoclimatic record is not of high enough temporal resolution to exclude the possibility that global sea level rose at a rate that exceeded these values for periods of less than about three centuries, nor can it provide a minimum constraint on how long it takes to attain such rates stating from an interval of slow sea level rise comparable to that we are experiencing now. The variations in the rate of global mean sea level rise observed in the Red Sea record do, however, suggest that the onset of rapid sea level rise can occur within the 300 years timescale resolved by that record.

A plausible high-end estimate based on paleoclimatic evidence, assuming that rates of global mean sea level rise as fast as $\sim 1.7 \mathrm{~m} /$ century can commence on a decadal time scale (an educated guess at how fast such a transition might occur), yields a global mean sea level rise of roughly $1.4 \mathrm{~m}$ in 2100 , somewhat higher than the high-end projection presented in the previous section (see Table 1.1, Figure 1.2).

An alternative geochronology for the Last Interglacial, preferred by some authors (e.g., Rohling et al., 2008), shortens the duration of the stage and would suggest that rates of sea level rise reached as 1.0 to $2.4 \mathrm{~m} /$ century. An estimate for 2100 based on the higher value of $\sim 2.4 \mathrm{~m}$ /century would yield a sea level of roughly $1.9 \mathrm{~m}$ in 2100 .

\subsection{Local sea level changes}

The previous section presented an additional projection for global mean sea level rise, focusing on the high end of the scenario range. Local sea level may differ substantially from the global mean. To arrive at a projection for local sea level, several effects need to be accounted for:

- gravitational effects and the effects of elastic deformation of the Earth's crust and uppermost mantle on local sea level arising from mass redistribution due to the melting of land-based ice (referred to as elastic and gravity effects);

- local expansion differences with respect to the global mean (dominated by ocean circulation changes)

- local land movement 


\subsubsection{Elastic and gravitational effects}

When ice masses on land melt, the released fresh water is not distributed evenly over the oceans. Large land-based ice masses exert a gravitational pull on the surrounding ocean, yielding higher relative sea levels in the vicinity of the ice mass. When the ice mass shrinks, this pull decreases, and sea level will actually drop in the vicinity of the ice sheet (the "near field") as water is redistributed away from it (Woodward, 1888; Vermeersen and Sabadini, 1999). Farther away from the land ice mass, in the "intermediate field", sea level does rise, but this rise is smaller than the global mean rise that would result from equal distribution of the melt water.

At even greater distances, in the "far field", local sea level rise becomes larger than the global mean rise. Moreover, the solid Earth deforms under the shifting loads and this deformation affects the gravity field, the distribution of the ocean water, and the vertical position of land. As a result of these local gravitational and elastic changes, a shrinking land ice mass yields a distinct pattern of local sea level rise sometimes referred to as its "fingerprint" (e.g., Plag and Juettner, 2001, Mitrovica et al. 2001). The elastic and gravitational effects can be incorporated by multiplying each of the global mean contributions from ice melt from glaciers and ice sheets by their respective relative fingerprint ratios.

Two approaches can be used to quantify the gravitational and elastic effects for small glaciers, which are distributed unevenly over the world. The first one is to use the data set on increase in sea level due to glacier melt by Dyurgerov and Meier (2005) covering the period from 1961-2003. From this data set, we can reconstruct sea level due to glacier melt for different regions over the last four decades. Taking the geographical location of the areas relative to the Netherlands, we can then simply calculate the local sea level rise due to changes in the geoid caused by the different small glacier areas (for a rigid Earth). This exercise results in a ratio of local to global mean sea level that varies over time depending on which areas are important, but ranges from $75 \%-90 \%$. It is smaller than $100 \%$ due to the contribution of a few glaciers close to the Netherlands, such as Iceland and Svalbard.

This analysis applies to the past sea level contribution by small glaciers. The local effect for future sea level rise may be different from the past contribution. In order to assess this point, the estimated regional contribution as presented by Van de Wal et al (2001) serves an indicator, as it uses a regional and temporal forcing under $2 \times \mathrm{CO} 2$ conditions. This results in a ratio of $80 \%$ for the local/global mean ratio. This number coincidently agrees with the one presented by Mitrovica et al (2001), which is based on a model of gravitational and elastic effects resulting from historical glacial melting between 1900 and 1961 . In all, the above analysis yields a scaling factor of $80 \%$ for the small glacier contribution along the Dutch coast.

Table 1.2: Relative fingerprint ratios along the Dutch coast for the Antarctic and Greenland ice sheets published in several studies

\begin{tabular}{|l|l|l|}
\hline & Antarctic Ice Sheet & $\begin{array}{l}\text { Greenland Ice } \\
\text { Sheet }\end{array}$ \\
\hline Mitrovica et al (2001) & 1.1 & 0.2 \\
Plag and Juettner (2001) & 2.6 & -2.5 \\
\hline
\end{tabular}


For the Greenland and Antarctic Ice Sheets, simple calculations for a rigid Earth yield a fingerprint ratio of 0.45 and 1.2 , respectively (Woodward 1888). Mitrovica et al (2001) and Plag and Juettner (2001) have addressed the impacts of the deformation of the Earth's crust in response to mass load changes on the fingerprints for these ice sheets. The fingerprint ratios along the Dutch coast obtained differ substantially between the two studies (see Table 1.2). The results published by Mitrovica et al (2001) are in line with earlier studies (e.g., Farrell and Clark, 1976; Clark and Primus, 1987) and also agree with calculations performed by Vermeersen and co-workers (DEOS, TU Delft, the Netherlands)

At present, the causes for the large differences in fingerprints presented by Mitrovica et al (2001) and others on one side and Plag and Juettner (2001) on the other hand are not fully explained. They are being analyzed in detail by Riva and Vermeersen (DEOS, TU Delft, the Netherlands) and Plag but no definite conclusions are possible at this stage. The causes of these differences are thought to be either in the way the sea level equation is solved or in different model assumptions, such as incorporation of variations in Earth rotation (Vermeersen, personal communication). In order to assess the impact of the current uncertainty in the fingerprints of the Antarctic and Greenland Ice Sheets on the local sea level projections, we have considered the two widely varying cases presented in Table 1.3 in Section 2.5.

\subsubsection{Local expansion}

Regionally, changes in steric sea level (caused by changes in temperature and salinity) can deviate substantially from the global mean value. Katsman et al. (2008) analyzed modeled steric changes in the northeast Atlantic Ocean for the twenty-first century as a function of atmospheric temperature rise. From the analysis, two types of model behavior emerge. Either the local changes are the same as the global mean changes, or an additional local rise is seen which increases with rising atmospheric temperatures. The latter behavior reflects a dynamical sea level change associated with a reduction of the strength of the meridional overturning circulation that occur in those model simulations (Levermann et al 2004).

In contrast, the direct (linear) relationship between regional sea level change and the meridional overturning circulation under global warming in the North Atlantic has been disputed by Landerer et al. (2007). While they also find an additional local rise, they relate this local rise to ocean circulation changes other than MOC changes. As in Katsman et al (2008), the contribution of local steric changes is assessed here from linear fits to the model data. The asymmetric behavior resulting from these possible changes in ocean dynamics is accounted for by defining separate uncertainty bands for the upper end and lower end. The analysis yields a contribution ranging from $-0.05 \mathrm{~m}$ to $+0.20 \mathrm{~m}$ (central estimate is $+0.03 \mathrm{~m}$ ). 


\subsubsection{Local land movement}

On average, the Netherlands experiences about $0.03 \pm 0.05 \mathrm{~m} /$ century subsidence as the result of post glacial rebound, about $0.07 \mathrm{~m} /$ century tectonic subsidence and about $0.01 \pm 0.05 \mathrm{~m} /$ century subsidence as the result of deep layer compaction (Kooi et al 1998). Hence, a $0.11 \pm 0.07 \mathrm{~m}$ contribution due to vertical land movement is included in the projections for 2100 . This number does not include the (usually very local) subsidence due to peat oxidation in polders and subsidence due to drainage and ground water and gas/oil extraction.

\subsection{High-end projection for sea level rise along the Dutch coast in 2100}

The final high-end projection for local sea level rise along the Dutch coast in 2100 can now be obtained by adding the estimates for each of the separate contributions, as was done for the scenario for global mean sea level rise ${ }^{19}$. However, as explained in the previous section, it is at present unclear what fingerprint ratios are appropriate for the Greenland Ice Sheet and the Antarctic Ice Sheets. Because of the large impact of the applied fingerprint ratios on the final results, we consider both cases, referred to as local projection $A$ (using the fingerprints presented in Mitrovica et al, 2001) and B (fingerprints presented by Plag and Juettner, 2001). Depending on the applied fingerprint ratio, the highend projection for local sea level rise along the Dutch coast yields 0.40 to $1.05 \mathrm{~m}$ (scenario $A$ ) or -0.05 to $+1.15 \mathrm{~m}$ (scenario $B$, excluding vertical land movement, Table 1.3 and Figure 1.3). With the inclusion of vertical land movement the respective high-end scenarios for local sea level rise become +0.50 to $+1.15 \mathrm{~m}$ (scenario A) and +0.05 to $+1.25 \mathrm{~m}$ (scenario B). Disregarding the elasto-gravity effect results in a high-end scenario for local sea-level rise of +0.55 to $+1.20 \mathrm{~m}$ without and +0.65 to $+1.30 \mathrm{~m}$ with vertical land movement.

The bandwidth for scenario $B$ is much larger than that for scenario A, because the large values for the fingerprint ratios further amplify the uncertainties associated with the ice sheet contributions. The fact that the two scenarios have almost the same upper bound is coincidental - if the estimates for the global mean contribution of the ice sheets had been different, this would have not been the case.

We strongly recommend further research aimed at resolving this important issue in order to reduce the uncertainty in the high-end projection for local sea level rise along the Dutch coast.

Table 1.3: High-end projection for local sea level rise along the Dutch coast (in $\mathrm{m}$ ) based on the fingerprints presented in Mitrovica et al (2001, scenario A), and those presented by Plag and Juettner (2001, scenario B). We currently have no scientific basis to prefer one of the two fingerprints.

\begin{tabular}{|l|l|l|}
\hline $\begin{array}{l}\text { vertical land } \\
\text { movement }\end{array}$ & $\begin{array}{l}\text { high-end projection A } \\
\text { (using Mitrovica et al, 2001) }\end{array}$ & $\begin{array}{l}\text { high-end projection B } \\
\text { (using Plag \& Juettner, 2001) }\end{array}$ \\
\hline excluded & 0.40 to $1.05 \mathrm{~m}$ & -0.05 to $1.15 \mathrm{~m}$ \\
\hline included & 0.50 to $1.15 \mathrm{~m}$ & +0.05 to $1.25 \mathrm{~m}$ \\
\hline
\end{tabular}




\subsubsection{Comparison to KNMI'06 projections}

Figure 1.3 and Table 1.4 compare the individual contributions and the final projection for local sea level rise along the Dutch coast developed here (black: scenario A; blue: scenario $B$, both without vertical land movement) and the KNMI'06 warm scenario (red, van den Hurk et al, 2006). The KNMI'06 warm scenario is the appropriate scenario for comparison in this case, since we focus on the high end of the range for sea level rise scenarios. It yields a local rise of 0.4-0.85 $\mathrm{m}$, assuming a $4 \mathrm{C}$ temperature rise in $2100^{20}$.

The contribution of the global mean thermal expansion and of the local expansion both display a larger bandwidth in the current assessment for the Delta Committee than in the warm scenario of KNMI'06, because of the larger range in atmospheric temperature rise that is considered.

Also the estimated contribution of the ice sheets differs. Since elastic and gravitational effects were not taken into account in KNMI'06, the estimated (uncertainty in the) contribution from the Greenland Ice Sheet was very different from high-end projections presented here. Depending on the applied fingerprint ratio, the contribution either becomes smaller (high-end projection $A$ ) or negative (high-end projection $B)^{21}$.

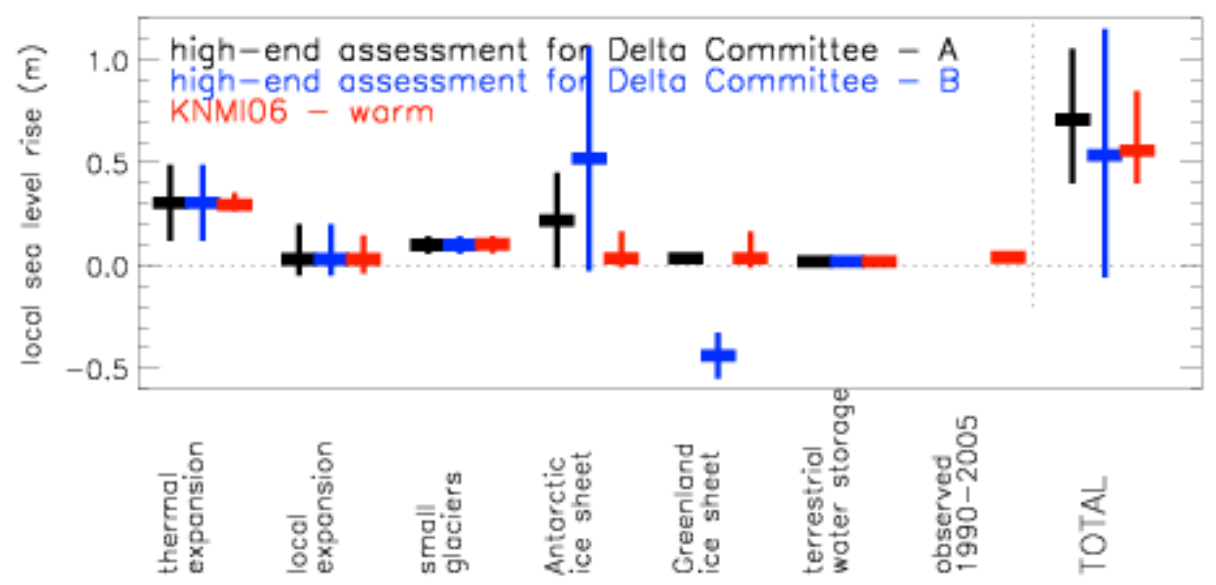

Figure 1.3: Comparison of individual contributions and total projected local sea level rise along the Dutch coast for 2100 as presented in this report (black: high-end projection $A$, using Mitrovica et al, 2001; blue: high-end projection B, using Plag \& Juettner, 2001), and in the KNMI'06 warm scenario (red, van den Hurk et al, 2006). In the KNMI'06 scenario, elasto-gravity effects were not accounted for and the contributions of the Greenland and Antarctic ice sheets were not treated separately. In this figure, the total contribution is split evenly between the two ice sheets.

20 Recently, the KNMI'06 scenarios for sea level rise were updated based on recent observations (as discussed in IPCC AR4 (2007), for example) and by incorporating elastogravity effects using the fingerprint ratios presented by Mitrovica et al (2001). The updated warm scenario (Katsman et al, 2008) is $0.4-0.8 \mathrm{~m}$, again assuming a $4 \mathrm{C}$ temperature rise in 2100 .

21 There is no significant difference between the updated ice sheet contributions in Katsman et al (2008) and those in high-end projection A. Both estimates apply the fingerprint ratio presented by Mitrovica et al (2001). 
The contribution from the Antarctic Ice Sheet assumed in this report is significantly larger than that assessed in KNMI'06 since it is estimated based on the possible effects of fast ice dynamics associated with marine ice sheet instability. In high-end projection B, the contribution of the Antarctic Ice Sheet (and its uncertainty) is further amplified by the large fingerprint ratio.

Table 1.4: Overview of all estimated contributions and the total high-end projections $A$ and $B$ for local sea level rise along the Dutch coast for 2100 assessed here (in $\mathbf{m}$ ), and the corresponding contributions reported in KNMI'06 for the warm scenario (4 $\mathrm{C}$ temperature rise). Vertical land movement is excluded. Numbers in brackets result from disregarding the elasto-gravity effect completely.

\begin{tabular}{|c|c|c|c|}
\hline component & assessment for the De & ta Committee & KNMI (2006) \\
\hline & high-end projection A & high-end projection B & warm scenario \\
\hline $\begin{array}{l}\text { global mean } \\
\text { thermal expansion }\end{array}$ & \multicolumn{2}{|c|}{+0.12 to +0.49} & +0.27 to +0.35 \\
\hline local expansion & \multicolumn{2}{|c|}{-0.05 to +0.2} & -0.04 to +0.15 \\
\hline small glaciers & \multicolumn{2}{|c|}{+0.06 to +0.14} & +0.06 to +0.15 \\
\hline Antarctic Ice Sheet & -0.01 to +0.45 & -0.03 to +1.07 & \multirow{2}{*}{$\begin{array}{l}-0.02 \text { to }+0.33 \\
\text { (not separated) }\end{array}$} \\
\hline $\begin{array}{l}\text { Greenland Ice } \\
\text { Sheet }\end{array}$ & +0.03 to +0.04 & -0.55 to -0.33 & \\
\hline $\begin{array}{l}\text { terrestrial water } \\
\text { storage }\end{array}$ & \multicolumn{2}{|c|}{0.0 to 0.04} & 0.0 to +0.04 \\
\hline total & 0.40 to 1.05 & -0.05 to 1.15 & \\
\hline $\begin{array}{l}\text { total, without } \\
\text { elasto-gravity }\end{array}$ & \multicolumn{2}{|c|}{$(+0.55$ to +1.2$)$} & 0.40 to 0.85 \\
\hline
\end{tabular}

\section{Sea level rise in the twenty-second century}

Although sea level rise projections may be required by those responsible for management of coastal systems on longer timescales than are generally provided for determining responses to other climate changes, making plausible projections of the local sea level is a challenging task. Robust sea level rise projections are not yet possible for this time frame since scientific understanding of some processes and models are incomplete. Moreover, for the period 2000-2100, at least the initial condition is constrained, and this cannot be said for the latter period. This particularly holds for the contributions of the Greenland Ice Sheet and West-Antarctic Ice Sheet to sea level rise. 


\subsection{Global mean thermal expansion}

For 2200, estimates of the global mean thermal expansion can be obtained by considering the limited set of climate model simulations that cover (part of) the twenty-second century and by applying the semi-empirical approach (Rahmstorf 2007) based on twenty-first century model results. When greenhouse gas concentrations are kept constant at levels observed in 2000, thermal expansion will raise global mean sea level by a couple of tens of centimeters (Wigley 2005). Such commitment simulations provide a low-end scenario for thermal expansion.

Climate model simulations that are of more relevance to the high-end scenario for sea level rise for the twenty-second century are those that assume either a stabilization of the CO2 concentration in 2100 at 700 ppm (IPCC AR4, 2007; Fig. 10.37), or a $1 \%$ per year increase in $\mathrm{CO} 2$ until a quadrupling of pre-industrial values is obtained (simulations end in the year 2140, see IPCC TAR, 2001; Fig 11.15 and the data in the CMIP3 database, 2007). On average, these model simulations yield a contribution of $0.4-1.0 \mathrm{~m}$ from global mean thermal expansion in 2200 with respect to 1990 . The rise in global mean atmospheric temperature associated with this rise is about $3-4 \mathrm{C}$.

When estimating the contribution from global mean thermal expansion by applying the semi-empirical approach using an analysis of model results for the twenty-first century (see Section 5.3.1) one has to acknowledge that the methodology has been contested (Schmith et al., 2007; Holgate et al., 2007; von Storch et al., 2008) and the caveats described in Section 5.3.1 should be kept in mind. The results are educated but rough estimates.

For an atmospheric temperature rise of $2.5-8 \mathrm{C}$ in 2200 , the analysis using the semi-empirical approach yields a central estimate of $0.8 \mathrm{~m}$ for the global mean thermal expansion, with a skewed distribution ranging from $0.3-1.8 \mathrm{~m}$ (the skewness results from the quadratic dependence of the expansion on global mean temperature assumed in the semi-empirical approach).

So the direct outcome of climate models and the application of the semiempirical approach yield a similar lower bound and central estimate, but the upper bounds differ considerably. Because of our focus on the high-end scenario, we estimate the contribution from global mean thermal expansion from the outcome of the semi-empirical approach (taking into account the skewness).

\subsection{Small glaciers}

As an estimate for the contribution of glaciers in 2200, we apply the scaling relation discussed in Section 2.2.2 to a temperature range of $2.5 \mathrm{C}$ to $8 \mathrm{C}$ (the same range used for the thermal expansion). This yields a eustatic contribution between 2000 and 2200 of $0.12-0.33 \mathrm{~m}$, close to twice the amount assessed for 2100. 


\subsection{Ice sheets}

Key uncertainty for (long-term) projections of sea level rise is the future behavior of the large ice sheets of Greenland and West-Antarctica. The amounts of ice currently stored in these ice sheets are sufficient to result in a $7 \mathrm{~m}$ global mean sea level rise from Greenland and $5 \mathrm{~m}$ from the West-Antarctic Ice Sheet, with the Amundsen Sea embayment containing an equivalent of $1.5 \mathrm{~m}$ global mean sea level, half that amount in currently-active glacier drainages. The question we are challenged to answer is to assess the potential rate at which these ice masses can contribute to sea level rise over the coming centuries.

Here, we provide some discussion of plausible scenarios of ice sheet change based on our expert opinion. In particular for 2200, these scenarios should be taken only as indicative of what is, in our opinion, plausible rather than of what is most likely. Since we know within bounds the current contribution of ice sheets to sea level rise and since acceleration of this contribution is unlikely to be rapid on a timescale of decades, this knowledge provides a constraint on the total contribution that may occur in the twenty-first century. For the twenty-second century, there is no such constraint.

\subsubsection{Antarctic Ice Sheet}

We base a conservative projection of the contribution of ASE to sea level rise to 2200 , on a simple continuation (no further acceleration) of the low discharge rate achieved at 2100 (see Section 2.2.3). This would produce around $0.22 \mathrm{~m}$ of sea level rise by 2200 . It is certainly clear that if such a rate of discharge is attained by 2100 , it is unlikely to be reduced thereafter and so this can provide a justifiable lower limit. Similarly, continuing the rate of contribution from the upper estimate of the higher scenario would suggest a total contribution by 2200 approaching $1.4 \mathrm{~m}$ global mean sea level rise. Given the uncertainty in these numbers, we omit here the small correction estimated to arise from additional accumulation.

While it is arguable whether these linear extrapolations are sensible, they certainly do not appear particularly extreme (they imply no further acceleration in the rates of discharge from the ice sheet after 2100). It would, at first glance, appear that exponential growth in the rate of discharge would be unlikely since it would imply rates of ice-discharge that could only be achieved by behavior within the ice sheet that is quite different from that we have seen up to now. However, to some extent, any plausible projection that seeks to bound possible behavior to 2200 must take account of the possibility that by 2100, ASE (and possibly marine glacier basins in EAIS) may already be undergoing a well-developed retreat, and that large areas of the ice-sheet, which are currently in equilibrium, may also start to contribute.

If climate change between now and 2100 produces, as predicted by IPCC projections, higher rates of warming across the Antarctic continent than the global mean, many areas that are currently not showing signs of change will begin to suffer loss during the period 2100-2200. Surface melting may begin on many ice shelves, and then as these ice shelves disintegrate (as has already been seen on the Antarctic Peninsula) many more glaciers will begin to accelerate 
and thin. By this time, areas of relatively stagnant ice within the ASE may be showing change due to the accumulated thinning of their neighboring glaciers, and the proportion of the Antarctic Peninsula that is losing ice may increase substantially. In short, much larger areas of the ice sheet may be implicated and the contribution to sea level rise may become substantially higher.

\subsubsection{Greenland Ice Sheet}

Based on the same assumptions formulated for 2100 , the additional sea level rise due to fast ice dynamics discussed in Section 2.2.3 is estimated at $+0.3 \mathrm{~m}$, which basically assumes a complete disappearance of the Jakobshavn Isbrae drainage basin. A further decrease of the surface mass balance by another 0.05 $\mathrm{m}$ for the moderate scenario and $0.3 \mathrm{~m}$ for the high scenario seems possible given the projections for the twenty-first century, adding up to a total contribution to sea level rise by 2200 of $0.5-0.8 \mathrm{~m}$.

\subsection{Plausible high-end scenario for global mean sea level rise for 2200}

The development of detailed model-based sea level rise projections for this time frame is not currently possible as scientific understanding of some processes is incomplete. In the previous sections, plausible but very rough projections for the main contributors to global mean sea level rise (thermal expansion of the ocean, and shrinking of the Greenland and Antarctic Ice Sheets) were discussed. The sum of these contributions yields a rough estimate for global mean sea level rise in 2200 of 1.5 to $3.5 \mathrm{~m}$ (see Figure 1.4 ).

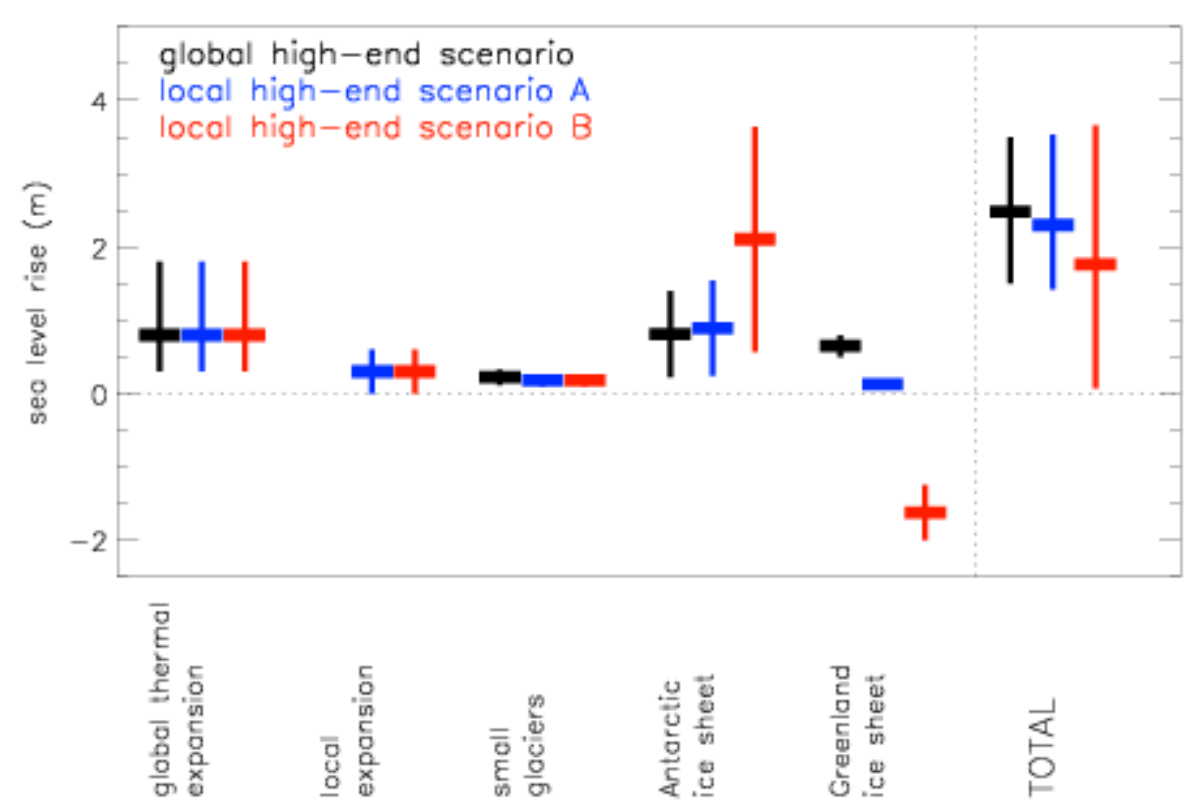

Figure 1.4: Individual contributions and total high-end projections for 2200 presented in this report (black: global mean sea level rise; blue/red: local sea level rise along the Dutch coast using the fingerprint ratios presented by Mitrovica et al (2001) and Plag \& Juettner (2001) respectively). Vertical land movement is excluded. 
Given the level of understanding of ice sheets available at this time, the estimates of the twenty-second century contribution from both Greenland and Antarctica are highly uncertain. However, their combined impact on global sea level is within the range suggested to have been achieved under natural rates of change at times of similar glacial conditions (see Section 2.2.3), and there is no reason to believe that these are unrealistic or unfeasible. The high-end scenario obtained in the previous section is consistent with the extension of the paleoclimatic estimate to 2200, which suggests a high-end scenario for global mean sea level rise of about 3 to $4 \mathrm{~m}$ in 2200 .

\subsection{Plausible high-end scenario for sea level rise along the Dutch coast for 2200}

When constructing a plausible high-end scenario for sea level rise along the Dutch coast for the twenty-second century, several local effects need to be taken into account: the possibility of a shutdown of the thermohaline circulation and its effect on local sea level, elastic and gravitational effects associated with shrinking land-based ice masses and vertical land movement.

As for 2100 , a $0.11 \pm 0.07 \mathrm{~m} /$ century contribution due to vertical land movement is easily included in the projections for 2200 .

For the Netherlands, the worst-case scenario with regard to local expansion due to changing ocean dynamics would be a complete collapse of the thermohaline circulation. Such a collapse would be associated with an additional local expansion of about $0.6 \mathrm{~m}$ in the North Atlantic Ocean. However, it is at present impossible to assign any likelihood to such a scenario, and at the other extreme, an unchanged thermohaline circulation cannot be ruled out either. This yields an estimate for the additional local expansion of 0.0-0.6 $\mathrm{m}$ in 2200 with respect to 2000.

As was pointed out in Section 2.4.1, the fingerprint ratio for the Greenland and Antarctic Ice Sheets required to properly take into account the elastic and gravitational effects is the subject of an ongoing scientific debate. This issue introduces a large uncertainty in scenarios for local sea level rise for the Dutch coast which amplifies the large uncertainties associated with the ice sheet contributions already involved in this long-term scenario. In Figure 1.4. we therefore present two scenarios for local sea level rise along the Dutch coast again, using the fingerprint ratios presented in Mitrovica et al (2001, high-end scenario A) and those presented in Plag \& Juettner (2001, high-end scenario B).

Without vertical land motion, high-end scenario A yields a local sea level rise of roughly 1.5 to $3.5 \mathrm{~m}$ along the Dutch coast; high-end scenario $B$ yields a rise of 0.0 to $3.5 \mathrm{~m}$ (final numbers are rounded off to $0.5 \mathrm{~m}$, see Figure 1.4 ). When the vertical land motion is included, both scenarios turn out $0.5 \mathrm{~m}$ higher (scenario A: 1.5 to $4 \mathrm{~m}$, scenario B: 0.5 to $4.0 \mathrm{~m}$ ). Without the elasto-gravity effect, the high-end scenario for local sea level rise for 2200 becomes +2.0 to $+4.0 \mathrm{~m}$ (both with and without vertical land movement because of the rounding off at $0.5 \mathrm{~m}$ ). 
As for the high-end scenario for local sea level rise for 2100 (Section 2.5), the large values for the fingerprint ratios for scenario B amplify the uncertainties associated with the ice sheet contributions. Again, the fact that the two scenarios only differ in their lower bound is coincidental - if the estimates for the global mean contribution of the ice sheets had been different, this would not have been the case. We therefore repeat our recommendation that further research aimed at resolving this important issue in order to reduce the uncertainty in the highend projection for local sea level rise along the Dutch coast is essential.

\section{Conclusions and recommendations}

In this report, we specifically explore, at the request of the Delta Committee, the high-end scenarios for global mean and local sea level rise for the years 2100 and 2200, using modeling results and expert judgment.

The high-end scenarios are presented as additional scenarios to earlier assessments of global mean sea level rise (IPCC AR4, 2007) and local sea level rise along the Dutch coast (KNMI, 2006).

Because of the caveats on our knowledge of current sea level changes (in particular of ice sheet dynamics), and hence our limitations in modeling its future behavior, the projections for sea level rise presented in this report are to be considered high-end scenarios of what - according to our expert judgment and based on the current level of scientific understanding - is plausible. It is by no means guaranteed that these high-end scenarios will remain valid as science progresses, that we bound the possibilities, or that the scenarios are agreed upon by the entire scientific community.

\subsection{Conclusions}

The high-end projection for global mean sea level rise in 2100 (Section 2.3) contains contributions from thermal expansion of the ocean, the shrinking of small glaciers, the Antarctic and the Greenland Ice Sheets and terrestrial water storage. It yields a global mean sea level rise of 0.55-1.10 m (see Table 1.1). The upper end of this scenario is substantially higher than that for the A1FI scenario reported by IPCC AR4. This is a reflection of the fact that we explicitly focus on the high end of the range of possibilities.

Local sea level may differ substantially from the global mean. To arrive at a projection for sea level rise along the Dutch coast (see Section 2.5), we consider elastic and gravity effects on local sea level arising from mass redistribution associated with melting of land-based ice masses, and local expansion differences with respect to the global mean and local vertical land movement (Section 2.4).

The quantification of the elastic and gravity effects associated with mass changes in the Greenland and Antarctic Ice Sheets is the subject of an ongoing scientific debate. In this report, we consider two widely varying cases in order to assess the impact of the current uncertainty in the fingerprints of the Antarctic and Greenland Ice Sheets on the local sea level projections, referred to as high-end 
scenario $A$ and $B$ (see Section 2.5). The two high-end projections for local sea level rise along the Dutch coast in 2100 yield $0.5-1.2 \mathrm{~m}$ (scenario $A$ ) and $0.05-$ $1.25 \mathrm{~m}$ (scenario $B$, both including vertical land movement). It should be noted that the fact that the two scenarios have almost the same upper bound is coincidental. The upper ends of the local scenarios are higher than that for the warm scenario reported by KNMI (2006). Again, this is a reflection of the fact that we explicitly focus on the high end of the possibilities.

The development of detailed model-based sea level rise projections for the year 2200 is not currently possible as scientific understanding of some processes is incomplete. In the Sections 3.1 to 3.3, plausible but very rough projections for the main contributors to global mean sea level rise (thermal expansion of the ocean, and shrinking of the Greenland and Antarctic Ice Sheets) were discussed. The sum of these contributions yields a rough estimate for global mean sea level rise in 2200 of 1.5 to $3.5 \mathrm{~m}$.

To construct a plausible high-end scenario for sea level rise along the Dutch coast for the twenty-second century, the following local effects were judged significant: the possibility of a shutdown of the thermohaline circulation and its effect on local sea level, elastic and gravitational effects associated with shrinking land-based ice masses and vertical land movement (see Section 3.5). As for 2100 , two scenarios are developed in order to assess the uncertainties in the quantification of the local contributions of the Greenland and Antarctic Ice Sheets. With vertical motion included, high-end scenario A yields a local sea level rise of roughly 1.5 to $4 \mathrm{~m}$ along the Dutch coast for 2200 , while high-end scenario $B$ yields a rise of 0.5 to $4 \mathrm{~m}$.

\subsection{Recommendations}

Sea level rise is a continuing, long-term process and will not cease in 2100 or in 2200. We therefore stress the need for flexible coastal management strategies, so that any decisions made now can be updated in light of new scientific understanding in the (near) future.

In addition, we stress that comprehensive monitoring of local sea level changes and global sea level rise is essential in order to narrow the current uncertainties and to be able to identify the possible need for further adaptations in coastal management. These observations essentially form an early warning system that could give us years to decades in which to prepare.

Global sea level predictions are severely hampered by a poor understanding of the dynamics of ice sheets. Further research on this issue is crucial in order to be able to reduce the uncertainties in the projections. Our ability to develop scenarios for local sea level rise is further complicated by the ongoing debate on the ratios between local and global mean sea level rise required to calculate the local contributions of the Antarctic and Greenland Ice Sheets. Progress in resolving this issue can be expected at a relatively short term. 


\section{Scientific background}

\subsection{Observed local sea level changes along the Dutch coast}

IPCC 4AR (see Ch. 5, Bindoff et al. 2007) reports a global mean rise of $1.8 \pm$ $0.5 \mathrm{~mm}$ /year deduced from tide gauges for the period 1961-2003, and an increased rise revealed by satellite radar altimetry of $3.1 \pm 0.7 \mathrm{~mm} /$ year for the period 1993-2003. These numbers represent an increased in ocean volume only (land motion is excluded).

Local sea level changes may differ substantially from the global mean; this is indeed the case for the Dutch coasts. Assessing changes of local sea level is a challenging task, for several reasons.

A basic question is, what "local sea level" actually is - "Local Sea Level" (LSL), which is the difference between ocean bottom and sea surface as given by tide gauges; - or "Sea Surface Height" (SSH) in a global reference frame. Here, the LSL definition makes more sense, as we are eventually interested in the threat to coastal defense.

A second question is how to attribute the different causes of LSL change, including natural subsidence or uplift of land, effects of gas, oil, or groundwater extraction, modifications of tidal dynamics induce by water works (such as closing the Zuiderzee in the 1930 s or the implementation of the Delta Plan in the 1950s), changing meteorology and changing volume of the ocean. This attribution is important as it gives an indication whether or not we have to assume that the present changes will continue into the future

Using monthly mean sea level data from PSMSL, Plag (pers. communication) estimated linear trends in LSL at various North Sea tide gauges for the time horizons 1840-1950, 1950-2008, and 1980-2003. In six out of eight Dutch locations he found larger trends in 1950-2008 than in 1840-1950; the trends vary considerably among the Dutch locations, with minimum values of $0.9 \mathrm{~mm} / \mathrm{yr}$ (West-Terschelling) and maximum values of $2.8 \mathrm{~mm} / \mathrm{yr}$ (Hoek van Holland) in 1950-2008.

Tide gauges are usually installed in harbors, and, particularly in the second half of the twentieth century, harbors were often modernized to improve accessibility of harbors to ships. Such efforts often lead to a significant if not dramatic increase of the tidal range.

For a series of German locations, located either on islands or at the coastline, Jensen and Mudersbach (2004) examined the changing tidal ranges, and found that many of them showed stationary tidal ranges until the 1950s; beginning in the late 1950s the tidal ranges began abruptly to rise. These ensuing trends were larger at the coastal locations, where the bigger harbors are, indicating that the modernization of harbors had a significant impact on the tidal range and thus on LSL. It is plausible that similar effects are contained in the PSMSL data for the Dutch tide gauges. Pfizenmayer (1997) found the mean rise of high tide levels in, for example, Den Helder and Esbjerg (Denmark) uncorrelated - apart from 
positive, but different trends. Likely, Den Helder was significantly affected by the closing of the Zuiderzee in the 1930s. Since most of the water works commenced in the 1950s, as part of either improvements in coastal defenses after the 1953 event or the modernizations of ports during post-war economic reconstruction, it may be better not to compare LSL change during the post-World War II time with the trends during the pre-World War II period. Indeed, climate related LSL change should be observable only with some lag following temperature rise, which may be traced to elevated GHG levels only since the 1980 s or later (e.g., Rybski et al., 2006).

Two stations that seem hardly affected by environmental modifications are Norderney and Helgoland in Germany. For Norderney (see Figure 1.5), a steady, non-accelerated increase from 1880 until 2006 in mean high tide water of 2.6 $\mathrm{mm} / \mathrm{yr}$ and in mean low tide water of $1.3 \mathrm{~mm} / \mathrm{yr}$ is reported (Niemeyer, personal communication), implying a LSL rise on the order of $2.0 \mathrm{~mm} / \mathrm{yr}$. Similar numbers are found for Helgoland (Thorenz, personal communication).

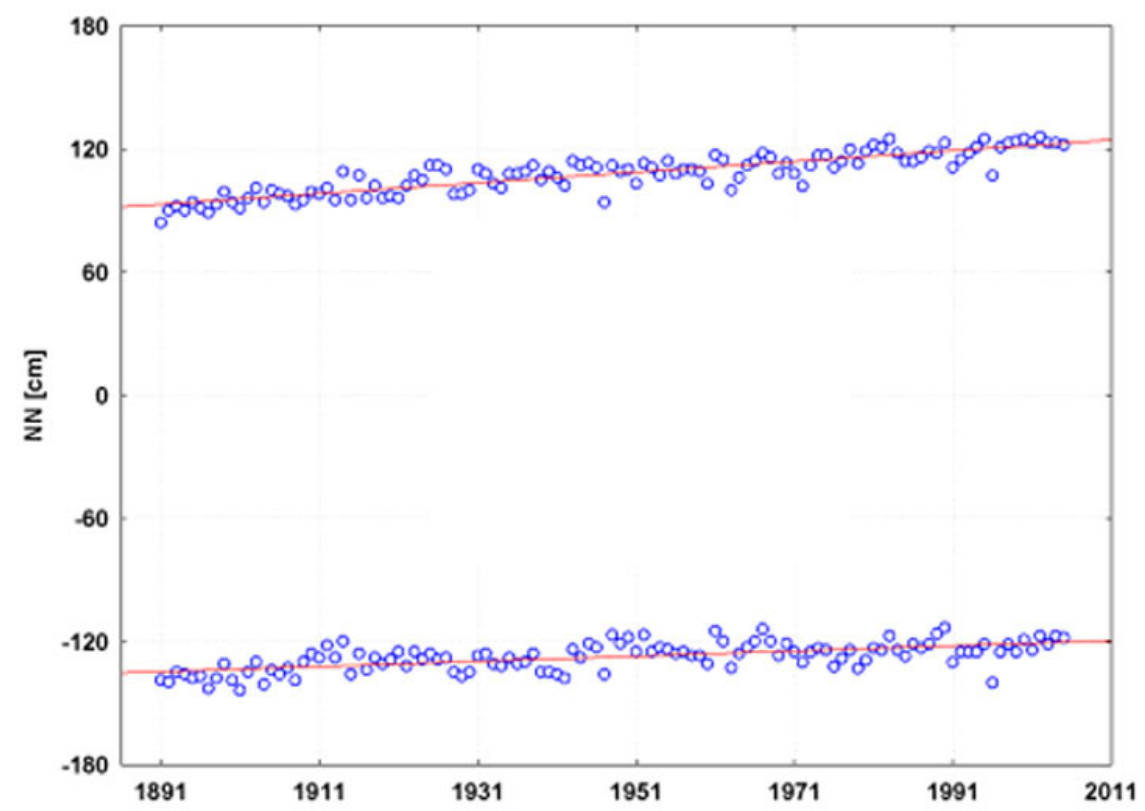

Figure 1.5: Rise of mean high (top) and low (bottom) tide levels in the North Sea, as recorded by the tide gauge at Norderney Riffgatt; the data are very likely homogeneous, i.e., free of spurious signals related to human interventions. (H.-D. Niemeyer; pers. comm.). The trend of mean annual high tide is given by 93,1 $+0.26 \cdot($ year-1891), and for the mean annual low tide by $-134,6+0.13 \cdot($ year-1891), in $\mathrm{cm}$.

In the framework of the CoastDat project, Weisse and Plüss (2005) simulated water levels variations in the North Sea in 1958-2008 using regional re-analysis of weather conditions. Thus, the model simulated only the effect of changing weather; factors related to ocean volume or local bathymetric changes were disregarded. They found an increase in mean tidal high waters along the Dutch coast of about $1 \pm 1 \mathrm{~mm} / \mathrm{yr}$. The primary cause was most likely the strengthening of mean westerly winds during this period when the North Atlantic Oscillation (NAO) rose, intensifying counterclockwise circulation in the North Sea and thereby increasing coastal water levels. The NAO has returned to a less 
westerly regime, and it remains to be seen what the coastal sea level in the North Sea does.

In summary: LSL trends for the Dutch tide gauges for the last 50 years vary spatially between $0.9 \mathrm{~mm} / \mathrm{yr}$ and $2.8 \mathrm{~mm} / \mathrm{yr}$. Since these tide gauges may not have captured the full range of spatial variations, we assume here a spatial variability of the LSL trend at the Dutch coast of $0.7 \mathrm{~mm} / \mathrm{yr}$ to $3.0 \mathrm{~mm} / \mathrm{yr}$ for the last 50 years.

Vertical land motion determined from Dutch GPS stations vary also on the order of about $2 \mathrm{~mm} / \mathrm{yr}$. Thus, part of the spatial variability in LSL likely originates in spatially variable vertical land motion. However, another significant component must be attributed to the local effect of water works affecting local bathymetry, while a smaller contribution may come from spatial variations in thermal expansion, ocean circulation and atmospheric forcing.

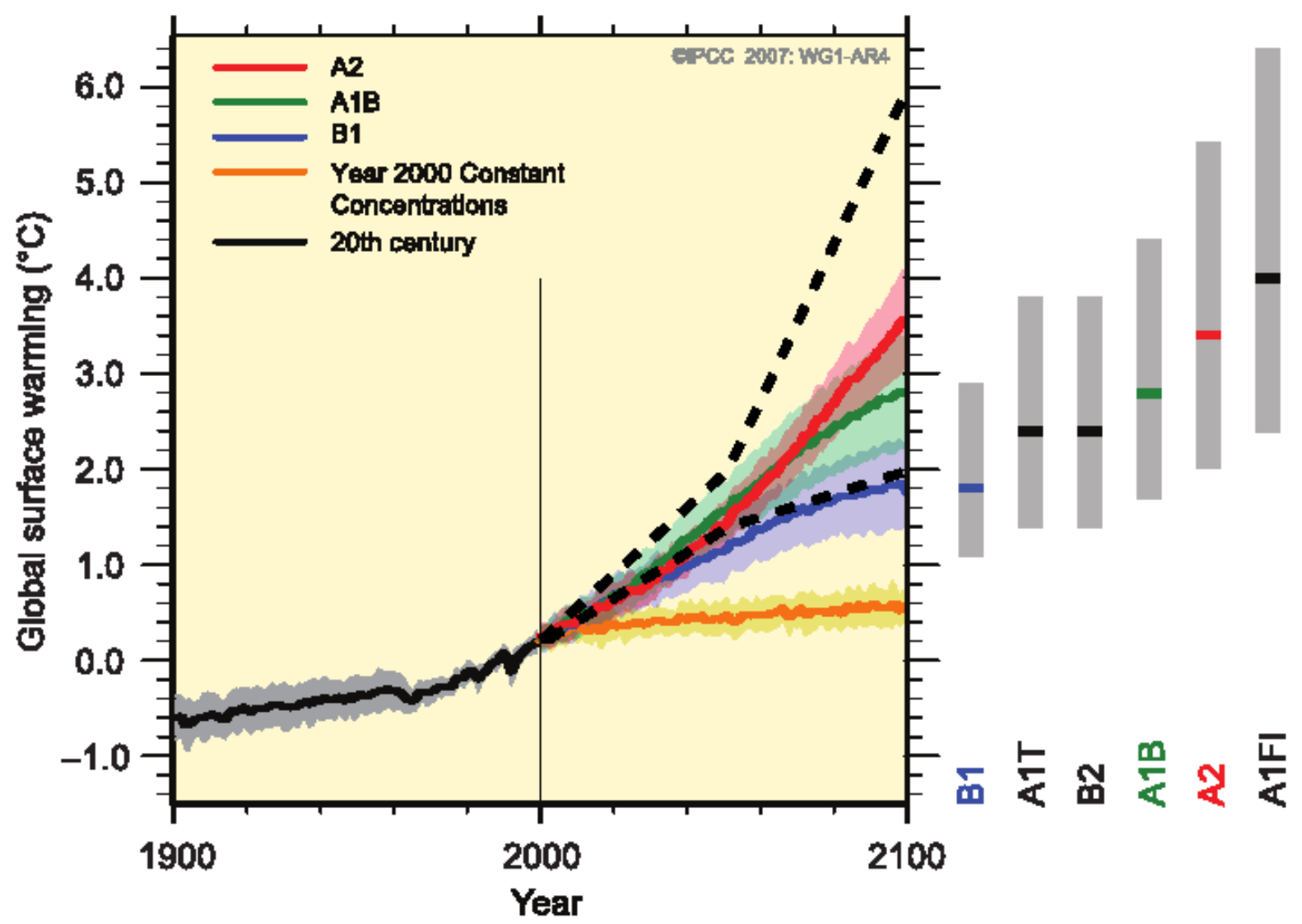

1.6: Dashed, black lines outline the assumed temperature evolution to 2100 used in this assessment. They are overlaid on multi-model global averages of surface warming (relative to 1980-1999) for the scenarios $A 2, A 1 B$ and $B 1$ and the experiment where concentrations were held constant at year 2000 values (solid, colored lines), shown as continuations of the 20th century simulations (reproduced from IPCC AR4, 2007; Figure SPM5). 


\subsection{High-end scenario for atmospheric temperature rise for 2100}

Except for the contribution of the Antarctic ice sheet to sea level rise, all contributions are assumed to be (partly) dependent on the rise in global mean atmospheric temperature projected for the course of the twenty-first century. The global mean atmospheric temperature rise associated with the scenarios is 2 C (limited) and 6 C (severe) in 2100 with respect to 1990, matching the projected range in global mean atmospheric temperature rise reported by IPCC 4AR for the A1FI scenario (see Ch. 10, Meehl et al. 2007).

The temperature evolution to 2100 used here are scaled versions of the SRES B1 and $A 2$ scenarios, and are assumed to be non-linear in time. For the low end of the range, it is assumed that the temperature curve flattens in the second half of the twenty-first century (similar to the curve for the B1 scenario in Fig. SPM-5 of IPCC 4AR) by defining that two-thirds of the temperature rise is already achieved in 2050. In contrast, for the high end of the range, it is assumed that the rate of temperature rise increases over the course of the twenty-first century (similar to the A2 scenario) by defining that only one-third of the rise is achieved in 2050.

\subsection{Global mean thermal expansion}

In IPCC AR4 (2007), the contribution of global mean thermal expansion to twenty-first century sea level rise is presented grouped by emission scenario obtained from climate model simulations (see Table 10.7). The ranges obtained for the different scenarios display a considerable overlap and are fairly wide. For the two extremes of the scenario ensemble (B1 and A1FI respectively), global mean thermal expansion is estimated to contribute 0.10-0.24 m and 0.17-0.41 $\mathrm{m}$ respectively. This large overlap indicates that uncertainties in the projections for global mean sea level are influenced by model uncertainties more than by uncertainties in emission scenarios (see Section 1.2). To treat this model uncertainty, it is advantageous to have a large model ensemble for the analysis of global mean thermal expansion. As with the KNMI'06 scenarios, we therefore analyze its contribution as a function of global mean atmospheric temperature rise.

The Delta Committee has requested that we explore the higher end of the scenarios for sea level rise. We therefore consider a temperature range of 2-6 C in 2100 , corresponding to the ranges projected for the most severe emission scenarios (IPCC 2007, Table SPM3; Section 5.2). These atmospheric temperature changes include (estimated of) the effects of the carbon cycle feedback. Since this feedback is absent in the climate model simulations available to analyze global mean thermal expansion, the largest temperature rise reached by these simulations is $5.2^{\circ} \mathrm{C}$, and there is a need to extrapolate the model results to a 6 C temperature rise in 2100 .

\subsubsection{Methodology}

To estimate the contribution of global mean thermal expansion makes to sea level rise as a function of atmospheric temperature rise, two idealized scaling relations for the expansion and the rise in global mean atmospheric temperature (Katsman et al, 2008; Rahmstorf, 2007) are applied. The first method (applied 
for the year 2100 only) involves an analysis of global mean thermal expansion as a function of atmospheric temperature rise from the set of 21st century model simulations available from the CMIP3 database (Meehl et al, 2007). The second method (applied for the years 2100 and 2200) is based upon the semi-empirical approach proposed by Rahmstorf (2007). Both methods have their limitations when applied to the high end of the scenario range (large atmospheric temperature rise, long time scales) and can only be expected to give reasonable estimates for a limited temperature range. This is discussed extensively below. Finally, for 2200, estimates of the global mean thermal expansion are obtained by considering the limited set of climate model simulations that cover (part of) the twenty-second century as well.

\section{CMIP3 analysis}

As described in Katsman et al (2008), the contribution of global mean thermal expansion $\left(\mathrm{TS}_{\mathrm{G}}\right.$ ) can be estimated based on an analysis of climate model simulations for the twenty-first century (Meehl et al, 2007). The dataset that is used for the analysis consists of 41 simulations forced by the $A 1 B, A 2$ or $B 1$ emission scenarios, obtained with 13 different climate models. The climate model simulations are corrected for model drift, assuming that the SRES scenario runs contain a similar drift as the accompanying pre-industrial control runs (Gregory et al, 2001), which can be subtracted. The dependency of $\mathrm{TS}_{\mathrm{G}}$ on the atmospheric temperature change is described by a linear fit through the data for 2100 (see Katsman et al, 2008; Fig. 3).

The linear fit that is found needs to be seen as a local, first order approximation to a non-linear relation, only valid for a certain limited temperature range. Katsman et al (2008) applied the method for a temperature range of 2-4 C, which coincides with the actual temperature rises reached by the set of models analyzed. Here, it is assumed that the linear fit is valid for atmospheric temperature rises outside this range as well. However, since none of the models analyzed actually reaches a $6 \mathrm{C}$ temperature rise, it is unclear how accurate the fit is for that temperature rise.

\section{Semi-empirical method}

The global mean thermal expansion in the twenty-first century can also be estimated semi-empirically, as outlined by Rahmstorf (2007), based on model simulations or observations. The method assumes a linear relation between the rate of global mean thermosteric sea level rise and the atmospheric temperature rise:

$\mathrm{dTS}_{\mathrm{G}} / \mathrm{dt}=\mathrm{SLS} \Delta \mathrm{T}_{\mathrm{atm}}$

with $\mathrm{dTS}_{\mathrm{G}} / \mathrm{dt}$ the rate of global mean thermal expansion, $\Delta \mathrm{T}_{\mathrm{atm}}$ the atmospheric temperature rise since pre-industrial times, and SLS the thermosteric "sea level sensitivity" (in $\mathrm{mm} / \mathrm{yr} / \mathrm{K}$ ). To estimate the global mean thermal expansion $\mathrm{TS}_{\mathrm{G}}$ over the period 2005-2100, the expression is integrated over time

$$
\begin{aligned}
\mathrm{TS}_{\mathrm{G}} & =\mathrm{SLS} \int \mathrm{dT}(\mathrm{t}) \mathrm{dt}^{\prime} \\
& =\mathrm{SLS} \int \Delta \mathrm{T}_{2005}+\left(\Delta \mathrm{T}_{\mathrm{atm}}(\mathrm{t})-0.3\right) \mathrm{t} / 95 \mathrm{dt}^{\prime}
\end{aligned}
$$

In this expression, $\Delta \mathrm{T}_{2005}$ is the atmospheric temperature rise between preindustrial times and 2005. $\Delta \mathrm{T}_{\mathrm{atm}}(\mathrm{t})$ represents the atmospheric temperature rise 
with respect to 1990 (most scenario results are expressed with respect to this base year). In the calculations, it is assumed that the temperature rise over $1990-2005$ is $0.3 \mathrm{C} . \Delta \mathrm{T}_{2005}$ is estimated at $0.9 \pm 0.1 \mathrm{C}$.

The rationale for assuming (as a first order approximation) a linear relation between the rate of thermosteric sea level rise and the atmospheric temperature rise can be explained as follows. When the expansion coefficient of the ocean is assumed linear, the rate of thermosteric sea level rise will be proportional to the rate of ocean warming: $\mathrm{dTSG} / \mathrm{dt} \sim \mathrm{dToc} / \mathrm{dt}$. In turn, the rate of ocean warming is directly linked to the ocean heat flux at the surface: dToc/dt $\sim$ Qsurf. Assuming that the effects of changes in wind can be neglected for the global mean, the ocean heat flux is proportional to the temperature difference between the ocean and the atmosphere: Qsurf Tatm-Toc.

Now assume that the atmosphere starts to heat fairly rapidly and monotonically (as can be expected for the case for a global warming scenario), starting from an equilibrium situation for which $\operatorname{Tatm}(0)=\operatorname{Toc}(0)$. At time $t$, the temperature $\operatorname{Tatm}(\mathrm{t})=\operatorname{Tatm}(0)+\mathrm{dTatm}(\mathrm{t})$. Since the heat capacity of the ocean is much larger than that of the atmosphere, the ocean temperature will rise much slower: $\operatorname{Toc}(\mathrm{t})=\operatorname{Toc}(0)+\varepsilon \mathrm{dTatm}(\mathrm{t})$ with $\varepsilon<1$. That is, the temperature difference at this time can be approximated as Tatm-Toc $=(1-\varepsilon) \mathrm{dTatm}(\mathrm{t}) \approx \mathrm{dTatm}(\mathrm{t})$. This yields the assumed linear relation between the rate of thermosteric sea level rise and the atmospheric temperature rise.

The semi-empirical approach is contested on statistical and physical grounds (Schmith et al., 2007; Holgate et al., 2007; Rahmstorf, 2007b; von Storch et al.,2008), and more research is needed to determine the skill of the methodology. The semi-empirical approach was constructed specifically for ongoing upward trends and not for general developments in sea level

(Rahmstorf, pers. comm.). It can only be expected to give reasonable results for the initial response to a rapid change away from a previous near-equilibrium. As was shown by von Storch et al (personal communication), the semi-empirical method has rather poor skill in predicting general sea level variations. Similarly, the approximation cannot be valid for types of forcing for which the pattern of forcing cannot be approximated just by the global mean temperature, like volcanic forcing. As expected based on the physical background given in the previous section, sea level variations in response to fluctuating atmospheric conditions can be predicted with much more skill based on ocean heat flux variations, as the latter provide a more direct link with sea level variations (von Storch et al, personal communication).

\subsubsection{Comparison of results for a 2-4 C temperature rise in 2100}

For the three emission scenarios considered (A1B / A2 / B1) the range for global mean thermal expansion between 1980-1999 and 2090-2099 reported by IPCC 4AR (Ch. 10) are $0.10-0.35 \mathrm{~m}$ (Table 10.7). For a temperature range of 2 to $4 \mathrm{C}$ in 2100 (which matches the temperatures reached by the climate models for these three emission scenarios) the estimates from the CMIP3 analysis are only slightly higher $(0.13-0.37 \mathrm{~m})$. The results from the semi-empirical approach using the twenty-first century SLS display a very similar central estimate but a wider range $(0.04-0.46 \mathrm{~m})$. When the SLS calculated for the twentieth century is 
applied, the estimate for global mean thermal expansion yields $0.06-0.52 \mathrm{~m}$ : again a fairly wide range but a central estimate that exceeds the others by 0.04 to $0.06 \mathrm{~m}$ (about 20\%). Also Rahmstorf (2007) reported that application of the semi-empirical approach based on twentieth century model data resulted in a $30 \%$ overestimation of global mean thermal expansion in comparison to the actual expansion seen in the model simulation.

\subsubsection{Discussion}

As discussed in the previous sections, estimating the contribution of global mean thermal expansion based on an analysis of the CMIP3 database (Katsman et al., 2008) and by the application of the semi-empirical approach (Rahmstorf, 2007) both have their limitations. Clearly, the debate on the applicability of the semiempirical approach for sea level rise projections is ongoing. However, since there are no other means by which we can estimate global mean thermal expansion outside the range of parameters (time, atmospheric temperature rise) covered by climate models, we do apply it here, but with caution and while validating it against the outcomes of climate model simulations whenever possible.

When applied in this way, the simple approaches are thought to be useful for exploring the sensitivity of thermal expansion to larger time horizons in combination with temperature scenarios for which climate model simulations are absent or scarce. While doing so one off course needs to keep in mind that the results of the approach are a first order approximation and will be more uncertain as one moves away further from the parameter range covered by climate models.

\subsubsection{High-end projection for the year 2100}

The contribution of global mean thermal expansion for 2100 is defined from the results of the CMIP3 analysis and the semi-empirical approach. The CMIP3 analysis yields a linear dependence of global mean thermal expansion on temperature of $4.85 \mathrm{~cm} / \mathrm{C}$, with an uncertainty of $7.3 \mathrm{~cm}(5-95 \%$ confidence interval). In order to apply the semi-empirical approach, the thermosteric sea level sensitivity (SLS) is analyzed from climate model simulations for the twentieth century, climate model simulations for the twenty-first century, and from observations (see Appendix I). Projections for the global mean thermal expansion in 2100 with respect to 2005 based on the individual approaches are given in Table 1.5 .

The final high-end projection for global mean thermal expansion reported here is obtained in the following way. First, central values are calculated over the full temperature range for the upper three analyses shown in Table $1.5^{22}$. Then, (skewed) uncertainty bands are defined by quadratic summation of uncertainties with regard to atmospheric temperature rise and SLS, again for each of the three analyses. The final high-end projection is the average over the results obtained

22 The observation-based estimates are left out, as they lie within the ranges obtained from the twentieth-century climate model simulations. 
from the CMIP3 analysis and the two semi-empirical results. It yields a contribution of $0.12-0.49 \mathrm{~m}$ in 2100.

Table 1.5: Global mean thermosteric sea level change $T S_{G}$ in 2100 (in m), including uncertainty ranges

\begin{tabular}{|l|l|l|}
\hline$\Delta T_{\text {atm }}$ & $2 \mathrm{C}$ & $6 \mathrm{C}$ \\
\hline CMIP3 analysis & $0.13-0.27$ & $0.32-0.47$ \\
\hline semi-empirical from climate models & & \\
\hline SLS $=1.2 \pm 0.8 \mathrm{~mm} / \mathrm{yr} / \mathrm{K}(20$ th $\mathrm{cty})$ & $0.07-0.36$ & $0.13-0.62$ \\
\hline $\mathrm{SLS}=1.0 \pm 0.7 \mathrm{~mm} / \mathrm{yr} / \mathrm{K}(21 \mathrm{st}$ cty & $0.04-0.32$ & $0.08-0.55$ \\
\hline semi-empirical from observations & & \\
\hline $\mathrm{SLS}=1.76 \mathrm{~mm} / \mathrm{yr} / \mathrm{K}(0-300 \mathrm{~m})$ & 0.32 & 0.55 \\
\hline $\mathrm{SLS}=1.67 \mathrm{~mm} / \mathrm{yr} / \mathrm{K}(0-700 \mathrm{~m})$ & 0.30 & 0.52 \\
& & \\
\hline
\end{tabular}

\subsubsection{High-end projection for the year 2200}

For 2200, rough estimates of the global mean thermal expansion are obtained by considering the limited set of climate model simulations that cover (part of) the twenty-second century and by applying the semi-empirical approach (see Section 5.3.1)

Climate model simulations for the twenty-second century assume either a stabilization of the CO2 concentration in 2100 at 700 ppm (IPCC AR4, 2007; Fig. 10.37), or a $1 \%$ per year increase in $\mathrm{CO} 2$ until a quadrupling of pre-industrial values is obtained (simulations end in the year 2140, discussed in IPCC TAR, 2001; Fig 11.15; more recent simulations are available from the CMIP3 database, 2007). On average, these model simulations yield a contribution of 0.4-1.0 m from global mean thermal expansion in 2200 with respect to 1990. The rise in global mean atmospheric temperature associated with this rise is about $3-4 \mathrm{C}$.

When estimating the contribution from global mean thermal expansion by applying the semi-empirical approach using an analysis of model results for the twenty-first century (see Appendix I0) one has to acknowledge that the methodology has been contested. More research is needed to determine the skill of this methodology and the outcome should therefore be treated with caution. For an atmospheric temperature rise of $2.5-8 \mathrm{C}$ in 2200 , the analysis using the semi-empirical approach yields a contribution of $0.3-1.8 \mathrm{~m}$ from global mean thermal expansion (central estimate $0.8 \mathrm{~m}$ ).

So both sources of information yield a similar lower bound and central estimate, but the upper bounds differ considerably. In all, we estimate the contribution from global mean thermal expansion by simply averaging the two central estimates. The uncertainty bands are defined by quadratic summation of (taking into account the skewness of the outcome of the semi-empirical approach), and assuming that the two ranges are largely independent as they are based on different data. This yields a contribution of about 0.4 to $1.5 \mathrm{~m}$ sea level rise by 2200 with respect to 2000 . 


\subsection{Ice sheets}

In the field of sea level rise projection, the models describing large ice sheets are not yet as well developed as climate models. Except on the longest timescales (i.e., tens of millennia), they have little demonstrable skill in simulating the past contribution of ice sheets to sea level change, and the agreement among experts about the magnitude, timing and regionality in the projections of ice sheet changes is very low.

Foremost among the reasons for this lack of skill is a lack of testing data. There is a paucity of well-mapped, and well-dated histories of past ice sheet changes that might be used to calibrate and test ice-sheet models. Until such histories can be drawn from the geological record and are used to build confidence in a new generation of ice-sheet models that capture all of the significant processes that lead to ice-sheet change, there will continue to be uncertainty in the prediction of the ice-sheets contribution to sea level rise on the timescale of a few decades to several millennia. In the absence of valid models for continental ice sheets, the projection of ice sheet behavior based on extrapolation of recent rates of ice loss or acceleration of ice loss presents a way forward, as IPCC AR4 also noted (see Ch. 10, Meehl et al., 2007).

A related issue was highlighted in IPCC 4AR and cited as a reason for the apparent increase in uncertainty since the last assessment,

"The TAR concluded that accelerated sea level rise caused by rapid dynamic response of the ice sheets to climate change is very unlikely during the 21st century (Church et al., 2001). However, new evidence of recent rapid changes in the Antarctic Peninsula, West Antarctica and Greenland (see Section 4.6.3.3) has again raised the possibility of larger dynamical changes in the future than are projected by state-of-the-art continental models, such as cited above, because these models do not incorporate all the processes responsible for the rapid marginal thinning currently taking place."

The most vulnerable parts of ice sheets are thought to be the so-called marine ice sheets (Appendix II), like the one that covers the majority of West Antarctica, a few glaciers in East Antarctica, and Jacobshavns Isbrae on Greenland.

\subsubsection{Antarctic ice sheet}

Observations provide support for the view that WAIS may lose a significant fraction of its mass on timescales relevant for coastal planning. There are, however, also reasons to believe that the process may not involve the entirety of WAIS (Appendix II). It is now very clear that of the three main areas of outflow in West Antarctica only the Amundsen Sea embayment (ASE) is currently showing signs of retreat. However, the imbalance in ASE is currently only contributing to sea level rise at a rate of $3 \mathrm{~cm} /$ century. This implies that any scenarios we develop for the period up to 2100, must take account of the fact that the contribution from ASE begins from a low initial rate.

Known unknowns 
Despite improvements in observations, our understanding of the marine ice sheet instability is at present inadequate to make realistic projections for several reasons. In particular, the models of collapse presented so far, indicate only the potential instability in the system, and those models cannot be used to explore rates at which collapse might be expected to proceed, or whether there are features in the system that could halt the retreat long enough for a new equilibrium, or on the other hand, a re-advance, to be established.

It appears likely that the rate at which collapse could occur, will be controlled by some rate-determining process that has to date not even be considered. These might include some processes that are rather subtle, and at present impossible to predict; for example, the rate at which the massively thick icebergs formed by the ice sheet retreat could be melted, and/or exported across a continental shelf that is considerably shallower than the potential iceberg thickness.

Similarly, at present the models indicate that retreat will proceed wherever there is a down-sloping bed inland. However, the bed beneath any ice sheet has considerable roughness, including many bumps and protuberances, which might serve to pin grounding line retreat, by providing a locally rising bed-slope. An important and un-addressed question is thus, how long could a particular bump pin a retreating grounding line, and under what circumstances could that be long enough for an equilibrium to be re-established within the ice sheet? Here, we would clearly benefit from a strong precedent within the geological record (see discussion in Section 5.3), which might allow us to determine the timing or a marine ice-sheet collapse that occurred from a similar starting point in the past. High-end projection for the Antarctic ice sheet contribution for 2100

Based on the results of continental ice-sheet models, IPCC AR4 projects (see Ch. 10, Meehl et al., 2007) that Antarctica will gain mass through 2100, because increases in accumulation are expected to exceed losses due to melting and ice dynamics. Based on the considerations above, we propose the following additional projections as complementary to those in AR4 for the purposes of risk management. They are based on plausible contributions from three areas of Antarctica that are already showing signs of change:

- The Amundsen Sea Embayment (ASE)

- The three marine glacier basins in East Antarctica that are showing recent thinning (EAIS-g);

- The northern Antarctic Peninsula (n-AP), an area that has suffered recent increases in atmospheric temperature, increase glacier melt, glacier retreat , and glacier acceleration ,

We first discuss a modest scenario based on continued increase in the glacier velocities in ASE and EAIS-g, and continued melting and glacier flow on in the nAP

ASE

The net imbalance that we now see in Pine Island Glacier (the best-measured glacier in the ASE) is around $-50 \%$, meaning that about $50 \%$ more ice is now leaving the glacier-basin than it being replaced by snow. This imbalance appears to have resulted from glacier accelerations that have produced an increase in flux since 1974 when the basin was close to balance. Analysis of repeat

interferometry and sequential Landsat imagery revealed several episodes of 
acceleration (1974-87, 1994-2000, and more recently to 2007), some of which were separated by periods of steady flow. Together these episodes increased the velocity of Pine Island Glacier by around $50 \%$ in 30 years.

The change in ASE discharge since 1974 suggests a growing imbalance and an increasing contribution to sea level rise. A most conservative projection of recent changes would be represented by a linear projection of the recent trend to 2100 . A less conservative interpretation that takes in account the clearly observable increase in the rate of change in the last decade would be to project to 2100 on the basis of continued acceleration in discharge for ASE at a rate $1.3 \%$ per year (this is a value that appears to match the changes since 1974). Figure 1.7 shows a compilation of observations of mass change in West and East-Antarctica. The changes imply that by 2100 , glacier discharge will be around 3 - 5 times the balance velocities, and the ASE basin will contributing to global sea level rise at a rate of $1-2 \mathrm{~mm}$ per year. Based on this scenario, the total contribution to sea level rise for the period $2000-2100$ is estimated to be $5.6-9.3 \mathrm{~cm}$.

Although this is a substantial extrapolation and implies mass loss from the ASE catchment, it does not represent a major change in the regime of the ASE ice sheet. Flow velocities achieved by 2100 are still around the magnitude that was seen on Jakobshavn Isbrae, prior to its recent acceleration.

\section{EAIS-g}

Accelerated ice stream discharge, but with lower rates of thinning, has been observed across the basins of three East Antarctic glaciers; Totten Glacier, the glacier which feeds Cook Ice Shelf around $150^{\circ} \mathrm{E}$, and Denman Glacier. These glaciers also have a marine character and may contain similar vulnerabilities to ASE. Together these glaciers have a balance flux of (respectively) 74.6, 28.0, and 18.6 Gigaton/year (Gt/yr). This gives a total balance flux for these glaciers of $121 \mathrm{Gt} / \mathrm{yr}$, which is a little less than that of the ASE basins. It seems reasonable to assume that these basins could make a similar, but probably slower, contribution up to 2100 . Insufficient data exist to allow an extrapolation similar to that done for ASE, and a simple scaling will have to suffice. The present loss from these glaciers appears to be around -11 Gt/yr, compared to the $-90 \mathrm{Gt} / \mathrm{yr}$ loss from ASE (values from ). For this conservative estimate, we assume that the projected loss develops similarly to that from ASE, and can be scaled by this initial rate. This implies this area will contribute $0.7-1.2 \mathrm{~cm}$ in the period 2000-2100.

\section{$\underline{n-A P}$}

The further loss of ice shelves around the Antarctic Peninsula, related glacier acceleration, and increased runoff from melt, are all likely consequences of continued warming on the northern Antarctic Peninsula. At present the contributions from the latter two processes appear to be roughly equal and give a current rate of contribution of $0.16 \pm 0.06 \mathrm{~mm}$ global sea level rise per year. The only published estimates are for the contribution from increasing melt water runoff (Vaughan, 2006), estimated to contribute 3.0 - $56 \mathrm{Gt} / \mathrm{yr}$ by 2050 . Taking this as a mean for the entire century implies a contribution of $0.8-15 \mathrm{~mm}$. If we assume, without strong justification, that glacier acceleration (due to both ice-shelf loss, and acceleration of tidewater glaciers) increases similarly, the total contribution is $2.4-45 \mathrm{~mm}$ in the period $2000-2100$. 
So under this modest scenario, which we could characterize as not implying any particularly extreme behavior, we see the Antarctic ice sheet contributing around $0.065-0.15 \mathrm{~m}$ to global sea level rise, by 2100 as a consequence of changing ice dynamics. To account for the increase in accumulation over Antarctica projected by IPCC AR4 (Meehl et al., 2007), we reduce this estimate by $0.08 \mathrm{~m}$, and arrive at a contribution of -0.01 to $0.07 \mathrm{~m}$.
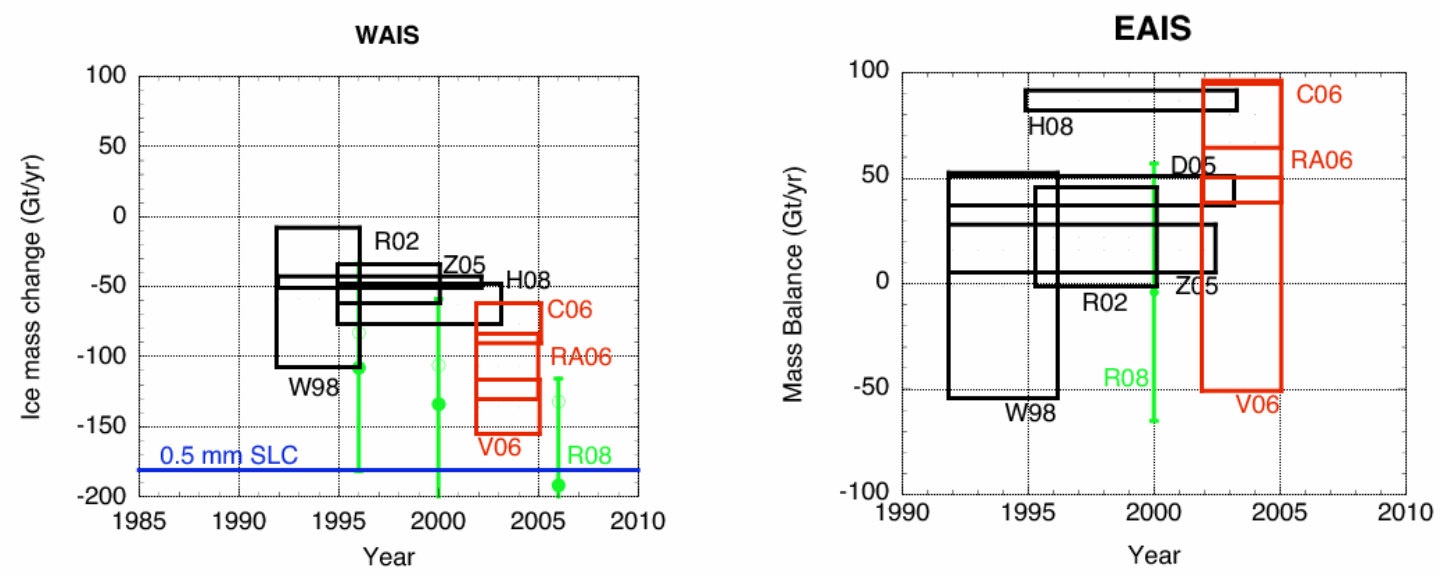

Figure 1.7: Various estimates of the mass balance of the (left) WAIS and (right) EAIS (Inferred from green - Insar measurements of ice velocity; red gravitational measurements (GRACE); black - radar altimetry). The numbers reflect the year of publication and the letter the first name of the first author [W98 (Wingham, et al., 1998), R02 (Rignot et al 2002), D05 (Davis, et al., 2005), Z05 (Zwally et al. 2005), C06 (Chen et al. 2006), RA06 (Ramilien et al. 2006), V06 (Velicogna et al. (2006), R08 (Rignot, 2008), H08 (Helsen et al 2008)]

Next, a severe scenario based on emerging collapse of ASE and EAIS- $g$, and accelerating melting and glacier flow on in the n-AP is developed.

\section{$\underline{A S E}$}

The scenarios described above do not, however, truly capture the idea of a collapse of the WAIS as imagined in several more serious depictions. In these, the retreat, and the contribution to sea level rise, is not limited by the acceleration of the glaciers taking ice to the oceans. For a marine ice sheet it is, after all, possible for the edge of the ice sheet to migrate inland, into increasingly deep ice (see Figure 1.16, Appendix II). This is the instability suggested by recent models, and this could cause a collapse of WAIS at rates that are higher than could be achieved by glacier acceleration alone. It is generally thought that a full-scale collapse would be promoted by the removal of ice shelves that fringe the grounded ice sheet and act to buttress it. On the Antarctic Peninsula, loss of Larsen B Ice Shelf, resulted in a speed-up of the glaciers that formerly fed it, by factors of $2-8$ times. If we imagine glacier acceleration at the upper end of this range we can come close to the rates of loss that could be described as a collapse. If the loss of ice from the glaciers across ASE increases to 8 times the balance value, it would result in an additional contribution of $3 \mathrm{~mm} / \mathrm{yr}$ to sea level rise. If this type of behavior followed an ice-shelf loss, it could, in theory 
dominate for much of the latter part of the century, giving a total contribution to SLR by 2100 , on the order of $25 \mathrm{~cm}$.

\section{EAIS-g}

If the marine glacier basins in East Antarctic ice sheet were to follow the progress of the ASE glaciers, effectively producing a 50\% excess in discharge over 30 years (from 2000), and then following exponential growth to 2100, this would imply around $19 \mathrm{~cm}$ global mean sea level contribution in the period 2000-2100.

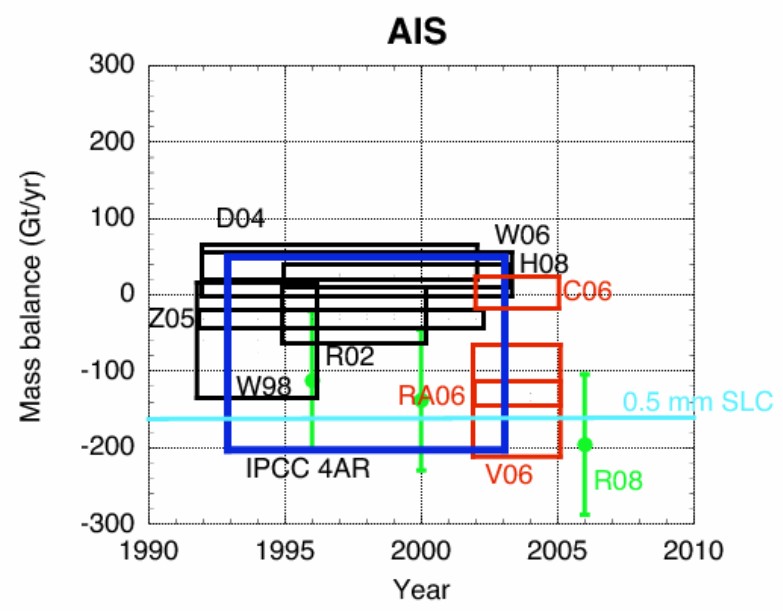

Figure 1.8: As Figure 1.7, but for the Antarctic Ice Sheet [W98 (Wingham, et al., 1998),

D04 (Davis, et al., 2004), W06 (Wingham et al, 2006), R02 (Rignot et al 2002), Z05 (Zwally et al. 2005), C06 (Chen et al. 2006), RA06 (Ramilien et al. 2006), V06 (Velicogna et al. (2006), R08 (Rignot, 2008), H08 (Helsen et al 2008)]. The blue box indicates the estimate as presented in the $4^{\text {th }}$ IPCC report.

$n-A P$

In this severe scenario, the contribution from the n-AP glaciers is unlikely to be a significant fraction of the total, and so little discussion is required. We note that the ice thickness on the northern Antarctic Peninsula (the 95 thousand $\mathrm{km}^{2}$ considered by Pritchard and Vaughan) is poorly surveyed, but is unlikely to contain more than $10 \mathrm{~cm}$ global mean sea level equivalent (GSL). So the potential contribution from this area is unlikely to be substantially greater than 5 $\mathrm{cm}$ GSL. For the purposes of this scenario, we assume that most of this $5 \mathrm{~cm}$ is lost by 2100.

The total sea level contribution for the severe scenario due to changing ice dynamics is $0.49 \mathrm{~m}$. To this estimate, we add again the $0.08 \mathrm{~m}$ increase in accumulation projected by IPCC AR4 to arrive at an upper estimate of $0.41 \mathrm{~m}$.

The modest and severe scenario discussed above serve as the lower and higher end of the high-end projection for the contribution of the Antarctic Ice Sheet to global mean sea level rise. It amounts to $-0.01 \mathrm{~m}$ to $0.41 \mathrm{~m}$.

High-end projection for the Antarctic ice sheet contribution for 2200

We base a conservative projection of the contribution of ASE to sea level rise to 2200 , on a simple continuation (no further acceleration) of discharge achieved at 
2100 (see Section 2.2.30). This would produce around $22 \mathrm{~cm}$ of sea level rise by 2200. It is certainly clear that if such a rate of discharge is attained by 2100 , it is unlikely to be reduced thereafter and so this can provide a justifiable lower limit. Similarly, continuing the rate of contribution from the upper estimate of the higher scenario would suggest a total contribution by 2200 approaching $1.4 \mathrm{~m}$ global mean sea level rise. Given the uncertainty in these numbers, we omit here the small correction estimated to arise from additional accumulation.

While it is arguable whether these linear extrapolations are sensible, they certainly do not appear particularly extreme (they imply no further acceleration in the rates of discharge from the ice sheet after 2100). It would, at first glance, appear that exponential growth in the rate of discharge would be absurd since it would imply rates of ice-discharge that could only be achieved by behavior within the ice sheet that is quite different from that we have seen up to now. However, to some extent, any plausible projection that seeks to bound possible behavior to 2200 must take account of the possibility that by 2100, ASE (and possibly marine glacier basins in EAIS) may already be undergoing a well-developed retreat, and that large areas of the ice-sheet, which are currently in equilibrium, may start to contribute.

If climate change between now and 2100 produces, as predicted by IPCC projections, higher rates of warming across the Antarctic continent than the global mean, many areas that are currently not showing signs of change, will begin to suffer loss during the period 2100-2200. Surface melting may begin on many ice shelves, and then as these ice shelves disintegrate (as has already been seen on the Antarctic Peninsula) many more glaciers will begin to accelerate and thin. By this time, areas of relatively stagnant ice within the ASE may be showing change due to the accumulated thinning of their neighboring glaciers, and the proportion of the Antarctic Peninsula that is losing ice may increase substantially. In short, much larger areas of the ice sheet may be implicated and the contribution to sea level rise may become substantially higher.

\section{Causes of retreat in the Amundsen Sea Embayment}

There appears to be broad agreement that thinning of the ASE portion of the West Antarctic ice sheet is a result of a driver within the ocean system. We expect this to be an increase in the rate of supply of warm (Circumpolar Deep Water) onto the adjacent continental sheet. From here the water could increase the rate of basal melting beneath ice shelves, and at the grounding line of the ice sheet itself. However, at present there is a paucity of data to show the exact nature of any changes that have gone on in the ocean system, and it is not possible to unambiguously link the hypothesized changes to a global warming signal. There are hypotheses that could make this connection, such as an increase in up-welling of water onto the continental shelf being driven by changing wind conditions, but these are not yet proved. Until that connection is made, it is a plausible hypothesis that anthropogenic climate change is causing changes in ASE, but not a certainty, and it remains a possibility that what we are seeing in the ASE is an expression of the inherent instability in a marine ice sheet, driven by some aspect of natural variability in the oceans.

For the purposes of building projections of sea level rise to allow reasonable adaptation strategies to be developed, establishing this connection between sea 
level rise (due to changing marine ice sheets) and anthropogenic change, may not see crucial at first glance. However, this connection is extremely important if the potential collapse of the ASE, or a larger part of WAIS, is to be used as an additional argument for emplacement of greenhouse gas emission (mitigation) strategies, to limit and slow climate change. So establishing this connection must be a major research priority.

\section{Increased snowfall rates}

Although most of the discussion presented here has been concerned with the capacity of ice sheets to contribute to sea level rise, it should not be overlooked that climate warming and attendant changes in atmospheric circulation may bring increased rates of snowfall to both Greenland and Antarctica. This could in turn lead to thickening of parts of both ice sheets, and act to slow sea level rise. However, it appears that at least for Antarctica, a robust result (common to many climate models) is that increased accumulation in Antarctica will amount to around to an increase of $5 \%$ of snowfall for each degree C, of warming. Given, even substantially magnified warming in Antarctica to 2100, this will not be sufficient to offset more than a fraction of the sea level rise resulting from thermal expansion, or worldwide glacier melt. For example, a linear rise in temperature of 5 C, 2000 and 2100, might produce an overall contribution of $7.5 \mathrm{~cm}$ to global sea level rise. However no clear evidence of enhanced accumulation has been observed yet.

While this increasing snowfall effect is often held up as a substantial factor on reducing sea level rise in future, in reality it has only a limited capacity to reduce the estimates presented here for sea level rise, and is likely to be dwarfed if ice sheets show a strong dynamic response to climate change.

In light of the above, we estimate that by 2200 and for our exploration of the upper limit of potential sea level rise projections, the Antarctic Ice Sheet may contribute between $0.2 \mathrm{~m}$ and $1.4 \mathrm{~m}$ to global mean sea level.

\subsubsection{Greenland ice sheet}

Unlike Antarctica, the Greenland ice sheet is subject to extensive surface melting in summer, the amount of melt is non-linearly dependent on surface temperatures and on average accounts for half of the mass loss. An important issue surrounding the response of the Greenland ice sheet to climate change is a long-term commitment to change. It has been suggested that if climate warming increases loss from the ice sheet, these increased losses will begin to reduce the elevation of the central accumulation zone of the ice sheet. The reduction in elevation will bring progressively more of the ice sheet below the altitude where it is prone by summer melt, and effectively causing greater imbalance in the ice sheet. Some models have been used to show that given a rise in local temperatures of $4.5^{\circ} \mathrm{C}$ Greenland could enter a phase of retreat that could only be reversed by a substantial increase in snowfall, or a subsequent cooling. Such a retreat might take on the order of a 1000 years to complete but is significant because once it is begun represents a very long-term commitment to sea level rise.

Given the current projections of temperature rise given by the IPCC-4AR, it is possible that by 2100 , Greenland could be close to entering a phase of 
"irreversible" retreat, with a long-term commitment to loss of much of the ice sheet in the coming millennia. However, it has not yet been determined if stable intermediate states of the ice sheet exist.

Future projections for the ice sheet require models forced by GCMs (Ridley et al., 2005; Gregory \& Huybrechts, 2006; Driesschaert et al., 2007) indicate that the total eustatic Greenland contribution to sea level rise will increase from 0.3 $\mathrm{mm} / \mathrm{yr}$ to $5 \mathrm{~mm} / \mathrm{yr}$ by 2100 and remain at $5 \mathrm{~mm} / \mathrm{yr}$ until 2200 . These models, which contributed towards the IPCC AR4 projections of sea level rise, include only the surface mass balance and slow ice dynamical processes (leading to ice berg calving) and do not include rapid dynamical processes.

Laser altimeter measurements over Greenland (Thomas et al., 2006) show increasing thickening rates above $2000 \mathrm{~m}$, reflecting increasing snowfall in a warming climate. But near-coastal thinning rates have increased substantially since the mid 1990s, and net mass loss more than doubled from an average of 4 - $50 \mathrm{Gt} / \mathrm{yr}$ between 1993/4 and 1998/9 to 57 - $105 \mathrm{Gt} / \mathrm{yr}$ between 1998/9 and 2004.

There are two main ice dynamical processes that could generate a rapid response to climate change:

The lubrication of the ice sheet base by surface runoff, leading to faster ice flow generally (Zwally et al., 2002, Joughin et al., 2008, Van de Wal, 2008). The retreat of the grounding line, acceleration and thinning of tidewater outlet glaciers (Nick \& Oerlemans, 2006).

Their effects on sea level rise were discussed in the IPCC AR4 (see Ch.10, Meehl et al., 2007) and approximations of their effect, based on the limited knowledge available, applied to the projected contributions of Greenland to sea level rise.

\section{Surface and basal runoff}

Mapping of the area of summer melt is routinely undertaken through analysis of satellite passive microwave imagery. Such observations indicate a very large inter-annual variability, primarily driven by the North Atlantic Oscillation, around a slight trend for increasing melt area over the last 30 years. Whether the passive microwave imagery provide insight in the melt volume is still a matter of debate. In addition much of the melt water percolates downwards in the firn and refreezes a process which is poorly understood and requires further research.

In the ablation zone of Greenland, surface meltwater collects in surface lakes or flows directly into moulins. Although the internal or subglacial pathways for transit of the meltwater to the margins are generally not known, Thomsen et al. (1998) assumed that water flowing into moulins quickly flows to the bottom and drains subglacially as occurs in alpine glaciers. Whether the drainage pathways tend to be vertical and channel melt water to the base of the ice sheet, or tend to be horizontal and remain englacial, markedly affects the local availability of water for basal lubrication. One indication that the water flow is largely subglacial, at least near the margins, is that the melt water primarily leaves the ice sheet in subglacial streams, and not in surface flow over the ice edges.

It is known that where there are high geothermal heat fluxes, such as in the North East of Greenland, localized sub-glacial melting occurs which causes the 
rapid ice flow observed over the drainage basin the North East of Greenland (Farnstock et al., 2001). Observations of a slight summer acceleration and winter deceleration of surface ice flow at Swiss Camp in Greenland led to the proposal that summer surface melt water might be finding its way to the ice bedrock to lubricate a seasonal onset of rapid ice flow (Zwally et al., 2002), like that observed on Alpine glaciers. This provides a positive feedback mechanism where increased melt leads to higher velocities and more ice in lower areas. Hence, a warmer climate in Greenland would increase the volume of lubricating surface melt water reaching the ice- bedrock interface, accelerating ice flow and increasing mass loss. The relative speedup of outlet glaciers, however, is less than 15\% (Joughin et al., 2008) where the dominant seasonal influence on flow is the calving front's annual advance and retreat. With other effects producing outlet-glacier speedups an order of magnitude larger, seasonal melt's influence on ice flow is likely confined to those regions dominated by ice- sheet flow.

Should warming allow the inland migration of the zone in which melt water lakes form on the surface of the ice sheet, and should ice-flow stresses be large enough to open crevasses in the vicinity of those new lakes, then thawing and enhanced lubrication of the bed in those regions will be likely. Even in the present climate, large "slush swamps" form in closed basins in the upper percolation zone, which would easily transition to lakes with increased melt. The total speed-up of flow will depend on the conditions produced by basal thawing if thick, soft, smooth subglacial tills are present there, order-of-magnitude changes could be possible, but in the more-likely event of bumpy bedrock, factor-of-two or smaller changes seem more likely (Parizek \& Alley, 2004). The only record of ice velocity measurements over 15 years, from an area with very large seasonal fluctuations, does not suggest that velocities have increased (Van de Wal et al., 2008 ). Beside drainage of lakes a more important process is the opening of crevasses by inflow of melt water from the surface. Quantification of the feedback mechanisms related to lubrication of the bed is part of ongoing research.

\section{Tidewater Outlet Glacier Acceleration}

Rapid thinning and velocity increase have been observed on major Greenland tidewater outlet glaciers during the last two decades (Rignot \& Kanagaratnam, 2006; Thomas et al., 2006). A possible explanation is that ocean warming at the grounding line causes a local thinning and terminus retreat leading to increased discharge from the interior and consequent further thinning and retreat.

Increased melt near the margin can also trigger the retreat and hence the acceleration of the flow.

The fastest flowing glacier in Greenland is Jakobshavn Isbrae located at the head of a deep fjord of the west coast at approximately $69^{\circ} .10^{\prime} \mathrm{N}, 49^{\circ} 50^{\prime} \mathrm{W}$. Its drainage basin covers $6 \%$ of the ice sheet. In 1992 the glacier terminus was moving at 5700 meters per year and remained somewhat constant until 1997. By 2003 , the glacier had accelerated to 12,600 meters per year. The increased discharge of icebergs has resulted in an additional $0.06 \mathrm{~mm}$ per year in the rate of global sea level rise. The floating glacier tongue, providing increased lateral stresses, rapidly retreated in 2000 and by 2003 had completely disappeared (Csatho et al., 2008). The increased glacier speed has caused increased crevassing such that the recreation of a homogeneous ice tongue, along with the back-stress it provides, is not likely in the foreseeable future. Furthermore, the 
bedrock under Jakobshavn consists of a deep $\sim 100 \mathrm{~km}$ long ravine ( $\sim 1 \mathrm{~km}$ below sea level) and ice thickness greater than 2000m (Legarsky \& Huang, 2006). It is possible that continued retreat of the Jakobshavn calving front could lead to a farther $100 \mathrm{~km}$ retreat and continued increase in discharge rate. Complete collapse of the Jakobshavn drainage basin would cause a readjustment of ice sheet drainage and amount to approximately $0.4 \mathrm{~m}$ of sea level rise.

The two major east coast tidewater glaciers of Kangerdlugssuaq (KL) and Helheim $(\mathrm{HH})$ represent 35\% of east Greenland's total discharge. The calving fronts of both glaciers appeared relatively stable from the mid-20th century until 2002, when $\mathrm{HH}$ retreated more than $7 \mathrm{~km}$ in 3 years. This was followed by a 5$\mathrm{km}$ retreat of $\mathrm{KL}$ during the winter of 2004 to 2005 . These retreats are much greater than the 1- to 2-km seasonal fluctuations previously observed and followed a sustained period of low-elevation ice thinning. Retreats were concurrent with accelerated ice flow. This acceleration increased rates of mass loss by 28 and $15 \mathrm{Gt} / \mathrm{yr}$ at $\mathrm{KL}$ and $\mathrm{HH}$, respectively, between 2000 and 2005, representing $>40 \%$ of the ice sheet's increase in mass loss. In 2006 both $\mathrm{KL}$ and $\mathrm{HH}$ started to decelerate and mass loss was reduced. It has been observed (Joughin et al., 2006) that following a period of glacial thinning the ice fronts of $\mathrm{KL}$ and $\mathrm{HH}$ retreated down the back side of a bathymetric high, which agrees well with earlier theoretical predictions. It is clear that the termini of these two glaciers has previously retreated during warm periods and advanced as quickly during cold periods in the 20th Century.

Dynamic re-equilibration after a perturbation in geometry may not always be as rapid as observed here. For example, Jakobshavn Isbrae has maintained high speeds for several years after retreat and acceleration. In this case, retreat from the fjord increased inflow from the sides, potentially resulting in lower thinning rates ( $15 \mathrm{~m} /$ year; Krabill et al., 2004). Likewise, many glaciers along Greenland's northwest coast have retreated into the ice sheet with sustained thinning at rates of a few meters per year but show no apparent change in speed (Rignot \& Kanagaratnam, 2006). This suggests that geometry and other characteristics unique to each glacier may determine the time scale over which discharge anomalies occur.

The prediction of discharge from Greenland's glaciers will likely require detailed bedrock geometry of at least the three largest glaciers, Jakobshaven, Kangerdlugssuaq and Helheim. Even though the latter two have halted their retreat, it seems unlikely that this is due to other than having found local pinning points. Their continued retreat into the steep east mountain range where they will cease to be tidewater glaciers is likely. Such a retreat is unlikely to result in discharge of more than $1 \%$ of the ice sheet mass. This is not the case with Jakobshaven which will remain a tidewater glacier for a further $100 \mathrm{~km}$ of retreat deep into the interior of the ice sheet. Such a retreat will likely result in the discharge of $\sim 10 \%$ of the ice sheet, although there is currently no model or precedent with which to predict the rate of discharge.

\section{Known unknowns}

Despite improvements in observation, our understanding of the surface melt ice percolation is at present inadequate to make realistic projections for several reasons. In particular, the decadal (Ikeda et al., 2001) and multidecadal (Knight et al., 2006) climatic oscillations influencing temperature over Greenland mean that short periods of observations of trends, such as those of GRACE \& ICESAT, 
are not appropriate for extrapolation for future prediction. Indeed, the decadal variability in the Arctic is under-sampled by all satellite observations. Thus the signal-to-noise on the observations of ice sheet processes given the modest warming to date is insufficient to place observational limits on the processes. There is currently insufficient knowledge of the bedrock characteristics of Greenland to determine the likely drainage of water percolating down from the surface. It is thus unclear that increased surface melt would cause increased areas of subglacial water, and increased sliding, or if flow channels are simply widened vertically.

Similarly to the requirements for models of marine ice sheets for Antarctica, there is currently no understanding on the instability of Jakobshavn Isbrae, how it will retreat and the rate at which it will drain the ice sheet interior. Models are being developed, but require highly detailed bedrock topography, often difficult to obtain in deep valleys where glaciers are highly crevassed. For Jakobshavn this is insufficiently known.

Predictions for the Greenland ice sheet are dependent on the representation of precipitation and air temperature in climate models. There is a considerable variability between IPCC AR4 GCMs on the relevant climatic processes (the amount of accumulation or the ablation in the present-day climate, the sensitivity of the SMB for climate warming, the impacts of changes in the atmospheric and ocean dynamics, and the impacts of the reduction and loss of summer sea ice in the Arctic).

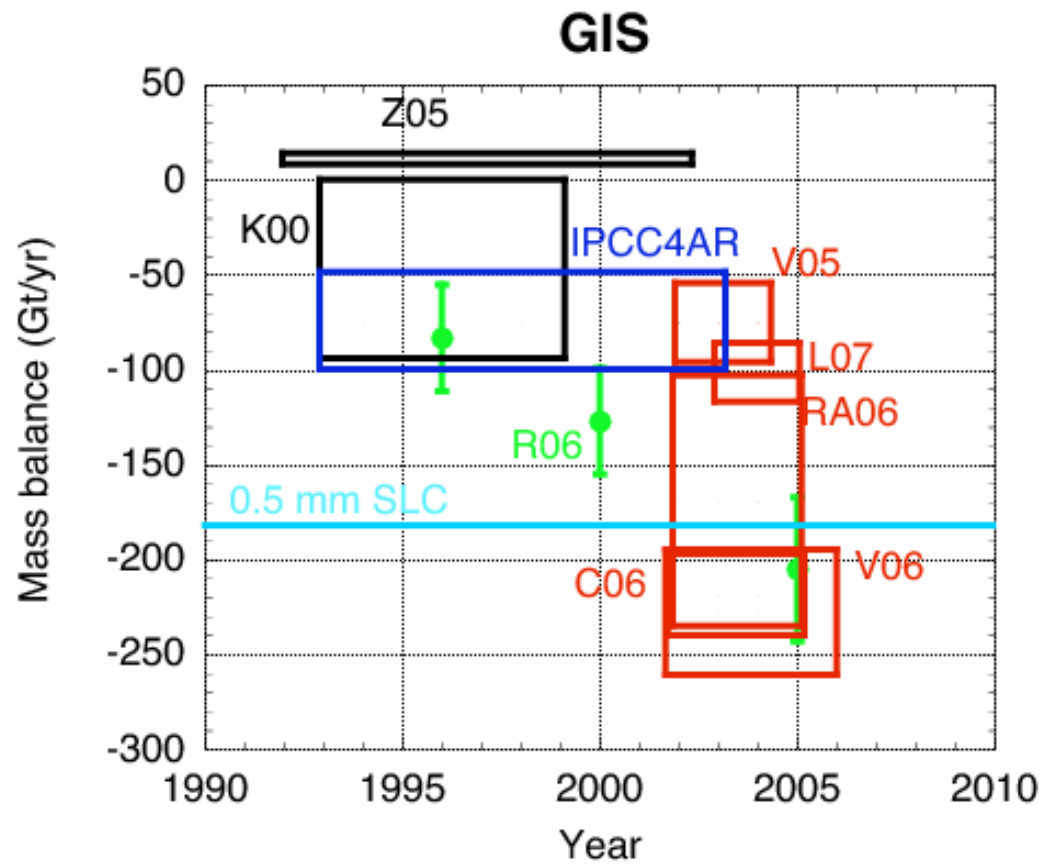

Figure 1.9: Various estimates of the mass balance of the Greenland ice sheet. Green Inferred from Insar measurements of ice velocity. Red - gravitational measurements (GRACE), black radar altimetry. Blue - IPCC AR4 estimate. The numbers reflect the year of publication and the letter the first name of the first author. The IPCC estimate is based on Z05, K00, V05, R06, CO6 ZO5 (Zwally et al. 2005), K00 (Krabill et al. 2000), R06 (Rignot and K 06), C06 (Chen et al. 2006), V06 (Velicogna et al. (2006), RA06 (Ramilien et al. 2006). 
Several estimates of mass change of the Greenland ice sheet have been compiled over the last decade. Simple budget calculations were attempted in the early nineties, but most recent estimates are based on remote sensing techniques. Basically three methods are used. Firstly, one can use altimetry measuring changes in surface height and converting this to a change in mass (e.g. Thomas et al. 2006).

This conversion critically depends on variability of the accumulation rate (Helsen et al. 2008) which is only poorly known. Secondly the outflow velocities can be estimated by Interferometric SAR (e.g. Rignot et al. 2008), given an ice thickness and accumulation rate. Thirdly mass change can be estimated from gravitational methods (e.g. Luthcke et al. 2007).

The three methods are not entirely mutually consistent in their estimates, which is partly due to differences in time period covered and partly unexplained at present. 1.9 shows a compilation of the estimates of mass change as well as the estimate used in the IPCC report. From the figure it appears that the Greenland ice sheet was more or less in equilibrium during the mid-nineties but started to lose mass over recent years. If we do not prefer one study or methodology in particular we can estimate the rate of ice loss to increase by $14 \mathrm{Gt} / \mathrm{yr}^{2}$. Integration to 2100 results in a contribution to global mean sea level of $0.19 \mathrm{~m}$. The linear approximation is of course a crude method, but given the lack of consistency in the result and the poor mechanistic understanding of the processes involved, it seems a reasonable approach. It might be noted that this value is slightly above the highest IPCC A1FI scenario for Greenland.

High-end projection for the Greenland ice sheet contribution for 2100

Unlike the storylines for Antarctica, Greenland ice discharge is a function of surface temperature (as well as ocean temperature at the tidewater glacier grounding lines). However, there is currently insufficient knowledge about the temperature sensitivity of tidewater glaciers and of basal sliding. We accept the IPCC AR4 assessment of mass loss, and associated sea level rise, for surface ablation and slow dynamics. Here we simply reassess the additional contribution from fast dynamical processes.

Assumption 1. Surface melt increases such that a $3+{ }^{\circ} \mathrm{C}$ local temperature rise by 2100 will result in much of the ice sheet surface experiencing summer runoff and percolation to and lubrication of the bedrock. We suggest that this will result in a doubling (Parizek and Alley, 2004) of the 1996 ice flux.

Assumption 2. Tidewater glaciers in the east and south $\left(21 \%\right.$ of $386 \mathrm{~km}^{3} \mathrm{a}^{-1}$ discharge) will gradually double from 1996 discharge until 2050 then rapidly slow to 1996 discharge rates when it is assumed that their termini are above sea level. Jakobshavn and the Northern tidewater glaciers $\left(18 \%\right.$ of $386 \mathrm{~km}^{3} \mathrm{a}-{ }^{1}$ total discharge) will be at 4 times their 1996 discharge rates by 2100 . All changes are linear to 2050 for the east and 2100 for the west.

Assumption 3. The surface mass balance component is based on the regressions for temperature sensitivity of ablation and accumulation derived in Gregory and Huybrechts (2006). Temperature profiles to 2100 are scaled versions of SRES $\mathrm{A} 1 \mathrm{~B}$ to reach 2100 (using a polynomial fit) with a global rise of $+2^{\circ} \mathrm{C}$ (limited) and $+6^{\circ} \mathrm{C}$ (severe, see Fig 1.6). Amplification of global temperatures over Greenland is assumed to be a factor 1.5 (Gregory \& Huybrechts, 2006). The 
basic dynamics, resulting in 1990 calving rates is assumed to be $0.25 \mathrm{~mm}$ a- 1 SLR per year (Driesschaert et al., 2007).

The resulting analysis, presented in Table 1.6, shows an additional sea level rise by 2100 due to fast ice dynamics of $\sim 10 \mathrm{~cm}$. This is entirely consistent with the IPCC AR4 suggestion of scaled-up parameterization for fast dynamics (from both ice sheets) of $17 \mathrm{~cm}$ for the worst case scenario A1FI.

Table 1.6: Additional changes in Greenland ice sheet (GIS) mass balance from storyline for fast ice dynamical processes compared with the surface mass balance based estimates. The temperature sensitivity of fast processes is unknown so no uncertainty is included.

\begin{tabular}{|l|l|l|l|l|l|}
\hline scenario & $\begin{array}{l}\Delta \mathrm{T}_{\text {atm }} \\
\text { Greenland } \\
\text { (global, in } \\
\mathrm{C})\end{array}$ & $\begin{array}{l}\Delta \text { GIS-mass } \\
\text { balance } \\
\text { (Gt/yr) }\end{array}$ & $\Delta \mathrm{MSL}(\mathrm{m})$ & $\begin{array}{l}\text { MSL SMB + } \\
\text { basic } \\
\text { dynamics } \\
(\mathrm{m})\end{array}$ & $\begin{array}{l}\text { Total } \\
\text { MSL }(\mathrm{m})\end{array}$ \\
\hline limited & $3.0(2.0)$ & -656 & +0.10 & 0.03 & 0.13 \\
\hline severe & $9.0(6.0)$ & -656 & +0.10 & 0.12 & 0.22 \\
\hline
\end{tabular}

High-end projection for the Greenland ice sheet contribution for 2200

Based on the same assumptions formulated for 2100 , the additional sea level rise due to fast ice dynamics discussed in Section 2.2.3 is estimated at $+0.3 \mathrm{~m}$ which basically implies a complete disappearance of the Jakobshavn Isbrae drainage basin. A further decrease of the surface mass balance by another $0.05 \mathrm{~m}$ for the moderate scenario and $0.3 \mathrm{~m}$ for the high scenario seems possible given the projections for the twenty-first century, adding up to a total contribution to sea level rise by 2200 of $0.5-0.8 \mathrm{~m}$. Clearly this is nothing more than educated guessing as processes are too poorly known.

\subsection{Paleo-climatological perspective}

\subsubsection{Introduction}

The present and expected future anthropogenic forcings to the climate lies outside the range that the Earth has experienced during the current interglacial stage, the Holocene, which began about 11.4 thousand years ago. To understand the breadth of behaviors sea level can exhibit in response to climatic forcings, it is therefore necessary to look farther back in Earth history. The last interglacial stage, which occurred between about 130 and $116 \mathrm{ka}$ and is known in Europe as the Eemian, is of particular interest for three reasons: it is recent enough that the potential exists to develop a high-resolution record of sea level variation, temperatures in many parts of the world were slightly warmer than at present, and ice sheet volumes were of similar magnitudes to the present. In Europe, pollen data suggest middle Eemian summer temperatures were about $2 \mathrm{C}$ warmer than today (Kaspar et al., 2005), while ice core data from both Greenland and Antarctica suggest polar temperatures in both hemispheres 3-5 C warmer than present (Jansen et al., 2007). In this respect, the Eemian may 
provide a partial analogue for the climate expected under a low-end warming scenario.

We caution, however, that the upper-end temperature projections employed in this report (4-6 C) exceed temperatures reflected by proxies for the last $800 \mathrm{ky}$ of Earth history, the full length of the current continuous ice core record (Lüthi et al., 2008). During interglacial stages in the middle Pliocene, about 3.0-3.3 million years ago, a combination of proxy data and models suggest average annual global surface temperatures were about $3 \mathrm{C}$ warmer than today (e.g., Haywood et al., 2007). Sea level is poorly constrained during this period, but may have occasionally exceeded present levels by $20 \mathrm{~m}$ or more (Miller et al., 2005; Billups and Schrag, 2003; Dowsett and Cronin, 1990; Wardlaw and Quinn, 1991). There is little prospect at present for determining rates of sea level change for this period.

Still higher temperatures characterized the middle Miocene, about 15 million years ago, while global average temperatures $6 \mathrm{C}$ higher than present have probably not occurred on a sustained basis since the middle Eocene, about forty million years ago. Sea level during these periods is even more poorly constrained, but several lines of evidence suggest ice sheet volume was small to nonexistent during most of the Eocene (e.g., Miller et al., 2005; Royer, 2006), which under modern tectonic conditions would lead to global sea levels about 64 meters higher than present (Lemke et al., 2007).

These ancient sea levels, however, do not imply that a warming of $6 \mathrm{C}$ would cause all ice sheets to melt. Rather, they suggest that major ice sheet loss, including partial melting of the East Antarctic Ice Sheet, may be a plausible outcome if such high temperatures were sustained for timescales comparable to astronomically-driven climatic variations (tens of millennia). While the Eemian and earlier Pleistocene interglacial stages are therefore imperfect models for future warming, they nonetheless provide the best record available for assessing plausible rates of ice sheet melt under interglacial conditions.

\subsubsection{Direct evidence of ice sheet extent in the Last Interglacial}

Direct evidence for the extent of the Greenland Ice Sheet (GIS) and the West Antarctic Ice Sheet (WAIS) during the Last Interglacial is ambiguous, in part because it is complicated by melting and ice flow. Koerner (1989) concluded based on oxygen isotope data that basal ices in the Camp Century ice core, northwest Greenland, and the Dye-3 ice core, southern Greenland, date to the Last Interglacial and that sediments trapped in these ices record the growth of GIS at the end of the Last Interglacial. During the Last Interglacial before this growth, he concluded, GIS must have been significantly smaller. Willerslev et al. (2007), however, presented a variety of new dates for the basal ice of the Dye-3 ice core to suggest that this ice dates to 400-800 ka; if these dates are accurate, they argue for less change in the size of GIS during the Last Interglacial.

In West Antarctica, Koerner (1989) found that the sedimentology of the basal, Last Interglacial-age ice in the Byrd ice core does not suggest a significant reduction of WAIS. Scherer et al. (1998) found middle-to-late Pleistocene age marine diatoms in diamictons from boreholes on ice stream $B$, which indicates at 
least partial collapse of WAIS at some point during the last $\sim 750 \mathrm{ky}$. This collapse could not, however, be dated to a specific interglacial stage.

\subsubsection{Oxygen isotope records of global ice volume}

When corrected for local temperature and salinity changes, the oxygen isotopic composition of marine carbonate, such as that precipitated by foraminifera, provides a record of global ice volume, the dominant factor in global sea level change over periods of hundreds to hundreds of thousands of years. Marine oxygen isotope records with a temporal resolution on the order of hundreds of years have been compiled for times as ancient as the Last Interglacial stage. One can construct a rough estimate of sea level by assuming simply that oxygen isotopic composition varies linearly with sea level change; this makes the implicit assumption that sea level and deep-ocean temperatures also vary linearly. (Waelbroeck et al. (2002) and Bintanja et al. (2005) demonstrated that this assumption can be reasonably accurate during deglaciations in some settings, but also can tend to overestimate sea level during deglaciations and commonly underestimates sea level during glaciations.)

Of particular interest are rates of sea level rise during intervals when sea level was within a few meters of present, which reflects ice sheets with volumes comparable to those of modern day ice sheets (see Table 1.7). Even if this ice volume were attained through a different combination of ice sheet melting than in the last glacial termination (e.g., through melting of GIS or WAIS while a significant North American or Scandinavian ice sheet remained), the remaining ice sheets would necessarily be of a scale comparable to the modern GIS or WAIS, rather than to the giant continental ice sheets of the glacial maxima, and likely exhibit similar dynamic behavior.

Lisiecki and Raymo (2005) compiled 57 globally distribution benthic foraminifera oxygen isotope curves (the LR04 stack) to construct a record with approximately 1000 year resolution. Sea level estimates derived by assuming a Last Glacial Maximum sea level of $-125 \pm 12 \mathrm{~m}$ (e.g., Peltier, 2004) are shown in Figures 1.10 and 1.11. The age model for LR04 is aligned with the GRIP ice core record to $120 \mathrm{ka}$, and we use this age model for aligning the other records discussed herein. Also shown in Figure 1.10 is a sea level curve derived by the same procedure from one particular high-resolution set of benthic foraminifera data, the MD95-2042 core drilled on the Iberian margin at $3.1 \mathrm{~km}$ depth. Shackleton et al. (2000).

With the caveats noted above, both records support a Last Interglacial global sea level higher than the present. The LR04 stack also hints at a short regression in the middle of the highstand, at around $124 \mathrm{ka}$.

The LR04 stack indicates that during the initial deglacial rise from $-9.5 \pm 6.8 \mathrm{~m}$ to $4.7 \pm 5.4 \mathrm{~m}$ sea level rose at $1.4 \pm 1.2 \mathrm{~m} /$ century for about one millennium. After possible mid-Eemian regression, sea level rose at $1.1 \pm 1.0 \mathrm{~m} /$ century for about one millennium. The MD95-2042 record suggests a similar rate of deglacial sea level rise, about $1.1 \pm 1.1 \mathrm{~m} /$ century for one millennium as sea level rose from $1.1 \pm 5.5 \mathrm{~m}$ to $13.8 \pm 5.5 \mathrm{~m}$. 


\subsubsection{Local sea level records}

Local sea level is not, however, simply a function of the volume of water in the global ocean. It is complicated by factors including the gravitational and isostatic effects of ice sheets, as well as local sediment compaction and tectonics. Marine oxygen isotopes can indicate that global ice volume was lower during the Eemian, but they alone cannot resolve the source of melting. To do that, and also to provide "ground truth" checks for global sea levels derived from the oxygen isotope records, it is necessary to employ records of ancient local sea levels. Such records come in a variety of forms. In subtropical and tropical localities, the highest elevation of fossil coral reefs, which grow up to within a few meters of local sea level, provide one source of constraints. Intertidal sediments, such as beach sands, provide another. Waves and biological activity can erode notches near sea level. Other sedimentary facies have characteristics suggestive of subtidal or freshwater deposition, and the fossil remains of foraminifera and diatoms can provide additional paleodepth constraints.

Throughout all of Earth history, determining accurate dates is critical to interpretation. At the distance of the Eemian, most dating techniques, including electron spin resonance dating, amino acid racemization, and thermoluminescene dating, have errors of many thousands of years. Uranium/thorium radiometric dating of biogenic carbonate is the most precise available technique, but a recent analysis suggests that the precision of $U / T h$ dates is often overestimated in the literature (Scholz and Mangini, 2007), and that, though quoted errors can be as small as a few hundred years (e.g., Thompson and Goldstein, 2005), diagenetic effects give rise to true age variability within most single samples of at least a couple thousand years.

As a consequence, few individual Pleistocene sea level records are suitable for assessing rates of sea level change.

This poor age resolution also makes it more difficult to assess global sea level from local sea level records. Although numerous indicators suggests levels of 2-6 m above present (e.g., Hearty et al., 2007; Cronin et al., 1981; Chen et al., 1991; Schellmann and Radtke, 2004) and perhaps even higher (Hearty et al., 2007), Lambeck and Nakada (1992) demonstrated the possibility of generating local highstands of 3-5 m from gravitational and isostatic effects even if total ice volume never fell below the present value. Nonetheless, at least two Eemian local sea level records are of high enough temporal resolution to provide some constraints on rates of sea level rise: the Red Sea record of (Rohling et al., 2008) and a Dutch record based primarily on the work of Zagwijn (1983) (see Figures 1.10 and 1.11).

The Red Sea record is a planktonic foraminiferal oxygen isotope record, but one that takes advantage of the particular hydrology of the Red Sea (Siddall et al., 2003) and is therefore essentially a local record of sea level at the Strait of Bab el Mandab. The Red Sea is sufficiently far from all major melt water sources, however, that gravitational effects cause minimal local deviation from global average sea level (Clark et al., 2002; Mitrovica et al., 2001). Using a hydrological model, Rohling et al. (2008) constructed a sea level record with a temporal resolution of $\sim 300$ years using the oxygen isotopic data from two Red Sea cores. Aligning the Rohling et al. (2008) data against the age model of Lisiecki and Raymo (2005) yields rates of sea level rise of about $1.4 \pm 0.9 \mathrm{~m}$ per century 
sustained for about one millennium during the late deglacial rise from $\sim-3.1 \pm$ $4.2 \mathrm{~m}$ to $\sim 9.4 \pm 4.2 \mathrm{~m}$. During variations in sea level within the interglacial stage sea level rose for at $0.9 \pm 1.1 \mathrm{~m}$ per century for about six centuries. (Rohling et al. (2008) use a different age model for the Last Interglacial, based on U/Th dates of corals from Barbados; if their age model is correct, the global and Red Sea rates are $45 \%$ faster than reported here.)

The Dutch Eemian sea level record of Zagwijn (1983) is based on sedimentological and micropaleontological data from numerous cores through the Amsterdam and Amersfoort basins, as well as cores along the Noord-Holland coast, in Friesland, and in the North Sea. Sea level indicators in these cores are provided by facies transitions representing, for example, the infiltration of marine water into a freshwater lake or the maximum elevation of clays deposited in a salt-marsh environment. Relative age constraints are provided by characteristic Eemian pollen zones, many of which have durations established to fairly high precision based upon the counting of varves in an annually-layered lacustrine diatomite in northwestern Germany (Zagwijn, 1996). We estimate absolute ages from these relative ages by aligning the sea level curve against the global oxygen isotope stack. Zagwijn's data, combined with subsidence estimates Kooi et al. (1998), indicate that a maximum local sea level of $0 \pm 5 \mathrm{~m}$ was attained in the Netherlands between $\sim 126.4$ to $\sim 122.8 \mathrm{ka}$. Sea level rose to this level from $38 \pm 5 \mathrm{~m}$ at $\sim 128 \mathrm{ka}$, achieving rates of about $\sim 2.4 \pm 0.9 \mathrm{~m}$ per century for the initial $\sim 10$ centuries. For the remainder of the rise, from $\sim-14 \pm 5 \mathrm{~m}$ to $\sim 0 \pm$ $0.5 \mathrm{~m}$, the Dutch data suggest an average rate of $0.6 \pm 0.2 \mathrm{~m}$ per century over a period of about 2500 years, but unfortunately the temporal resolution during this period is far poorer than during the initial period. Current data do not resolve sea level variations within the peak of the Last Interglacial, and it is important to emphasize that the $0.6 \mathrm{~m} /$ century rate is an average rate over an extended period of time and does not preclude significantly more rapid variations. Taken at face value, however, these results suggest that sea level may have risen more slowly in the Netherlands during the mid-Eemian than the global average, likely reflecting gravitational and isostatic effects related to the proximity of melting northern hemisphere ice sheets.

\subsubsection{Conclusions}

The global sea level records provided by oxygen isotopes and the local record of the Red Sea suggest that rates of global sea level rise reached $1.2 \pm 0.5$ $\mathrm{m} /$ century during intervals within the Last Interglacial when ice sheets of the scale of the present GIS and WAIS were the only major melt water contributors (Table 1.7). Under an alternative age model for the Last Interglacial, rates may have been as high as $1.7 \pm 0.7 \mathrm{~m} /$ century. The paleoclimatic record is not of high enough temporal resolution to exclude the possibility that global sea level rise exceeded these values for intervals of less than $\sim 3$ centuries in length, nor can it constrain how long it takes to attain such rates stating from an interval of minimal sea level rise. However, the changes in rate observed in the Red Sea record suggest that the onset of rapid sea level rise can occur within the $\sim 3$ century timescale resolved by that record and might take place much more rapidly. As a high-end estimate, we would therefore estimate that rates of global sea level rise as fast as $\sim 1.7 \mathrm{~m} /$ century could commence on a decadal timescale (an educated guess at how fast such a transition might occur), yielding sea levels 
of $\sim+50 \mathrm{~cm}$ in $2050, \sim+1.4 \mathrm{~m}$ in 2100 , and $\sim+3.1 \mathrm{~m}$ in 2200 . (The alternative age model for the Last Interglacial yields a high-end estimate of $\sim 2.4$ $\mathrm{m} /$ century, producing sea levels of $\sim+70 \mathrm{~cm}$ in 2050, +1.9 $\mathrm{m}$ in 2100, and $\sim$ $+4.3 \mathrm{~m}$ in 2200.) Given temperatures exceeding Pleistocene bounds by the last half of the century, even faster rates may also be feasible but cannot be constrained by the current paleoclimatic record.

Table 1.7: Paleoclimatic estimates of rates of sea level rise during intervals near modern values

\begin{tabular}{|l|l|l|l|l|l|l|}
\hline Data Set & $\begin{array}{l}\text { Time } \\
(\mathrm{ka})\end{array}$ & $\begin{array}{l}\text { Rate } \\
\text { (m/cty) }\end{array}$ & $\begin{array}{l}\text { Sea Level } \\
\text { From }\end{array}$ & $\begin{array}{l}\text { Rise }(\mathrm{m}) \\
\text { To }\end{array}$ & Duration & $\begin{array}{l}\text { Sampling } \\
\text { Interval }\end{array}$ \\
\hline $\begin{array}{l}127- \\
126\end{array}$ & $1.4 \pm 1.2$ & $-9.5 \pm 6.8$ & $4.7 \pm 5.4$ & $\begin{array}{l}1.0 \pm 0.7 \\
\mathrm{ky}\end{array}$ & $\sim 1 \mathrm{ky}$ \\
\hline & $\begin{array}{l}124- \\
123\end{array}$ & $1.1 \pm 1.0$ & $-2.7 \pm 5.4$ & $8.8 \pm 6.8$ & $\begin{array}{l}1.0 \pm 0.7 \\
\mathrm{ky}\end{array}$ & $\sim 1 \mathrm{ky}$ \\
\hline MD95-2042 & $\begin{array}{l}127- \\
126\end{array}$ & $1.1 \pm 1.1$ & $1.1 \pm 5.5$ & $\begin{array}{l}13.8 \pm \\
5.5\end{array}$ & $\begin{array}{l}1.1+0.5 \\
\mathrm{ky}-0.2\end{array}$ & $\sim 300 \mathrm{y}$ \\
$\mathrm{ky}$ & & & & & \\
\hline Red Sea & $\begin{array}{l}127- \\
126\end{array}$ & $1.4 \pm 0.9$ & $-3.1 \pm 4.2$ & $9.4 \pm 4.2$ & $\begin{array}{l}970 \pm 130 \\
\mathrm{y}\end{array}$ & $\sim 300 \mathrm{y}$ \\
\hline & 124 & $0.9 \pm 1.1$ & $5.8 \pm 4.2$ & $\begin{array}{l}10.8 \pm \\
4.2\end{array}$ & $\begin{array}{l}580 \pm 130 \\
\mathrm{y}\end{array}$ & $\sim 300 \mathrm{y}$ \\
\hline Netherlands & $\begin{array}{l}126- \\
124\end{array}$ & $0.5 \pm 0.2$ & $-7.2 \pm 4.6$ & $\begin{array}{l}-0.1 \pm \\
0.5\end{array}$ & $\begin{array}{l}1.6 \pm 1.1 \\
\mathrm{ky}\end{array}$ & $\sim 1.6 \mathrm{ky}$ \\
\hline
\end{tabular}




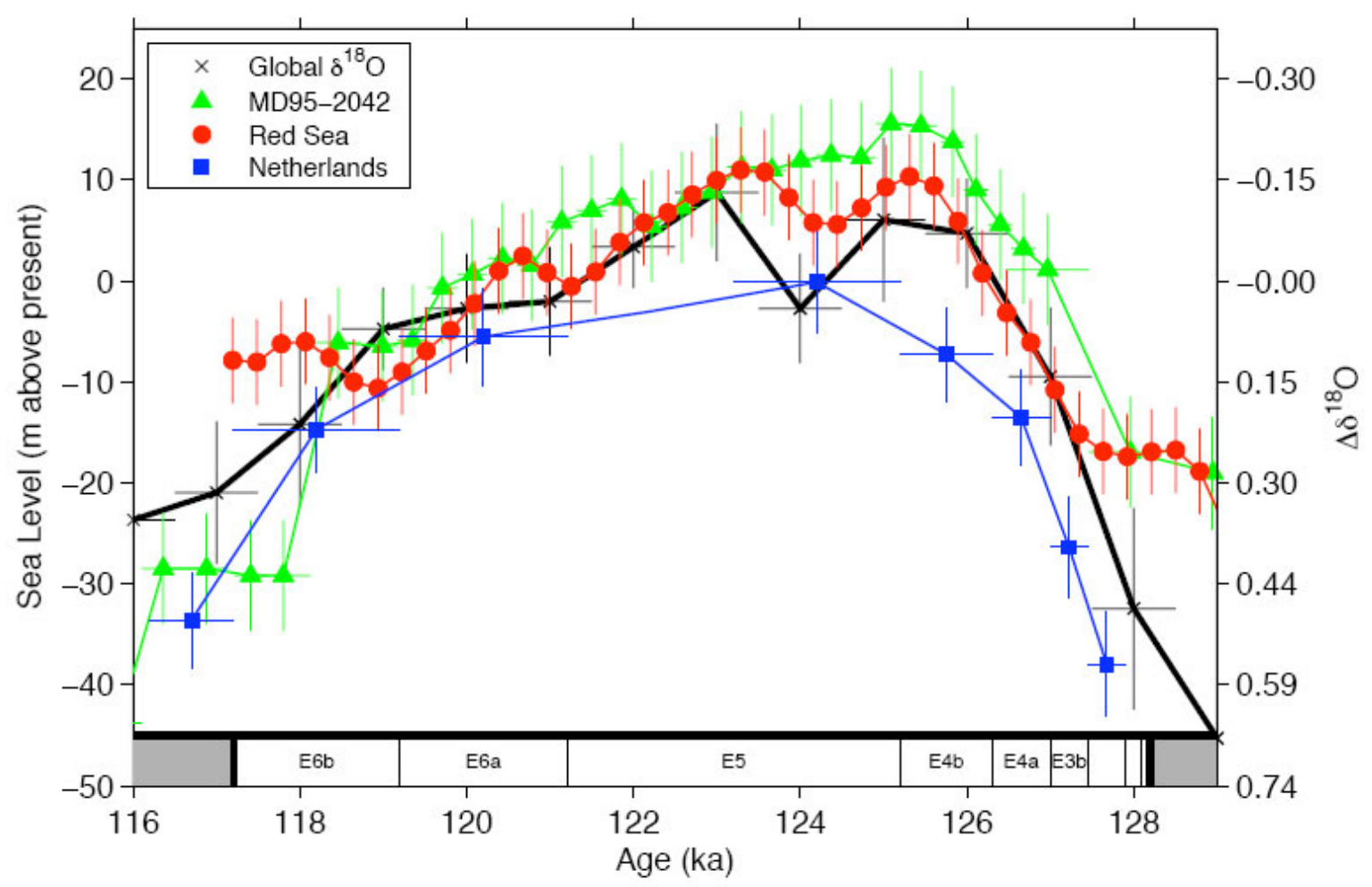

Figure 1.10: Last Interglacial local sea level records from the Red Sea (Rohling et al., 2008) and the Netherlands (Zagwijn, 1983) compared to global sea level records derived from the global benthic foraminifera oxygen isotope curve of Lisiecki and Raymo (2005) and the high-resolution benthic foraminifera oxygen isotope curve from Iberian core MD95-2042 (Shackleton et al., 2000). The Red Sea curve is the average of the KL-11 and KL-09 cores, smoothed with a 290-year Gaussian filter. The MD95-2042 curve is smoothed with a 700-year Gaussian filter, and its age model has been slightly adjusted (by < 1500 y) from that of Shackleton et al. (2000) to align with LR04. Sea level records were derived from the benthic oxygen isotope curves by linear scaling to $125 \mathrm{~m}$ of sea level change from the present to the Last Glacial Maximum (e.g., Peltier, 2004). The deviations of oxygen isotopes from modern values are shown on the right $y$-axis. Compared to the original Rohling et al. (2008) age model, the Red Sea record is stretched temporally by $45 \%$ and the short mid-Eemian regression recentered from 122.3 to $124.3 \mathrm{ka}$ in order to align with the Lisiecki and Raymo (2005) age model. Vertical error bars are $2 \sigma$ for the Red Sea and benthic oxygen isotope curves and derived primarily from a range of plausible subsidence rates for the Dutch record (Kooi et al., 1998). Durations of the Eemian pollen zones (indicated along the bottom) used for dating the Dutch record are taken from Zagwijn (1996) and placed in time so that the Dutch record aligns with the Lisiecki and Raymo (2005) curve. The Dutch E5 highstand is assumed to take place during the first half of E5 based on the relative position of the maximum flooding surface within the Amsterdam-Terminal core (van Leeuwen et al., 2000). The Zagwijn (1983) data has been adjusted for long-term isostatic subsidence, tectonic subsidence, and compaction using the backstripping-derived Quaternary rate estimates of Kooi et al. (1998), which total about $60 \pm 40 \mathrm{~mm} / \mathrm{ky}$ of subsidence for the Eemian. 


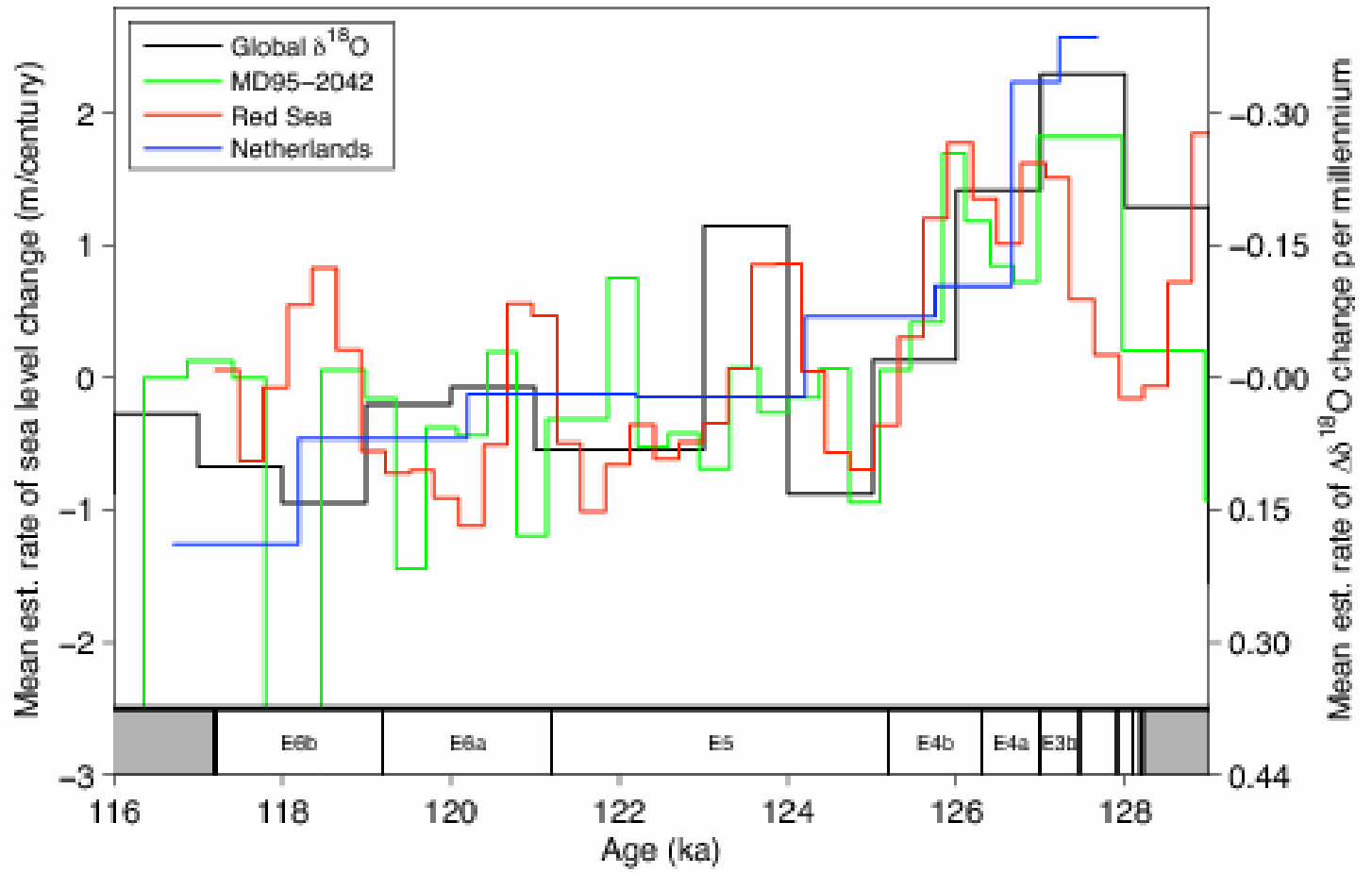

Figure 1.11: Mean rate of sea level rise estimated from the sea level records displayed in Figure 1.10. 
To estimate the contribution of global mean thermal expansion semi-empirically, a linear relation between the rate of thermosteric sea level rise and the atmospheric temperature rise is assumed:

$\mathrm{dTS}_{\mathrm{G}} / \mathrm{dt}=\mathrm{SLS} \Delta \mathrm{T}_{\mathrm{atm}}$

with $\mathrm{dTS}_{\mathrm{G}} / \mathrm{dt}$ the rate of global mean thermal expansion, $\Delta \mathrm{Tatm}$ the atmospheric temperature rise since pre-industrial times, and SLS the thermosteric "sea level sensitivity" (in mm/yr/K). Estimates of SLS can be obtained in various ways.

\section{Sea level sensitivity from climate model simulations}

Twentieth century simulations of global mean thermal expansion (and the accompanying pre-industrial control runs required for drift correction) are analyzed from eight climate models (Meehl et al, 2007b). The corrected (solid) and uncorrected (dashed) time series are shown in Figure 1.12. All changes are given with respect to the year 1905 . Note that many of the twentieth century model simulations display a drift of up to ten centimeters per century, which is in fact larger than the signal in TSG that remains after drift correction (see Fig. 1.12). This is an important caveat of the model simulations. It suggests major disequilibrium in parts of the (deep) ocean, which will probably affect the ocean heat uptake in a warming scenario in a different way than in the control run. It is by no means guaranteed that simply subtracting the drift diagnosed from a control run properly adjusts for this fundamental (and probably non-linear) deficit.

A linear fit of the rate of global mean thermal expansion dTSG/dt (10-year smoothing applied) and the simulated temperature rise Tatm yields very model-dependent results (see Fig. 1.13). Separate fits for each model yield a range of $\mathrm{SLS}=2.3 \mathrm{~mm} / \mathrm{yr} / \mathrm{K}$ to $\mathrm{SLS}=0.3 \mathrm{~mm} / \mathrm{yr} / \mathrm{K}$ (see Table 1.5 ). The SLS can also be analyzed from the available 21 st century simulations of global mean thermal expansion. Again, SLS appears very model-dependent, ranging from $\mathrm{SLS}=2.2 \mathrm{~mm} / \mathrm{yr} / \mathrm{K}$ to $\mathrm{SLS}=0.4 \mathrm{~mm} / \mathrm{yr} / \mathrm{K}$ (see Table 1.8, Fig. 1.13). Table 1.5 shows that for most models, the value for SLS is robust over time. Exceptions are cgcm3.1 and miroc_hi. In particular the latter displays a large reduction of the SLS.

The ensemble mean value of the eight models is used as the central estimate for the model-based SLS from both the twentieth century and the twenty-first century climate model simulations (see Table 1.8). The large spread is an indication that model uncertainties (and possibly, model biases) are large compared to the random errors of the individual fits. The uncertainty in SLS is therefore estimated as 1.3 times the standard deviation of the model spread in SLS such that it covers the $10-90 \%$ range (assuming a Gaussian distribution). Calculated in this way, the model-based estimate for SLS for the 20th century yields $\mathrm{SLS}=1.2 \pm 0.8 \mathrm{~mm} / \mathrm{yr} / \mathrm{K}$. The model-based estimate for SLS for the $21 \mathrm{st}$ century then yields $\mathrm{SLS}=1.0 \pm 0.7 \mathrm{~mm} / \mathrm{yr} / \mathrm{K}$, slightly smaller than that obtained from the 20th century model simulations. Since the semi-empirical approach was designed specifically for ongoing upward trends (see Section 5.3.1) SLS 
calculations based on twenty-first century model data can be expected to be more reliable than those obtained for the twentieth century.

\section{Sea level sensitivity from hydrographic observations}

Domingues et al (2008) constructed time series for global mean thermal expansion from 1950-2003 (taking into account, among others, recently discovered instrumental biases), for depths of 0-300 $\mathrm{m}$ and 0-700 $\mathrm{m}$. Using these time series and the observed global mean atmospheric temperature, they calculated an observation-based thermosteric SLS over the second half of the 20th century. Their results are presented in Figure 1.14 for time series of thermal expansion for the two depths, and for two different temperature time series. The SLS obtained in this way yield SLS $=1.76 \mathrm{~mm} / \mathrm{yr} / \mathrm{K}$ (average value for $0-300 \mathrm{~m}$ ) and $S L S=1.67 \mathrm{~mm} / \mathrm{yr} / \mathrm{K}(0-700 \mathrm{~m})$. An estimate for the uncertainty in these numbers for SLS has not been formally addressed, but is expected to be substantial judging from Fig. 1.15. For the twentieth century, the changes in both $\mathrm{dTSG} / \mathrm{dt}$ and $\Delta$ Tatm are dominated by natural variability. For such processes, the existence of a clear linear relation between dTSG/dt and $\Delta T_{\text {atm }}$ is less plausible than for a greenhouse-forced scenario like the ones projected by climate models for the twenty-first century.

The observation-based SLS obtained from upper-ocean temperature data only, because there are not enough data available to assess the SLS over the full ocean depth with confidence. As a consequence, the resulting projections for 2100 will also be larger than those based on climate model simulations for the full ocean depth.

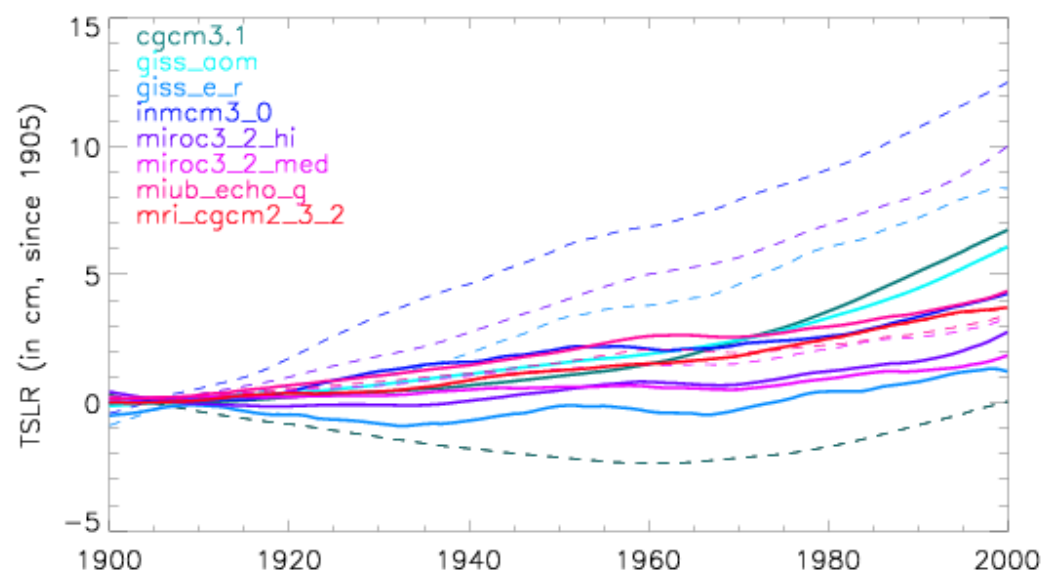

Figure 1.12: Twentieth century simulations of global mean thermal expansion (solid: drift-corrected data; dashed: original, uncorrected data) 


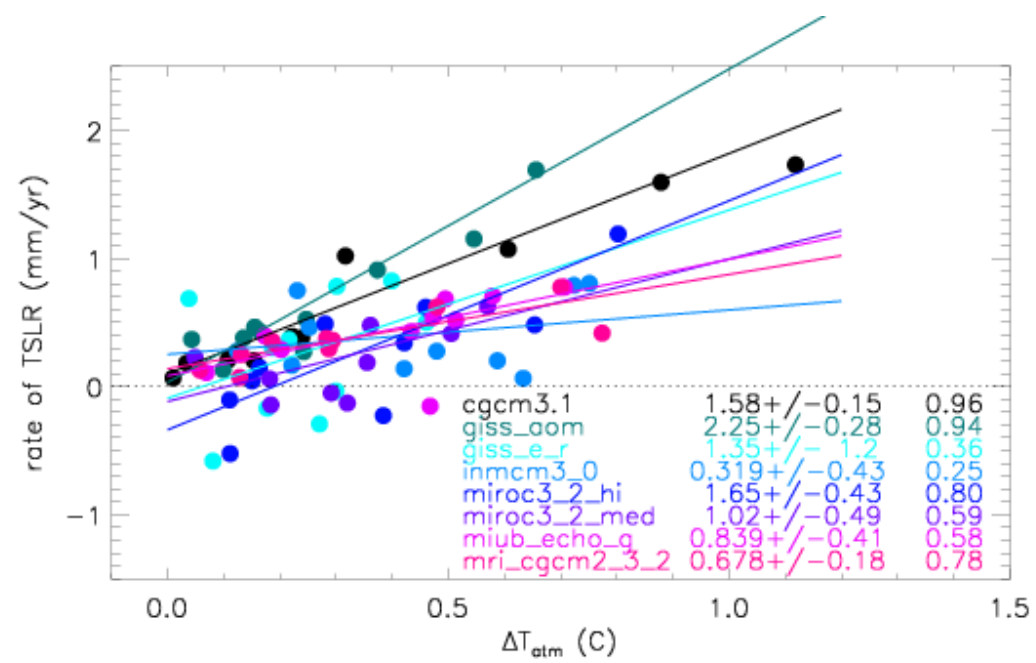

Figure 1.13: Thermosteric sea level sensitivity from 20th century simulations presented in Fig. 1.12

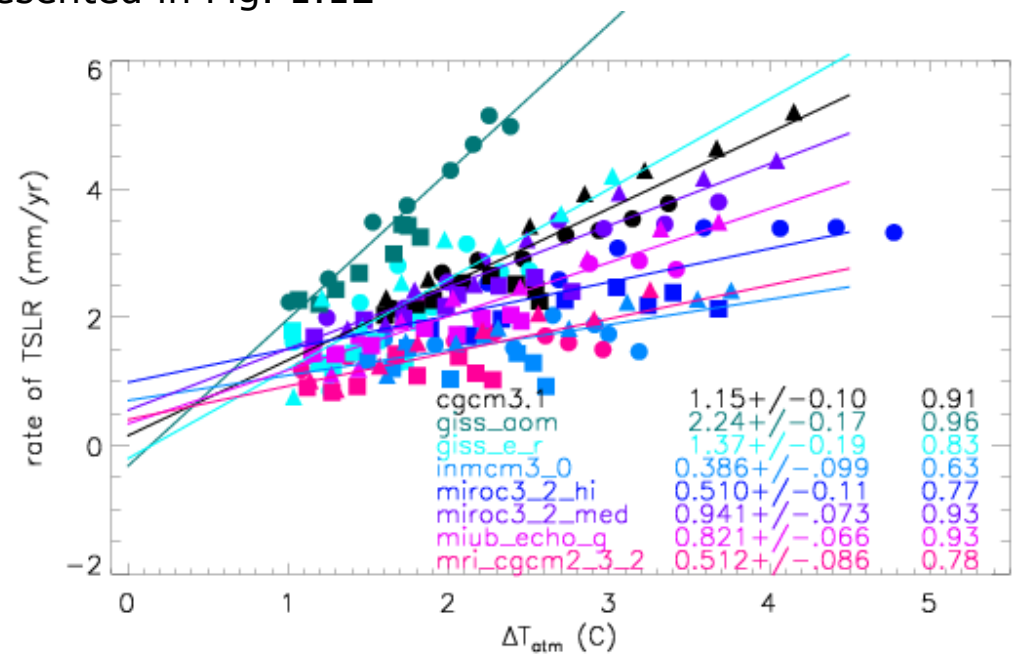

Figure 1.14: Thermosteric sea level sensitivity from 21st century simulations.

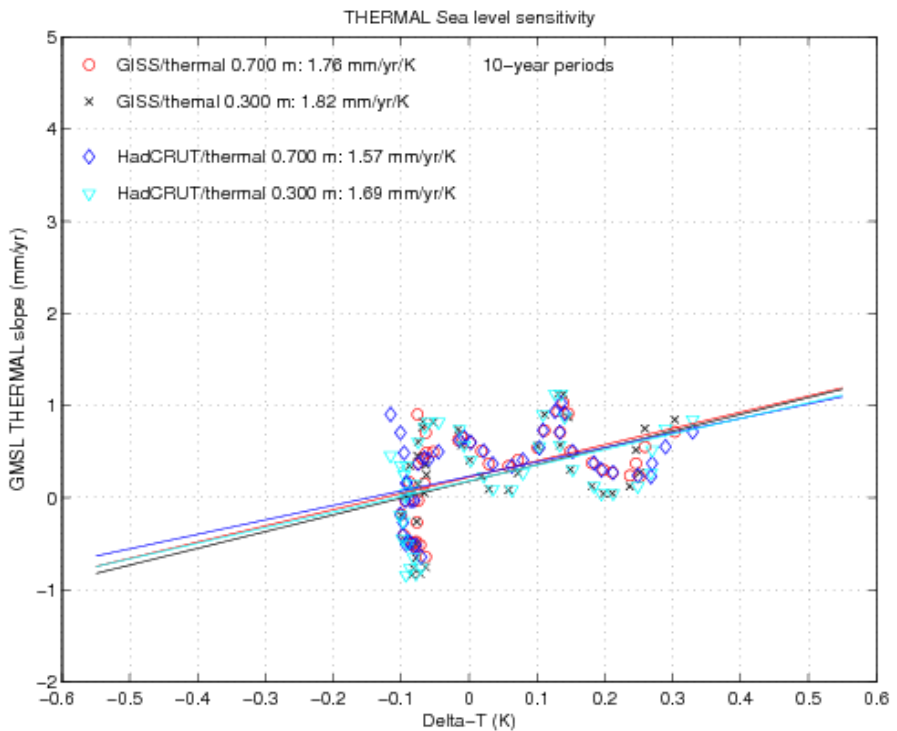

Figure 1.15: Observed rate of thermal expansion as a function of temperature rise, and fits for thermosteric sea level sensitivity from observations (courtesy of Catia Domingues, CSIRO) 
Table 1.8: Sea level sensitivity for the 20th century and 21 st century from model simulations

\begin{tabular}{|l|l|l|}
\hline model & $\begin{array}{l}\text { SLS 20 } \\
(\mathrm{mm} / \mathrm{yr} / \mathrm{K})\end{array}$ & $\begin{array}{l}\text { SLS 21st century } \\
(\mathrm{mm} / \mathrm{yr} / \mathrm{K})\end{array}$ \\
\hline cgcm3.1 & 1.6 & 1.2 \\
\hline Giss_aom & 2.3 & 2.2 \\
\hline Giss_e_r & 1.4 & 1.4 \\
\hline inmcm3_0 & 0.32 & 0.39 \\
\hline miroc3_2_hi & 1.7 & 0.51 \\
\hline miroc3_2_med & 1.0 & 0.94 \\
\hline miub_echo_g & 0.84 & 0.82 \\
\hline mri_cgcm2_3_2 & 0.68 & 0.51 \\
\hline $\begin{array}{l}\text { mean } 1.3 \times \text { standard } \\
\text { deviation) }\end{array}$ & $1.2(0.8)$ & $1.0(0.7)$ \\
\hline
\end{tabular}


There has been a longstanding concern that an ice sheet that rests on rock that is below sea level, and whose bed slopes downwards from the margin to the interior, is an essentially unstable system . Such ice sheets are described as "marine ice sheets", and work is still continuing today to determine whether the theories concerning their potential instability are indeed correct. In essence, the theory of marine ice-sheet instability is that a small inland migration of the icesheet grounding line ${ }^{23}$ would lead to an acceleration of ice-flow out of the ice sheet. This would mean that equilibrium between input to the ice sheet (primarily through snowfall) was insufficient to match the loss from the ice sheet (by melting into the oceans, and iceberg calving, see Figure 1.16), causing a further migration of the grounding line inland and further exacerbate the effect. There is a possibility that this type of positive feedback could lead to a runaway "collapse" of the ice sheet, which would stop only where the retreat encountered a rising bed slope. The timescale over which such a collapse might occur is not well understood but for large sections of an ice sheet, would probably not run to completion on less than century scales.

Today, there are a few examples of marine ice sheets left on Earth. The largest covers the majority of West Antarctica, although a few glaciers in East Antarctica also have large catchment basins below sea-level. In Greenland, there is only one glacier basin, that of Jacobshavns Isbrae (glacier), that appears to contain a similar prominent inland slope, and could potentially display the marine ice sheet instability mechanism. A comparison of the subglacial topography from each of these basins (see Figure 1.17), as well as recent observations of changes in the ice, suggest that the strongest inland bed slope, and probably the strongest tendency to instability, exists in that portion of the WAIS which drains into the Amundsen Sea - the so-called Amundsen Sea embayment (ASE). So far, most research concerning the stability of marine ice sheets has focused on ASE, and so, notwithstanding the other areas of marine ice sheets identified above, the discussion that follows focuses on this area.

\section{Recent developments in understanding of the marine ice-sheet instability}

A small group of glaciological experts surveyed in year 2000 , collectively believed that within the next 200 years there remained a $30 \%$ probability of collapse of the West Antarctic ice sheet causing sea level rise at a rate of 2 $\mathrm{mm} /$ year) and a $5 \%$ probability that it would contribute at rates of over 1 $\mathrm{cm} /$ year.

Since that opinion was gathered, great scientific progress has been made in observing WAIS, but it is difficult to imagine that any of improved understanding would have the effect of reducing the risk expressed by the experts at that time. Conversely, several observations have re-invigorated concern over the stability of marine ice sheets in general, and the WAIS in particular:

It is now clear that the flow of inland ice sheets can be impacted by the loss of floating ice shelves (e.g. Jacobshavn, and Larsen B/C), supporting the idea that

23 The grounding line is the point at which ice flowing from the ice sheet towards the ocean starts to float. 
the health of marine ice sheets is to some extent dependant on their ice shelves. The retreat of several ice shelves along the Antarctic Peninsula provides strong evidence that these features are vulnerable to warming atmosphere and ocean . Furthermore, it is now known that ice shelves around the ASE are thinning and have been thinning for several decades .

The continued acceleration of ice-sheet thinning and glacier-flow in the Amundsen Sea embayment (ASE) of West Antarctica can no longer be argued to have resulted from a few years of unusually low-snowfall rates, as was possible at the time that the expert opinion was gathered. It is now clear that the thinning of this entire section of the ice sheet results from glacier-acceleration. For at least one glacier (Pine Island Glacier) in the ASE, all the elements of positive feedback, that might be expected to lead to collapse of a marine ice sheet have now been observed: ice-shelf thinning and retreat, glacier acceleration, grounding line retreat, and inland thinning of the glacier . Finally, recent improvements in numerical analysis of the stability of marine ice sheets, which are seen as a breakthrough by many ice sheet modellers, reinforce earlier concerns that marine ice sheets may be inherently unstable.

Together, these observations provide support for the view that WAIS may lose a significant fraction of its mass on timescales relevant for coastal planning. It appears entirely possible that the ASE is showing the early signs of entering a phase of large scale retreat - glacier acceleration, retreat of the grounding line, and thinning of the ice sheet that, in places, reaches hundreds of kilometres back into the glacier basins. There are, however, also reasons to believe that the process may not involve the entirety of WAIS. It is now very clear that of the three main areas of outflow in West Antarctica, only the ASE is currently showing signs of retreat. Flow in the parts of WAIS that feed the Ronne/Filchner and Ross ice shelves appears either to be close to balance between gains and losses; in some regions, the ice is thickening. Only the ASE is still showing high rates of thinning, acceleration and grounding line retreat that could be interpreted as the beginnings of collapse. This observation might allow us to limit our concerns, at least through 2100 , to this area alone. A detailed airborne survey of the ASE area appears to show how much ice is vulnerable. It appears that a total of $\sim 75$ $\mathrm{cm}$ of global sea level rise equivalent is available from the two mains glaciers in this area (Pine Island and Thwaites glaciers) .

A consideration of Figure 1.17, which provides a digest of recent estimates of mass change in ASE, indicates the reasons for recent concerns. It shows that the rate of change is providing a significant contribution to sea level rise $(\sim 3 \mathrm{~cm}$ / century) and is still increasing. A consideration of that trajectory, gives some understanding of the difficulty surrounding the projection of the change even as little as one decade (let alone one century) into the future.

In summary, concern over a potential collapse in ASE is supported by many more observations compared to when the Vaughan and Spouge risk estimate was undertaken. Indeed, there appear to be few observations that would suggest that those risks estimates should now be reduced. However, the imbalance in ASE is currently only contributing to sea level rise at a rate of $3 \mathrm{~cm} /$ century. This is highly significant, because it implies that any scenarios we develop for the period up to 2100 , must take account of the fact that the contribution from ASE begins from a low initial rate. 

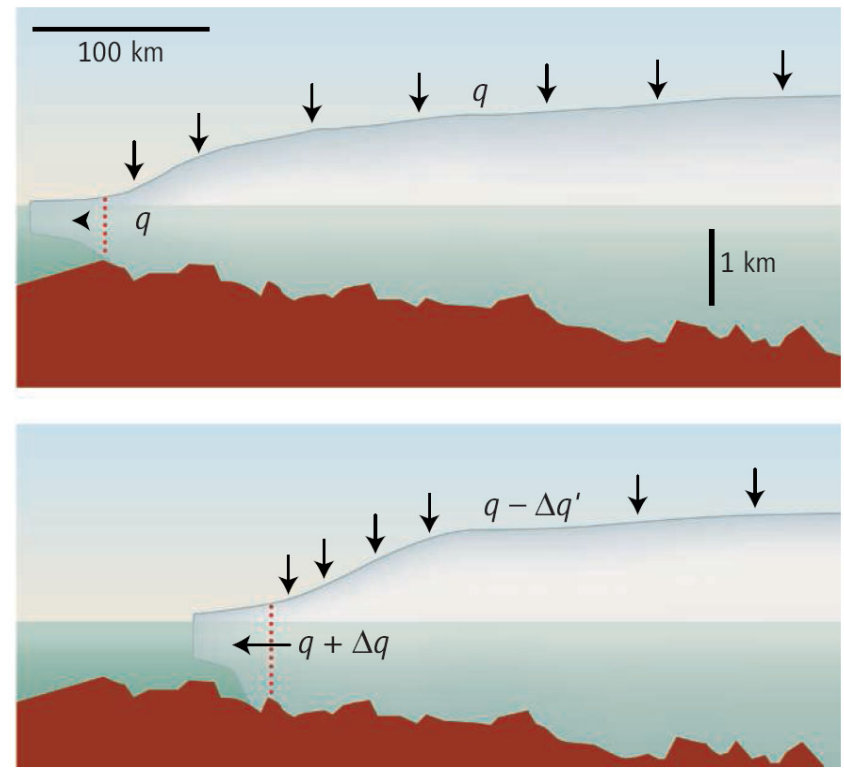

Figure 1.16: Marine ice sheets, such as the Amundsen Sea Embayment of the ice West Antarctic Ice Sheet, contain a unique potential for rapid retreat, often termed collapse. In the top panel, the ice sheet is in equilibrium; influx from snowfall $(q)$ is balanced by outflow. A small retreat (lower panel) will provoke changes in both the influx and the outflow. If these changes act to promote further retreat, the ice margin is unstable and may rapidly retreat inland. The most recent analyses suggest that discharge is increased as the depth of the bed at the point of floatation is increased, and that this is generally an unstable system. (Image reproduced courtesy of Science Magazine)

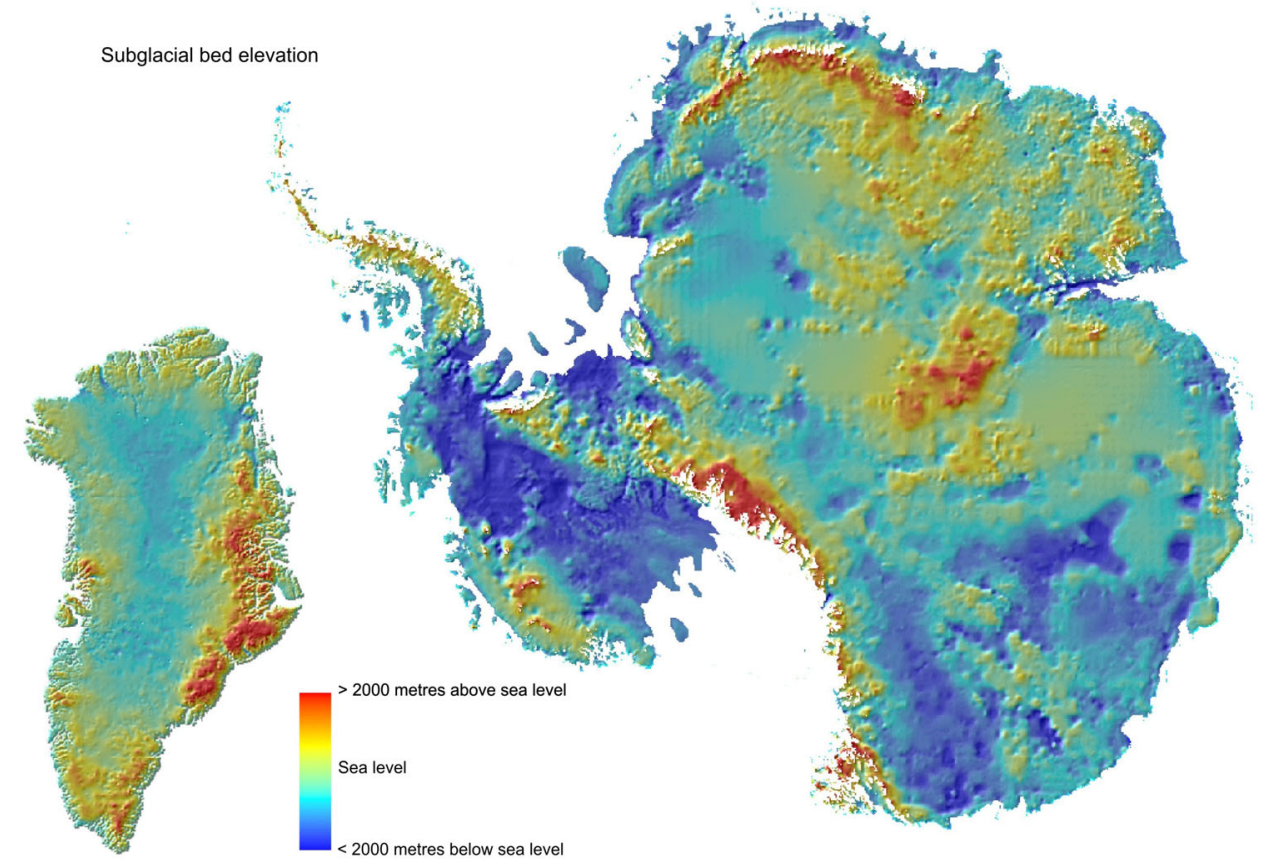

Figure 1.17: Bed elevation for the grounded parts of the Greenland and Antarctic ice sheets. This demonstrates the greater areas and bed depth beneath the marine ice of Antarctica compared to Greenland. 


\section{References}

Alley RB, Clark PU, Huybrechts P, Joughin I, 2005, Ice-sheet and sea level changes, Science, 456-460.

Bamber, J.L., Alley, R.B. and Joughin, I., 2007, Rapid response of modern day ice sheets to external forcing, Earth and Planetary Science Letters, 257, 1-13.

Billups, K., Schrag, D. P., 2003, Application of benthic foraminiferal Mg/Ca ratios to questions of cenozoic climate change. Earth and Planetary Science Letters 209, 181-195.

Bindoff, N., Willebrand, J., Artale, V., Cazenave, A., Gregory, J., Gulev, S., Hanawa, K., Le Qur, C., Levitus, S., Nojiri, Y., Shum, C. K., Talley, L. D., and Unnikrishnan, A.. 2007, Observations: Oceanic climate change and sea level. In S. Solomon, D. Qin, M. Manning, Z. Chen, M. Marquis, K. B. Averyt, M. Tignor, and H. L. Mille, editors, Climate Change 2007:The Physical Science Basis. Contribution of Working Group 1 to the Fourth Assessment Report of the Intergovernmental Panel on Climate Change. Cambridge University Press, Cambridge, United Kingdom and New York, NY, USA.

Bindschadler, R. A.,2002, History of lower Pine Island Glacier, West Antarctica, from Landsat imagery, J. Glaciol., 48, 536-544.

Bintanja, R., van de Wal, R. S. W., Oerlemans, J., 2005, Modelled atmospheric temperatures and global sea levels over the past million years. Nature 437, 125128.

Bougamont, M., Bamber, J.L., Ridley, J.F., Gladstone, R.M., Greuell, W., Hanna, E., Payne, A.J. and Rutt, I., 2007, Impact of model physics on estimating the surface mass balance of the Greenland ice sheet, Geophys. Res. Lett., 34, L17501.

Chao, B.F., Y. H. Wu, Y. S. Li ,2008, Impact of Artificial Reservoir Water Impoundment on Global Sea Level, Science 320. no. 5873, pp. 212 - 214, DOI: 10.1126/science.1154580,

Chen, J. H., Curran, H. A., White, B., Wasserburg, G. J., 1991, Precise chronology of the last interglacial period: 234U-230Th data from fossil coral reefs in the Bahamas. Geological Society of America Bulletin 103, 82-97.

Chylek, P., M. K. Dubey, and G. Lesins ,2006, Greenland warming of 1920-1930 and 1995-2005, Geophys. Res. Lett., 33, L11707, doi:10.1029/2006GL026510.

Clark, P. U., Mitrovica, J. X., Milne, G. A., Tamisiea, M. E., 2002, Sea level fingerprinting as a direct test for the source of global meltwater pulse ia. Science 295, 2438-2441. 
Clark, J.A. and J. A. Primus, 1988, Sea level change resulting from future retreat of ice sheets: an effect of $\mathrm{CO} 2$ warming of the climate. In "Sea level Changes", ed., Tooley and Shennan, Blackwell, pp, 356-370

Cook, A., et al. 2005, Retreating glacier-fronts on the Antarctic Peninsula over the last 50 years, Science, 22, 541-544.

Cronin, T. M., Szabo, B. J., Ager, T. A., Hazel, J. E., Owens, J. P., 1981, Quaternary climates and sea levels of the U.S. Atlantic Coastal Plain. Science $211,233-240$.

Csatho B, Schenk T, Van Der Veen CJ and Krabill WB., 2008, Intermittent thinning of Jakobshavn Isbrae, West Greenland, since the Little Ice Age, J. Glac., 131-144.

Davis, C. H., et al. ,2005, Snowfall-driven growth in Antarctic Ice Sheet mitigates recent sea level rise, Science, 308, 1898-1901.

Domingues, C. M., Church, J. A., White, N. J., Gleckler, P. J., Wijffels, S. E., Barker, P. M., and Dunn, J. R., 2008, Rapid upper-ocean warming helps explain multi-decadal sea level rise. Nature 453, 1090-1093, doi:10.1038/nature07080

Dowsett, H. J., Cronin, T. M., 1990, High eustatic sea level during the middle Pliocene: Evidence from the southeastern U.S. Atlantic Coastal Plain. Geology 18, 435-438.

Driesschaert, E., Fichefet, T., Goosse, H., Huybrechts, P., Janssens, I., Mouchet, A., Munhoven, G., Brovkin, V. and Weber, S. L., 2007, Modeling the influence of Greenland ice sheet melting on the Atlantic meridional overturning circulation during the next millennia, Geophys. Res. Lett., L10707.

Duplessy, J.C, D. M. Roche and M. Kageyama, 2007, The Deep Ocean During the Last Interglacial Period, Science 316, 89-91, DOI: $10.1126 /$ science. 1138582

Dyurgerov, M. B. and Meier, M. F., 2005, Glaciers and the Changing Earth System: A 2004 Snapshot. Occasional Paper 58, University of Colorado, Institute of Arctic and Alpine Research. Available from http://instaar.colorado.edu/other/occ papers.htm.

Fahnestock M, Abdalati W, Joughin I, Brozena J, Gogineni P., 2001, High geothermal heat row, basal melt, and the origin of rapid ice how in central Greenland, Science, 294, 2338-2342.

Farrell, W. E. and Clark, J. A.,1976, On Postglacial Sea Level. Geophysical Journal International, 46, 647667. doi:10.1111/j.1365-246X.1976.tb01252.x.

Giovinetto, M. B., and C. R. Bentley, 1985, Surface balance in ice drainage systems of Antarctica, Antarctic Journal of the United States, 20, 6-13. 
Gregory, J. M., and P. Huybrechts, 2006, Ice-sheet contributions to future sea level change, Philosophical Transactions of the Royal Society A-Mathematical Physical and Engineering Sciences, 364, 1709-1731.

Hanna, E., Huybrechts, P., Steffen, K., Cappelen, J., Huff, R., Shuman, C., Irvine-Fynn, T., Wise, S. and Griffiths, M., 2008, Increased runoff from melt from the Greenland Ice Sheet: A response to global warming, J. Climate 21, 331-341.

Haywood, A. M., Valdes, P. J., Peck, V. L., 2007, A permanent El Niño-like state during the Pliocene? Paleoceanography 22, PA1213, doi:

10.1029/2006PA001323, doi:10.1029/2006pa001323.

Hearty, P. J., Hollin, J. T., Neumann, A. C., O'Leary, M. J., McCulloch, M., 2007, Global sea level fluctuations during the Last Interglaciation (MIS 5e). Quaternary Science Reviews 26, 2090-2112.

Helsen, M.M, M.R. van den Broeke, R.S.W. van de Wal, W.J. van de Berg, E. van Meijgaard, C.H. Davis, Y. Li, I. Goodwin, 2008, Elevation changes in Antarctica mainly determined by accumulation variability, Science, 320, 1626-1629, doi: $10.1126 /$ science. 1153894

Holgate, S., S. Jevrejeva, P. Woodworth, and S. Brewer, 2007, Comment on "A Semi-Empirical Approach to Projecting Future Sea level Rise", Science 317: 1866 [DOI: $10.1126 /$ science.1140942]

Holt, J. W., et al., 2006, New boundary conditions for the West Antarctic ice sheet: subglacial topography beneath Thwaites and Smith glaciers, Geophys. Res. Let., 33, L09502, doi: 09510.01029/02005GL025561.

Houghton, J. T., Ding, Y., Griggs, D. J., Noguer, M., van der Linden, P. J., Dai, X., Maskell, K., and Johnson, C. A., editors, 2001, Climate Change 2001: The scientific basis. Contribution of Working Group I to the Third Assessment Report of the Intergovernmental Panel on Climate Change. Cambridge University Press. $881 \mathrm{pp}$.

Howat, I.M., Joughin, I., and Scambos, T.A., 2007, Rapid changes in ice discharge from Greenland outlet glaciers, Science, 315, 1559-1561.

Hughes, T., 1986, The Jakobshanvs effect Geophys. Res. Lett., 13, 46-49.

Ikeda, M., Wang, J., Zhao, J.-P., 2001, Hypersensitive decadal oscillations in the Arctic/subarctic climate, Geophys. Res. Lett., 28, 1275-1278.

Jansen, E., Overpeck, J., Briffa, K. R., Duplessy, J.-C., Joos, F., MassonDelmotte, V., Olago, D., Otto-Bliesner, B., Peltier, W. R., Rahmstorf, S., Ramesh, R., Raynaud, D., Rind, D., Solomina, O., Villalba, R., Zhang, D., 2007, Paleoclimate. In: Solomon et al. (2007), Ch. 6, pp. 433-498.

Janssens, I. and Huybrechts, P., 2000, The treatment of meltwater retention in mass-balance parameterization of the Greenland ice sheet, Annals of Glaciology, 31, 133-140. 
Jensen, J., and C. Mudersbach, 2004, Zeitliche Änderungen der

Wasserstandsreihen an den Deutschen Küsten. In in G. Gönnert, H. Grassl, D. Kelletat, H. Kunz, B. Probst, H. von Storch and J. Sündermann: Klimaänderung und Küstenschutz, Hamburg 2004, 115-128

Joughin, I., Das, S.B., King, M.A., Smith, B.E., Howat, I.M. and Moon, T., 2008, Seasonal speedup along the western flank of the Greenland Ice Sheet, Science, 320, 781-783.

Joughin I, Howat I, Alley RB, Ekstrom G, Fahnestock M, Moon T, Nettles M,, Truffer M. and, Tsai VC, 2008, Ice-front variation and tidewater behavior on Helheim and Kangerdlugssuaq Glaciers, Greenland, J. Geophys. Res., 113, F1, F01004.

Joughin, I., et al.. 2003, Timing of recent accelerations of Pine Island Glacier, Antarctica, Geophys. Res. Let., 30, 1706, doi: 1710.1029/2003GL017609.

Kaspar, F., Kühl, N., Cubasch, U., Litt, T., Jun. 2005, A model-data comparison of European temperatures in the Eemian interglacial. Geophysical Research Letters 32, L11703, 10.1029/2005gl022456.

Katsman, C. A., Hazeleger, W., Drijfhout, S. S., van Oldenborgh, G. J., and Burgers, G., 2008, Climate scenarios of sea level rise for the north- east Atlantic Ocean: a study including the effects of ocean dynamics and gravity changes induced by ice melt. Climatic Change. in press, available from www.knmi.nl/ katsman/Papers/climatescenario.pdf.

Knight, J.R., Folland, C.K., Scaife, A.A., 2006, Climate impacts of the Atlantic multidecadal oscillation, Geophys. Res. Lett., 33, art. no. L17706

KNMI (2006): Klein Tank, A.M.G., J.J.F. Bessembinder, B.J.J.M. van den Hurk, G. Lenderink, A.P. van Ulden, G.J. van Oldenborgh, C.A. Katsman, H.W. van den Brink, F. Keller, G. Burgers, G.J. Komen, W. Hazeleger and S.S. Drijfhout, Climate in the 21st century; four scenarios for the Netherlands, KNMI publication: PR, KNMI brochure, 30/5/2006.

Koerner, R. M., 1989, Ice core evidence for extensive melting of the Greenland Ice Sheet in the Last Interglacial. Science 244, 964-969.

Kooi, H., Johnston, P., Lambeck, K., Smither, C., Molendijk, R., Dec. 1998, Geological causes of recent (100 yr) vertical land movement in the Netherlands. Tectonophysics 299, 297-316, 10.1016/s0040-1951(98)00209-1.

Krabill, W., Hanna, E., Huybrechts, P., Abdalati, W., Cappelen, J., Csatho, B., Frederick, E., Manizade, S., Martin, C., Sonntag, J., Swift, R., Thomas, R. and Yungelet, J., 2004, Greenland Ice Sheet: Increased coastal thinning, Geophys. Res. Lett., 31, L24402, doi:10.1029/2004GL021533.

Lambeck, K., Nakada, M., 1992, Constraints on the age and duration of the last Interglacial period and on sea level variations. Nature 357, 125-128. 
Landerer, F. W., J. H. Jungclaus and J. Marotzke, 2007, Regional dynamic and steric sea level change in response to the IPCC-A1B scenario, Journal of Physical Oceanography, Vol. 37, No. 2, p. 296-312.

Lemke, P., et al., 2007, Observations:Changes in Snow, Ice and Frozen Ground., in Climate Change 2007: The Physical Science Basis. Contribution of Working Group I to the Fourth Assessment Report of the Intergovernmental Panel on Climate Change, edited by S. Solomon, et al., pp. 339-383, Cambridge University Press, Cambridge, United Kingdom and New York, NY, USA.

Legarsky J. and Huang H., 2006, Detection of main channel thickness from radar data at Jakobshavn Isbrae, Greenland, J. Glac, 52, 315-317.

Lisiecki, L. E., Raymo, M. E., 2005, A Pliocene-Pleistocene stack of 57 globally distributed benthic _180 records. Paleoceanography 20, 1-17.

Lüthi, D., Le Floch, M., Bereiter, B., Blunier, T., Barnola, J.-M., Siegenthaler, U., Raynaud, D., Jouzel, J., Fischer, H., Kawamura, K., Stocker, T. F., 2008, Highresolution carbon dioxide concentration record 650,000-800,000 years before present. Nature 453, 379-382, doi:10.1038/nature06949.

Manning, M. and Petit, M., 2003, A Concept Paper for the AR4 Cross Cutting Theme: Uncertainties and Risk

Meehl, G., Stocker, T. F., Collins, W. D., Friedlingstein, P., Gaye, A. T., Gregory, J. M., Kitoh, A., Knutti, R., Murphy, J. M., Noda, A., Raper, S. C. B., Watterson, I. G., Weaver, A. J., and Zhao, Z.-C., 2007, Global climate projections. In S.

Solomon, D. Qin, M.Manning, Z. Chen,M.Marquis, K. B. Averyt, M. Tignor, and H. L. Mille, editors, Climate Change 2007: The Physical Science Basis. Contribution of Working Group 1 to the Fourth Assessment Report of the Intergovernmental Panel on Climate Change. Cambridge University Press, Cambridge, United Kingdom and New York, NY, USA.

Mercer, J. H., 1978, West Antarctic ice sheet and CO2 greenhouse effect: a threat of disaster, Nature, 271, 321-325.

Miller, K. G., Kominz, M. A., Browning, J. V., Wright, J. D., Mountain, G. S., Katz, M. E., Sugarman, P. J., Cramer, B. S., Christie-Blick, N., Pekar, S. F., 2005, The Phanerozoic record of global sea level change. Science 310, 1293-1298.

Mitrovica, J. X., Tamisiea, M. E., Davis, J. L., and Milne, G. A., 2001, Recent mass balance of polar ice sheets inferred from patterns of global sea level change. Nature, 409, 1026-1029.

Morris, E. M., and D. G. Vaughan, 2003, Spatial and temporal variation of surface temperature on the Antarctic Peninsula and the limit of viability of ice shelves, in Antarctic Peninsula Climate Variability: Historical and Paleoenvironmental Perspectives. Antarctic Research Series, 79, edited by E. Domack, et al., pp. 6168, AGU, Washington, DC.

Nick, E.M. and Oerlemans, J., 2006, Dynamics of tidewater glaciers: comparison of three models, J. Glac., 52, 183-190. 
Overpeck, J.T., B.L. Otto-Bliesner, G.H. Miller, D.R. Muhs, R.B. Alley, and J.T. Kiehl, 2006, Paleoclimatic Evidence for Future Ice-Sheet Instability and Rapid Sea level Rise, Science 311: 1747-1750 [DOI: 10.1126/science.1115159]

Parizek, B.R.and Alley R.B., 2004, Implications of increased Greenland surface melt under global-warming scenarios: ice-sheet simulations, Quat. Sci. Rev. 23, 1013-1027.

Payne, A. J., et al., 2004, Recent dramatic thinning of largest West Antarctic ice stream triggered by oceans, Geophys. Res. Let., 31, doi:10.1029/1204GL021284.

Peltier, W. R., 2004, Global glacial isostasy and the surface of the ice-age Earth: The ICE-5G (VM2) model and GRACE. Annual Review of Earth and Planetary Sciences 32, 111-149, doi: 10.1146/annurev.earth.32.082503.144359.

Pfizenmayer, A., 1997, Zusammenhang zwischen der niederfrequenten Variabilität in der grossräumigen atmosphärischen Zirkulation und den Extremwasserständen an der Nordseeküste. Diplomarbeit Institut für Geographie Universität Stuttgart

Plag, H.-P., 2006, Recent relative sea level trends: an attempt to quantify the forcing factors, Phil. Trans. Roy. Soc. London, A, 364, 1841-1869.

Plag, H.-P. \& Jüttner, H.-U., 2001, Inversion of global tide gauge data for present-day ice load changes, in Proceed. Second Int. Symp. on Environmental research in the Arctic and Fifth Ny-Ålesund Scientific Seminar, edited by T. Yamanouchi, Special Issue, No. 54 in Memoirs of the National Institute of Polar Research, pp. 301-317.

Pritchard, H. (in prep), Continental ice-sheet change from Icesat altimetry.

Pritchard, H., and D. G. Vaughan, 2007, Widespread acceleration of tidewater glaciers on the Antarctic Peninsula, J. Geophys. Res., 112, doi: 10.1029/2006JF000597.

Rahmstorf, S., 2007, A semi-empirical approach to projecting future sea level rise. Science, 315, 368 - 370. doi:10.1126/science.1135456.

Rahmstorf, S. ,2007b), Response to Comments on "A Semi-Empirical Approach to Projecting Future Sea level Rise", Science 317: 1866 [DOI:

10.1126/science.1141283]

Ramillien, G., et al. ,2006), Interannual variations of the mass balance of the Antarctica and Greenland ice sheets from GRACE, Glob. Planetary Change, 53, 198-208.

Ridley, J.K., Huybrechts, P., Gregory, J.M. and Lowe, J.A., 2005, Elimination of the Greenland ice sheet in a high CO2 climate, J. Climate, 18, 3409-3427. 
Rignot, E., 2008, Changes in West Antarctic ice stream dynamics observed with ALOS PALSAR data, Geophys. Res. Let. 35, L12505, doi:10.1029/2008GL033365

Rignot, E., et al., 2008, Recent Antarctic ice mass loss from radar interferometry and regional climate modelling, Nature Geoscience, 1, doi:10.1038/ngeoXXXX.

Rignot, E., and P. Kanagaratnam ,2006, Changes in the velocity structure of the Greenland ice sheet, Science, 311, 986-990.

Rignot, E., et al. , 2002, Acceleration of Pine Island and Thwaites Glacier, West Antarctica, Annals of Glaciology, 34, 189-194.

Rignot, E. J., 1998, Fast recession of a West Antarctic Glacier, Science, 281, 549551.

Rohling, E. J., Grant, K., Hemleben, C., Siddall, M., Hoogakker, B. A. A., Bolshaw, M., Kucera, M., 2008, High rates of sea level rise during the last interglacial period. Nature Geoscience 1, 38-42, doi:10.1038/ngeo.2007.28.

Royer, D. L., 2006, CO2-forced climate thresholds during the Phanerozoic. Geochimica et Cosmochimica Acta 70, 5665-5675.

Rybski, D., A. Bunde, S. Havlin, and H. von Storch, 2006, Long-term persistence in climate and the detection problem. Geophys. Res. Lett. 33, L06718, doi:10.1029/2005GL025591

Scambos, T. A., et al., 2004, Glacier acceleration and thinning after ice shelf collapse in the Larsen B embayment, Antarctica, Geophys. Res. Let., 31, L18402.

Schellmann, G., Radtke, U., 2004, A revised morpho- and chronostratigraphy of the Late and Middle Pleistocene coral reef terraces on Southern Barbados ,West Indies). Earth-Science Reviews 64, 157-187.

Scherer, R. P., Aldahan, A., Tulaczyk, S., Possnert, G., Engelhardt, H., Kamb, B., 1998, Pleistocene collapse of the West Antarctic Ice Sheet. Science 281, 82-85.

Schmith, T., S. Johansen, and P. Thejll , 2007, Comment on "A Semi-Empirical Approach to Projecting Future Sea level Rise", Science 317, 5846), 1866c. [DOI: 10.1126/science.1143286]

Scholz, D., Mangini, A., 2007, How precise are U-series coral ages? Geochimica et Cosmochimica Acta 71, 1935-1948.

Schoof, C., 2007a, Ice sheet grounding line dynamics: steady states, stability and hysteresis, J. Geophys. Res., 112, doi:10.1029/2006JF000664.

Schoof, C., 2007b, Marine ice sheet dynamics. Part I. The case of rapid sliding, Journal of Fluid Mechanics, 573, 27-55.

Shackleton, N. J., Hall, M. A., Vincent, E., 2000, Phase relationships between millennial-scale events $64,000-24,000$ years ago. Paleoceanography $15,565-$ 569. 
Shepherd, A., et al. , 2001a, Inland thinning of the Amundsen Sea sector, West Antarctica, Geophys. Res. Let., 29, art. no.1364, doi:1310.1029/2001GL014183.

Shepherd, A., et al. , 2001b, Inland thinning of Pine Island Glacier, Science, 291, 862-864.

Shepherd, A., et al. , 2004, Warm ocean is eroding West Antarctic Ice Sheet, Geophys. Res. Let., 31, doi:10.1029\2004GL021106.

Siddall, M., Rohling, E. J., Almogi-Labin, A., Hemleben, C., Meischner, D., Schmelzer, I., Smeed, D. A., 200, Sea level fluctuations during the last glacial cycle. Nature $423,853-858$

Solomon, S., Qin, D., Manning, M., Chen, Z., Marquis, M., Averyt, K. B., Tignor, M., and Mille, H. L., editors , 2007, Climate Change 2007: The Physical Science Basis. Contribution of Working Group 1 to the Fourth Assessment Report of the Intergovernmental Panel on Climate Change. Cambridge University Press, Cambridge, United Kingdom and New York, NY, USA.

Thomas, R., E. Frederick, W. Krabill, S. Manizade, and C. Martin, 2006, Progressive increase in ice loss from Greenland, Geophys. Res. Lett., 33, L10503, doi:10.1029/2006GL026075.

Thompson, W. G., Goldstein, S. L., 2005, Open-system coral ages reveal persistent suborbital sealevel cycles. Science 308, 401-405.

Thomsen, H.H., Thorning, L. and Braithwaite, R.J., 1998, Glacier-Hydrological Conditions on the Inland Ice North-East of Jakobshavn/Ilusissat, West Greenland: Report 138 (Gronlands Geologiske Undersogelse, Copenhagen, Denmark, 1998).

van Leeuwen, R. J. W., Beets, D. J., Bosch, J. H. A., Burger, A. W., Cleveringa, P., van Harten, D., Waldemar, G. F., Pouwer, R., de Wolf, H., 2000, Stratigraphy and integrated facies analysis of the Saalian and Eemian sediments in the Amsterdam-Terminal borehole, the Netherlands. Geologie en Mijnbouw 79, 161196.

van de Wal, R. S. W. and Wild, M. , 2001, Modelling the response of glaciers to climate change, applying volume-area scaling in combination with a high resolution GCM. Climate Dynamics, 18, 359-366.

van de Wal, R.S.W., M. Wild, and J. de Wolde, 2001, Short-term volume change of the Greenland ice sheet in response to doubled $\mathrm{CO} 2$ conditions. Tellus, 53B, 94-102.

van de Wal, RSW and W. Boot, M. R. van den Broeke, C. J. P. P. Smeets, C. H. Reijmer, J. J. A. Donker, and J. Oerlemans, 2008, Large and Rapid Melt-Induced Velocity Changes in the Ablation Zone of the Greenland Ice Sheet, Science 321: 111-113 [DOI: 10.1126/science.1158540] 
Vaughan, D. G. , 2006, Recent trends in melting conditions on the Antarctic Peninsula and their implications for ice-sheet mass balance, Arctic, Antarctic and Alpine Research, 38, 147-152.

Vaughan, D. G., and R. J. Arthern , 2007, Why is it so hard to predict the future of ice sheets? Science, 315, 1503-1504.

Vaughan, D. G., et al. , 2006, New boundary conditions for the West Antarctic ice sheet: Subglacial topography beneath Pine Island Glacier, Geophys. Res. Let., 33, L09501, doi:09510.01029/02005GL025588.

Vaughan, D. G., and J. R. Spouge , 2002, Risk estimation of collapse of the West Antarctic ice sheet, Clim. Change, 52, 65-91.

Velicogna, I., and J. Wahr , 2006, Measurements of time-variable gravity show mass loss in Antarctica, Science, 311, 1754-1756.

von Storch, H., E. Zorita and J.F. González-Rouco, 2008, Relationship between global mean sea level and glob al mean temperature and heat flux in a climate simulation of the past millennium, submitted

Waelbroeck, C., Labeyrie, L., Michel, E., Duplessy, J., McManus, J., Lambeck, K., Balbon, E., Labracherie, M., 2002, Sea level and deep water temperature changes derived from benthic foraminifera isotopic records. Quaternary Science Reviews 21, 295-305.

Vizcainio, M., Mikolajewicz, U., Groger, M., Maier-Reimer, E., Schurgers, G., Winguth, A.M.E., in press, Long-term ice sheet-climate interactions under anthropogenic greenhouse forcing simulated with a complex Earth System Model , Climate Dynamics.

Wallis, D. W., and D. J. Wingham (In submission), The thinning of Pine Island Glacier is Acelerating, Geophys. Res. Lett.

Wardlaw, B. R., Quinn, T. M., 1991. The record of Pliocene sea level change at Enewetak Atoll.Quaternary Science Reviews 10, 247-258.

Weertman, J. , 1974 , Stability of the junction of an ice sheet and an ice shelf, J. Glaciol., 13, 3-11.

Weisse, R. and A. Plüß, 2005: Storm related sea level variations along the North Sea Coast as simulated by a high-resolution model 1958-2002, Ocean Dynamics, 56(1), 16-25, DOI: 10.1007/s10236-005-0037-y

Wigley, TML, 2005 . The Climate Change Commitment, Science Vol. 307. no. 5716, pp. 1766 - 1769, DOI: 10.1126/science.1103934

Willerslev, E., Cappellini, E., Boomsma, W., Nielsen, R., Hebsgaard, M. B., Brand, T. B., Hofreiter, M., Bunce, M., Poinar, H. N., Dahl-Jensen, D., Johsen, S., Steffensen, J. P., Bennike, O., Schwenninger, J.-L., Nathan, R., Armitage, S., de Hoog, C.-J., Alfimov, V., Christi, M., Beer, J., Muscheler, R., Barker, J., Sharp, M., Penkman, K. E. H., Haile, J., Taberlet, P., Gilbert, M. T. P., Casoli, A., 
Campaniu, E., Collins, M., 2007. Ancient biomolecules from deep ice cores reveral a forested southern Greenland. Science 317, 111-114.

Wingham, D. J., et al. , 1998 , Antarctic elevation change from 1992 to 1996, Science, 282, 456-458.

Wingham, D. J., et al. , 2006 , Mass balance of the Antarctic ice sheet, Philosophical Transactions of the Royal Society A: Mathematical, Physical and Engineering Sciences, DOI: 10.1098/rsta.2006.1792.

Woodward, R. S. , 1888 . On the form and position of mean sea level. United States Geological Survey Bulletin 48, 87-170.

Zagwijn, W. H., 1983. Sea level changes in the Netherlands during the Eemian. Geologie en Mijnbouw 62, 437-450.

Zagwijn, W. H., 1996. An analysis of Eemian climate in Western and Central Europe. Quaternary Science Reviews 15, 451-469.

Zwally HJ, Abdalati W, Herring T, Larson K, Saba J and Steffen K, 2002, Surface melt-induced acceleration of Greenland ice-sheet flow, Science, 297, 218-222.

Zwally, H. J., et al. , 2005, Mass changes of the Greenland and Antarctic ice sheets and shelves and contributions to sea level rise: 1992 - 2002, J. Glaciol., 51, 509-527. 


\title{
CHAPTER II - Winds and storm surges along the Dutch coast
}

\begin{abstract}
The height of storm surges and wind waves is extremely important for a lowlying country like the Netherlands. By law, coastal defense has to withstand a water level that on average occurs only once every 10,000 years. The question then arises whether and how climate change affects the heights of extreme surges and waves. We here address this question along several lines of reasoning. As surges and waves are the result of winds, we first investigate projected changes in the wind climate on the North Sea. The projections are taken from climate change simulations using comprehensive global climate models, as well as from downscaling exercises using regional climate models, constrained by the global models. In a second step these winds are used to drive storm surge and wind wave models. We use different global models, different regional models, and different forcing scenarios. The results are all consistent and point to changes being small compared to the uncertainty in present day 10,000 year return values.
\end{abstract}

\section{Introduction}

Storm surges and waves are a major threat for coastal areas. Especially low-lying countries like the Netherlands are vulnerable as large areas can easily be flooded. During the last great flood in 1953, nearly $4 \%$ of the Dutch territory was inundated, and about 1850 people lost their lives. In reaction to that catastrophe the Dutch government adopted the Delta Plan (Deltacommissie 1960-61). It foresaw in massive improvements in existing dikes and the damming off of large parts of the Scheldt-Meuse-Rhine delta. As a standard, Dutch law (Wet op de waterkering; go to http://wetten.overheid.nl/ and type waterkering into the search window) requires coastal defense to withstand a water level that on average is reached only once in 10,000 years.

The required 10,000 -year return level ${ }^{24}$ is determined statistically from past water levels. This is only possible when the background environment does not change with time. An important aspect of the environment is the climate with its possible effects on sea level and storm climate. Other aspects are changing bathymetry due to sedimentation and erosion or local water works. The rising sea level is dealt with in Chapter I. We here focus on possible wind changes that may result from global warming and their consequences for wave heights and storm surges along the Dutch coast.

\footnotetext{
24 Mathematically, this is a well defined term. However, its actual determination and interpretation is made difficult by climate variability not being strictly "white" (cf. Bunde et al. 2004). The term is conveniently adopted by the Dutch community, but it is not an uncontested concept, and other communities use different design criteria.
} 
The first integrated effort to assess possible changes in North Sea climate was the WASA project (WASA Group 1998). They concluded "that neither the storm climate nor the wave climate has undergone significant systematic changes" in the $20^{\text {th }}$ century, but that large decadal variability exists. For the future (time of doubled $\mathrm{CO}_{2}$ concentration) their results point to a moderate increase of winds, waves and surges in the North Sea. However, these changes are within the range of previously observed variations and therefore cannot be unequivocally ascribed to climate change. These results were mainly confirmed by a follow-up project called STOWASUS (Kaas et al. 2001). In the present report we concentrate on newer results that were mainly obtained from the PRUDENCE (http://prudence.dmi.dk) and Essence (Sterl et al. 2007, 2008) projects, and put them in the perspective of other published work.

\section{Past and future changes of near-surface marine wind fields}

\subsection{Past changes / Variability}

The storm climate in the European sector has undergone considerable variations on time scales of decades and longer (WASA Group 1998). It has intensified from about 1960 s onwards until about the mid-1990s. Here, the level of activity reached was comparable to that at the beginning of the 20th century (Alexandersson et al. 1998, 2000). The analysis of Alexandersson et al. (2000) has been updated in the last IPCC report (IPCC 2007) until 2004. It shows that storm activity has weakened considerably in the last decades. Considering even longer time periods, Bärring and von Storch (2004) showed that such decadal variations have not been unusual and that no discernible long term trend in storm activity could be detected so far. Similar results have been obtained by Bärring and Fortuniak (2008), Alexander et al. (2005), and Matulla et al. (2007).

Analyses of long term variations in the storm climate covering data of a century or more are usually based on proxy data. While such analyses allow for an assessment of the long term fluctuations, their spatial detail remains limited. Therefore, they are usually complemented with the analysis of spatially more detailed, but shorter global (e.g., Kalnay et al. 1996, Uppala et al. 2005) or regional (e.g., Feser et al. 2001) reanalysis and hindcast data. For the North Sea such a high-resolution hindcast for the past five decades is now available, the variability of which appears to be in good agreement with that obtained from proxy data (Weisse et al. 2005). In the following data from this hindcast will be used to assess the climate change signals obtained from climate model simulations.

\subsection{Projections}

\subsubsection{IPCC}

The recent IPCC-report (IPCC,2007) contains a short section about projected wind changes over Europe (see Section 11.3.3.5) which does not explicitly 
address the North Sea. Overall, some models are found to predict an increase in storminess over middle and northern Europe, while others predict a decrease.

The results from the climate model runs performed in preparation of the IPCCreport were analyzed for the KNMI'06 climate change scenarios for the Netherlands (KNMI 2006). From the coupled models for which results were available, those four were selected that best reproduced the current circulation over Europe (Van Ulden and Van Oldenborgh, 2006) ${ }^{25}$. Three of these four models show a slight increase of annual maximum daily-mean wind speed over the southern North Sea, and one shows no changes. Expressed in terms of 50 or 100 -year return values of wind speed, the increase amounts to $0.5-1.5 \mathrm{~m} / \mathrm{s}$ (dependent on model) at the end of this century under an SRES A1b forcing scenario. This change is much smaller than the internal (year-to-year) variability (see Fig. 6-7 of KNMI 2006). The increase is the same for all return times, meaning that percentage changes are lower for long return times than for short ones.

For the height of storm surges not only the wind speed, but also the wind direction is very important. For the Dutch coast northerly winds are most dangerous because they have the longest fetch. This was demonstrated last November, when the water level in Hoek van Holland was the highest since 1953, while the wind strength barely reached $9 \mathrm{Bf}$. However, the wind direction was north-north-west all the way from Iceland. An illustration is given by the right panel of 2.6 below. It displays the meteorological situation leading to the highest modeled surge in Hoek van Holland in the Essence-WAQUA/DCSM98 ensemble (see Section 3.1). The long fetch is clearly visible.

None of the models used to create the KNMI'06 scenarios exhibits a change to more northerly winds, while three show a tendency to westerly winds becoming more frequent. These are the same models that exhibit the small change in annual-maximum daily-averaged wind speeds. All models underestimate the frequency of northerly winds relative to ERA-40.

From this one can conclude that climate change will not have dramatic consequences on the surge heights at the Dutch coast. This is backed by forcing a simple parametric surge model (Van den Brink et al. 2004) with the winds from the AR4 models considered above. Despite the small increase in wind speed the surge levels remain centered around their present value because the frequency and strength of northerly winds do not change.

\subsubsection{Regional climate modelling - PRUDENCE}

Within the PRUDENCE project (http://prudence.dmi.dk) ensemble simulations for future climate conditions have been performed using different regional and global models and emission scenarios. In the following we focus on a subset of these simulations, namely those performed with the Swedish Rossby Center regional climate model (RCAO) using data from two different global models and two different emission scenarios (Räisänen et al. 2003). We concentrate on these 
simulations, as they have been used later to derive storm surge (Woth 2005, Woth et al. 2006) and wind wave (Grabemann and Weisse 2008) projections for the North Sea, which enables us to provide a consistent picture of changing meteo-marine conditions.

Figure 2.1 shows the distribution of annual mean and annual $99 \%$-ile wind speeds from these experiments, averaged over the 10 -box centered at $5.5 \circ \mathrm{E}$, 54.3०N. Results for this box are typical for the southern North Sea. For comparison, also the results obtained from a high resolution hindcast (Weisse et al. 2005, Weisse and Guenther 2007) for present day conditions are shown.

All climate simulations considerably underestimate present day annual mean and annual 99\%-ile wind speeds. Projected future changes for 2071-2100 are small and not systematic for annual mean wind speeds. For annual $99 \%$-ile wind speeds (see Figure 2.1b) the situation is slightly different. The climate change simulations point towards a small increase for 2071-2100. The increase is larger when the RCAO model is driven by the ECHAM4/OPYC3 model instead of the HadAM3H model. None of the changes is statistically significant for the HadAM3H driven simulations. For the ECHAM4/OPYC3 driven simulations the change in annual $99 \%$-ile wind speeds is about $5 \%$ relative to the control simulation and significant at the $99 \%$ level.
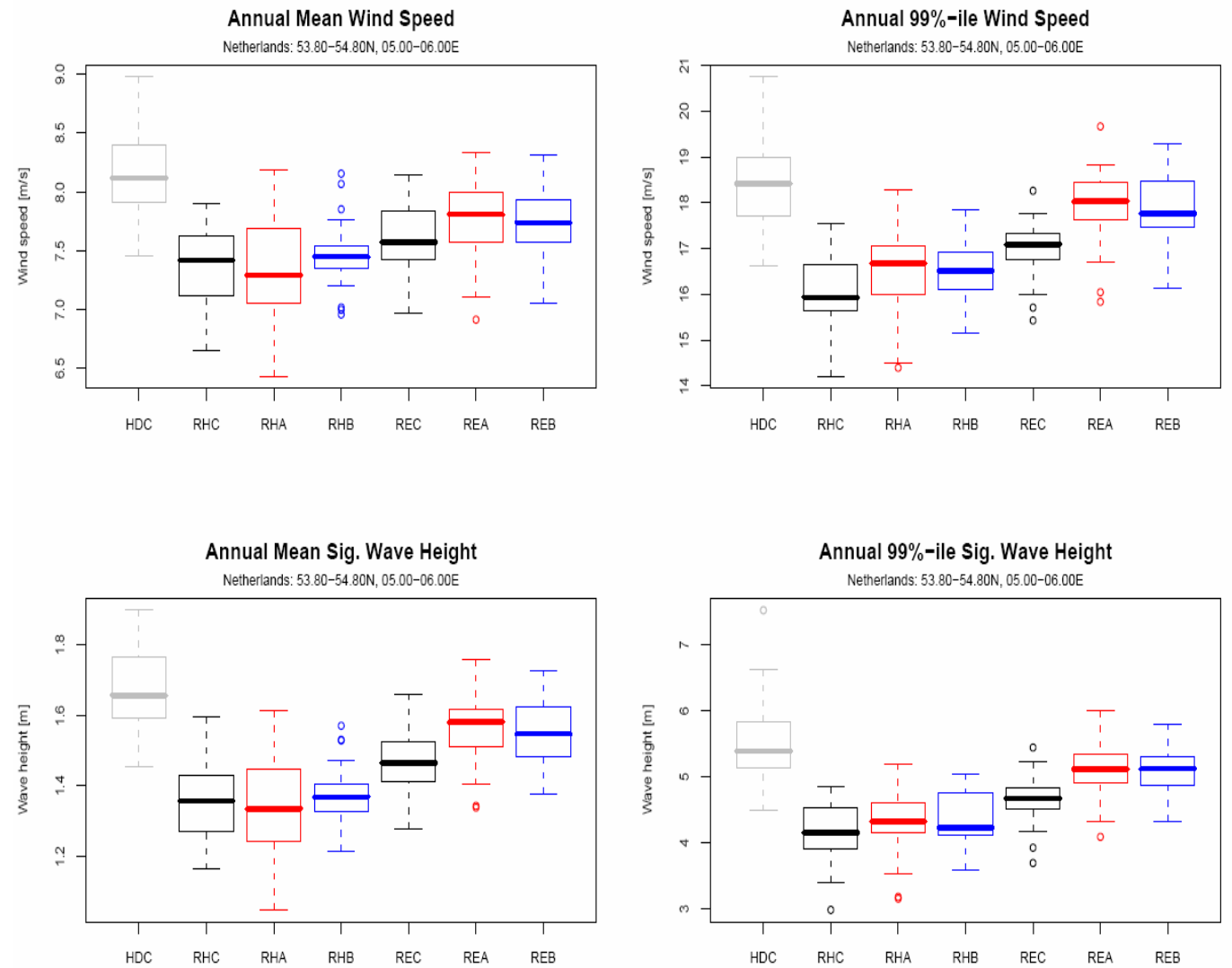

Figure 2.1: Distribution of annual mean (left column) and annual 99\%-ile (right column) of wind (upper row) and significant wave height (lower row) for the 10-box centered at $5.5^{\circ} \mathrm{E}, 54.3^{\circ} \mathrm{N}$. The colors denote the different experiments: present day (1961-1990) or control simulation (black); projections for 2071-2100 for A2 scenarios (red), and B2 scenarios (blue). The labels on the $x$-axis denote the different model and scenario combinations: $R$ denotes the $R C A O$ regional climate model, $E$ and $H$ denote that global 
forcing data from respectively ECHAM4/OPYC3 and HadAM3H were used, and $A, B$, and $C$ denote $A 2, B 2$ or control experiment. Values from a high resolution hindcast (Weisse et al. 2005, Weisse und Guenther 2007) are shown in gray (labled HD). The boxes denote upper and lower $25 \%$-iles, that is $50 \%$ of the values are located within each box. The whiskers extend over 1.5 of the inter-quartile ranges, and outliers are indicated by circles. The horizontal bar in each plot denotes the median.

Considering the entire ensemble reveals that uncertainties are considerable. While all experiments point towards an increase in annual mean and $99 \%$-ile wind speeds (see Figure 2.2), the ensemble size is too small to reliably test for the significance of the changes. Formally none of the differences passes a t-test at the $99 \%$ confidence level, and the spatial details vary considerably among models and simulations (Grabemann and Weisse 2008). Therefore results may not be very robust but could be sensitive to even small shifts in the position or direction of the major storm track. This view is backed by Rockel and Woth (2007) who tested the significance of changes in extreme wind speeds over Europe from a larger ensemble of RCM simulations, including the simulations discussed here. According to Rockel and Woth (2007) there is no general and clear statement about changes in extreme wind conditions, but the results depend on area and season. For central Europe they find statistically significant changes in the winter season. They also point out that some of the models show a clear underestimation of extreme wind conditions. This is in accordance with Pryor et al. (2005) who conclude that climate change signals in wind speed are in the same order of magnitude as differences between the climate control runs and reanalysis data. A similar result can be inferred from Figure 2.1a,b.

Debernard and Røed (2008) performed a similar exercise and dynamically downscaled GCM results using RACM, their regional climate model, as well as the WAM wave model and a surge model. In the south-eastern North Sea they find a slight ( 2\%) change of the mean and the $99 \%$-ile of wind, but no significant change for the most extreme winds. They do not show separate results for wind for the different GCMs and forcing scenarios, but from the respective results for significant wave height and storm surge one may infer that the changes are not larger than the differences between models and scenarios, thus corroborating the results above.
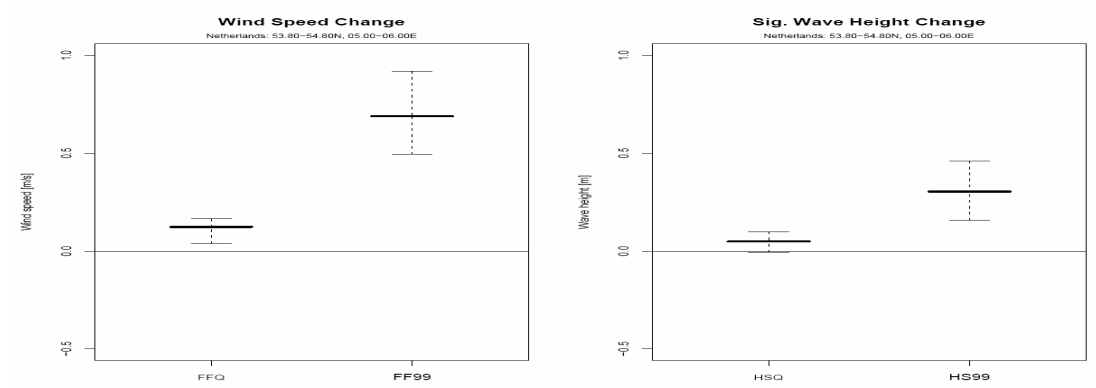

Figure 2.2: Range of climate change signals (2071-2100 minus 1960-1990) for all experiments considered in Fig. 1 for near-surface marine wind speed (left) and significant wave height (right), averaged over the $1^{\circ}$-box centered at 5.5०, $54.3^{\circ} \mathrm{N}$. Left in each panel is the annual mean, right the 99\%-ile changes. The whiskers extend from the lowest to the highest value found in all simulations considered in Figure 2.1, the horizontal line in-between indicates the mean. 


\subsubsection{Global climate modelling - Essence}

In the Essence project (Sterl et al. 2007, 2008) a 17-member ensemble of present and future climate under an SRES A1b emission scenario (Nakicenovic et al. 2000) was performed using the ECHAM5/MPI-OM climate model. For the grid points on the North Sea Figure 2.3 shows the fraction of wind speeds exceeding 8 $\mathrm{Bf}(17 \mathrm{~m} / \mathrm{s})$ for 30-degree sectors for the present (1950-2000) and future climates (2050-2100). In the left panel the averages over the ensemble are plotted together with the values derived from the ERA-40 reanalysis (Uppala et al. 2005).

Winds in the Essence ensemble tend to be higher than those from ERA-40. Most probably this is a consequence of the surface roughness, which in ERA-40 is larger due to its dependence on sea state. The higher winds are due to more south-easterly winds in the northern part of the domain and more south-westerly winds in the southern part. Both directions are not relevant for surges along the Dutch coast, where the highest surges are reached for north-westerly winds. The differences between the present and the future climate are small. Changes are only seen in the two southernmost points, where strong south-westerly winds increase. A comparison with the right panel, in which all 17 members of the ensemble are plotted separately, shows that the differences are smaller than the natural variability. It can be anticipated that an increase of south-westerly winds will not change surge heights at the Dutch coast.
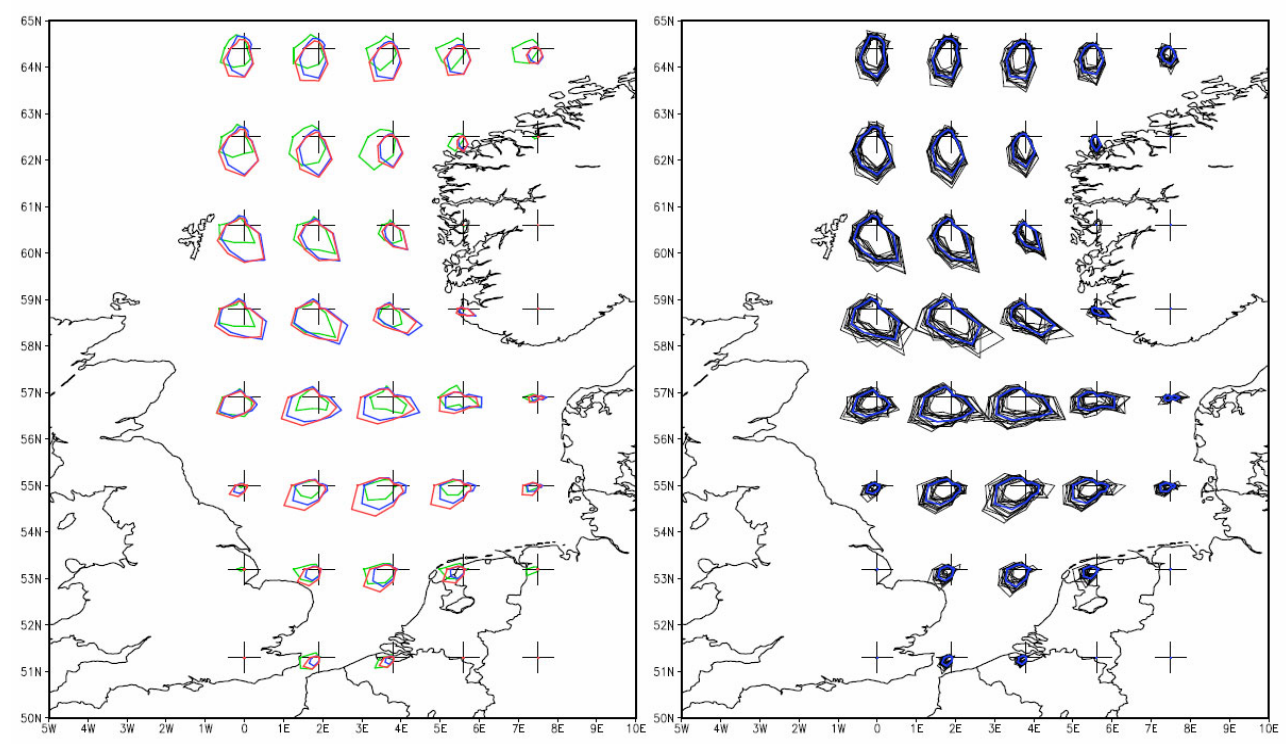

2.3: Fraction of winds exceeding $8 \mathrm{Bf}(17 \mathrm{~m} / \mathrm{s})$ per 30 -degree sector for all grid points in the North Sea. Left: Means over all Essence members for the present (1950-2000, blue) and future (2050-2100, red) climates. For comparison, ERA-40 is added in green. Right: All 17 members for the present climate and their mean (blue).

In Figure 2.4 the annual maxima of wind speed at the grid point $5 \circ \mathrm{E}, 55 \circ \mathrm{N}$ are presented in a Gumbel plot. The values are rank-ordered and plotted as a function of the Gumbel variate, the transformed rank variable. The values are fitted to a Generalized Extreme Value (GEV) distribution, the theoretical distribution for extreme values (Coles 2001). In accordance with Figure 2.3 the 
values for the future climate are higher than those for the present one. The increase is small but statistically significant, although the respective $95 \%$ confidence intervals marginally overlap even for the 10,000-year return value.

An important question when using model results to infer changes in extremes is whether the models do not systematically underestimate extremes in the present climate. The lack of reliable extreme wind measurements at sea hampers answering this questions. For the Essence ensemble we here put forward two pieces of evidence suggesting that the model correctly represents extreme winds. Figure 2.5 is a Gumbel plot of winds at $5 \circ \mathrm{E}, 55^{\circ} \mathrm{N}$ in the southern North Sea from different models for the present climate. The models are the four GCMs that have been used in the KNMI'06 scenarios (KNMI 2006) and the Essence ensemble, and a run using the regional climate model RACMO (Lenderink et al. 2003), driven by boundary conditions from ERA-40.

Furthermore, the values from ERA-40 (Uppala et al. 2005) and from the NCEP/NCAR reanalysis (Kalnay et al. 1996) are included. The lines are all parallel to each other, but have different offsets. As explained above, 10-m winds depend on surface roughness. As different models employ different parameterizations of surface roughness, they can, under otherwise identical circumstances, come up with different wind speeds.

This is particularly evident for the ERA-40 and the RACMO results. While the large-scale pressure field of the later is constrained by the former, the wind speeds are different. This is mainly due to a lower surface roughness in RACMO as compared to ERA-40. More important than the absolute level of winds in Figure 2.5 is the fact that all curves are parallel and none of them shows signs of saturation at the highest extremes. This indicates that the winds have not yet reached a strength that cannot be resolved by even the most coarse of the models. Therefore, these models should be able to simulate changes in extreme values.

The second piece of evidence comes from Figure 2.6. Its left panel is a Gumbel

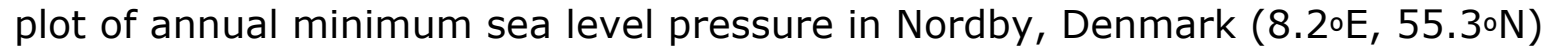
from observations and from the Essence ensemble. This point was chosen because a pressure minimum in this area leads to long wind fetches over the North Sea and therefore to the highest surges at the Dutch coast. This is illustrated in the right panel, which depicts the pressure and the wind field related to the highest surge that occurred in Hoek van Holland in the EssenceWAQUA/DCSM98 ensemble (see next section). In the Gumbel plot (left panel) observed and simulated values yield parallel curves, indicating that the model simulates well the distribution of extremely low pressures. There is no sign of an artificial lower bound on pressure in the model. 


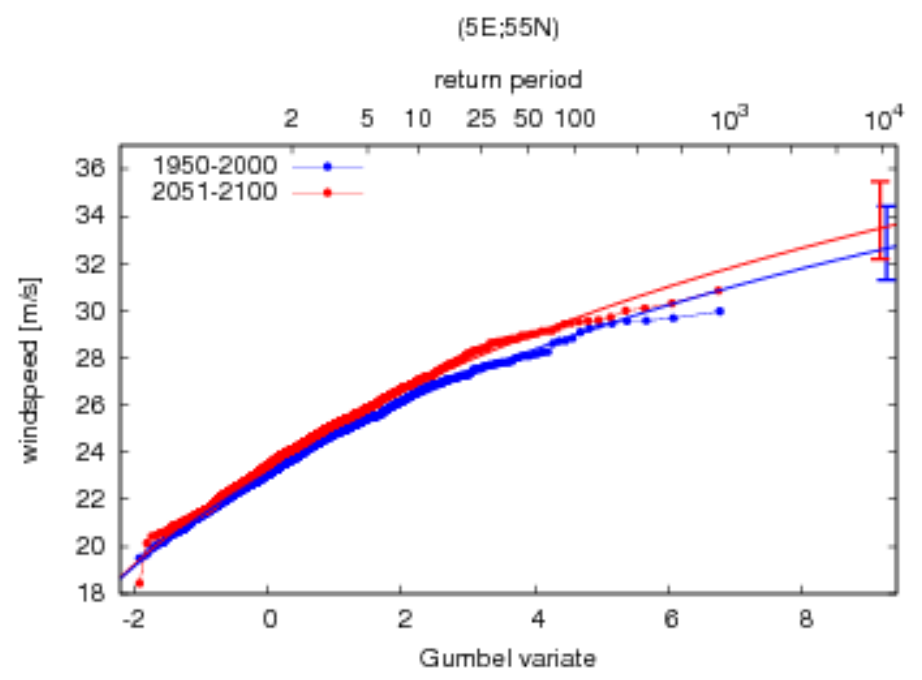

2.4: Gumbel plot for Essence annual maximum wind speeds for the same location as used in Figure $2.1\left(5^{\circ} \mathrm{E}, 55^{\circ} \mathrm{N}\right)$. Blue refers to the present $(1950-2000)$, red to the future (2050-2100) climate. The Gumbel variate (lower horizontal axis) is a transformed rank variable. It is directly related to the return time (upper horizontal axis), the average time between two occurrences of a given value. The lines are the fits to a GEV distribution. The error bars at the right margin give the 95\% confidence intervals for the 10,000-year return values.

Return level plot of daily-mean wind speed at $(5 \mathrm{E}, 55 \mathrm{~N})$

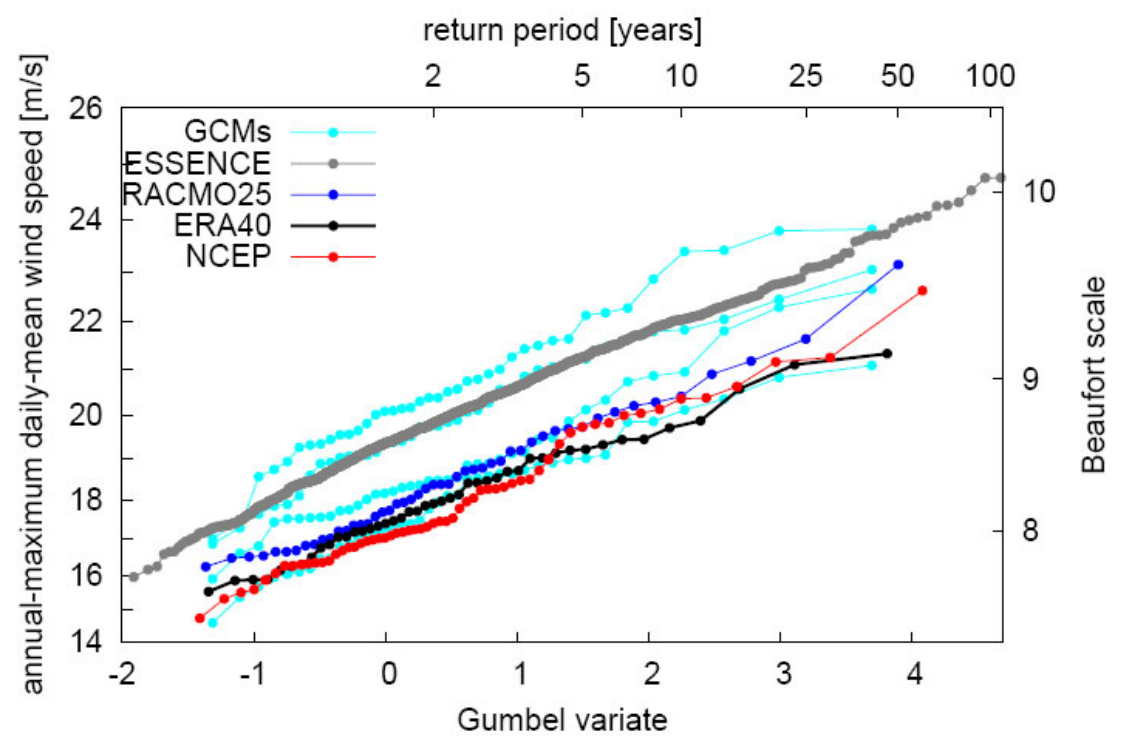

Figure 2.5. Gumbel plot of annual-maximum wind speed at $5^{\circ} \mathrm{E}, 55^{\circ} \mathrm{N}$. The cyan lines labeled GCMs refer to the four GCMs used in the KNMI'06 scenarios (KNMI 2006), and the blue line labeled RACMO25 to a run with the regional climate model RACMO at $25 \mathrm{~km}$ resolution, driven by ERA-40 boundary conditions. Values from the ERA-40 and the NCEP/NCAR reanlyses are represented by the black and red symbols, respectively. Figure 2.6: Gumbel plot of annual-minimum sea level pressure in Nordby, Denmark $\left(8.2^{\circ} \mathrm{E}, 55.3^{\circ} \mathrm{N}\right.$; left), and wind and pressure fields for the situation leading to the highest surge in Hoek van Holland that occurred in the Essence-WAQUA/DCSM98 ensemble (right). 


\section{Projected changes of local storm surges}

\subsection{Approach}

To infer future surge heights, projected winds have to be translated into surge heights. For surges along the Dutch coast northerly winds are most important. They have the longest fetch, and maximum water levels are reached when they blow all the way down from the Norwegian Sea into the southern North Sea. Thus not only the strength of the wind (the wind speed), but also its direction is important, and changes in both of them have to be taken into account. In Section 2 we showed that increasing wind speeds were limited to south-westerly directions. A first guess is therefore that surge heights along the Dutch coast are not affected much by climate change.

To test this hypothesis the output from different storm surge models driven by the winds discussed in the previous sections was analyzed. Wind fields from the RCAO ensemble (see Section 2.2.2) were used to drive the TRIMGEO ${ }^{26}$ model for present day (1961-1990) and future (2071-2100) climate conditions (Woth et al. 2006, Woth 2005). Results are discussed in Section 3.3.

The winds from the Essence ensemble were used to drive WAQUA/DCSM98 (see http://www.waqua.nl/systeem/documentatie/usedoc/waquapublic/waq general.pdf), the storm surge model operationally used at KNMI (see http://www.knmi.nl/ jwdv/WAQUA). This model is usually driven by winds from a high-resolution limited area model for weather forecasting. To verify that the low-resolution Essence winds are a suitable forcing we use ERA-40 winds (Uppala et al. 2005), interpolated to Essence resolution, to drive WAQUA/DCSM98. To account for the underestimation of surface winds in ERA-40 relative to Essence that was noted in Figure 2.5 the ERA-40 winds were increased by $10 \%$. The modelled annual maximum surge heights follow the same distribution as the observed surge heights (see Figure 2.7), and in 30 of the 44 years the same event was responsible for the annual maximum in the model and in the observations. The model-observation difference shows no systematic dependence on surge height. Together, we conclude that the combination EssenceWAQUA/DCSM98 is suitable to study extreme storm surges. 


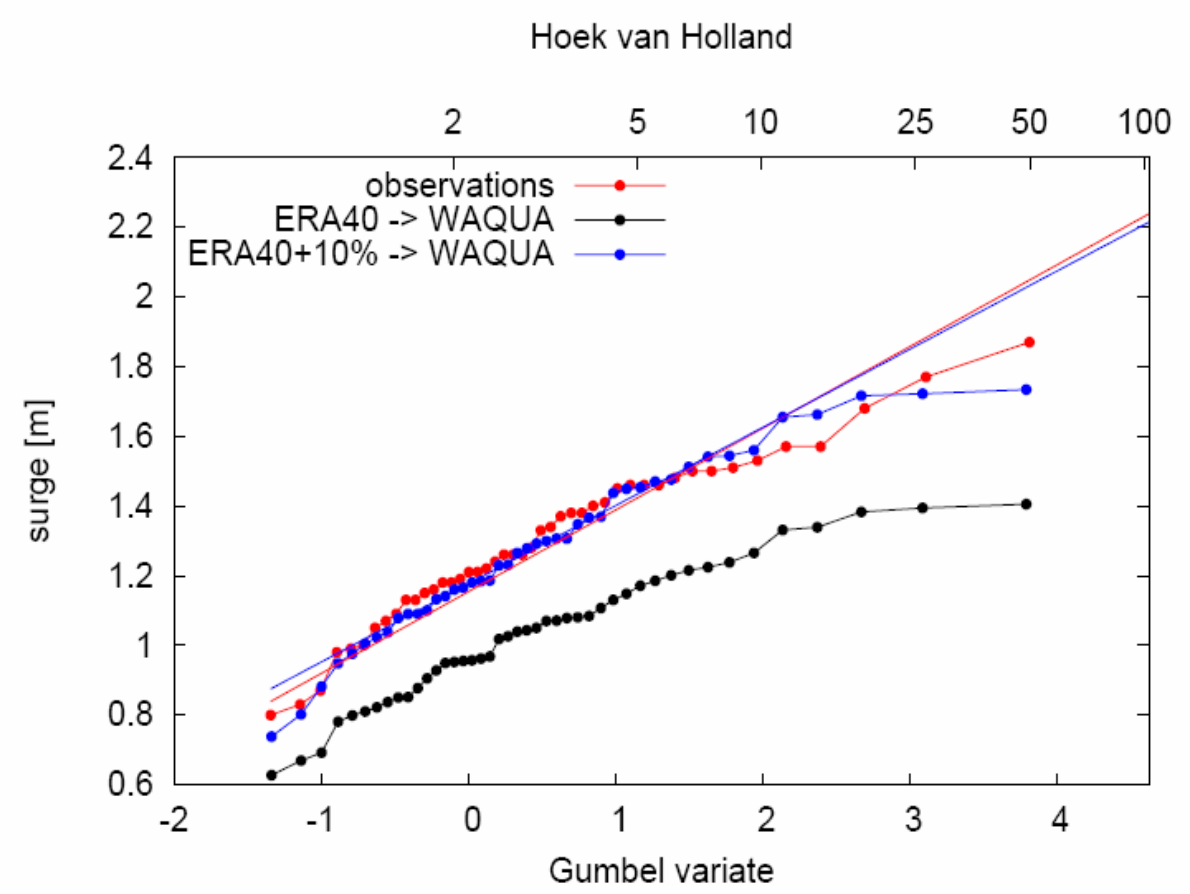

Figure 2.7: Gumbel plot of annual-maximum surge heights in Hoek van Holland for the period 1958-2002. Compared are observations and results from WAQUA/DCSM98 forced by ERA-40 winds.

All results on surges shown here are based on direct model output. In general these values are not levels right at the shore line, but at locations well in front of it, e.g., the $10 \mathrm{~m}$ line or so. Therefore, a regression-based localization step is needed, which relates off-shore (grid-box) surge levels to shore line values. The technique has been introduced by Langenberg et al. (1999) and was refined by Grossmann et al. (2007) for the Elbe estuary and Woth and Weisse (2008) for the German North Sea coast. The localization step is incorporated in WAQUA/DCSM98 by subtly changing the model bathymetry to produce output that is directly comparable to the reading of the local tide gauge. Our main concern here is changes in surge levels. As long as the bathymetry does not change, the proportionality between surge levels at the shore line and those at any location to which the model applies will not change. The results reported below, although strictly speaking only valid for the model grid point closest to the coast, are therefore also relevant for the water level at the shore line.

\subsection{Uncertainty}

Dutch law requires coastal defense systems to withstand a water level which on average would occur only once every 10,000 years. This level has to be estimated from the existing 118 years of data. Not surprisingly, extrapolating over two orders of magnitude yields a large error bar. This is illustrated in Figure 2.8 for the station Hoek van Holland, where black denotes observations. The GEV-fit yields a best estimate of $3.6 \mathrm{~m}$ for the 10,000 year return value, but the $95 \%$ confidence interval ranges from $2.9 \mathrm{~m}$ to $6.4 \mathrm{~m}$. The confidence interval is determined using the profile likelihood. The chance that the real value is lower than the lower bound or higher than the upper bound is both $2.5 \%$. 


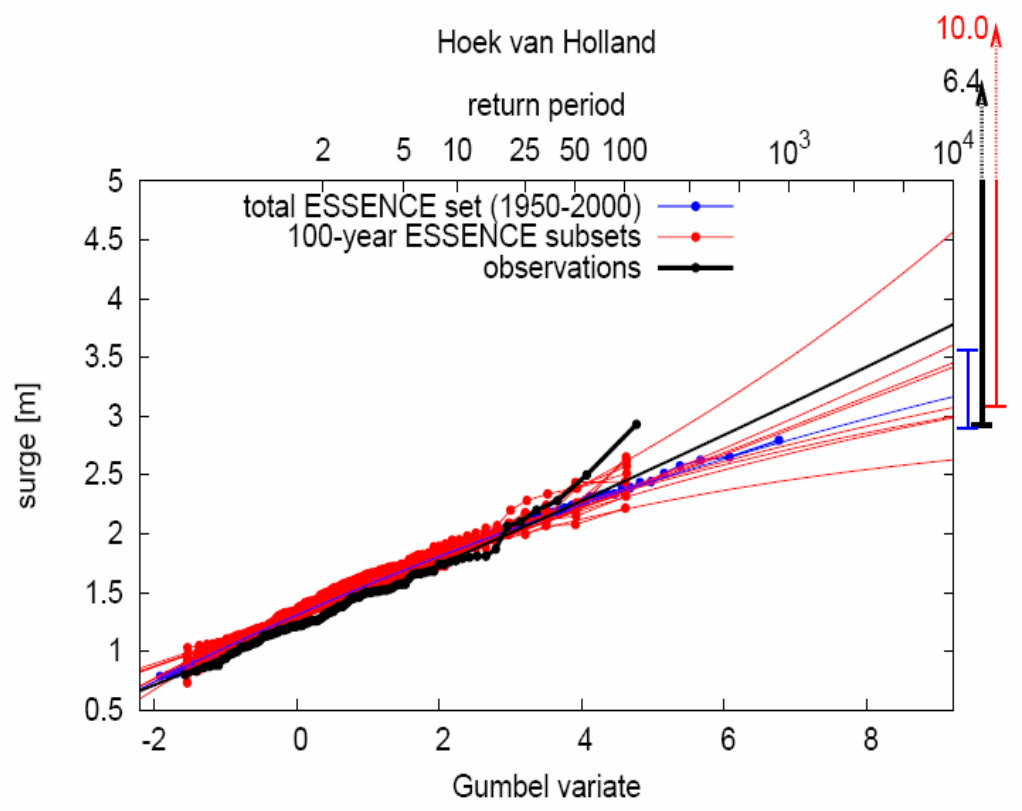

Figure 2.8: Gumbel plot for surge heights at Hoek van Holland. Black: Observations (thick) and GEV fit (thin). Red: data from 100 year chunks of Essence-WAQUA/DCSM98 (thick) and corresponding fits (thin). Blue: All Essence data together. The bars at the right margin indicate the 95\% confidence intervals for the 10,000-year return value. The red bar is for the curve with the highest best estimate of $4.5 \mathrm{~m}$.

This result is stressed by the results from the Essence-WAQUA/DCSM98 ensemble. The red dots and lines in Figure 2.8 are for arbitrary 100 -year segments of the ensemble (years 1950-2000 from two members). The respective GEV fit yields best estimates ranging from $2.6 \mathrm{~m}$ to $4.5 \mathrm{~m}$, and the $95 \%$ confidence interval for the latter value ranges from $3 \mathrm{~m}$ to $10 \mathrm{~m}$. From these results it is obvious that the impact of climate change on surge heights cannot reliably be inferred from short time series. The sampling error would be much larger than the signal, which in the light of Section 2 we anticipate to be small. Only the whole ensemble $(17 \times 50$ years, blue) yields a confidence interval that may be small enough to detect a climate change signal.

\subsection{Regional climate modeling}

There are considerable variations among different estimates for extreme surge levels such as 50-yr return values (Flather et al. 1998, Lowe et al. 2001, Lowe and Gregory 2005). Estimates based on changes of more frequent surge levels (such as annual $99 \%$ percentiles) appear to be somewhat robust and seem to provide a more consistent picture. When wind fields from the RCAO ensemble discussed in Section 2.2.2 are used, increases in 99\%-ile surge levels along the German, Dutch and Danish coasts are found irrespective of model and scenario from which the wind fields was obtained (Woth 2005, Woth et al. 2006). For the Netherlands in winter (DJF) estimates of changes in the annual $99 \%$ percentile surge levels are in the order of $5-10 \%$ for $2070-2100$ (von Storch and Woth 2008). For most of the Dutch coast this remains within the range of observed (hindcast) variability within the past 50 years. An identical result is obtained by Debernard and Røed (2008). These authors also report that changes for the moderate B2 scenario (Nacicenovic et al. 2000) are actually higher than for the 
A2 scenario. As they only have one run for each GCM their result may reflect decadal variability rather than climate change.

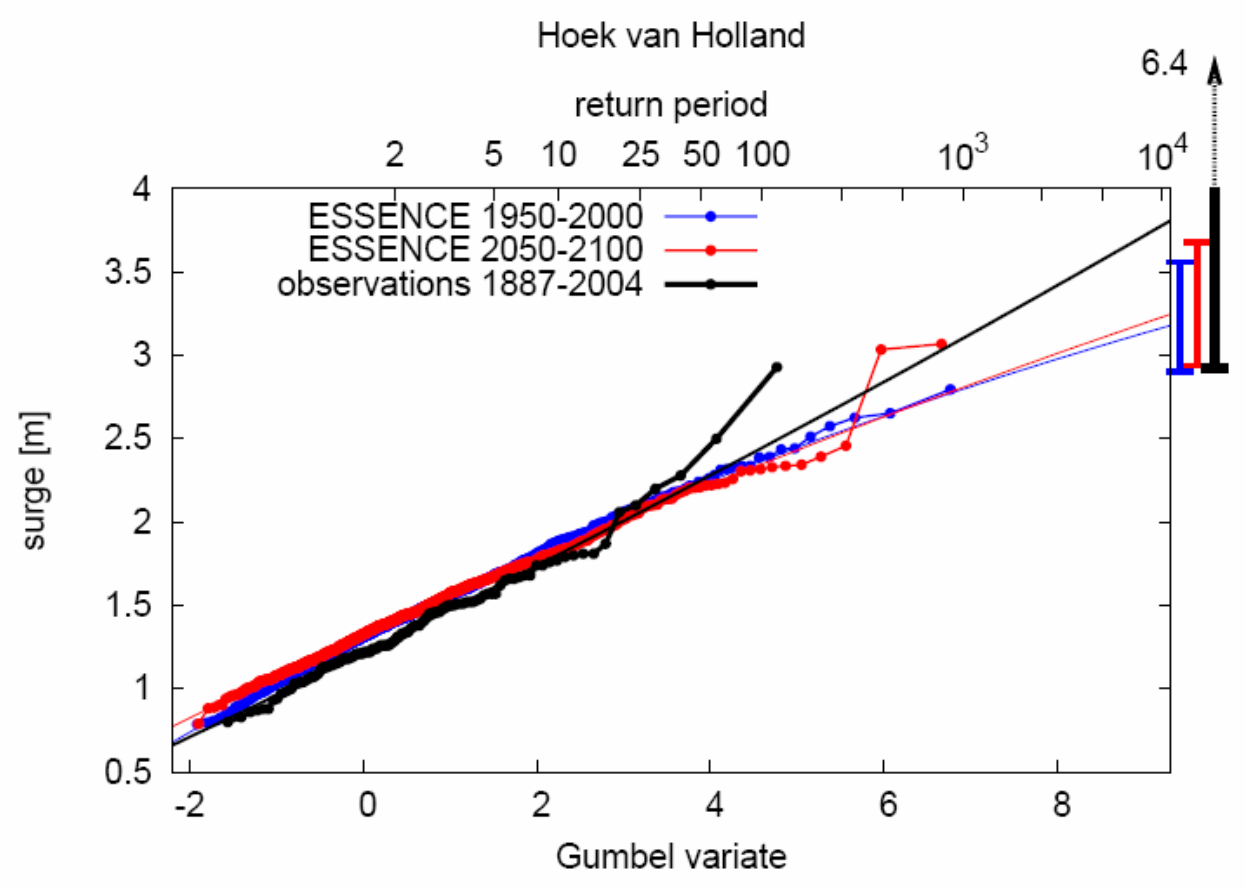

Figure 2.9: Gumbel plot for surge heights at Hoek van Holland from the EssenceWAQUA/DCSM98 ensemble. Black: observations (same as in Figure 2.8), blue: presentday climate (1950-2000, same as in Figure 2.8), red: future climate (2050-2100). The bars in the right margin indicate the $95 \%$ confidence interval.

\subsection{Results from Essence}

The statistical robustness that was lacking in the regional modelling efforts is provided by the Essence-WAQUA/DCSM98-ensemble. Figure 2.9 shows a Gumbel plot of modelled annual maximum surge heights at Hoek van Holland for the present (1950-2000) and the future climate (2050-2100). The fits as well as the confidence intervals for the 10,000-year return value are practically identical. Within the limits of natural variability there is no change of surge heights due to global warming along the Dutch coast.

\section{Projected change of wind waves}

Grabemann and Weisse (2008) used the wind fields from the RCAO ensemble described in Section 2.2 to derive projections of changing wave conditions in the North Sea. They run the wave model WAM in a nested version with about $5 \times 5$ $\mathrm{km}$ horizontal resolution in the North Sea and a coarser grid (about $50 \times 50 \mathrm{~km}$ ) for relevant parts of the Northeast Atlantic. Sea-ice from the climate change simulations was also accounted for. The following discussion is based on the experiments of Grabemann and Weisse (2008), and the figures have been obtained from their data. 
Figure $2.1 \mathrm{c}$, d show the distributions of annual mean and annual $99 \%$-ile significant wave height averaged over the 1 -box centered at $5.5 \circ \mathrm{E}, 54.3 \circ \mathrm{N}$. For comparison, also the results obtained from a high-resolution hindcast (Weisse and Günther 2007) for present day conditions are shown.

All climate simulations considerably underestimate present day annual mean and annual 99\%-ile significant wave heights. Climate change signals for 2071-2100 are small and statistically not significant in the simulations driven by the HadAM3H model. In the experiments driven by the ECHAM4/OPYC3 model the changes are larger and reach $10 \%$ for the annual $99 \%$-ile wave heights. They are statistically significant at the $99 \%$ level. These results are consistent with those from the wind changes discussed in Section 2.2.2.

The same conclusions that were drawn for wind speed in Section 2.2.2 also hold for waves: Most experiments point towards an increase in annual mean and 99\%-ile significant wave heights for 2071-2100 (see Figure 2.2), but the ensemble size is too small to reliably test for the significance of the changes. None of the differences passes a t-test at the $99 \%$ confidence level, and the spatial details vary considerable among models and simulations (Grabemann and Weisse 2008). The results of Debernard and Røed (2008) corroborate these findings. They also find a slight increase in the $99 \%$-ile of significant wave height along the Dutch coast with large differences between forcing models and forcing scenarios.

\section{Summary and discussion}

We have investigated possible impacts of climate change on wind and windrelated quantities in the North Sea and especially along the Dutch coast. Global and regional climate modeling employing different climate models as well as different forcing scenarios suggest a slight increase in extreme wind speeds in the southern North Sea, which is reflected in a slight increase in the height of wind waves. The increase in wind speed is the result of increasing south-westerly winds which are not relevant for extreme surges along the Dutch coast. Not surprisingly, extreme surge heights do not change.

Surge heights were assessed using hydrodynamic surge models under the assumption of unchanged sea level and bathymetry. To first order approximation mean sea level rise can be added linearly to the surge height. Nonlinear effects are in the order of $10 \%$ of the change in mean sea level (Kauker and Langenberg 2000, Lowe and Gregory 2005). Results using the Essence-WAQUA/DCSM98 combination confirm these findings.

Local changes in bathymetry caused by erosion and sedimentation as well as waterworks may have a significant effect on surge heights. Von Storch and Woth (2008) showed that the reduction of flood planes and dredging had a much larger impact on surge heights in Hamburg than did climate change. The situation of Hamburg $140 \mathrm{~km}$ land-inwards at the end of a large estuary is not representative for the Dutch coast. More research is needed to assess the effects of changes in the morphology on surge heights along the Dutch coast. 
Changes in bathymetry may also alter the propagation of swell waves in coastal waters. This effect has not been investigated.

Apart from wind strength and direction, also the duration and frequency of storms may influence surge heights, and two or more consecutive storms might excite eigenfrequencies of the North Sea basin, which could lead to extreme surge heights. We did not investigate these effects separately. From the fact that we find no signs of a second population in our Gumbel plots we conclude that these effects are not important.

\section{References}

Alexander, L.V., Tett, S.F.B. and Jonsson, T. , 2005, Recent observed changes in severe storms over the United Kingdom and Iceland, Geophys. Res. Lett., 32, L13704, doi:10.1029/2005GL022371.

Alexandersson, H., T. Schmith, K. Iden, and H. Tuomenvirta , 1998, Long-term variations of the storm climate over NW Europe. Global Atmos. Oc. System, 6, 97-120.

Alexandersson, H., H. Tuomenvirta, T. Schmidth, and K. Iden, 2000, Trends of storms in NW Europe derived from an updated pressure data set, Climate Res., $14,71-73$

Bärring, L. and H. von Storch, 2004, Scandinavian storminess since about 1800 , Geophys. Res. Lett., 31, L20202, doi:10.1029/2004GL020441.

Bärring, L. and K. Fortuniak, 2008, Multi-indices analysis of Scandinavian storminess 1780-2005, Int. J. Climatol., submitted.

Bunde, A., J.F. Eichner, S. Havlin, and J.W. Kantelhardt, 2004, Return intervals of rare events in records with long term persistence, Physica A, 342, 308-314.

Coles, S., 2001, An Introduction to Statistical Modeling of Extreme Values, Springer-Verlag, $208 \mathrm{pp}$.

Debernard, J.B., and L.P. Røed, 2008, Future wind, wave and storm surge climate in the Northern Seas: a revisit, Tellus, 60A, 472-438, doi: 10.1111/j/1600-0870.2008.00312.x.

Deltacommissie, 1960-61, Rapport Deltacommissie, 's-Gravenhage; Staatsdrukkerij- en Uitgeverijbedrijf, 6 Delen. Deel I: Eindverslag en interimadviezen. Deel II-IV: Beschouwingen over stormvloeden en getijbeweging. Deel V: Onderzoekingen betreffende de opzet van het Deltaplan en de gevolgen van de werken. Deel VI: Onderzoekingen van belang voor het ontwerpen van dijken en dammen; sociaal-economische aspecten van het Deltaplan. Dutch only. 
Feser, F., R. Weisse, and H. von Storch, 2001, Multi-decadal atmospheric modeling for Europe yields multi-purpose data, EOS Transactions, 82, pp 305 \& 310.

Flather, R.A., J.A. Smith, J.D. Richards, C. Bell and D.L. Balckman, 1998, Direct estimates of extreme storm surge elevations from a 40-year numerical model simulation and from observations, Global Atmos. Oc. System, 6, 165-176.

Grabemann, I., and R. Weisse, 2008, Climate change impact on extreme wave conditions in the North Sea: an ensemble study, Ocean Dynamics, submitted.

Grossmann, I., K. Woth, and H. von Storch, 2007, Localization of global climate change: Storm surge scenarios for Hamburg in 2030 and 2085, Die Küste, 71, 169-182.

IPCC, 2007, Climate Change 2007: The Physical Science Basis. Contribution of Working Group I to the Fourth Assessment Report of the Intergovernmental Panel on Climate Change (IPCC), Solomon, S., D. Qin, M. Manning, Z. Chen, M. Marquis, K. B. Averyt, M. Tignor and H. L. Miller (eds.), Cambridge University Press, Cambridge, UK, and New York, NY.

Kaas, E., U. Andersen, R.A, Flather, J.A. Willimas, D.L. Blackman, P. Lionello, F. Dalan, E. Elvini, A. Nizzero, P. Malguzzi, A. Pfizenmayer, H. von Storch, D. Dillingh, M. Phillipart, J. de Ronde, M. Reistad, K.H. Midtbø, O. Vignes, H. Haakenstad, B. Hackett, I. Fossum and L. Sidselrud, 2001, Synthesis of the STOWASUS-2100 project: Regional storm, wave and surge scenarios for the 2100 century, Danish Climate Centre Report 01-3, 22pp.

Kauker, F., and H. Langenberg, 2000, Two models for climate change related development of sea levels in the North Sea - a comparison, Climate Research, $15,61-67$.

Kalnay, E., M. Kanamitsu, R. Kistler, W. Collins, D. Deaven, L. Gandin, M. Iredell, S. Saha, G. White, J. Woollen, Y. Zhu, M. Chelliah, W. Ebisuzaki, W. Higgins, J. Janowiak, K.C. Mo, C. Ropelewski, J. Wang, A. Leetmaa, R. Reynolds, R. Jenne, and D. Joseph, 1996, The NCEP/NCAR reanalysis project, Bull. Am. Meteorol. Soc., $77,437-471$.

KNMI, 2006, KNMI Climate Change Scenarios 2006 for the Netherlands. KNMI Scientific report WR 2006-01. Available from KNMI, P.O. Box 201, 3730 AE De Bilt, The Netherlands.

Langenberg, H., A. Pfizenmayer, H. von Storch and J. Sündermann , 1999, Storm related sea level variations along the North Sea coast: natural variability and anthropogenic change, Cont. Shelf Res., 19, 821-842.

Lenderink, G., van den Hurk, B., van Meijgaard, E., van Ulden, A.P., Cuijpers, J. , 2003, Simulation of present-day climate in RACMO2: first results and model developments, KNMI Technical Report 252, 24 pp. Available from KNMI, P.O. Box 201, 3730 AE De Bilt, The Netherlands. 
Lowe, J.A. and J.M. Gregory, 2005, The effects of climate change on storm surges around the United Kingdom, Phil. Trans. R. Soc., 363, 1313-1328.

Lowe, J.A., J.M. Gregory, and R.A. Flather, 2001, Changes in the occurrence of storm surges around the United Kingdom under a future climate scenario using a dynamic storm surge model driven by Hadley Centre climate models, Clim. Dyn., $18,179-188$.

Matulla, C., W. Schöner, H. Alexandersson, H. von Storch, and X.L. Wang, 2007, European storminess: Late 19th century to present, Clim. Dyn., doi: $10.1007 / \mathrm{s} 00382-007-0333-y$

Nakicenovic, N. et al., 2000, Special Report on Emissions Scenarios: A Special Report of Working Group III of the Intergovernmental Panel on Climate Change, 599 pp., Cambridge University Press, Cambridge, U.K. Available online at: http://www.grida.no/climate/ipcc/emission/index.htm.

Pryor, S.C., R.J. Barthelmie and E. Kjellström, 2005, Potential climate change impact on wind energy resources in northern Europe: analyses using a regional climate model, Clim. Dyn., 25, 815-835.

Räisänen, J., U. Hansson, A. Ullerstig, R. Döscher, L. Graham, C. Jones, H. Meier, P. Samuelsson, and U. Willen, 2003, GCM driven simulations of recent and future climate with the Rossby Centre coupled atmosphere-Baltic Sea regional climate model RCAO, SMHI, Norrköping, Rossby Centre, 61 pp.

Rockel, B. and K. Woth, 2007, Extremes of near-surface wind speed over Europe and their future changes as estimated from an ensemble of RCM simulations, Climatic Change, 82, doi:10.1007/s10584-006-9227-y.

Sterl, A., R. Haarsma, F. Selten, W. Hazeleger, and H. Dijkstra, 2007, The ESSENCE project - the power of a large model ensemble, Biennial Scientific Report 2005-2006, KNMI, De Bilt, pp 114-118.

Sterl, A., C. Severijns, G.J. van Oldenborgh, H. Dijkstra, W. Hazeleger, M. van den Broeke, G. Burgers, B. van den Hurk, P.J. van Leeuwen, and P. van Velthoven, 2008, When can we expect extremely high surface temperatures? Geophys. Res. Lett., 35, L14703, doi: 10.1029/2008GL034071.

Uppala, S.M., P.W. Kallberg, A.J. Simmons, U. Andrae, V. da Costa Bechtold, M. Fiorino, J.K. Gibson, J. Haseler, A. Hernandez, G.A. Kelly, X. Li, K. Onogi, S. Saarinen, N. Sokka, R.P. Allan, E. Andersson, K. Arpe, M.A. Balmaseda, A.C.M. Beljaars, L. van de Berg, J. Bidlot, N. Bormann, S. Caires, F. Chevallier, A. Dethof, M. Dragosavac, M. Fisher, M. Fuentes, S. Hagemann, E. Holm, B.J. Hoskins, L. Isaksen, P.A.E.M. Janssen, R. Jenne, A.P. McNally, J-F. Mahfouf, J-J. Morcrette, N.A. Rayner, R.W. Saunders, P. Simon, A. Sterl, K.E. Trenberth, A. Untch, D. Vasiljevic, P. Viterbo, and J. Woollen, 2005, The ERA-40 re-analysis, Quart. J. Roy. Meteor. Soc., 131, 2961-3012.

Van Den Brink, H.W., G.P. Können, J.D. Opsteegh, G.J. van Oldenborgh, and G. Burgers, 2004, Improving $10^{4}$-year surge level estimates using data of the 
ECMWF seasonal prediction system, Geophys. Res. Lett., 31, L17210, doi: 10.029/2004GL020610.

Van Ulden, A.P., and G.J. Van Oldenborgh, 2006, Large-scale atmospheric circulation biases and changes in global climate model simulations and their importance for climate change in Central Europe, Atmos. Chem. Pys. 6, 863-881, Sref-ID: 1680-7324/acp/2006-6-863.

Von Storch, H., and K. Woth, 2008, Storm surges, perspectives and options, Sust. Sci., 3, 33-44, doi: 10.1007/s11625-008-0044-2.

The WASA-Group (1998): Changing waves and storms in the Northeast Atlantic? Bull. Am. Meteorol. Soc., 79, 741-760.

Weisse, R., and H. Günther, 2007, Wave climate and long-term changes for the Southern North Sea obtained from a high-resolution hindcast 1958-2002, Ocean Dynamics, 57, 161-172, doi:10.1007/s10236-006-0094-x.

Weisse, R., H. von Storch, and F. Feser, 2005, Northeast Atlantic and North Sea storminess as simulated by a regional climate model 1958-2001 and comparison with observations, J. Climate, 18, 465-479, doi: 10.1175/JCLI-3281.1.

Woth, K., 2005, North Sea storm surge statistics based on projections in a warmer climate: How important are driving GCM and the chosen emission scenario? Geophys. Res. Lett., 32, L22708, doi: 10.1029/2005GL023762.

Woth, K., R. Weisse, and H. von Storch, 2006, Climate change and North Sea storm surge extremes: An ensemble study of storm surge extremes expected in a changed climate projected by four different Regional Climate Models, Ocean Dynamics, 56, 3-15.

Woth K., and R. Weisse, 2008, High resolution projections of possible future changes in North Sea storm surge extremes, Proceedings JCOMM 2007, Seoul (in press). 


\section{CHAPTER III - Effects of climate change on the Rhine discharges}

This Chapter integrates and summarizes Appendix III-a: 'Future Rhine discharge as a result of climate change, and Appendix III-b: 'Effect of flooding in Germany upon the peak discharge at Lobith'.

\section{Introduction}

The Rhine rises in the Swiss Alps and flows, after crossing Germany, France and the Netherlands, approximately $1300 \mathrm{~km}$ further into the North Sea. Its basin covers an area of $185,000 \mathrm{~km}^{2}$. The lower parts of the basin and all branches in the Netherlands are protected against flooding by dikes. The point where the Rhine enters the Netherlands, i.e. Lobith forms the outlet of the river basin and the upper corner of the Rhine delta. Slightly downstream of Lobith the Rhine breaks up in three branches Waal, Lek and IJssel.

The Rhine, being one of the largest rivers in Europe, affects the economy and environment of one of the most densely populated areas in Europe. Historically, the Rhine is one of the busiest waterways in Europe forming the major transport route between the Rotterdam harbour and the German hinterland. The major part of the fresh water in the Netherlands comes from the Rhine. Its water is used for many purposes: drinking water, irrigating crops, industrial cooling water, generation of hydroelectricity and prevention of sea-water intrusion (salt) from the North Sea into Dutch polders that are below sea level.

Although the Netherlands benefits economically from the River Rhine, floods of the River Rhine form a major threat in the low lying adjacent polders in the Netherlands. Protection against the floods from the River Rhine is therefore a major water management issue in the Netherlands. Changes in the hydrology of the Rhine due to (anthropogenic) climate change will thus affect all the activities including the risk of flooding. For adaptation policies in the Netherlands it is of particular importance how much (or how little) Rhine water may enter the Netherlands in future. In the Netherlands, therefore, projects to assess the effects of climate change on the hydrology of the Rhine have been carried out from 1988 onwards.

\subsection{Objectives}

Recognizing the relevance of the effects of climate change on the Rhine the new Dutch Delta commission asked to review the existing studies on possible changes in Rhine discharges. This report summarizes findings of this review. The review focuses on changes in average seasonal flows as well as on flood events. Although important, changes in low flows receive relatively little attention.

\subsection{Main results}

It will be shown that under the climate scenarios currently applied: peak discharges currently considered being very high will become normal; 
the design discharge will increase, however the magnitude is very uncertain the current hydraulic properties of the Rhine limit the potential increase of the design discharge substantially; summer flows will be, depending on the scenario, little or extremely reduced.

\section{The hydrology of the Rhine basin}

Geographically the Rhine basin can be divided into three regions: the mountainous Alpine region, upstream of Basel (Switzerland); the low mountain ranges and hilly areas in Germany and France, between Basel and Bonn (Germany) referred to as the upper Rhine and the lowlands, downstream of Bonn, referred to as the lower Rhine. Approximately, the three areas cover respectively 20,60 and $20 \%$ of the basin. The contribution to the water supply of these areas differs throughout the year as their importance for low, average and peak flows does.

- The annual average flow is determined by the amount and distribution of precipitation and evaporation in the basin. As the Alpine region receives relatively much rainfall and annual evaporation is relatively small at higher altitudes, it supplies relatively much water; $40 \%$, on an annual average basis in the lower Rhine.

- Low flows may occur in all seasons, however, for the lower part of the Rhine the late summer is the main low flow season. In this season the contribution from the Alpine region may rise to more than $90 \%$ at Lobith. This is due to the snowmelt, release of water from the Alpine lakes and reservoirs, a precipitation maximum in summer and the relatively low evaporation rates at higher altitudes. Release of water from glaciers can be ignored. The contribution from the other regions is small due to the relatively higher evaporation rates.

- Flood events occur mainly during winter and early spring. In the flood season, the region between Basel and Cologne forms the main source of water due to the low evaporation rates. Little water is produced in the Alpine region as the precipitation is temporarily stored as snow at the higher altitudes.

- Extreme flood events occur during the winter period. They are caused by series of low pressure areas tracking over the basin while releasing great amounts of rainfall. The large flow volumes are generated in the German and French parts of the basin during rainfall periods lasting several days over large areas of the catchment. In winter evaporation rates are low resulting in soils being saturated with water. Snowmelt plays hardly a role under current conditions, however, frozen soils occasionally lead to more extreme runoff volumes. Due to the size and shape of the basin, the volume as well as the height of the discharge peak strongly depends on the direction, speed and rainfall intensity associated with the low pressure areas and less to intensities of individual storms. Different flood events show therefore quite different genesis. However, the 10 day precipitation volume variability correlates well with the variability in peak discharge in winter. In its delta (The Netherlands) 
as well as those areas where the Rhine flows through a very wide valley, the floodplains are embanked. Embankments narrow the river bed and therefore limit the space for the rivers, leading to higher peak discharges. The levels of protection against flooding of these dikes differ from place to place and thus the height of the embankments. Very high discharges however may locally cause overflow of and/of burst of these embankments leading to uncontrolled flooding of the valley floors. This flooding attenuates the peak flow in the river further downstream.

Changes in future discharges are therefore determined by:

1. The variation and change in the amount of precipitation and evaporation in the different seasons and regions. This affects all flows in all seasons.

2. Change in temperature that will change the distribution between snow and rainfall in the Alpine region (particularly in winter). Temperature determines the length of the snow season and affects the regime of the river. After all snow accumulates and leads to delayed runoff.

3. The change in evaporation (particularly during the summer/growing season when evaporation is large). This has mainly effects on low and summer flows

4. The change in (local) temperature, which has a large influence in controlling 2 . and 3 . Temperature rise results into a shift from a combined rainfall-snowmelt river into a rainfall dominated river at Lobith, leading to higher winter and lower summer flows.

5. The change in the (relative) variability of multi-day precipitation amounts and for the Rhine in particular of the 10-day precipitation amounts. This affects in particular the magnitude of peak flows at Lobith. Increases of the 10-day precipitation variability tend to increase peak flows while decreased variability leads to decreased peak flows.

6. Changes in the hydraulic properties of the river embanked flood plains, may lead to either higher or lower discharges. Flooding of these embankments limits the maximum discharge peaks that reach the Netherlands.

\section{Methods used to assess future discharge changes of the River Rhine}

Figure 3.1. illustrates the steps taken to assess the impact of climate change on water management.

For scenarios until 2050, emission scenarios play a minor role and differences in projections are almost entirely determined by differences in the results from the various climate models. Operational scenarios used for the water management purposes are therefore mainly based on the outcomes of different climate models 
in combination with hydrologic/hydraulic models. In hydrological applications the upper three boxes as usually treated as a single box.

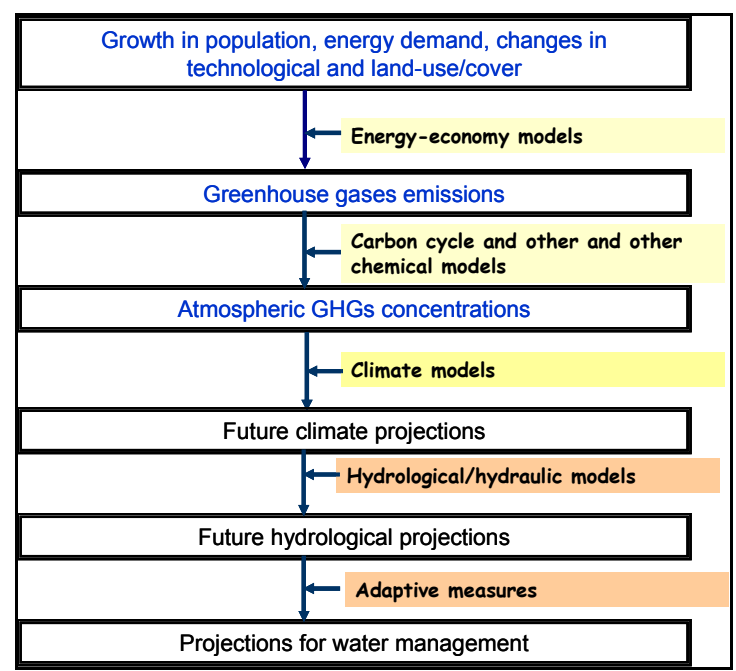

Figure 3.1: Steps needed to assess the impact of climate change on water management

Climate models calculate runoff. Studies for large river basins in the world have been carried out using climate models only, where the focus was mainly on representation of annual yield, however not for the River Rhine. Climate models do not, however, account for accumulation of the water through the drainage basin, nor for hydraulic effects such as flood wave propagation and flood wave attenuation in the river channels. Changes in river discharge due to climate change are usually modeled with separate hydrological models, where the hydrological models simulate the runoff to the rivers or to the outlet of the river basins. Recent studies in the Rhine basin include also hydraulic modelling. Here the hydrological models are linked to hydraulic models, where the hydrological model simulates the runoff to the river and the hydraulic model reproduces the routing and propagation of the flood wave through the main river channel eventually by taking the flooding of the areas adjacent to the river channel into account. In the Netherlands the hydrogical models that are mostly used in the River Rhine basin are the Rhineflow model and the HBV model; the hydraulic model applied is the Sobek 1-dimensional model.

Recent assessments for changes in the Rhine discharge use climate models or climate scenarios which are projected on the Rhine basin by one of the following methods:

1. A delta approach in which the projected changes in the relevant climate parameters such as precipitation are 'added' to historical time series. These adapted time series, in turn, are used as input for the hydrological model.

2. By using the (daily) output from a (global or regional) climate model directly as input for the hydrological model. 
All scenarios used for the Netherlands water management purposes are based on the first approach. With respect to the assessment of extreme flood events some more specific methods are applied that will be described separately.

\subsection{Delta approach (or incremental scenarios), by using a combination of changes in average climate conditions and hydrological models}

In the delta approach the future changes in the relevant climatic parameters (the 'deltas') are either taken from a climate scenario (e.g. one of the four KNMI'06 climate scenarios) or from the changes simulated with a regional or global climate model (respectively a RCM or a GCM). In the latter case the changes (the deltas) are obtained from the differences between the control run (that represents the current climate) and the perturbed run (representing the future climate given a certain greenhouse gas emission scenario). The differences (deltas) are used to transform historically observed climatic time series into possible future time series. Those transformed series are then used to drive a hydrological model that is calibrated to the characteristics of the river basin of interest. Similar to the application of the delta method for climatic time series, the delta method can also be used to circumvent or correct for biases encountered in the hydrological model; i.e. the (discharge) results from the hydrological model are not used directly but the changes in the discharge characteristics simulated by the hydrological model are used to adapt the historically observed discharge characteristics.

In many applications of the delta approach only changes in average climatic parameters are considered. A disadvantage of this 'classic' delta method is that by considering average changes only, it is implicitly assumed that there is no difference between the historical and future climate variability; the future climate variability is inherited from the historically observed series. This e.g. also implies that the number of wet days in the future climate is the same as in the historically observed climate. This disadvantage is important for assessing the changes in the peak discharges. The change in the peak discharge of the Rhine is not only sensitive to the change in the average precipitation but it turns out to be very sensitive to changes in the relative variability of multi-day precipitation amounts as well (e.g. Buishand and Lenderink, 2004). Thus delta methods that take only average changes into account are less suitable to asses the changes peak discharges. This does not disqualify delta methods in general since adapted delta methods are available.

\subsection{Directly linking of the climate model results into the hydrological models, or direct approach}

In this approach time series from a climate model are used directly to drive the hydrological model. An advantage of this approach is that changes in climate variability simulated by the climate model are taken into account. A disadvantage is that climate models still have difficulties with reproducing observed rainfall characteristics. This means that despite the terminology 'direct', in practice various bias corrections of the climate model output are needed to account for 
systematic differences between the climate model control run and the corresponding observations.

\subsection{Approaches specifically applied to assess extreme flood events}

Assessments of changes in extreme flows, and in particular the design discharge, have made use of alternative and/or additional methods. These include the use of empirical relations between (changes in) monthly or 10-day average discharges and (changes in) discharge peaks; extreme value analysis to (statistically) extrapolate to return periods between $\sim 50$ and 1250 years; the use of long (1000-year) synthetic climate time series to obtain long discharge time series; the use of $1 \mathrm{D}$ or $2 \mathrm{D}$ hydraulic models to more realistically account for the propagation of discharge peaks through the river channel and to take into account the effects of retention measures and dike overflow.

\section{Estimates of future Rhine discharge}

For the Netherlands the most recent assessments of changes in the River Rhine discharge developed for water management purposes are based on the four KNMI'06 climate scenarios ( $G, G+, W, W+$ ). These scenarios replaced the scenarios that were drawn up in 2000 for the National Commission on Water management in the $21^{\text {st }}$ century, also known as the WB21 climate scenarios.

Each of the four KNMI'06 climate scenarios gives, for 2050 as well as for 2100 , a single number for the change per variable. These numbers are uniform for the Netherlands and according to KNMI these numbers can also be used as indicative for the river basins of the Meuse and the Rhine with the exception of the Alpine region. As during dry periods $50 \%$ of the water is supplied by the Alpine region, estimates of changes in low flows should be treated with care.

According to the KNMI'06 scenarios in 2100 average winter temperatures increase from 1.8 to $4.6^{\circ} \mathrm{C}$ and in summer the increase is between 1.7 and 5.6 ${ }^{\circ} \mathrm{C}$. The coldest winter day per year increases up to $5.8^{\circ} \mathrm{C}$, and the warmest summer day per year $7.6^{\circ} \mathrm{C}$. Precipitation in winter increases between 7 and $28 \%$ and summer precipitation changes from -38 to $+12 \%$. Regarding summer drying it is important to realize that the scenarios with the largest precipitation decrease in summer have the largest potential evaporation increases (up to $30 \%)$.

\subsection{Changes in average seasonal flow}

To arrive at discharge scenarios two hydrological (soil moisture accounting) models have been applied, the Rhineflow model (version 3) and the HBV model. In the most recent studies the discharge scenarios were obtained as follows. Based on the KNMI'06 climate scenarios the historical time series (1961-1995) for precipitation, temperature and evaporation were perturbed using the classic delta approach (no changes in climate variability) where the average 10-daily change was used. These perturbed time series were used to drive the hydrological models. Table 3.1 presents the results of Rhineflow for 2050 and 
2100 (for 2200 no relevant climate change information was available) for summer and winter.

Table 1.1: Average Rhine discharge $\left(\mathrm{m}^{3} / \mathrm{s}\right)$ observed at the end of the 20th century, and projections for 2050 and 2100 (meaningful values for 2200 cannot be derived). The ranges for 2050 and 2100 are obtained by applying the KNMI'06 climate scenarios to the Rhineflow-3 rainfall-runoff model. Discharges are rounded to the nearest $50 \mathrm{~m}^{3} / \mathrm{s}$. The percentages are rounded to the nearest $5 \%$. Summer refers to Aug Oct and winter to Jan - Mar.

\begin{tabular}{|l|c|c|c|c|}
\hline & $\mathbf{1 9 6 8 - 1 9 9 8}$ & $\mathbf{2 0 5 0}$ & $\mathbf{2 1 0 0}$ & $\mathbf{2 2 0 0}$ \\
\hline $\begin{array}{l}\text { Avg. summer flow } \\
\left(\mathrm{m}^{3} / \mathrm{s}\right)\end{array}$ & 1700 & $1100-1700$ & $700-1700$ & n.a. \\
\hline $\begin{array}{l}\text { Change in avg. } \\
\text { summer flow (\%) }\end{array}$ & & $-35-0$ & $-60-0$ & n.a. \\
\hline $\begin{array}{l}\text { Avg. winter flow } \\
\left(\mathrm{m}^{3} / \mathrm{s}\right)\end{array}$ & 2750 & $2950-3200$ & $3100-3600$ & n.a. \\
\hline $\begin{array}{l}\text { Change in avg. winter } \\
\text { flow }(\%)\end{array}$ & & $+5-+15$ & $+15-+30$ & n.a. \\
\hline
\end{tabular}

For 2050 these numbers are little different from the results obtained by combining the same climate scenarios to the HBV-Rhine model (Te Linde, 2007). Both in summer and winter the HBV-Rhine model gives somewhat smaller average discharges (up to $70 \mathrm{~m}^{3} / \mathrm{s}$ ) which results in about $4 \%$ larger decreases in summer and about $2 \%$ smaller increases in winter

Figure 3.2 compares the changes in average monthly discharges with estimates from earlier studies (since 1988). The figure nicely illustrates that the trend to higher discharges during the flood season, December to April is rather robust as it appears in nearly all scenarios. The magnitude suggested by the new KNMI'06 scenarios is comparable with the earlier proposed changes. However, according to the new KNMI G+ and W+ scenarios, the conditions during the dry season in late summer become much dryer than earlier envisaged.

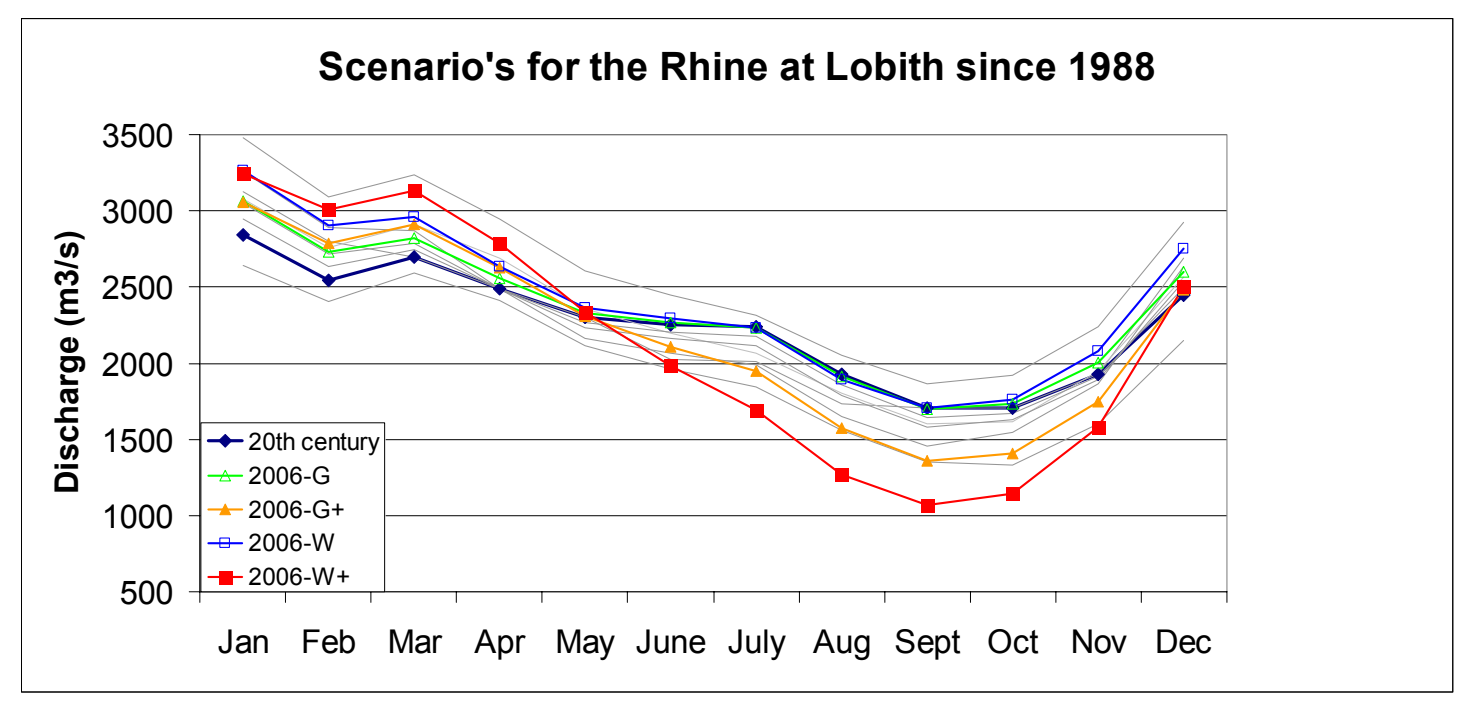

Figure 3.2: A comparison between future average monthly Rhine discharge assuming the KNMI'06 scenarios for 2100 projected on the Rhine basin and earlier studies (grey thin lines) (Deltares, 2008). 


\subsection{Future flood frequency}

Future flood frequency has been assessed using the four KNMI'06 climate scenarios for 2100 and applying the delta method to the historical 1961-1995 series. The resulting perturbed series were used to run the Rhineflow-3 model. The results and details of the assessment (Deltares, 2008) are given in Table 3.2.

Table 3.2: Projections of flood events for 2100 with return periods between 50 and 1250 years compared to the current return values (all values rounded to $500 \mathrm{~m}^{3} / \mathrm{s}$ ). The average changes in 10-day discharge volumes from Rhineflow were used to perturb the historical daily discharge series at Lobith for 1901-2004 (an additional delta method applied to the observed discharge series). A Gumbel distribution was successively fitted to the (perturbed) annual maxima above $7000 \mathrm{~m}^{3} / \mathrm{s}$. The minimum estimate corresponds with the $G$ scenario and the maximum estimate with $W+$. Note that flooding (controlled or uncontrolled) is not taken into account (Deltares, 2008).

\begin{tabular}{|l|c|c|c|c|c|}
\hline & \multicolumn{5}{|c|}{ Return period (yr) } \\
\hline & $\mathbf{5 0}$ & $\mathbf{1 0 0}$ & $\mathbf{2 5 0}$ & $\mathbf{5 0 0}$ & $\mathbf{1 2 5 0}$ \\
\hline $\begin{array}{l}\text { Estimated from measured series (1901- } \\
\text { 2004) }\end{array}$ & 12,000 & 13,000 & 14,000 & 15,000 & 16,000 \\
\hline $\begin{array}{l}\text { Estimate from base line simulation (1901- } \\
\text { 2004) }\end{array}$ & 11,500 & 12,500 & 14,000 & 15,000 & 16,000 \\
\hline Minimum estimate 2100 (G) & 13,000 & 14,500 & 16,000 & 17,000 & 18,500 \\
\hline Maximum estimate 2100 (W+) & 15,500 & 17,000 & 18,500 & 20,000 & 21,500 \\
\hline
\end{tabular}

The table shows that the return period of a peak discharge of $15,500 \mathrm{~m}^{3} / \mathrm{s}$, which is currently roughly 1000 years, decreases to 50 years under the $W+$ climate scenario in 2100. Assuming the same scenario, the return period of the 1995 flood (with a peak of about $12,000 \mathrm{~m}^{3} / \mathrm{s}$ ) would reduce from 50 years to about 10 years (not shown).

\subsection{Changes in the 1250-year discharge based on the KNMI'06 climate scenarios}

Changes in the 1250-year discharge have been assessed using a variety of methods. The following assessments have been made using the KNMI'06 climate scenarios in combination with scaling or delta methods:

- De Wit et al. (2007) found for the increase in the 1250-year discharge under the KNMI'06 climate scenarios for 2050 a range between 16,500 and 17,500 $\mathrm{m}^{3} / \mathrm{s}$ (rounded to $500 \mathrm{~m}^{3} / \mathrm{s}$ ) applying rough scaling of earlier results. Their range for 2100 is $17,500-20,000$.

- Te Linde (2007) used two KNMI'06 climate scenarios ( $G$ and W+) for 2050 to transform 1,000 years of synthetic daily data simulated with the KNMI weather generator for the Rhine basin (De Wit and Buishand, 2007) into future series and coupled these to HBV-Rhine and the hydraulic model Sobek (but without the possibility of flooding in Germany). Fitting a Gumbel 
distribution to all the simulated annual discharge maxima resulted in an increase in the 1250-year discharge to 17,000 under the $G$ scenario and $19,250 \mathrm{~m}^{3} / \mathrm{s}$ under the $\mathrm{W}+$ scenario (both rounded to $250 \mathrm{~m}^{3} / \mathrm{s}$ ).

- Deltares (2008) used the four KNMI'06 climate scenarios for 2100 and applied the delta method to the historical 1961-1995 series. The resulting perturbed series were used to run the Rhineflow-3 model. The average changes in (10day) discharge volumes from Rhineflow were used to perturb the historical daily discharge series at Lobith for 1901-2004 (also by the delta method). Fitting a Gumbel distribution to the annual maxima above $7000 \mathrm{~m}^{3} / \mathrm{s}$ led to estimates of the 1250 -year discharge between 18,500 and $21,500 \mathrm{~m}^{3} / \mathrm{s}$ (rounded to $500 \mathrm{~m}^{3} / \mathrm{s}$ ).

Table 3.3: Effect of the change in precipitation variability on extreme Rhine discharge compared to the

\begin{tabular}{|c|c|c|}
\hline Parameter & HadRM2 & HadRM3H \\
\hline Average winter precipitation & $+8 \%$ & $+25 \%$ \\
\hline 10-day winter precipitation variability & $+25 \%$ & $-16 \%$ \\
\hline $\begin{array}{l}\text { Resulting } Q_{1250} \text { excluding precipitation variability } \\
\text { change }\left(\mathrm{m}^{3} / \mathrm{s}\right)\end{array}$ & 18,500 & 22,000 \\
\hline $\begin{array}{l}\text { Resulting } Q_{1250} \text { including precipitation variability } \\
\text { change }\left(\mathrm{m}^{3} / \mathrm{s}\right)\end{array}$ & 22,000 & 18,000 \\
\hline
\end{tabular}

effect of change in average winter precipitation (results rounded to $500 \mathrm{~m}^{3} / \mathrm{s}$ ).

\subsection{Changes in the 1250-year discharge based on climate models (direct approach)}

None of the above methods included changes in the variability of the climate. The results of a series of studies that aimed at directly linking the climate model output to hydrological models show that this is a major drawback of the classic delta method (Buishand and Lenderink, 2004). These studies used two versions of the UK Hadley Centre Regional Climate Model (RCM), HadRM2 and HadRM3H. The simulation results of both RCMs differ considerably. The focus here is on the effect of the 10-day precipitation variability in winter for which even the sign of the change is opposite. For the HadRM2 model a delta method was applied that does account for the changes in the precipitation variability while the results of the HadRM3H model were directly linked to the Rhineflow-3 model. However, to reproduce the historical climate bias correction of the HadRM3H model was performed. By fitting a Gumbel distribution to annual maxima of the discharge volumes at Lobith the change in the 1000-year discharge was assessed which is almost identical to the change in the 1250-year discharge, $\mathrm{Q}_{1250}$. For both models two experiments were performed, one in which the change in precipitation variability was included and one in which it was ignored. Table 3.3 presents the results of those experiments.

The results clearly show strong dependency of the extreme Rhine discharge to the change in variability in 10-day precipitation. Even if the average winter precipitation would moderately increase, but the variability would increase substantially, this would lead to a relatively large increase of the 1250 -year 
discharge (HadRM2). In contrast, the effect of a large increase of the average winter precipitation can be partly compensated by a reduction of the precipitation variability (HadRM3H).

\subsection{Estimated range of the future 1250 -year discharge and statistical uncertainty}

Given our present knowledge and taking into account the large uncertainties identified we can only provide very rough estimates of the future 1250 -year discharge of the Rhine (currently $16,000 \mathrm{~m}^{3} / \mathrm{s}$ ). For 2050 a range of 16,500 to $19,000 \mathrm{~m}^{3} / \mathrm{s}$ seems feasible whereas for 2100 a range of 17,000 to $22,000 \mathrm{~m}^{3} / \mathrm{s}$ has been derived (see Table 3.4).

Table 3.4: Peak discharge of the Rhine $\left(\mathrm{m}^{3} / \mathrm{s}\right)$ in 2050 and 2100 obtained by applying the KNMI'06 climate scenarios and results from climate models to relatively simple rainfall-runoff models for the Rhine basin in combination with statistical methods. The reference value refers to the 1250-year discharge at Lobith.

\begin{tabular}{|l|c|c|c|c|}
\hline & $\begin{array}{c}\text { Reference } \\
\text { value }\end{array}$ & $\mathbf{2 0 5 0}$ & $\mathbf{2 1 0 0}$ & $\mathbf{2 2 0 0}$ \\
\hline Peak discharge $\left(\mathrm{m}^{3} / \mathrm{s}\right)$ & 16,000 & $16,500-19,000^{\dagger}$ & $17,000-22,000^{\dagger}$ & n.a. \\
\hline Change in \% & & $3-19$ & $6-38$ & n.a. \\
\hline
\end{tabular}

${ }^{\dagger}$ These ranges are rough estimates based on limited knowledge. Apart from the uncertainty in the mean meteorological conditions, the 2100 range is also due to the large sensitivity of peak discharges to changes in multi-day precipitation variability, a precipitation characteristic which has not been included yet in the KNMI'06 scenarios. The uncertainty related to hydrological modelling and hydraulic effects (see below) is not included.

Note that due to the statistical extrapolation to the return period of 1250 years the current 1250 -year discharge has a $95 \%$ confidence interval as large as $13,000-18,500 \mathrm{~m}^{3} / \mathrm{s}$ (Diermanse, 2004; results rounded to $500 \mathrm{~m}^{3} / \mathrm{s}$ ). The projected upper values for 2050 and 2100 are thus above the present $95 \%$ uncertainty maximum of $18,500 \mathrm{~m}^{3} / \mathrm{s}$. Further note, that the projected future 1250 -year discharge values also have a large statistical uncertainty.

\subsection{Assessing the maximum flow arriving at the Netherlands}

All assessments mentioned above ignore the effect of flooding upstream of the Netherlands. The flow capacity of the embanked sections of the River Rhine however limits the maximum discharge. At very high stages the water level may exceed the crests of the embankments, and lead to overflow and probably to breaches in the embankments. Locally this will lead to (uncontrolled) flooding; further downstream it leads to attenuation of the flood wave in the river channel. This effect is addressed by Lammersen (2004) in a study that estimated the effects of retention measures and extreme floods along the upper and lower Rhine upon the Dutch Rhine branches.

For the purpose of the assessment, 1,000 years synthetic discharge series were generated by the KNMI weather generator combined with the HBV hydrological model. The eight highest floods were analyzed using a 1-dimensional hydraulic model that simulated the propagation of the flood wave through the main river 
channel and included the effect of both retention (controlled flooding) and uncontrolled flooding.

Along the upper Rhine, the effect of uncontrolled flooding upon the flood wave was taken into account by using a very simple method of retaining water in retention areas and releasing it later, after the flood wave has passed. Water flowing in the flooded area parallel to the Rhine and probably flowing back to river further downstream, was not taken into account at the upper Rhine.

In the case of the lower Rhine, the 1-dimensional hydraulic model was tuned using the results of a 2-dimensional inundation model. The 2-D model included the levels of the embankments, and both the effects of dike breaches and overtopping of the crests were simulated. Each dike collapse or overflow was modeled as a retention basin. Water flows behind the dike parallel to the Rhine which enter the Rhine further downstream again were modeled as parallel streams to the Rhine. An example of the flooded areas and the flow patterns behind the dikes along the lower Rhine is given in Figure 3.3, while Figure 3.4 illustrates the effects of flooding on the discharge in the Rhine stretch between Bonn and Lobith.

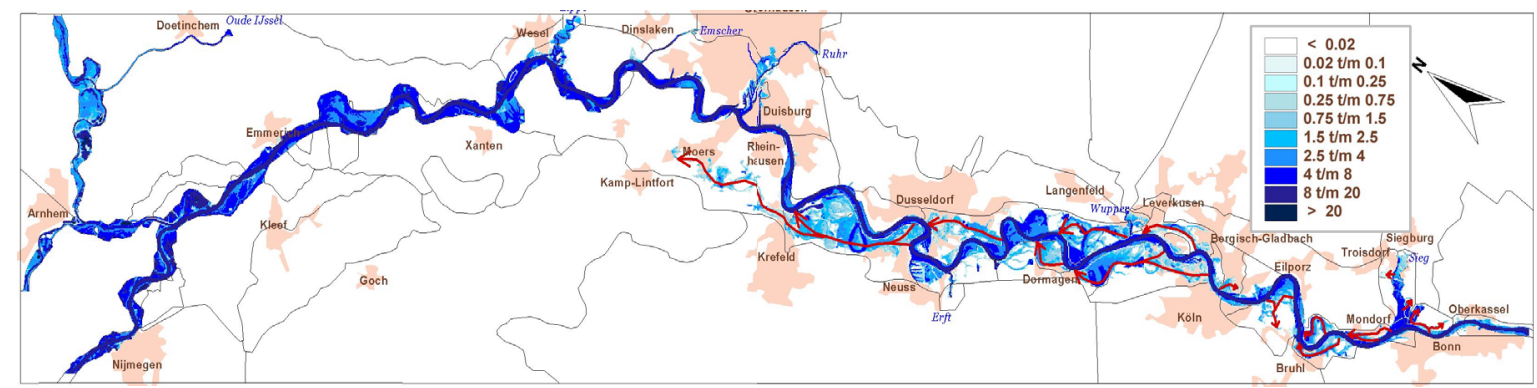

Figure 3.3: Flooding along the lower Rhine (dike situation 2020): maximum water depths [m] and main streams behind the dikes (Lammersen, 2004).

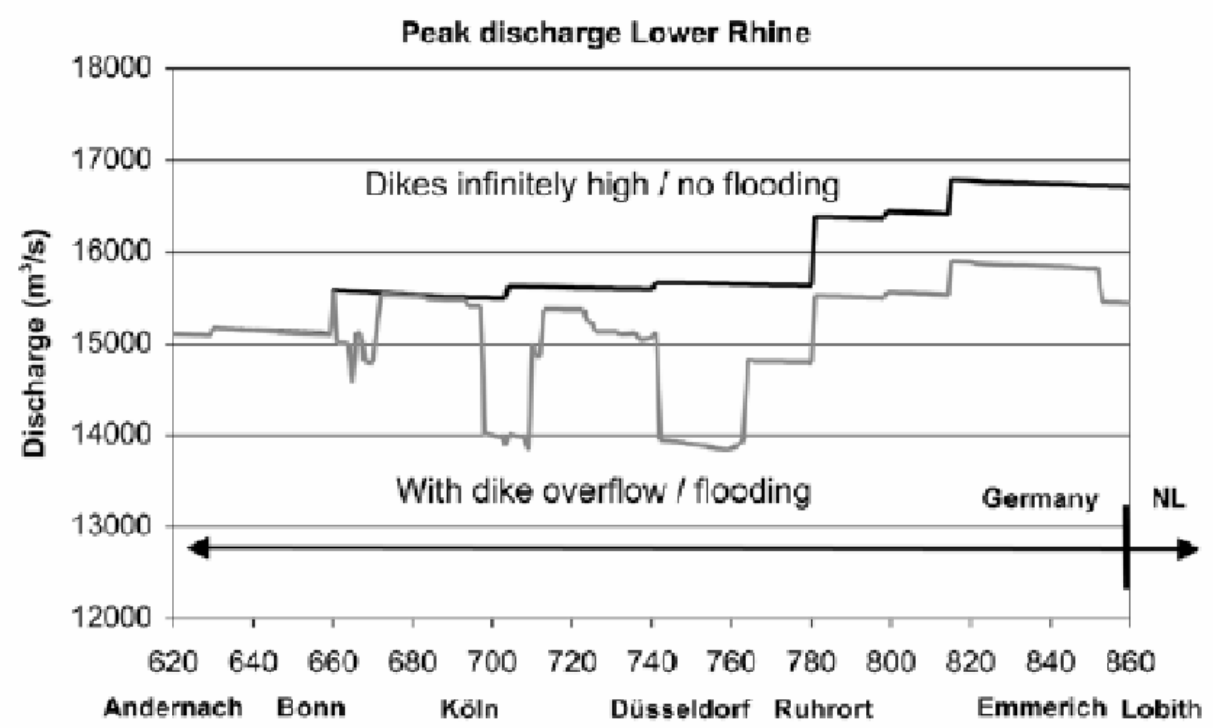

Figure 3.4: Development of an extreme discharge peak with and without dike overflow/flooding (dike situation 2020, flood wave HW8); (Lammersen, 2004) . 
In addition to the study by Lammersen (2004), where peak discharges without flooding did not exceed $19,000 \mathrm{~m}^{3} / \mathrm{s}$ at Lobith, Gudden (unpublished) incrementally increased the highest discharge peak up to more than $22,000 \mathrm{~m}^{3} / \mathrm{s}$ and assessed the effect of flooding using the same 2D-model mentioned earlier. In this study, however, only the flooding along the lower Rhine was taken into account.

Figure 3.5 shows the resulting peak discharges of both studies. It is clear, that flooding along the Rhine substantially reduces the maximum discharge arriving at Lobith (German-Dutch border). The results of Lammersen (2004), that take into account dike overflows along the upper as well as the lower Rhine, show that there is a relationship between the reduction of the peak flow and the magnitude of the peak flow, but the strength of this relationship is rather uncertain. This is due to the origin and the genesis of the flood wave, since a flood coming from the upper Rhine will be affected by flooding along the upper as well as the lower Rhine, while a flood wave coming from the middle or the lower Rhine will be affected by flooding along the lower Rhine only. By taking only the effects of flooding along the lower Rhine into account, Gudden (unpublished) shows that under the 2020 flood prevention in Germany peak flows at Lobith will not exceed approximately $17,500 \mathrm{~m}^{3} / \mathrm{s}$. Since flooding along the upper Rhine is neglected this $17,500 \mathrm{~m}^{3} / \mathrm{s}$ is rather an upper estimate than a lower estimate.

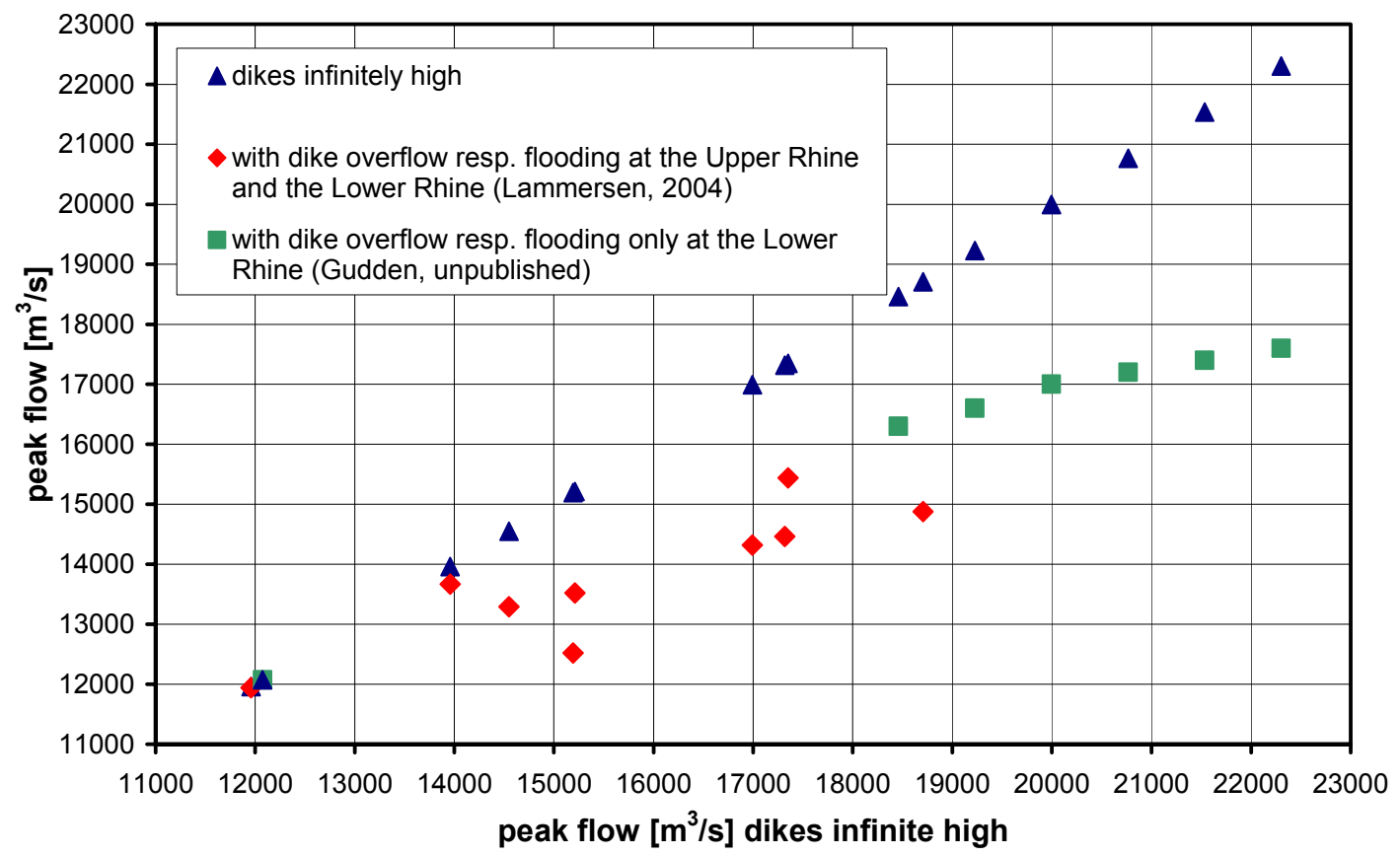

Figure 3.5: Peak flows at Lobith with and without dike overflow along the upper and the lower Rhine, dike situation 2020 (after Lammersen, 2004) and with and without dike overflow along the lower Rhine, dike situation 2020 (after Gudden, unpublished).

Despite the uncertainties, both studies make clear that peak discharges at Lobith are considerably reduced due to flooding upstream of Lobith. From Figure 3.5 it can be concluded, that discharges of $16,500-19,000 \mathrm{~m}^{3} / \mathrm{s}$, i.e. the range of the 1250-year discharge projected for 2050 under the assumption that no flooding in 
Germany occurs (Beersma et al., 2008) will be reduced to approximately 15,500 $-17,000 \mathrm{~m}^{3} / \mathrm{s}$ and the projected 1250 -year discharges of $17,000-22,000 \mathrm{~m}^{3} / \mathrm{s}$ for 2100 will be reduced to approximately $16,000-17,500 \mathrm{~m}^{3} / \mathrm{s}$ under the 2020 flood protection level in Germany.

It should be noted that in the 2020 dike situation the flow capacity along most parts of the northern part of the lower Rhine is around $17,500 \mathrm{~m}^{3} / \mathrm{s}$. When, as a result of the combined effect of climate change and higher dikes upstream in Germany, peak flows larger than $17,500 \mathrm{~m}^{3} / \mathrm{s}$ would arrive at the northern lower Rhine, this will lead to uncontrolled flooding in this area and, as a result of transborder flooding through old river valleys, to uncontrolled flooding in the eastern part of the Netherlands as well.

\section{Conclusions}

- Assuming the current KNMI climate scenarios, the difference between winter and summer discharges of the River Rhine will increase. Average winter discharge will increase between 5 and $30 \%$ while the average summer discharge will decrease between 0 and $60 \%$.

- The magnitude of the change in winter discharge is such that it is likely that high discharges now being considered as rare events will become normal events. For example, the 1995 event, with a peak discharge of approximately $12,000 \mathrm{~m}^{3} / \mathrm{s}$ and currently a return period of about 50 years would change into a 10-year event in 2100 assuming the 'worst' KNMI'06 scenario (W+).

- The 1250-year discharge peak that may arrive at Lobith in 2050 and 2100 depends on the climate change as well as on the future flood protection level in Germany. Therefore the following points have to be considered:

1. Taking into account the different climate scenarios and the hydrology of the Rhine basin, but assuming no flooding in Germany (sufficiently high dikes) the 1250-year discharge at Lobith may increase from $16,000 \mathrm{~m}^{3} / \mathrm{s}$ to $16,500-19,000 \mathrm{~m}^{3} / \mathrm{s}$ in 2050 and to $17,000-22,000 \mathrm{~m}^{3} / \mathrm{s}$ in 2100 ('pessimistic estimate').

2. Under the same climate and hydrological conditions, but assuming the flood protection situation of 2020 with consequently more frequently (severe) flooding in Germany the 1250-year discharge at Lobith is expected to be (much) smaller i.e. 15,500 - 17,000 $\mathrm{m}^{3} / \mathrm{s}$ for 2050 and $16,000-17,500 \mathrm{~m}^{3} / \mathrm{s}$ for 2100 ('optimistic estimate')

3. The future flood protection situation in Germany in 2050 and 2100 will depend on future adaptation strategies in Germany. The discharges mentioned in the 'pessimistic estimate' can only arrive the Netherlands, if safety levels in Germany will be enhanced to such a magnitude, that no flooding could occur, This would demand a huge operation both technically and financially. For certain stretches of the main river such an operation seems technically almost infeasible (e.g. near Cologne). Therefore the 'pessimistic estimate' must be regarded too pessimistic about the situations to be expected in 2050 and 2100. On the other hand, when 
climate change will progress as projected, it can be expected that adaptations will occur in Germany sooner or later. How much this will affect the peak flows at Lobith strongly depends on where in the Rhine basin and what measures are taken. This makes it difficult to estimate, to what extend the 'optimistic estimate' is too optimistic to describe the situations to be expected in 2050 and 2100.

4. It should be noted that in the 2020 dike situation the flow capacity along most parts of the northern part of the lower Rhine is around $17,500 \mathrm{~m}^{3} / \mathrm{s}$. When, as a result of the combined effect of climate change and higher dikes upstream in Germany, peak flows larger than $17,500 \mathrm{~m}^{3} / \mathrm{s}$ would arrive at the northern lower Rhine, this will lead to uncontrolled flooding in this area and, as a result of trans-border flooding through old river valleys, to uncontrolled flooding in the eastern part of the Netherlands as well.

- Although it is very likely that the 1250 -year discharge at Lobith (the design discharge) will increase two major sources of uncertainty are identified that are not yet be fully recognized in water management:

1. an increase of the variability of the 10 -day precipitation amounts may lead to a relatively large increase of the 1250 -year discharge. Therefore there is a need to i) get a better understanding of how this type of variability may change in the future climate, and ii) to transfer these changes appropriately to the hydrological models. The large uncertainty about the (sign of the) change of the 10-day precipitation variability is therefore a major source of the uncertainty of the future change in peak discharges and thus of the future 1250-year discharge;

2. uncontrolled flooding in the Rhine valley upstream of the Netherlands substantially reduces the discharge peaks arriving at Lobith. Under the flood protection measures in the year 2020 in Germany, the maximum discharge that can reach Lobith is not larger than $17,500 \mathrm{~m}^{3} / \mathrm{s}$. The future reduction of discharge peaks as a result of flooding in Germany will however depend on the flood protection situation in Germany around 2050 or 2100. 


\section{Appendix III-a - Future Rhine discharge as a result of climate change - review for the new Dutch Delta committee}

\section{Summary}

Together with the Rijkswaterstaat-Waterdienst report "Effect of flooding in Germany upon the peak discharge at Lobith" (Lammersen, 2008) this report forms the background material for the Summary report: "Effects of climate change on the Rhine discharges, a review" by J. Beersma, J. Kwadijk and R. Lammersen. These three reports together serve to inform the new Dutch Delta committee on possible effects of climate change on the discharge behavior of the Rhine as well as on the hydraulic effects as a result of flooding upstream of the Netherlands.

Table A.1(S): Average Rhine discharge (m3/s) observed at the end of the 20th century, and projections for 2050 and 2100 (meaningful values for 2200 cannot be derived). The ranges for 2050 and 2100 are obtained by applying the KNMI'06 climate scenarios to the Rhineflow-3 rainfall-runoff model. Discharges are rounded to the nearest $50 \mathrm{~m} 3 / \mathrm{s}$. The numbers between brackets are the relative changes compared to the end of the 20th century (1968 - 1998) and are rounded to the nearest 5\%. Summer refers to Aug - Oct and winter to Jan - Mar.

\begin{tabular}{|l|c|c|c|c|}
\hline Discharge characteristic & $\begin{array}{c}\text { End } 20^{\text {th }} \\
\text { century }\end{array}$ & 2050 & 2100 & 2200 \\
\hline $\begin{array}{l}\text { Avg. summer flow }\left(\mathrm{m}^{3} / \mathrm{s}\right) \\
(\text { Change in \%) }\end{array}$ & 1700 & $\begin{array}{c}1100-1700 \\
(-35-0)\end{array}$ & $\begin{array}{c}700-1700 \\
(-60-0)\end{array}$ & n.a. \\
\hline $\begin{array}{l}\text { Avg. winter flow }\left(\mathrm{m}^{3} / \mathrm{s}\right) \\
(\text { Change in \%) }\end{array}$ & 2750 & $\begin{array}{c}2950-3200 \\
(5-15)\end{array}$ & $\begin{array}{c}3100-3600 \\
(15-30)\end{array}$ & n.a. \\
\hline
\end{tabular}

Table A.2(S): Peak discharge of the Rhine (m3/s) in 2050 and 2100 obtained by applying the KNMI'06 climate scenarios and results from climate models to relatively simple rainfall-runoff models for the Rhine basin in combination with statistical methods. The reference value refers to an average return period of 1250 year, which is of particular interest for flood management (so called design discharge used for the design of river dikes, river infrastructure and flood plains).

\begin{tabular}{|l|c|c|c|c|}
\hline & $\begin{array}{c}\text { Reference } \\
\text { value }\end{array}$ & 2050 & 2100 & 2200 \\
\hline $\begin{array}{l}\text { Peak discharge }\left(\mathrm{m}^{3} / \mathrm{s}\right) \\
(\text { Change in \%) }\end{array}$ & 16,000 & $\begin{array}{c}16,500-19,000^{\dagger} \\
(3-19)\end{array}$ & $\begin{array}{c}17,000-22,000^{\dagger} \\
(6-38)\end{array}$ & n.a. \\
\hline
\end{tabular}

+ These ranges are rough estimates based on limited knowledge. Apart from the uncertainty in the mean meteorological conditions, the 2100 range is also due to the large sensitivity of peak discharges to changes in multi-day precipitation variability, a precipitation characteristic which has not been included yet in the KNMI'06 scenarios. The uncertainty related to hydrological modelling and hydraulic effects is not included. Lammersen (2004) found that large discharge peaks will be reduced significantly under the current (and near future) river conditions due to flooding in Germany. Such reductions are assessed in the additional Waterdienst report (Lammersen, 2008). 


\section{Introduction}

This report assesses the results of studies involving the effects of future climate change on the discharge behaviour of the river Rhine. Responding to the questions raised by the new Dutch Delta committee both changes in the average discharge of the Rhine (including changes in the annual discharge cycle) and changes in extreme discharges are discussed. This report relies on state-of-theart climate scenarios as well as available studies and simulations with rainfallrunoff models. The latest KNMI climate scenarios, i.e. the KNMI'06 scenarios (Van den Hurk et al., 2006; for a summary see Section 5), serve as a reference but relevant additional information is included too.

The Delta committee asked for changes in 2050, 2100 and 2200. To our knowledge no state-of-the-art climate scenarios or climate model results are available (shortly) for hydrological modelling of the Rhine beyond 2100 . Therefore no meaningful results for 2200 can be presented.

This assessment is restricted to changes in discharge volumes at Lobith (i.e. the point where the Rhine enters the Netherlands) due to (anthropogenic) climate changes in the Rhine basin. In this approach, the changes in discharge volumes are solely determined by the changes in precipitation, evaporation and temperature. Other (policy relevant) anthropogenic factors that determine the rainfall-runoff behaviour of the Rhine such as changes in the riverbeds or flood plains, or limitations related to infrastructure of the river system are not included (since they are not the competence of KNMI). The quantification of the reduction of peak discharges at Lobith as a result of flooding in Germany is assessed in the additional Waterdienst report (Lammersen, 2008).

\section{Future changes in the average discharge of the Rhine}

Based on observations from the $20^{\text {th }}$ century, the average discharge of the Rhine at Lobith is characterized by a clear annual cycle with the largest average discharges (about $2750 \mathrm{~m}^{3} / \mathrm{s}$ ) found in winter (January - March) and the smallest average discharges (about $1700 \mathrm{~m}^{3} / \mathrm{s}$ ) found in late summer (September and October), see Figure A.1. The maximum in winter is related to the small evaporation during winter and the resulting saturation of soil moisture. The minimum in late summer is caused by both the much larger evaporation during summer and the steady reduction of accumulated snow in the Alpine region that melts from spring until late summer.

The general picture of the impact of future climate change on the average discharge of the Rhine is that the annual cycle will be enhanced; i.e. larger average discharges during winter and smaller average discharges in (late) summer (see Figure A.1). For the Rhine the climatic factors that determine the change in discharge characteristics are:

The variation and change in the amount of precipitation and evaporation in the different seasons and regions. This affects all flows in all seasons.

Change in temperature that will change the distribution between snow and rainfall in the Alpine region (particularly in winter). Temperature determines the length of the snow season and affects the regime of the river. After all snow accumulates and leads to delayed runoff. 
The change in evaporation (particularly during the summer/growing season when evaporation is large). This has mainly effects on low and summer flows The change in (local) temperature, which has a large influence in controlling 2. and 3. Temperature rise results into a shift from a combined rainfall-snowmelt river into a rainfall dominated river at Lobith, leading to higher winter and lower summer flows.

The change in the (relative) variability of multi-day precipitation amounts and for the Rhine in particular of the 10-day precipitation amounts. This affects in particular the magnitude of peak flows at Lobith. Increases of the 10-day precipitation variability tend to increase peak flows while decreased variability leads to decreased peak flows.

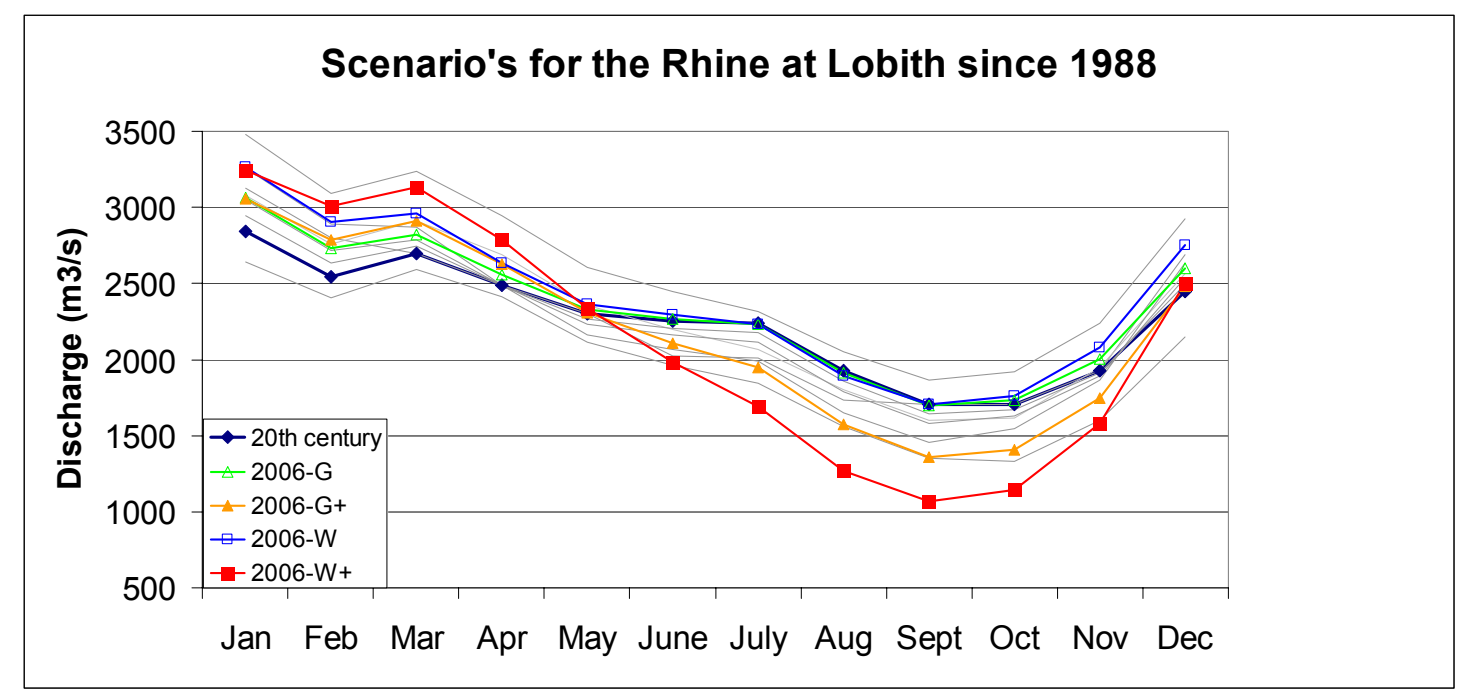

Figure A.1: Average discharge of the Rhine at Lobith for the current situation (thick blue line), and for 2050 under the KNMI'06 climate scenarios (thin coloured lines) and earlier studies (thin grey lines).

Table A.4 (see Section 4) presents for all reviewed studies both for 2050 and 2100 the relative changes in average summer and winter discharge under the applied climate scenarios and discharge models. The table also gives a summary of the relevant climate change characteristics and a brief description of the used methodology. Figures A. 2 and A.3, respectively, present summaries of these results for winter and summer. 
Relative change in mean winter discharge

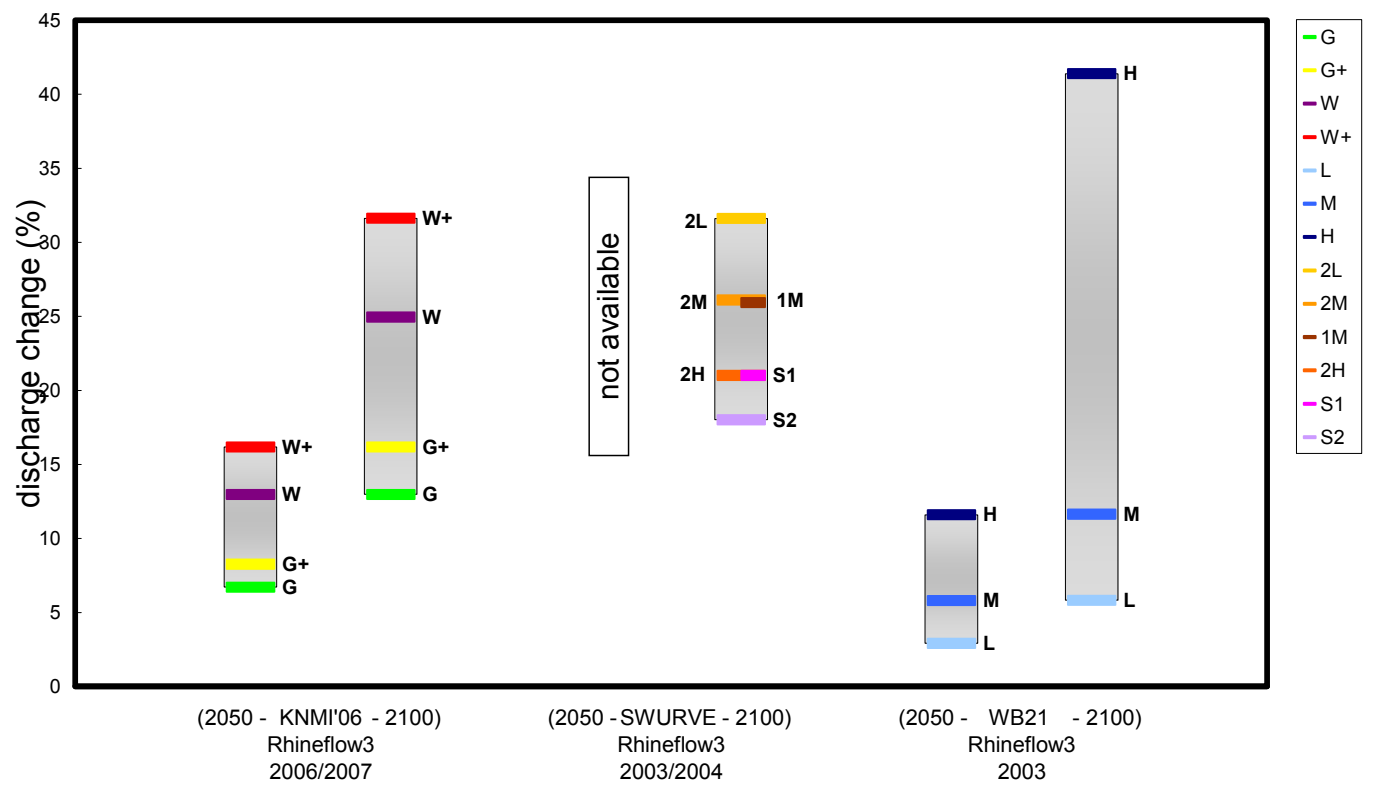

Figure A.2: Relative change in mean winter (Jan - Mar) discharge based on the Rhineflow-3 rainfall-runoff model and different climate scenarios starting from the KNMI'06 scenarios on the left. The odd columns refer to 2050 and the even columns to 2100. The abbreviations for the individual scenarios are explained in the main text and in Table A.3 (see Section 4).

\subsection{Relative changes in winter for 2050 (see Figure A.2)}

- The combination of the four KNMI'06 climate scenarios (G, G+, W and $\mathrm{W}+$ ) with the Rhineflow-3 model gives a discharge increase between 6.7 and $16.2 \%$ (Van Deursen, 2006). The same climate scenarios combined with the HBV-Rhine model give slightly smaller increases with a range of $5.1-13.7 \%$ (see Table A.3 in Section 4; Te Linde, 2007). This approximately $2 \%$ difference demonstrates that the uncertainty related to the rainfall-runoff model is small compared to the uncertainty from the climate scenarios.

- For comparison the most important earlier results are also shown. Under the WB21 climate scenarios (Middelkoop et al., 2000) and Rhineflow-3 (Van Deursen, 2003) an increase of $2.9-11.6 \%$ was found. Note that the smallest increase of $2.9 \%$ is for a climate change scenario with global mean temperature rise in 2050 of $0.5^{\circ} \mathrm{C}$. The lowest global temperature rise in the $\mathrm{KNMI} 06$ scenarios is $1.0^{\circ} \mathrm{C}$.

\subsection{Relative changes in winter for 2100 (see Figure A.2)}

- The combination of the KNMI'06 climate scenarios with the Rhineflow-3 model gives a discharge increase between 13.0 and 31.6\% (Van Deursen, 2007). These scenarios have not been yet combined with the HBV-Rhine model.

- Other results from earlier studies are available from the EU-Swurve project, where the HadRM2 and HadRM3 regional climate models (RCMs) from the Hadley Centre were combined with Rhineflow-3 (Shabalova et al., 2003; Buishand en Lenderink, 2004; Lenderink et al., 2007). They fit well in the KNMI'06 scenario range for the change in average winter discharge. 
The $2 \mathrm{~L}$ to $2 \mathrm{H}$ range (with $2 \mathrm{M}$ a 'middle' value) is obtained by combining the HadRM3 changes in precipitation and temperature with, a small $(L)$, intermediate $(\mathrm{M})$ and large $(\mathrm{H})$ increase of the potential evaporation, thereby showing the sensitivity of the change in winter discharge to the change in evaporation only. S1 and S2 represent the results for scenarios based on HadRM2. Note that the scenario in which the $25 \%$ increase in the $\mathrm{CV}_{10}$ of precipitation is ignored (S1) gives a $3 \%$ smaller increase of the average discharge than S2, the corresponding scenario in which this increase in not ignored. However, ignoring the $16 \%$ decrease in winter $\mathrm{CV}_{10}$ in HadRM3H scenario $1 \mathrm{M}$ gives the same results as the corresponding HadRM3H scenario that includes this decrease in variability (2M). See also C. Sensitivity to changes in precipitation variability (on page 8 ).

- The WB21 climate scenarios for 2100 (Middelkoop et al., 2000) combined with Rhineflow-3 (Van Deursen, 2003) gave a range of $5.8-41.4 \%$. Again, the global mean temperature rise $\left(1.0^{\circ} \mathrm{C}\right)$ that leads to the smallest increase of $5.8 \%$ is half of that in the lowest KNMI'06 scenarios ( $G$ and $G+$ ).

Relative change in mean summer discharge

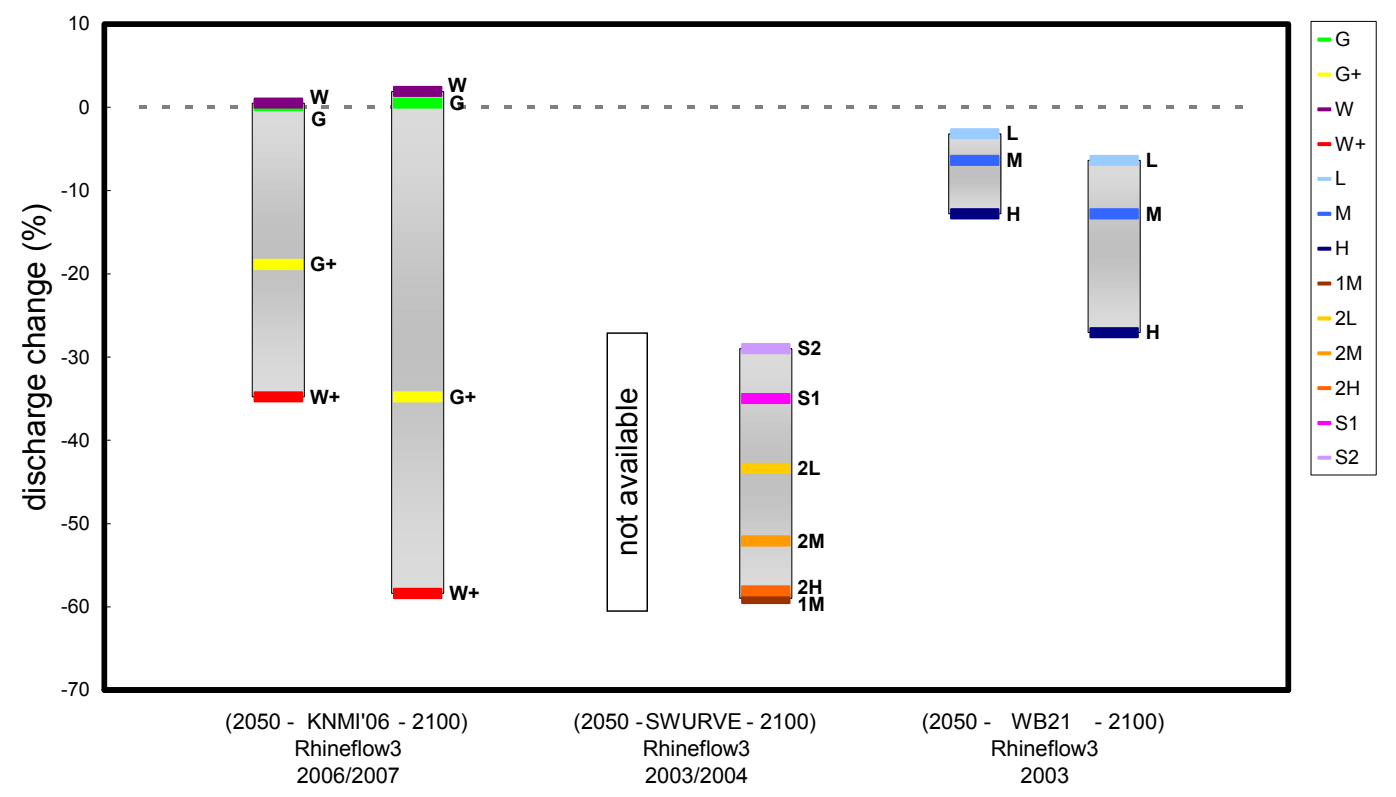

Figure A.3: Relative change in mean summer (Aug - Oct) discharge based on the Rhineflow-3 rainfall-runoff model and different climate scenarios. The odd columns refer to 2050 and the even columns to 2100. The abbreviations for the individual scenarios are explained in the main text and in Table A.3 (see Section 4).

\subsection{Relative changes in summer for 2050 (see Figure A.3)}

- The combination of the KNMI'06 climate scenarios with the Rhineflow-3 model gives a range of -34.8 to $+0.5 \%$ (Van Deursen, 2006). The same climate scenarios combined with the HBV-Rhine model give slightly larger decreases with a range of -38.9 to $-0.4 \%$ (see Table A.3 in Section 4 ; Te Linde, 2007). In this case the difference between Rhineflow-3 and HBV is about one tenth of the largest change.

- For comparison, the WB21 climate scenarios (Middelkoop et al., 2000) in combination with Rhineflow-3 lead to a range of -12.8 till $-3.2 \%$ (Van Deursen, 2003). The WB21 H(igh) scenario for 2050 combined with HBVRhine gives a decrease of $15.5 \%$ (see Table A.3 in Section 4; Te Linde, 
2007) which is slightly larger than the $12.8 \%$ decrease for that scenario combined with Rhineflow-3. The reason for the relatively small range under the WB21 scenarios compared to the KNMI'06 scenarios is that the former are based on scaling of a single GCM (UK Hadley Centre, UKHI) in which the summer drying in the Rhine basin is relatively moderate. The various climate models that have been used in constructing the KNMI'06 scenarios reveal that the projected future summer drying in Europe varies from no drying to severe drying. This uncertainty (i.e. lack of consensus between climate models) is expressed by the much larger range under the KNMI'06 climate scenarios.

- The possibility of severe summer drying was already recognized before the KNMI'06 scenarios were issued. For the 'national drought study' (Klopstra et al., 2005) a new dry scenario was constructed, in addition to the WB21 scenarios. This additional dry scenario was based on the HadRM3H RCM with a much larger summer drying ( $20 \%$ less precipitation over the basin) than the UKHI GCM (2.1\% less precipitation over the basin) used for the WB21 scenarios. In combination with Rhineflow-3 this resulted in a $47.5 \%$ decrease of the average summer discharge (see scenario D in Table A.3 in Section 4; Beersma et al., 2003). This decrease is outside the KNMI'06 range but again this is a result based on a single climate model which was in comparison with other climate models at that time and in combination with the relatively large increase in potential evaporation in summer that was used $(+24 \%)$ already considered to be quite extreme (Beersma et al., 2003).

\subsection{Relative changes in summer for 2100 (see Figure A.3)}

- The combination of the KNMI'06 climate scenarios with the Rhineflow-3 model gives a range of -58.4 to $+1.9 \%$ (Van Deursen, 2007). These scenarios have not yet been combined with the HBV-Rhine model.

- Under the WB21 climate scenarios and Rhineflow-3 a range of -27.1 to $-6.4 \%$ was obtained (Van Deursen, 2003). This considerably smaller range can be explained using the same arguments as for the 2050 changes in summer (see above).

- For 2100 the results from the EU-Swurve project, where the HadRM2 and HadRM3 RCMs were combined with Rhineflow-3 (Shabalova et al., 2003; Buishand en Lenderink, 2004; Lenderink et al., 2007), fit well in the KNMI'06 scenario range. The $2 \mathrm{~L}$ to $2 \mathrm{H}$ range (with $2 \mathrm{M}$ a 'middle' value) is obtained by combining the HadRM3 RCM changes in precipitation and temperature with a small, intermediate and large increase of the potential evaporation, again showing the sensitivity of the change in summer discharge to the change in evaporation only. The Swurve results also show that both RCMs that were used have a considerable summer drying (comparable to that in the $\mathrm{KNMI}^{\prime} \mathrm{O} 6 \mathrm{G}+$ and $\mathrm{W}+$ scenarios) which is most pronounced in the (more recent) HadRM3 model. S1 and S2 again represent the results for scenarios based on HadRM2. The scenario in which the $28 \%$ increase in the $\mathrm{CV}_{10}$ of summer precipitation is ignored (S1) gives a $6 \%$ larger decrease of the average discharge than the corresponding scenario in which this decrease is included (S2). And ignoring the $43 \%$ increase in summer $\mathrm{CV}_{10}$ in $\mathrm{HadRM} 3 \mathrm{H}$ scenario $1 \mathrm{M}$ gives a $7 \%$ larger decrease of the average discharge compared to the corresponding HadRM3H scenario that does not ignore the increase in precipitation variability $(2 \mathrm{M})$. 


\section{Future changes in the peak discharge of the Rhine}

Extreme or peak discharges are discharges that are considered here to have an average return period of at least 1000 years. Of particular interest for the Dutch water management is the so called design discharge for the Rhine which is defined to be the discharge at Lobith with an average return period of 1250 years. The design discharge for the Rhine currently is $16,000 \mathrm{~m}^{3} / \mathrm{s}$ and is used for the design of river dikes, river infrastructure and flood plains. In order to place the future changes in the right perspective it is important to note that this value has considerable uncertainty. This uncertainty is related to the statistical extrapolation to the return period of 1250 years obtained from an extreme value analysis based on much shorter historical discharge records. The current design discharge has a $95 \%$ confidence interval of $13,060-18,370 \mathrm{~m}^{3} / \mathrm{s}$ (Diermanse, 2004). The projected future changes in this value are also very uncertain (see point e. below).

Table A.4 (see Section 4) presents, in a similar way as Table A.3, for all reviewed studies both for 2050 and 2100 the peak discharges for return periods between 1000 and 1250 years (or their relative changes compared to the current design discharge of $16,000 \mathrm{~m}^{3} / \mathrm{s}$ ) under the applied climate scenarios and discharge models. Figure A.4 summarizes the relevant results.

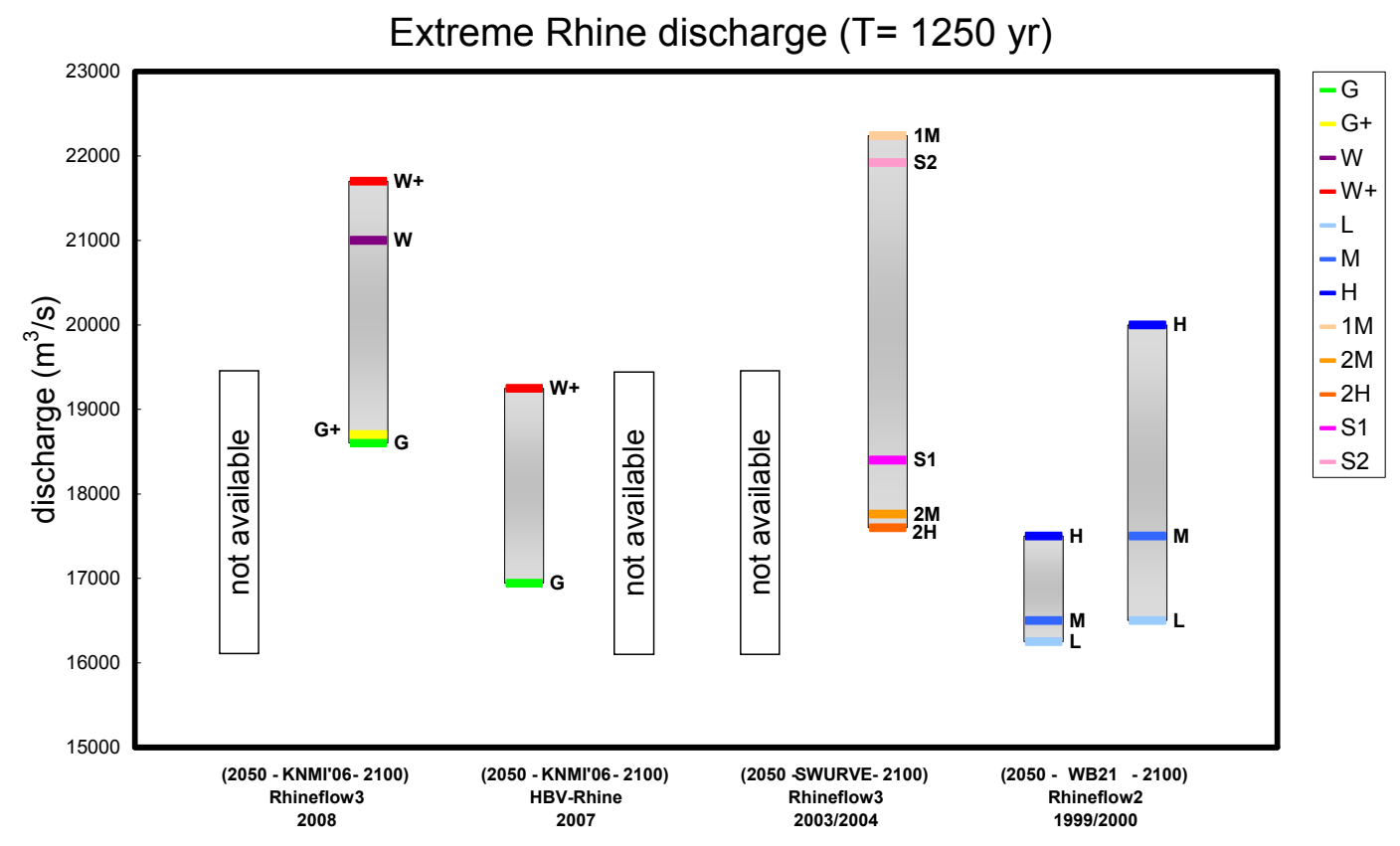

Figure A.4. Range of future peak discharges for different models, methods and climate scenarios. The odd columns refer to 2050 and the even columns to 2100. 


\subsection{Peak discharges under the KNMI'06 climate scenarios}

De Wit et al. (2007) present two rough methods to scale the discharge results obtained with the old WB21 scenarios to the new KNMI'06 scenarios (Kors et al., 2000; see Table A.4 Section 4; column 'Methodology' for details). Method A gives for the four KNMI'06 scenarios for 2050 a range of $16,400-17,280 \mathrm{~m}^{3} / \mathrm{s}$ and method $B$ a range of $16,800-17,600 \mathrm{~m}^{3} / \mathrm{s}$. Note that the value of $17,600 \mathrm{~m}^{3} / \mathrm{s}$ under the $\mathrm{W}+$ scenario for method $\mathrm{B}$ is likely an underestimate because the associated increase in the average winter discharge under the $\mathrm{W}+$ scenario for 2050 is considerably larger than under the WB21 H(igh) scenario for 2050 (see Figure A.2).

For 2100 method $A$ gives a range of $17,280-19,840 \mathrm{~m}^{3} / \mathrm{s}$ and method $B 17,600$ $-19,200 \mathrm{~m}^{3} / \mathrm{s}$. Note that the value of $19,200 \mathrm{~m}^{3} / \mathrm{s}$ under the $\mathrm{W}+$ scenario for method $B$ is likely an overestimate because in this case the increase in the average discharge in winter under the $\mathrm{W}+$ scenario is considerably smaller than under the WB21 $\mathrm{H}$ scenario.

Also using the KNMI'06 scenarios, Te Linde (2007) presents for 2050 for the G and $\mathrm{W}+$ scenarios results based on HBV-Rhine coupled to the hydraulic model Sobek (but without the possibility of flooding in Germany) and 1000 years of synthetic daily rainfall and temperature data simulated with the KNMI Rainfall generator for the Rhine basin (Beersma, 2002; De Wit and Buishand, 2007). Under the G scenario the increase in 1250 -year discharge is $5.9 \%$ which corresponds with a discharge of $16,940 \mathrm{~m}^{3} / \mathrm{s}$ and under the $\mathrm{W}+$ scenario the increase amounts $20.3 \%$ resulting in $19,250 \mathrm{~m}^{3} / \mathrm{s}$ (see Figure A.4). Note that this latter value is more than $1000 \mathrm{~m}^{3} / \mathrm{s}$ larger than all the other values for the KNMI'06 scenarios that are based on the scaling methods.

Deltares (2008) used the four KNMI'06 climate scenarios for 2100 and applied the delta method to the historical 1961 - 1995 series. The resulting perturbed series were used to run the Rhineflow-3 model. The average changes in (10-day) discharge volumes from Rhineflow were used to perturb the historical daily discharge series at Lobith for 1901 - 2004 (also by the delta method). Fitting a Gumbel distribution to the annual maxima above $7000 \mathrm{~m}^{3} / \mathrm{s}$ led to estimates of the 1250 -year discharge between 18,500 and $21,500 \mathrm{~m}^{3} / \mathrm{s}$ (rounded to 500 $\left.\mathrm{m}^{3} / \mathrm{s}\right)$.

\subsection{Peak discharges under the WB21 climate scenarios}

The results for 2050 based on the WB21 H(igh) climate scenario, Rhineflow-2, and two statistical models to derive changes in peak discharges gave a 8 to $12 \%$ increase in 1000-year discharge (Middelkoop, 1999; Middelkoop et al., 2000), corresponding with a presented 1250-year discharge scenario range of 16,250 $17,500 \mathrm{~m} 3 / \mathrm{s}$.

For 2100 the $\mathrm{M}$ (iddle) and $\mathrm{H}$ (igh) scenario respectively gave a 8 to $12 \%$ and a 25 to $30 \%$ increase in 1000-year discharge, corresponding with a presented $1250-$ year discharge scenario range of $16,500-20,000 \mathrm{~m}^{3} / \mathrm{s}$ (see Figure A.4). Note that some doubts have been raised about the observed drop in the relative change of the quantiles from $40 \%$ for the 100 -year discharge to $25 \%$ for the 1000 -year discharge in the study by Middelkoop (1999), which may be due to the coarse approximation of the upper tail of the distribution of the 10-day discharge (Buishand and Lenderink, 2004). 


\subsection{Sensitivity to changes in precipitation variability}

In the results discussed above potential changes in the variability of winter precipitation have not been incorporated. Although the new KNMI'06 climate scenarios do give information about how the daily precipitation variability changes, this information is not passed to the hydrological models. This is due to the applied classical delta method that only takes the changes in the mean into account (no change in variability). For a description of the delta method and a comparison with other methods, such as the direct method, see e.g. Lenderink et al. (2007). Moreover, for peak discharges it is not the change in the daily precipitation variability that matters but the change in variability of multi-day precipitation amounts, and for the Rhine in particular the change in the relative variability of 10 -day precipitation amounts (usually denoted as $\mathrm{CV}_{10}$ ). The KNMI'06 scenarios do not provide any information on the changes in this quantity. However, other studies show that it is of crucial importance for estimating the change in peak discharge.

In the EU-Swurve project (Shabalova et al., 2003; Buishand and Lenderink, 2004; Lenderink et al., 2007) the Rhineflow-3 model was coupled to two versions of the Hadley Centre RCM, HadRM2 and HadRM3H. The HadRM2 run gives for the Rhine basin at the end of the $21^{\text {st }}$ century a moderate $8 \%$ increase in winter precipitation and a $25 \%$ increase in the variability of the 10 -day precipitation sums. The (newer) HadRM3H run on the other hand gives a $25 \%$ increase in winter precipitation and a $16 \%$ decrease of the 10 -day precipitation variability. Both RCM simulations have been combined with Rhineflow-3 with and without allowing for the change in 10-day precipitation variability. Ignoring the increase in 10 -day precipitation variability found in the HadRM2 run leads to a $15 \%$ increase of the 1250 -year discharge to $18,400 \mathrm{~m}^{3} / \mathrm{s}$ whereas including the $25 \%$ increase in 10-day precipitation variability gives a $37 \%$ increase resulting in $21,900 \mathrm{~m}^{3} / \mathrm{s}$ (see S1 and S2 in Figure A.4 respectively; Shabalova et al., 2003; Buishand and Lenderink, 2004). In the Rhineflow-3 simulation with perturbed HadRM3H data that ignores the decrease in 10-day precipitation variability an increase of $39 \%$ was found leading to a 1250 -year discharge of $22,200 \mathrm{~m}^{3} / \mathrm{s}$. The simulation that included the $16 \%$ decrease in 10 -day precipitation variability gave only a $11 \%$ increase resulting in $17,760 \mathrm{~m}^{3} / \mathrm{s}$ (see $1 \mathrm{M}$ and $2 \mathrm{M}$ in Figure $\mathrm{A} .4$ respectively; Buishand and Lenderink, 2004; Lenderink et al, 2007). This large sensitivity of the 1250-year discharge to changes in the variability of 10-day precipitation amounts is also found in a study for the river Meuse in which the HBV-Meuse model is combined with three different GCM-RCM combinations (Leander et al., 2008).

Unfortunately, the number of studies assessing changes in the multi-day precipitation variability in climate models is rather limited. In Leander et al. (2008) in two of three GCM-RCM simulations a substantial $20 \%$ reduction of the variability of 10 -day precipitation $\left(\mathrm{CV}_{10}\right)$ was found. In an ensemble of $19 \mathrm{GCM}$ simulations Räisänen (2002) found decreases of monthly precipitation variability for high northern latitudes in the fall and winter seasons but for most other areas of the world increases in the variability of monthly precipitation were found although the changes predicted by individual GCMs varied substantially.

\subsection{Limitations of the peak discharge results}

In addition to the above overview, a number of (conceptual) limitations of the quantitative results for the future peak discharge for the Rhine are identified: 
- The Swurve work identified that the change in peak discharges in the Rhine is very sensitive to changes in the variability of multi-day precipitation amounts in winter but did not give 'a final answer'.

- The magnitude and sign of the changes in the variability of multi-day precipitation is not well established and therefore very uncertain.

- In all climate scenarios (including the KNMI'06 scenarios) the possibility of changes in the variability of multi-day precipitation is not taken into account.

- Even if this (apparently crucial) information would be available, methods to pass this additional information reliably and effectively to the hydrological models have not fully matured and are still under development (e.g. Buishand and Lenderink, 2004; Leander et al., 2008; ongoing BSIK-ACER project).

In all but one study, in which the hydraulic model Sobek was used (Te Linde, 2007), the hydraulic component is completely ignored. During extreme discharges hydraulic processes in the Rhine play a crucial role in the conversion from discharge volumes (obtained with a hydrological model) to discharge peaks. Ignoring the hydraulic behaviour may lead to a considerable uncertainty regarding the changes in peak discharges (J. Kwadijk, personal communication), in particular when flooding of dikes occurs. Ignoring flooding in Germany will lead to a significant overestimation of the discharge peak that reaches Lobith (Lammersen, 2004). A quantitative assessment of the hydraulic effects of flooding in Germany is given in the additional Rijkswaterstaat Waterdienst report (Lammersen, 2008).

\subsection{Statistical uncertainty of the future 1250-year discharge}

It was already noted that the $95 \%$ confidence interval of $13,060-18,370 \mathrm{~m}^{3} / \mathrm{s}$ for the current value of the design discharge of the Rhine (Diermanse, 2004) is large, which is (mainly) related to the statistical extrapolation to the return period of 1250 years. Note that the upper/lower value of this range is about $17 \%$ larger/smaller than the design value of $16,000 \mathrm{~m}^{3} / \mathrm{s}$ (best estimate). It might be expected that the statistical uncertainty of future peak discharges is at least as large.

For the standard error of the change in the 1000-year discharge under the HadRM3H scenarios Buishand and Lenderink (2004) give an estimate of about $6 \%$; for the HadRM2 scenarios this standard error amounts to about $9 \%$ (due to the shorter length of this scenario run). These standard errors only account for uncertainty due to the limited sample size and not for other sources of uncertainty (e.g. regarding the underlying probability distribution). Applying the relative standard error of $6 \%$, and assuming that the error is normally distributed, gives for the change in the peak discharge in the Swurve scenario $2 \mathrm{H}$ a $95 \%$ confidence interval of approximately -500 to $3700 \mathrm{~m}^{3} / \mathrm{s}$ and for scenario $1 \mathrm{M}$ an interval of 3500 to $8700 \mathrm{~m}^{3} / \mathrm{s}$. The (small) overlap of these confidence intervals indicates that the statistical uncertainty stemming from the extrapolation to the required peak discharge is of comparable size as the uncertainty due to the climate scenarios used in Swurve. This is a clear indication of the large uncertainty involved in the estimation of the change in the future peak discharge. 


\subsection{Estimated range of the future 1250-year discharge}

Given our present knowledge and taking into account the large uncertainties identified we can only provide very rough estimates of the future 1250-year discharge of the Rhine (currently $16,000 \mathrm{~m}^{3} / \mathrm{s}$ ). For 2050 a range of 16,500 to $19,000 \mathrm{~m}^{3} / \mathrm{s}$ seems feasible whereas for 2100 a range of 17,000 to $22,000 \mathrm{~m}^{3} / \mathrm{s}$ has been derived. The upper values are well above the present upper bound of $18,370 \mathrm{~m}^{3} / \mathrm{s}$ of the $95 \%$ confidence interval for the design discharge (Diermanse, 2004). Note again that these future projections are theoretical discharge volumes, because under the current (and near future) river conditions large discharge peaks will lead to flooding in Germany in the upper and lower Rhine (Lammersen, 2004) as a result of which the discharge peak at Lobith will be reduced. Such reductions are dealt with in the additional Rijkswaterstaat Waterdienst report (Lammersen, 2008). From the meteorological point of view, however, there is no reason to assume that future discharge volumes that can be generated within the Rhine basin are limited.

\subsection{Improving the estimates of the future 1250-year discharge}

What do we need to obtain improved estimates of future changes in peak discharges for the Rhine including reliable uncertainty estimates?

Systematic analyses of climate models (both GCMs and RCMs) regarding changes in variability of multi-day precipitation in combination with changes in the average precipitation in the Rhine catchment area.

- Improvement of the methods to correctly pass all the climate change information that is relevant for the hydrological response, either from stateof-the-art climate scenarios, or from the climate models directly, to the hydrological models. One option would be to extend the ongoing work for the Meuse (Leander et al., 2008) to the Rhine. In the ongoing BSIK-ACER project (http://ivm5.ivm.vu.nl/adaptation/project/acer) both a direct model approach and an adapted delta approach (in which changed variability is taken into account) will be combined with HBV-Rhine to project changes in the discharge extremes. The climate change from the latest (RCM) RACMO run forced by the ECHAM-5 GCM will be compared with the KNMI'06 scenarios.

Evaluation of the (un)certainty of the changes in peak discharges due to the hydraulic behaviour of the Rhine (conversion from large discharge volumes to discharge peaks). And more specific, assess quantitatively the effects of flooding in Germany on discharge peaks at Lobith based on scenarios for the future flood protection level (and dike heights) in Germany (see additional Waterdienst report; Lammersen, 2008).

\section{Overview tables}

Table A.3: Changes in average Rhine discharge during summer and winter for 2050 and 2100 for different climate scenarios and discharge models. 


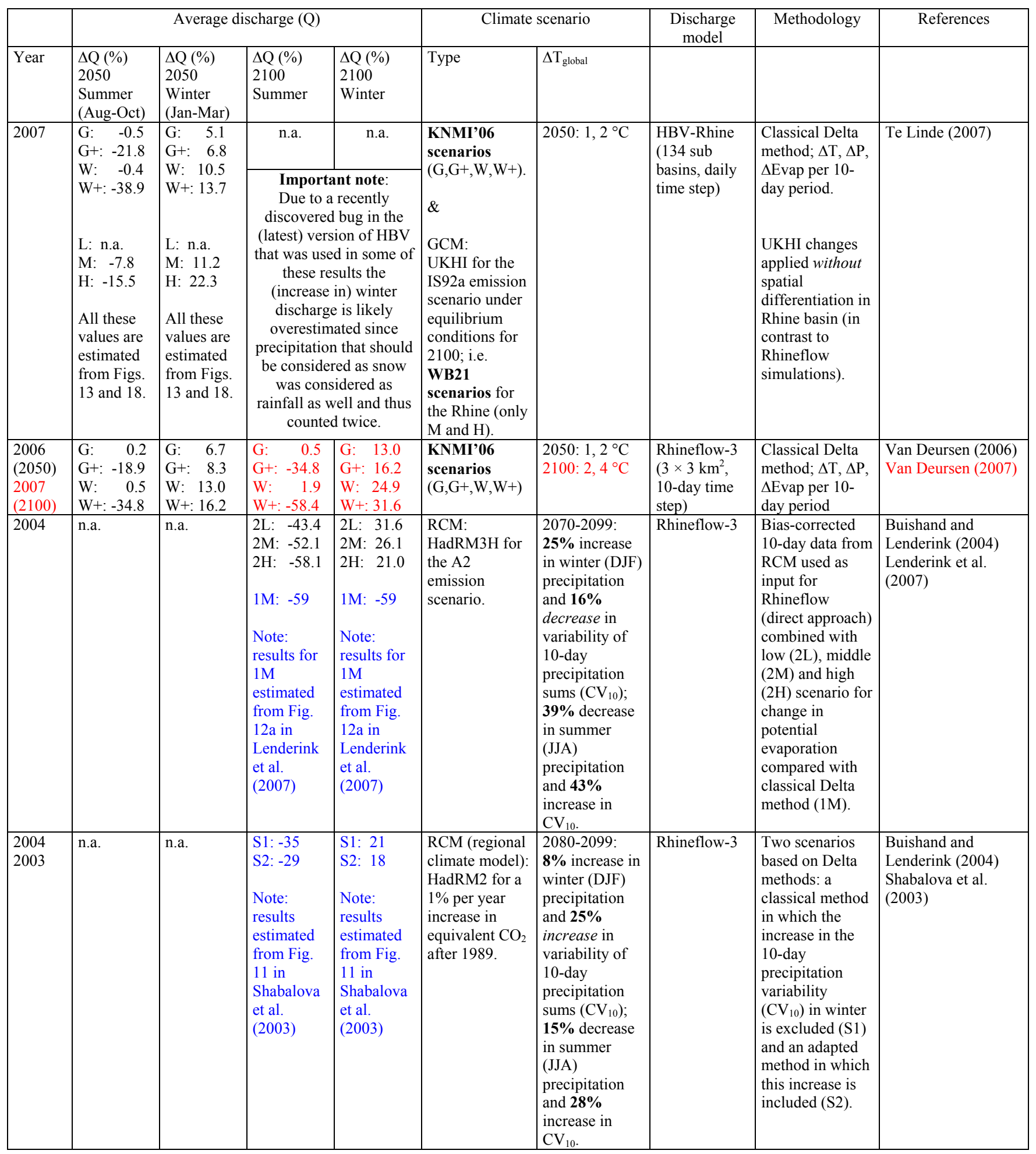




\begin{tabular}{|c|c|c|c|c|c|c|c|c|c|}
\hline & \multicolumn{4}{|c|}{ Average discharge (Q) } & \multicolumn{2}{|c|}{ Climate scenario } & \multirow{2}{*}{$\begin{array}{c}\text { Discharge } \\
\text { model }\end{array}$} & \multirow[t]{2}{*}{ Methodology } & \multirow[t]{2}{*}{ References } \\
\hline Year & \begin{tabular}{|l}
$\Delta Q(\%)$ \\
2050 \\
Summer \\
(Aug-Oct)
\end{tabular} & \begin{tabular}{|l}
$\Delta Q \mathrm{Q}(\%)$ \\
2050 \\
Winter \\
$($ Jan-Mar) \\
\end{tabular} & \begin{tabular}{|l|}
$\Delta \mathrm{Q}(\%)$ \\
2100 \\
Summer
\end{tabular} & \begin{tabular}{|l|}
$\Delta \mathrm{Q}(\%)$ \\
2100 \\
Winter
\end{tabular} & Type & $\Delta \mathrm{T}_{\text {global }}$ & & & \\
\hline \multirow[t]{2}{*}{2003} & $\begin{array}{ll}\text { (L: } & -3.2) \\
\text { M: } & -6.4 \\
\text { H: } & -12.8\end{array}$ & $\begin{array}{|lc|}\text { L: } & 2.9) \\
\text { M: } & 5.8 \\
\text { H: } & 11.6\end{array}$ & \begin{tabular}{|lr} 
L: & -6.4 \\
M: & -12.8 \\
H: & -27.1
\end{tabular} & $\begin{array}{lr}\text { L: } & 5.8 \\
\text { M: } & 11.6 \\
\text { H: } & 41.4\end{array}$ & $\begin{array}{l}\text { GCM: } \\
\text { UKHI for the } \\
\text { IS92a emission } \\
\text { scenario under } \\
\text { equilibrium } \\
\text { conditions for } \\
2100 \text {; i.e. } \\
\text { WB21 } \\
\text { scenarios for } \\
\text { the Rhine (L, } \\
\text { M, H). } \\
\&\end{array}$ & \begin{tabular}{|l} 
Scaled UKHI: \\
$0.5,1,2^{\circ} \mathrm{C}$ \\
$(2050-\mathrm{L}, 2050-$ \\
$\mathrm{M}, 2050-\mathrm{H})$ \\
$1,2,4^{\circ} \mathrm{C}$ \\
$(2100-\mathrm{L}, 2100-$ \\
$\mathrm{M}, 2100-\mathrm{H})$.
\end{tabular} & \multirow[t]{2}{*}{ Rhineflow-3 } & $\begin{array}{l}\text { UKHI }(\mathrm{H}, 2100) \\
\text { and scaled } \\
\text { UKHI (other L, } \\
\text { M and H). }\end{array}$ & Van Deursen (2003) \\
\hline & D: -47.5 & D: 6.4 & D: n.a. & D: n.a. & $\begin{array}{l}\text { New dry } \\
\text { scenario for } \\
2050 \text { (D) for } \\
\text { national } \\
\text { drought study. }\end{array}$ & $\begin{array}{l}\text { Prescribed } \Delta T, \\
\Delta \mathrm{P} \text { and } \\
\Delta \text { Evap (D) }\end{array}$ & & $\begin{array}{l}\text { Classical Delta } \\
\text { method; } \Delta \mathrm{T}, \Delta \mathrm{P}, \\
\Delta \text { Evap per } 10- \\
\text { day period (D) }\end{array}$ & $\begin{array}{l}\text { Beersma et al. } \\
(2003)\end{array}$ \\
\hline \multirow[t]{2}{*}{1999} & -7.8 & 11.9 & -12.4 & 41.1 & \multirow{2}{*}{$\begin{array}{l}\text { GCM: } \\
\text { UKHI for the } \\
\text { IS92a emission } \\
\text { scenario under } \\
\text { equilibrium } \\
\text { conditions for } \\
2100 \text {. }\end{array}$} & \multirow[t]{2}{*}{$\begin{array}{l}\text { UKHI: } \\
2050\left(\sim 2^{\circ} \mathrm{C}\right) \text {, } \\
2100\left(\sim 4{ }^{\circ} \mathrm{C}\right)\end{array}$} & \multirow{2}{*}{$\begin{array}{l}\text { Rhineflow-2 } \\
\left(1 \times 1 \mathrm{~km}^{2},\right. \\
10 \text {-day time } \\
\text { step, } \\
\text { Thornthwaite- } \\
\text { Mather } \\
\text { evaporation })\end{array}$} & $\begin{array}{l}\text { UKHI based } \\
\text { Delta method. }\end{array}$ & \multirow[t]{2}{*}{ Van Deursen (1999) } \\
\hline & \multicolumn{4}{|c|}{$\begin{array}{l}\text { (Estimated from Fig. } 4.4 \text { in } \\
\text { Van Deursen, 1999) }\end{array}$} & & & & $\begin{array}{l}\Delta \mathrm{T}, \Delta \mathrm{P} \\
\text { interpolated to } \\
0.5^{\circ} \times 0.5^{\circ} \text { grid. }\end{array}$ & \\
\hline
\end{tabular}


Table A.4: Similar as Table A.3 but for peak discharge (T $\approx 1250 \mathrm{yr})$. Note that no distinction is made between summer and winter.

\begin{tabular}{|c|c|c|c|c|c|c|c|}
\hline & \multicolumn{2}{|c|}{ Design discharge (Q) } & \multicolumn{2}{|c|}{ Climate scenario } & Discharge model & Methodology & References \\
\hline Year & \begin{tabular}{|l|}
$\Delta \mathrm{Q}(\%)$ \\
2050 \\
\end{tabular} & \begin{tabular}{|l|}
$\Delta \mathrm{Q}(\%)$ \\
2100 \\
\end{tabular} & Type & $\begin{array}{l}\Delta \mathrm{T}_{\text {global }} \text { (and/or } \\
\Delta \mathrm{P})\end{array}$ & & & \\
\hline 2008 & $\begin{array}{l}\text { G: n.a. } \\
\text { G+: n.a. } \\
\text { W: n.a. } \\
\text { W+: n.a.: }\end{array}$ & $\begin{array}{l}\text { G: } 18,600 \\
\text { G+: } 18,700 \\
\text { W: } 21,000 \\
\text { W+: } 21,700 \\
\text { Notes: draft } \\
\text { results based } \\
\text { on Deltares. } \\
(2008) ; \mathrm{Q} \text { in } \\
\mathrm{m}^{3} / \mathrm{s} \text { rather } \\
\text { than } \Delta \mathrm{Q} \text { in } \% .\end{array}$ & $\begin{array}{l}\text { KNMI'06 } \\
\text { scenarios } \\
(\mathrm{G}, \mathrm{G}+, \mathrm{W}, \mathrm{W}+)\end{array}$ & 2100: $2,4^{\circ} \mathrm{C}$ & $\begin{array}{l}\text { Rhineflow-3 } \\
\left(3 \times 3 \mathrm{~km}^{2}, 10 \text {-day }\right. \\
\text { time step })\end{array}$ & $\begin{array}{l}\text { Two successive } \\
\text { classical Delta- } \\
\text { methods: 1) } \Delta \mathrm{T}, \Delta \mathrm{P}, \\
\Delta \text { Evap per } 10 \text {-day } \\
\text { period. } 2 \text { ) } \Delta \mathrm{Q} \text { per } 10 \text { - } \\
\text { day period used to } \\
\text { transform historical } \\
\text { daily discharge time } \\
\text { series. } \\
\text { Gumbel distribution } \\
\text { fitted to transformed } \\
\text { annual discharge } \\
\text { maxima exceeding } 7000 \\
\mathrm{~m}^{3} / \mathrm{s} \text {. }\end{array}$ & Deltares (2008) \\
\hline 2007 & $\begin{array}{l}\text { G: } 5.9 \\
\text { G+: n.a. } \\
\text { W: n.a. } \\
\text { W+: } 20.3 \\
\text { Peak discharge } \\
\text { (ref. } \\
\text { 16,000 } \mathrm{m}^{3} / \mathrm{s} \text { ): } \\
\text { G: } 16,940 \\
\text { W+: } 19,250\end{array}$ & $\begin{array}{l}\text { G: n.a. } \\
\text { G+: n.a. } \\
\text { W: n.a. } \\
\text { W+: n.a.: }\end{array}$ & $\begin{array}{l}\text { KNMI'06 } \\
\text { scenarios } \\
(\mathrm{G}, \mathrm{G}+, \mathrm{W}, \mathrm{W}+)\end{array}$ & 2050: $1,2^{\circ} \mathrm{C}$ & $\begin{array}{l}\text { HBV-Rhine } \\
\text { (134 sub basins, } \\
\text { daily time step) } \\
+ \text { Sobek } \\
+1000 \text {-yr data } \\
\text { simulated with the } \\
\text { Rainfall generator } \\
\text { for the Rhine basin }\end{array}$ & $\begin{array}{l}\text { Classical Delta- } \\
\text { method; } \Delta \mathrm{T}, \Delta \mathrm{P}, \\
\Delta \text { Evap per } 10 \text {-day } \\
\text { period. } \\
\text { Gumbel distribution } \\
\text { fitted to } 1000 \text { annual } \\
\text { discharge maxima. }\end{array}$ & Te Linde (2007) \\
\hline 2007 & $\begin{array}{l}\text { Method A: } \\
\text { G: } 16,640 \\
\text { G+: } 16,960 \\
\text { W: } 17,280 \\
\text { W+: } 16,640 \\
\text { Method B: } \\
\text { G: } 16,800 \\
\text { G+: } 16,800 \\
\text { W: } 17,600 \\
\text { W+: } 17,600 \\
\text { Note: Q in } \mathrm{m}^{3} / \mathrm{s} \\
\text { rather than } \Delta \mathrm{Q} \\
\text { in } \% .\end{array}$ & $\begin{array}{l}\text { Method A: } \\
\text { G: } 17,280 \\
\text { G+: } 17,920 \\
\text { W: } 18,560 \\
\text { W+: } 19,840 \\
\text { Method B: } \\
\text { G: } 17,600 \\
\text { G+: } 17,600 \\
\text { W: } 19,200 \\
\text { W+: } 19,200 \\
\\
\text { Note: Q in } \\
\mathrm{m}^{3} / s \text { rather } \\
\text { than } \Delta \text { Q in } \% .\end{array}$ & $\begin{array}{l}\text { KNMI'06 } \\
\text { scenarios } \\
(\mathrm{G}, \mathrm{G}+, \mathrm{W}, \mathrm{W}+)\end{array}$ & $\begin{array}{l}\text { 2050: } 1,2^{\circ} \mathrm{C} \\
\text { 2100: } 2,4^{\circ} \mathrm{C}\end{array}$ & $\begin{array}{l}\text { Rhineflow-3 (for } \\
\text { changes in avg. } \\
\text { discharge) } \\
\text { + 'basic scaling' and } \\
\text { comparison with } \\
\text { WB21 results (for } \\
\text { changes in peak } \\
\text { discharge) }\end{array}$ & $\begin{array}{l}\text { Two rough methods to } \\
\text { scale KNMI'06 } \\
\text { scenarios based on } \\
\text { results for WB21 } \\
\text { scenarios (Kors et al., } \\
\text { 2000). Method A: } \\
\text { "WB21 rule of thumb } \\
\text { for the Meuse", i.e. } \\
\text { change in design } \\
\text { discharge equals change } \\
\text { in extreme 10-day } \\
\text { precipitation sum } \\
\text { (return period of } 10 \\
\text { year) in winter, applied } \\
\text { to the Rhine. Method B: } \\
\text { use design discharge of } \\
\text { the WB21 scenario that } \\
\text { resembles most the } \\
\text { change in the average } \\
\text { discharge. Note that the } \\
\text { latter method will likely } \\
\text { underestimate the } \\
\text { change in the design } \\
\text { discharge under the W+ } \\
\text { scenario for } 2050 \text { and } \\
\text { overestimate it for } 2100 \\
\text { (see main text). }\end{array}$ & De Wit et al. (2007) \\
\hline
\end{tabular}




\begin{tabular}{|c|c|c|c|c|c|c|c|}
\hline & \multicolumn{2}{|c|}{ Design discharge (Q) } & \multicolumn{2}{|c|}{ Climate scenario } & \multirow[t]{2}{*}{ Discharge model } & \multirow[t]{2}{*}{ Methodology } & \multirow[t]{2}{*}{ References } \\
\hline Year & $\begin{array}{l}\Delta \mathrm{Q}(\%) \\
2050\end{array}$ & $\begin{array}{l}\Delta \mathrm{Q}(\%) \\
2100\end{array}$ & Type & $\begin{array}{l}\Delta \mathrm{T}_{\text {global }} \text { (and/or } \\
\Delta \mathrm{P})\end{array}$ & & & \\
\hline 2004 & n.a. & $\begin{array}{l}\text { 1M: } 39 \% \\
2 \mathrm{M}: 11 \% \\
2 \mathrm{H}: 10 \% \\
\text { Decrease of } \\
\mathrm{CV}_{10} \text { strongly } \\
\text { reduces the } \\
\text { increase of the } \\
\text { 10-1000 year } \\
\text { (and design) } \\
\text { discharge. }\end{array}$ & $\begin{array}{l}\text { RCM: } \\
\text { HadRM3H } \\
\text { running A2 } \\
\text { emission } \\
\text { scenario } \\
\text { (3 runs for } \\
2070-2099 \\
\text { and } 3 \text { control } \\
\text { runs for } \\
1961-1990) \text {. }\end{array}$ & $\begin{array}{l}2070 \text { - 2099: } \\
\mathbf{2 5 \%} \text { increase in } \\
\text { winter (DJF) } \\
\text { precipitation and } \\
\mathbf{1 6 \%} \text { decrease in } \\
\text { variability of } 10- \\
\text { day precipitation } \\
\text { sums }\left(\mathrm{CV}_{10}\right) ; \mathbf{1 4 \%} \\
\text { decrease in } \\
\text { autumn }(\mathrm{SON}) \\
\text { precipitation and } \\
\mathbf{1 8 \%} \text { increase in } \\
\mathrm{CV}_{10} .\end{array}$ & $\begin{array}{l}\text { Rhineflow-3 } \\
+ \text { Gumbel } \\
\text { distribution fitted to } \\
\text { the annual 10-day } \\
\text { maxima }\end{array}$ & $\begin{array}{l}\text { Two methods. Method } \\
\text { 1: classical Delta } \\
\text { method applied to bias- } \\
\text { corrected RCM control } \\
\text { run used as input for } \\
\text { Rhineflow (ignores } \\
\text { decrease of } \mathrm{CV}_{10} \text { ). } \\
\text { Method } 2 \text { : bias- } \\
\text { corrected RCM data } \\
\text { used as input for } \\
\text { Rhineflow (direct } \\
\text { approach, includes } \\
\text { decrease of CV } 10 \text { and } \\
\text { changes in other } \\
\text { properties of the } \\
\text { precipitation } \\
\text { distribution).In addition } \\
\text { middle (M) and high } \\
\text { (H) scenario for change } \\
\text { in potential evaporation. } \\
\text { In total } 3 \text { combined } \\
\text { scenarios: } 1 \mathrm{M} \text { (classical } \\
\text { Delta method), } 2 \mathrm{M} \text { and } \\
2 \mathrm{H} \text {. }\end{array}$ & $\begin{array}{l}\text { Buishand and } \\
\text { Lenderink (2004) } \\
\text { Lenderink et al. } \\
(2007)\end{array}$ \\
\hline $\begin{array}{l}2004 \\
2003\end{array}$ & n.a. & $\begin{array}{l}\text { S1: } 15 \% \\
\text { S2: } 37 \% \\
\text { Increase of } \\
\mathrm{CV}_{10} \text { leads to } \\
\text { more than } 2 \\
\text { times as large } \\
\text { increase of the } \\
\text { 10-1000 year } \\
\text { (and design) } \\
\text { discharge. }\end{array}$ & $\begin{array}{l}\text { RCM (regional } \\
\text { climate model): } \\
\text { HadRM2 for a } \\
1 \% \text { per year } \\
\text { increase in } \\
\text { equivalent } \mathrm{CO}_{2} \\
\text { after } 1989 \\
\text { (without } \\
\text { sulphate aerosol } \\
\text { forcing). }\end{array}$ & $\begin{array}{l}2080-2099: \\
\mathbf{8 \%} \text { increase in } \\
\text { winter (DJF) } \\
\text { precipitation and } \\
\mathbf{2 5 \%} \text { increase in } \\
\text { variability of } 10- \\
\text { day precipitation } \\
\text { sums }\left(\mathrm{CV}_{10}\right) ; \mathbf{1 9 \%} \\
\text { increase in } \\
\text { autumn }(\mathrm{SON}) \\
\text { precipitation and } \\
\mathbf{2 \%} \text { decrease in } \\
\mathrm{CV}_{10} .\end{array}$ & $\begin{array}{l}\text { Rhineflow-3 } \\
+ \text { Gumbel } \\
\text { distribution fitted to } \\
\text { the annual 10-day } \\
\text { maxima }\end{array}$ & $\begin{array}{l}\text { Two scenarios based on } \\
\text { Delta methods: a } \\
\text { classical method in } \\
\text { which the increase in } \\
\text { the } 10 \text {-day precipitation } \\
\text { variability }\left(\mathrm{CV}_{10}\right) \text { in } \\
\text { winter is excluded (S1) } \\
\text { and an adapted method } \\
\text { in which this increase is } \\
\text { included (S2). } \\
\text { Effect of analysis of } 10- \\
\text { day maxima rather than } \\
\text { daily maxima is only an } \\
\text { underestimation of } \\
\text { about } 4 \% \text { of the given } \\
\text { increase in design } \\
\text { discharge for } \mathrm{S} 2 \text {. }\end{array}$ & $\begin{array}{l}\text { Buishand and } \\
\text { Lenderink (2004) } \\
\text { Shabalova et al. } \\
(2003)\end{array}$ \\
\hline 2000 & $\begin{array}{l}\text { Scenarios for } \\
\text { design } \\
\text { discharge (ref. } \\
16,000 \mathrm{~m}^{3} / \mathrm{s} \text { ): } \\
\mathrm{L}: 16,400 \\
\text { M: } 16,800 \\
\mathrm{H}: 17,600\end{array}$ & $\begin{array}{l}\text { L: } 16,800 \\
\text { M: } 17,600 \\
\text { H: } 19,200\end{array}$ & & & $\begin{array}{l}\text { No model but simple } \\
\text { scaling: See } \\
\text { Methodology (next } \\
\text { column) }\end{array}$ & $\begin{array}{l}\text { Rule of thumb based on } \\
\text { Middelkoop (1999): } \\
\text { Change design } \\
\text { discharge }=5 \% \text { per }{ }^{\circ} \mathrm{C} \text {. } \\
\text { "WB21 rule of thumb } \\
\text { for the Rhine". }\end{array}$ & Kors et al. (2000) \\
\hline $\begin{array}{l}1999 \\
2000\end{array}$ & $\begin{array}{l}\text { L: n.a. } \\
\text { M: n.a. } \\
\text { H: } 8-12 \% \\
\text { Scenarios for } \\
\text { design } \\
\text { discharge (ref. } \\
\text { 16,000 } \mathrm{m}^{3} / \mathrm{s} \text { ): } \\
\text { L: } 16,250 \\
\text { M: } 16,500 \\
\text { H: } 17,500\end{array}$ & $\begin{array}{l}\text { L: n.a. } \\
\text { M: } 8-12 \% \\
\text { H: } 25-30 \% \\
\\
\text { L: } 16,500 \\
\text { M: } 17,500 \\
\text { H: } 20,000\end{array}$ & $\begin{array}{l}\text { GCM: } \\
\text { UKHI for the } \\
\text { IS92a emission } \\
\text { scenario under } \\
\text { equilibrium } \\
\text { conditions for } \\
2100 \text { consistent } \\
\text { with WB21 } \\
\text { scenarios. }\end{array}$ & $\begin{array}{l}\text { UKHI } \\
\text { 2050: } 0.5,1,2{ }^{\circ} \mathrm{C} \\
(\mathrm{L}, \mathrm{M}, \mathrm{H}) ; \\
2100: 1,2,4{ }^{\circ} \mathrm{C} \\
(\mathrm{L}, \mathrm{M}, \mathrm{H}) . \\
\mathbf{1 3 \%} \text { increase in } \\
\text { winter } \\
\text { precipitation in } \\
\text { Central Germany } \\
\text { in } 2050 \text { and } \mathbf{2 4 \%} \\
\text { in } 2100(\mathrm{H} \\
\text { scenario). }\end{array}$ & $\begin{array}{l}\text { Rhineflow-2 } \\
\text { + statistical models: } \\
\text { See Methodology } \\
\text { (next column) }\end{array}$ & $\begin{array}{l}\text { Statistical downscaling } \\
\text { of 10-day discharges } \\
\text { from Rhineflow to peak } \\
\text { discharges using: } \\
\text { i) Conditional Peak } \\
\text { Model } \\
\text { ii) Wavelets }\end{array}$ & $\begin{array}{l}\text { Middelkoop (1999) } \\
\text { Middelkoop et al. } \\
\text { (2000) }\end{array}$ \\
\hline
\end{tabular}


Table A.5: Similar as Table A.4 but for other river basins in Europe.

\begin{tabular}{|c|c|c|c|c|c|c|c|}
\hline & \multicolumn{2}{|c|}{ Design discharge $(\mathrm{Q})$} & \multicolumn{2}{|c|}{ Climate scenario } & \multirow[t]{2}{*}{ Discharge model } & \multirow[t]{2}{*}{ Methodology } & \multirow[t]{2}{*}{ References } \\
\hline Year & \begin{tabular}{|l|}
$\Delta \mathrm{Q}(\%)$ \\
2050 \\
\end{tabular} & \begin{tabular}{|l|}
$\Delta \mathrm{Q}(\%)$ \\
2100 \\
\end{tabular} & Type & $\begin{array}{l}\Delta \mathrm{T}_{\text {global }} \text { (and/or } \\
\Delta \mathrm{P})\end{array}$ & & & \\
\hline 2007 & n.a. & $\begin{array}{l}\text { A: } ~ 7 \% \\
\text { B: } \sim 0 \% \\
\text { C: } \sim 45 \% \\
\text { Decrease of } \\
\mathrm{CV}_{10} \text { in A and } \\
\text { B almost } \\
\text { compensates } \\
\text { the effect of } \\
\text { the increase in } \\
\text { winter } \\
\text { precipitation } \\
\text { on the design } \\
\text { discharge. } \\
\text { Design } \\
\text { discharge } \\
\text { sensitive to } \\
\text { changes in } \\
\text { CV } \\
\text { Howe } \\
\text { certain how un- } \\
C_{10} \text { will } \\
\text { change in } \\
\text { future climate! }\end{array}$ & $\begin{array}{l}\text { Three different } \\
\text { GCM-RCM } \\
\text { combinations: } \\
\text { HadAM3H- } \\
\text { RACMO (A), } \\
\text { HadAM3H- } \\
\text { RCAO (B) } \\
\text { ECHAM4- } \\
\text { RCAO (C) } \\
\text { under the A2 } \\
\text { emission } \\
\text { scenario. }\end{array}$ & $\begin{array}{l}2071-2100 . \\
\text { Summary: } \\
\mathbf{2 0 - 4 0 \%} \text { increase } \\
\text { in winter } \\
\text { precipitation; } \\
\mathbf{2 0 - 3 0 \%} \text { decrease } \\
\text { in variability of } \\
10 \text {-day } \\
\text { precipitation sums } \\
\left(\mathrm{CV}_{10}\right) \text { in } \\
\text { HadAM3H driven } \\
\text { runs (A and B) but } \\
\text { very small } \\
\text { increase in } \\
\text { ECHAM4 driven } \\
\text { run (C). }\end{array}$ & HBV-Meuse & $\begin{array}{l}\text { Bias-corrected RCM } \\
\text { data used as input for } \\
\text { HBV model (direct } \\
\text { approach, accounts for } \\
\text { changes in } \mathrm{CV}_{10} \text { and in } \\
\text { other properties of } \\
\text { precipitation } \\
\text { distribution). } \\
\text { Nearest-neighbour } \\
\text { resampling to generated } \\
\text { synthetic sequences } \\
\text { long enough to enhance } \\
\text { estimation of changes in } \\
\text { design discharge } \\
\text { Meuse. }\end{array}$ & Leander et al. (2008) \\
\hline 2005 & n.a. & $\begin{array}{l}\text { Changes in } 10 \text { - } \\
\text { year event: } \\
-18 \text { to }+37 \% \\
\text { Changes in } 50 \text { - } \\
\text { year event: } \\
-33 \text { to }+59 \% \\
\text { Note, for the } \\
10 \text {-year event, } \\
\text { negative } \\
\text { changes } \\
\text { (decreases) } \\
\text { were found for } \\
\text { only } 2 \\
\text { catchments and } \\
\text { for } 5 \\
\text { catchments the } \\
\text { changes were } \\
\text { very small. }\end{array}$ & $\begin{array}{l}\text { RCM: } \\
\text { HadRM3H }\end{array}$ & $2071-2100$ & $\begin{array}{l}\text { Spatially-generalised } \\
\text { rainfall-runoff model } \\
\text { for } \\
15 \text { small }\left(<500 \mathrm{~km}^{2}\right) \\
\text { catchments across } \\
\text { Great Britain }\end{array}$ & $\begin{array}{l}\text { RCM data used as input } \\
\text { for rainfall-runoff } \\
\text { model (direct approach, } \\
\text { no bias correction, } \\
\text { spatial downscaling to } \\
\text { the catchment scale). }\end{array}$ & Kay et al. (2005) \\
\hline 2002 & $\begin{array}{l}\text { Change in } 10- \\
\text { year discharge: } \\
6.6-23 \% \\
\text { and increases } \\
\text { up to } 30 \% \text { for } \\
\text { the } 50 \text { year } \\
\text { event. }\end{array}$ & n.a. & $\begin{array}{l}\text { GCM: } \\
\text { HadCM2 } \\
\text { for } 2050\end{array}$ & $\begin{array}{l}\text { NOTE } \\
\text { In this study the } \\
\text { relevance of } \\
\text { changes in the } \\
\text { rainfall variability } \\
\text { for changes in the } \\
\text { probability and } \\
\text { magnitude of } \\
\text { floods is stressed. }\end{array}$ & $\begin{array}{l}\text { CLASSIC model for } \\
\text { the Severn catchment } \\
\text { situated in Wales and } \\
\text { western England. } \\
\text { This is a catchment } \\
\text { in which the highest } \\
\text { flows are generally } \\
\text { due to prolonged } \\
\text { rainfall during the } \\
\text { winter. }\end{array}$ & $\begin{array}{l}3 \text { daily rainfall } \\
\text { scenarios derived from } \\
\text { monthly changes } \\
\text { (representing: } 1 \\
\text { increase in frontal } \\
\text { systems, } 2 \text { increase in } \\
\text { convective systems and } \\
3 \text { increase in average } \\
\text { rainfall without change } \\
\text { in rainfall variability). }\end{array}$ & $\begin{array}{l}\text { Prudhomme et al. } \\
(2002)\end{array}$ \\
\hline
\end{tabular}

\section{The KNMI'06 climate scenarios}

In 2006 KNMI released four new climate scenarios for the Netherlands (Van den Hurk et al, 2006). These scenarios replaced the scenarios that were drawn up in 2000 for the National Commission on Water management in the $21^{\text {st }}$ century, also known as the WB21 climate scenarios. The KNMI'06 climate scenarios are consistent and plausible pictures of possible future climates. They are intended 
for use in studies exploring the impact of climate change, and to formulate possible adaptation strategies. Projections of future climate are by nature uncertain due to uncertainties in greenhouse gas emissions, which in turn are due to uncertainties in population growth, and economic, social and technological developments, and due to uncertainties in climate modeling as a result of limited knowledge of the complex processes in the climate system. In addition, uncertainty increases when we go from the global scale to regional and local scales. Based on results from a large number of recent global and regional climate models as well as observed climatic series, the relation between global warming, changes in air circulation over Western Europe and climate change in the Netherlands was mapped systematically. To be able to deal in some way with the uncertainties four climate scenarios were selected from the broad range of possible futures. KNMI considers these four scenarios most relevant for Dutch policies. For each scenario a complete picture of the future climate is presented, and each of the four scenarios is considered plausible. However, it is not possible to indicate which scenario is more probable. Each of the four climate scenarios gives, for 2050 as well as for 2100, a single number for the change per variable. These numbers are uniform for the Netherlands and according to KNMI they can also be used as indicative for the river basins of the Meuse and the Rhine with the exception of the Alpine region (Van den Hurk et al., 2006).

The four KNMI'06 climate scenarios are denoted as: G, G+, W and W+. G and $\mathrm{G}+$ are scenarios in which the global mean temperature increase is moderate ("Gematigd"). In the W and W+ ("Warm") scenarios the global mean temperature rise is twice as large. The ' + ' (plus) is used to denote the scenarios in which the atmospheric circulation over Western Europe significantly changes, basically resulting in larger regional temperature increases throughout the year, in larger precipitation increases in winter and a precipitation decrease in summer. In the four scenarios for 2100 average winter temperatures increase from 1.8 to $4.6^{\circ} \mathrm{C}$ and average summer temperatures from 1.7 to $5.6^{\circ} \mathrm{C}$. The coldest winter day per year increases up to $5.8^{\circ} \mathrm{C}$, and the warmest summer day per year up to $7.6^{\circ} \mathrm{C}$. Precipitation in winter increases between 7 and $28 \%$ and summer precipitation changes from -38 to $+12 \%$. Regarding summer drying it is important to realize that the scenarios with the largest precipitation decrease in summer have the largest potential evaporation increases (up to 30\%). More details of the KNMI'06 scenarios for 2100 are given in Table A.5. 
Table A.6: Climate change in the Netherlands around 2100 for the four KNMI'06 climate scenarios compared to the baseline period $1976-2005$.

2100

Global temperature rise

Change in air circulation patterns

Winter Average temperature

Coldest winter day per

year

Average precipitation

amount

Number of wet days $(\geq 0.1$ $\mathrm{mm}$ )

10-day precipitation sum

exceeded once in 10 years

Maximum average daily

wind speed per year

Summer Average temperature

Warmest summer day per

year

Average precipitation

amount

Number of wet days ( $\geq 0.1$ $\mathrm{mm}$ )

Daily precipitation sum exceeded once in 10 years Potential evaporation

\begin{tabular}{|c|c|c|c|}
\hline G & G+ & W & W+ \\
\hline $\begin{array}{l}+2^{\circ} \mathrm{C} \\
\text { no } \\
+1.8^{\circ} \mathrm{C}\end{array}$ & $\begin{array}{l}+2^{\circ} \mathrm{C} \\
\text { yes } \\
+2.3^{\circ} \mathrm{C}\end{array}$ & $\begin{array}{l}+4^{\circ} \mathrm{C} \\
\text { no } \\
+3.6^{\circ} \mathrm{C}\end{array}$ & $\begin{array}{l}+4^{\circ} \mathrm{C} \\
\text { yes } \\
+4.6^{\circ} \mathrm{C}\end{array}$ \\
\hline$-2.1^{\circ} \mathrm{C}$ & $+2.9^{\circ} \mathrm{C}$ & $+4.2^{\circ} \mathrm{C}$ & $+5.8^{\circ} \mathrm{C}$ \\
\hline$+7 \%$ & $+14 \%$ & $+14 \%$ & $+28 \%$ \\
\hline$\%$ & $+2 \%$ & $0 \%$ & $+4 \%$ \\
\hline$+8 \%$ & $+12 \%$ & $+16 \%$ & $+24 \%$ \\
\hline $1 \%$ & $+4 \%$ & $-2 \%$ & $+8 \%$ \\
\hline$+1.7^{\circ} \mathrm{C}$ & $+2.8^{\circ} \mathrm{C}$ & $+3.4^{\circ} \mathrm{C}$ & $+5.6^{\circ} \mathrm{C}$ \\
\hline$-2.1^{\circ} \mathrm{C}$ & $+3.8^{\circ} \mathrm{C}$ & $+4.2^{\circ} \mathrm{C}$ & $+7.6^{\circ} \mathrm{C}$ \\
\hline$-6 \%$ & $-19 \%$ & $+12 \%$ & $-38 \%$ \\
\hline $3 \%$ & $-19 \%$ & $-6 \%$ & $-38 \%$ \\
\hline$-27 \%$ & $+10 \%$ & $+54 \%$ & $+20 \%$ \\
\hline$-7 \%$ & $+15 \%$ & $+14 \%$ & $+30 \%$ \\
\hline
\end{tabular}




\section{Appendix III-b: Effects of flooding in Germany upon the peak discharge at Lobith}

\section{Introduction}

Together with the report "Future Rhine discharge as a result of climate change review for the new Dutch Delta committee" (Beersma et al, 2008) this report forms the background material for the Summary report: "Effects of climate change on the Rhine discharges, a review" by J. Beersma, J. Kwadijk and R. Lammersen. These three reports together serve to inform the new Dutch Delta committee on possible effects of climate change on the discharge behavior of the Rhine as well as on the hydraulic effects as a result of flooding upstream of the Netherlands.

Based on a review of recent results, KNMI concludes (Beersma et al, 2008), that the 1250 -year discharge at Lobith of $16,000 \mathrm{~m}^{3} / \mathrm{s}$ (i.e. the current design discharge in the Netherlands) may increase to $16,500-19,000 \mathrm{~m}^{3} / \mathrm{s}$ in 2050 and to $17,000-22,000 \mathrm{~m}^{3} / \mathrm{s}$ in 2100 . After 2100 meaningful values could not be derived. Along with this numbers, they emphasise, that there are huge uncertainties due to the mean meteorological conditions and the large sensitivity of peak discharge to changes in multi-day precipitation variability. However when such high flood waves move through the River Rhine, large areas in Germany will be flooded The flooding in Germany will reduce the (peak-) discharge at Lobith substantially. Although uncontrolled flooding is mentioned as a source of uncertainty, this effect is not taken into account in the KNMI review.

This paper presents the current knowledge about the effect of flooding in Germany upon the (peak-) discharge of extreme floods at Lobith. Therefore it provides additional information for the future Rhine discharge as a result of climate change.

\section{River Rhine basin and present protection levels along the Rhine}

The basin of the River Rhine, situated in Western Europe, has an area of 185,000 $\mathrm{km}^{2}$. The river begins in the Alps and after $1320 \mathrm{~km}$ it reaches the North Sea. Large areas along the Upper Rhine, the Lower Rhine and the Dutch Rhine branches are protected against flooding by dikes to prevent frequent flooding of large, densely populated floodplains. In the Middle Rhine section the river flows through a narrow valley. In this section only local flood protection occurs.

Along the Rhine the level of protection against flooding differs from place to place (see Figure B.1 left). It varies from protection against flooding, with return periods of 1000 respectively 200 years along the Upper Rhine, 100 years along the southern part of the Lower Rhine, 200 years in the middle part of the Lower Rhine and rises up to a protection against floods, with a return period of once in 
500 years in the Northern part of the Lower Rhine and 1250 years along the Dutch Rhine branches.

To reduce water level in the river in order to prevent dike overflow flood reduction measures such as retention basins, dike relocations and lowering the floodplain are planned along the Upper Rhine, the Lower Rhine and the Dutch Rhine Branches to be realized until 2020 or have been already realized recently. Because of the narrow valley, there is no room for flood reduction measures along the Middle Rhine.

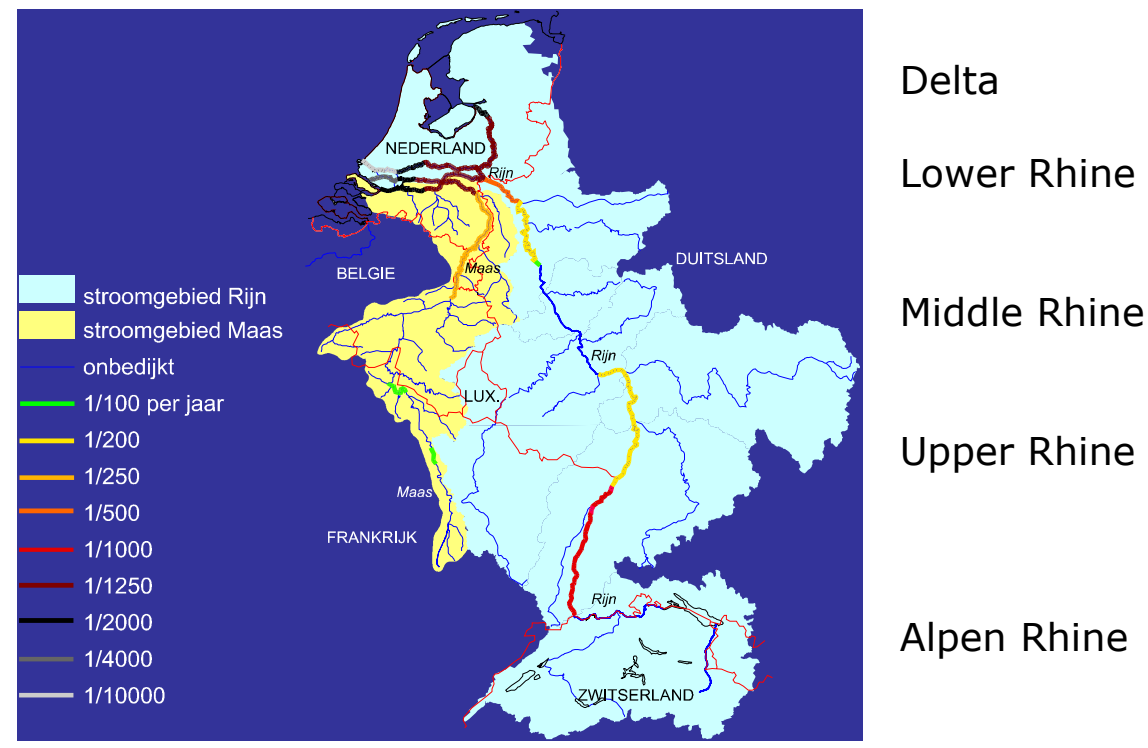

Figure B.1: River Rhine and Maas basin with flood protection levels along the River Rhine and Maas.

\section{Research Method}

Between 2002 and 2004 for the first time research has been carried out to investigate the effects of retentions measures and flooding along the Lower Rhine and the Dutch Rhine branches (Lammersen, 2004). Figure B.2 gives an overview of the method, which has been used.

The stochastic weather generator, developed by the Dutch Meteorological Institute (KNMI) was used to produce an artificial time series of 1000 year of precipitation and temperature (Buishand and Brandsma, 2001). The input consisted of 30 years of measured meteorological data of 34 different weather stations distributed all over the Rhine catchment area. The generated time series, with the same statistics as the historical data, was then put into a rainfallrunoff model of the complete Rhine basin (HBV) and was transformed to discharge. A selection was made of the 16 most extreme events, based on the HBV results at Andernach and Lobith. These 16 extreme events were then put into a 1-dimensional flood routing model to compute the 16 highest discharge waves at Andernach in a more accurate way, taking into account the retention measures along the Rhine upstream of Andernach (for more information see Eberle et al., 2004 and Lammersen, 2004). Also the flooding, which occurs when 
water level in the river exceed dike crest height, is taken into account, using a very simple method of retaining water in retention areas along the Upper Rhine and releasing it later, when the flood wave has passed to the downstream area. Water flowing in the flooded area parallel to the Rhine and probably flowing back to river further downstream, was not taken into account.

With the two most extreme discharge waves at Andernach flood simulations have been performed using the 2-dimensional model Delft-FLS. A Delft-FLS model was made of the Rhine downstream Rhine-km 642 (which is downstream of Andernach) using a $100 \mathrm{~m} \times 100 \mathrm{~m}$ grid on top of a digital terrain model. In this model dikes and flood walls are modeled as grid cells. When the water level reaches the dike level a dike collapse occurs. In case of a flood wall, or a natural levee, the floodwall or levee simply overflows and no collapse is simulated. Two situations have been considered: the year 2002 and 2020, with the dike levels of 2002 and 2020 respectively. The input of the 2D-model consisted of the discharge at Andernach and the tributaries of the Rhine. The output consisted of information about locations of a dike collapse or an overflow, inflow to the protected area, flood patterns inside the protected area, effect on the discharge wave and finally the discharge capacity of the Rhine (for more information see Gudden, 2004, and Lammersen, 2004).

The results of the 2D flood simulations were then transferred to a 1-dimensional SOBEK-model. Each dike collapse or overflow was modeled as a retention basin. Water flowing behind the dike parallel to the Rhine and further downstream entering the Rhine again where modeled as parallel steams to the Rhine. Parameters like surface area, capacity, inflow and outflow were based on information from the Delft-FLS model (for more information see van der Veen et al., 2004a and Lammersen, 2004). This made it possible to simulate the effects of flooding upon the discharge wave in the Rhine in a more detailed manner, than it was possible for the Upper Rhine. Using the SOBEK-model the effect of flood reduction measures in Northrhine-Westfalia was studied in combination with the effects of dike overflows (Van der Veen et al., 2004a, Van der Veen et al., 2004b, Mehlig, 2004 and Lammersen, 2004).

In addition to the study by Lammersen (2004) Gudden (unpublished) made calculations with even higher peakdischarges. He only used the 2-D-model for the lower Rhine, which had been used in the study above. Gudden only took into account the flooding along the Lower Rhine.

\section{Extreme floods and flooding in Germany due to extreme rainfall}

The results of Lammersen (2004) showed that due to the lower protection level, extensive flooding occurs along the Upper Rhine and the Lower Rhine in Germany when water levels exceed the dike crest (see Figure B.3).Figure B.4 gives an example of the flooded area along the German Lower Rhine, with blue areas being flooded and red arrows indicating major flow paths behind the dikes that develop during the flooding. The simulations showed that already discharges larger than $11,000 \mathrm{~m}^{3} / \mathrm{s}$ at Köln will cause large-scale inundations along the German Lower Rhine. Flooding starts along the southern part of the Lower Rhine between Bonn/Köln and Düsseldorf/Dormagen. At higher discharges also areas 
along the middle part of the Lower Rhine between Düsseldorf/Dormagen and the confluence with the Ruhr River will be flooded. Further downstream no inundation occurs in the dike situation shown. When dikes would collapse or overflow, flows parallel to the Rhine will develop, also resulting in the flooding of areas having a higher protection level (see Figure B.2). These flows parallel to the Rhine partly return into the main river downstream. This causes interaction of flooding and flood wave propagation, which is very difficult to predict accurately.

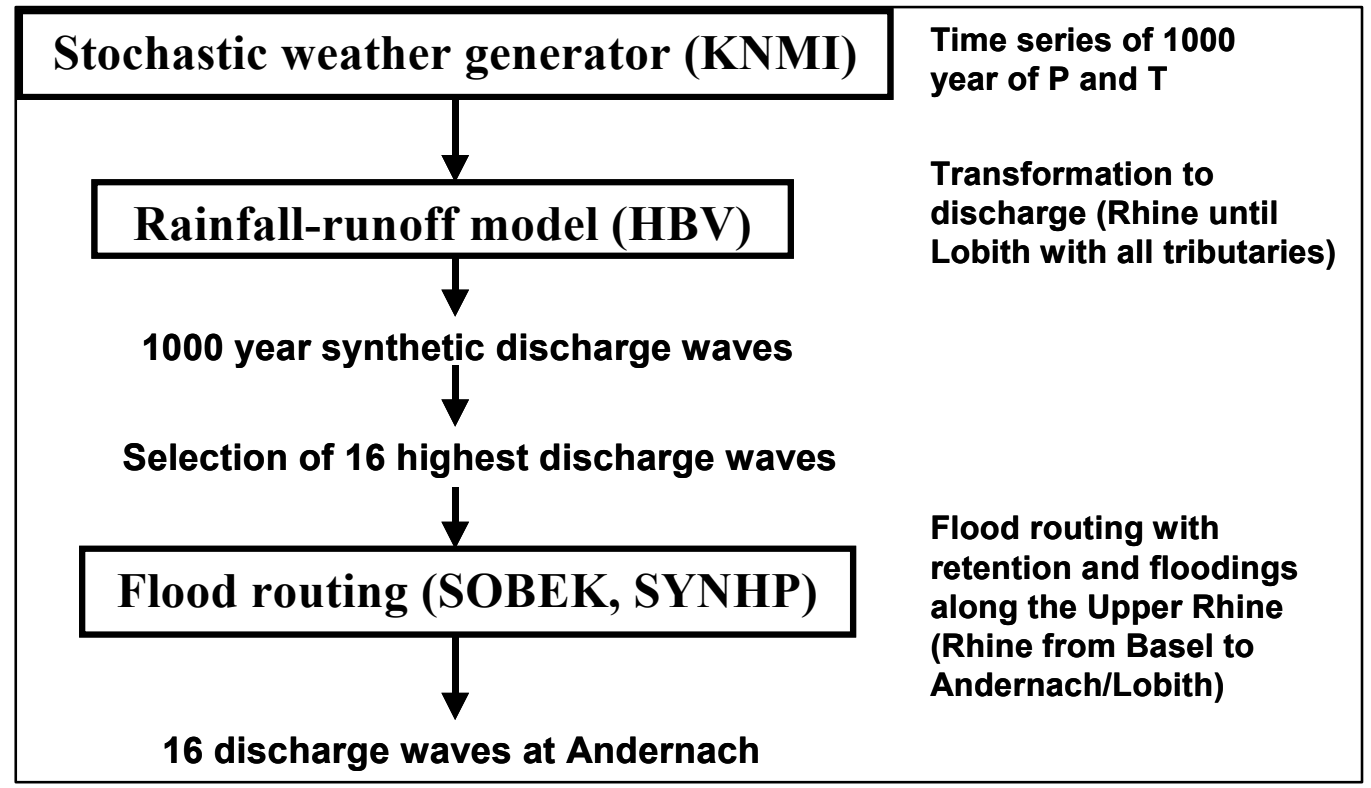

$\downarrow$

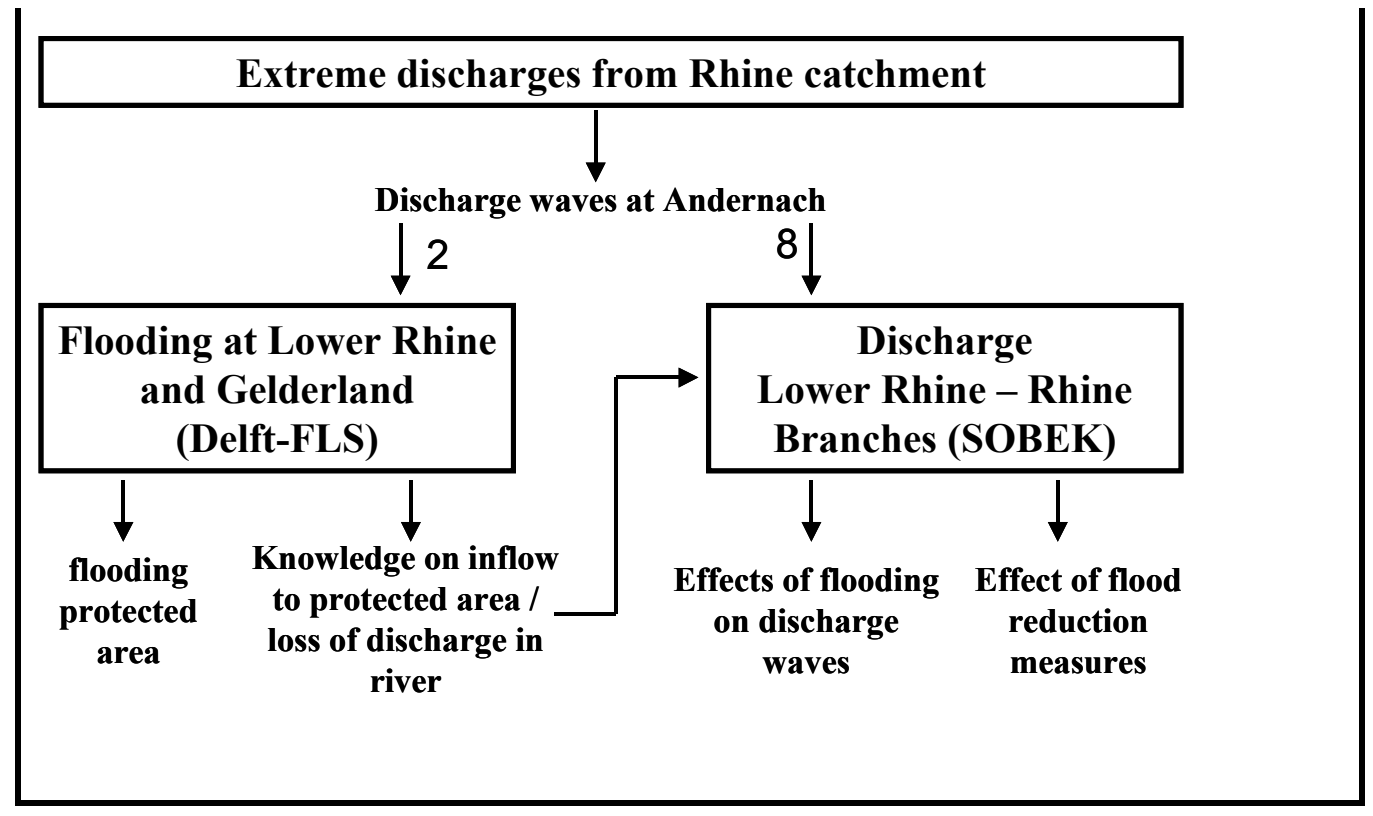

Figure B.2: Research method

In cases where even higher discharges would reach the Lower Rhine area for example because of climate change and/or rising dike levels upstream, dike 
overflow also can occur in the northern part of the Lower Rhine. This would probably lead to cross border flooding. Figure B.5 shows such a situation

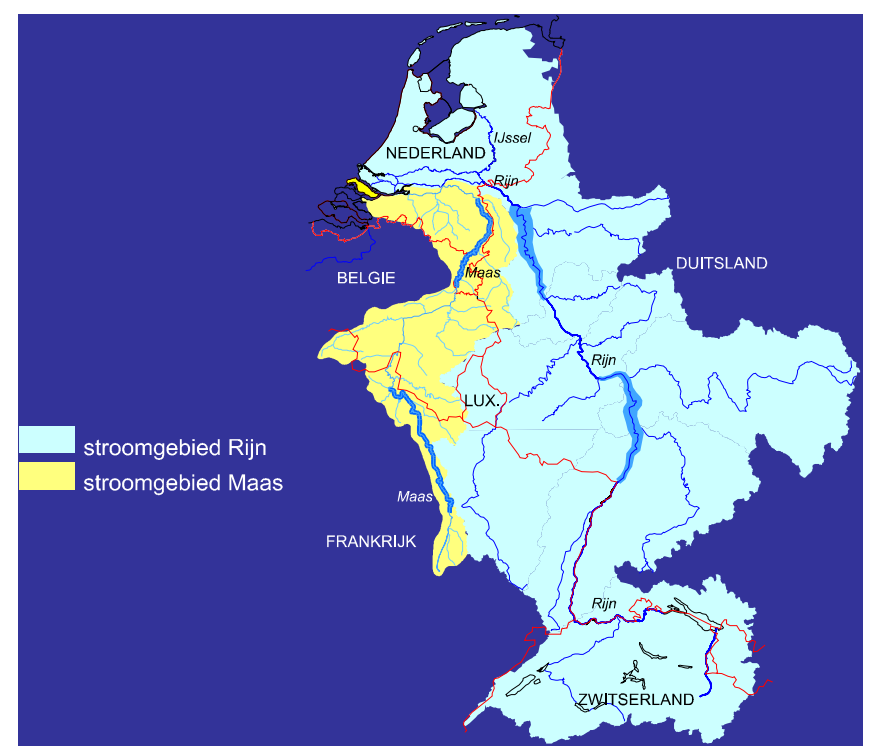

Figure B.3: River Rhine and Maas basin with potentially flooded areas along Rhine and Maas upstream the Netherlands.

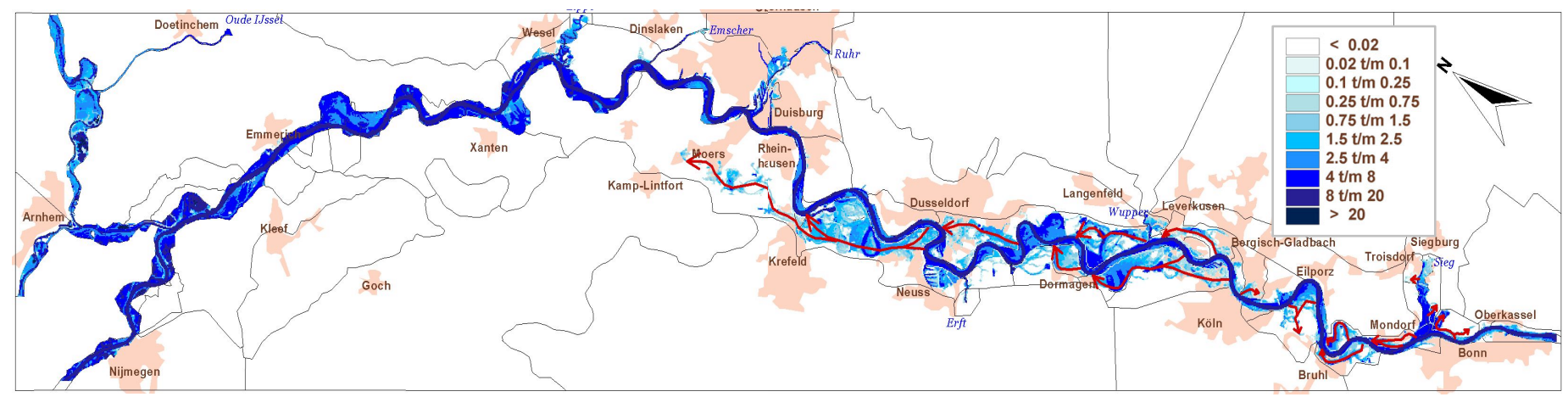

Figure B.4: Flooding along the lower Rhine (dike situation 2020): maximum water depths [m] and main streams behind the dikes.

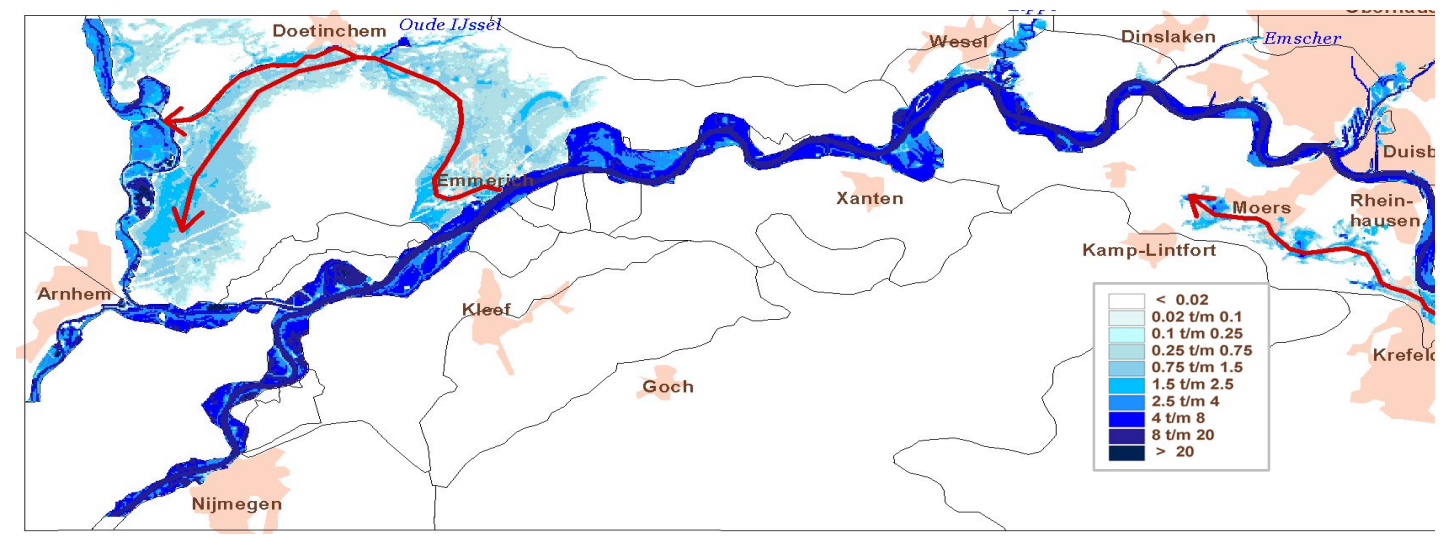

Figure B.5: Example for a trans-border flooding at the German-Dutch border: maximum water depths $[\mathrm{m}]$, extreme scenario. 


\section{Peak flow and peak flow development along the Rhine}

Figure 6 shows the effect of the flooding on the development of the discharge peak along the lower Rhine. Assumed is a flood wave of $15,000 \mathrm{~m}^{3} / \mathrm{s}$ peak discharge near Bonn and two scenarios for dike crest height. In the first scenario, represented by the black line, calculations were done assuming infinitely high dikes, so no overflow occurs. In this situation the peak discharge increases along the Rhine due to additional inflow of tributaries. Taking dike overflow into account (second scenario, represented by the dotted line) the peak discharges decreases sharply at certain points along the river as a result of local overflow of dikes. In this scenario peak discharges also rise sharply at locations where water, which is flowing parallel to the River Rhine behind the dikes, returns to the main stream.

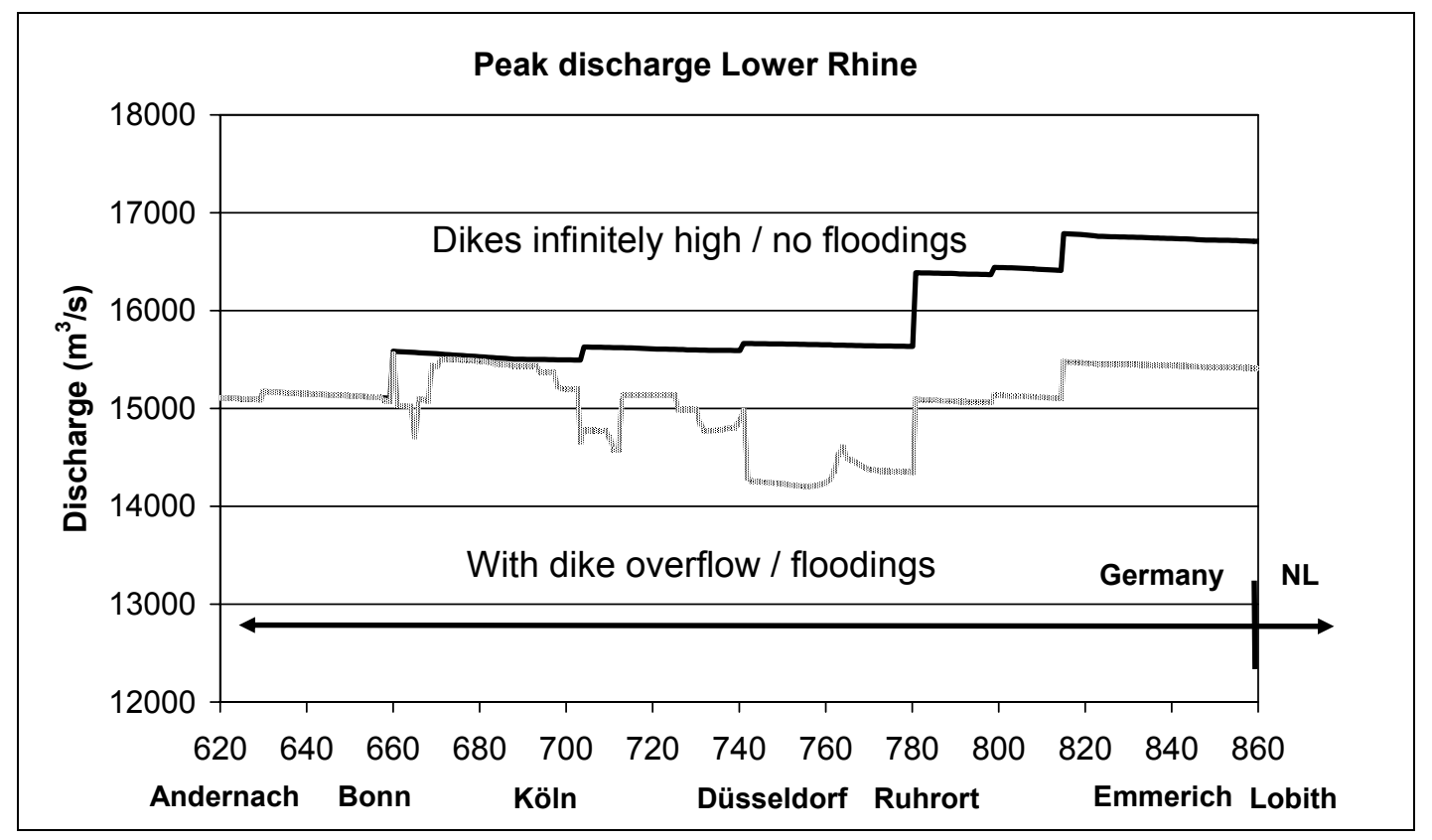

Figure B.6: Development Maximum discharge with and without dike overflow (dike situation 2020, flood wave HW8); (from Lammersen, 2004).

As a result of the dike overflow along the upper and the lower Rhine, peak discharges at Lobith are reduced significantly.

Figure B.7 illustrates this for a selection of floods with a very high peak discharge. In this figure the results of two studies are combined. The calculations mentioned by Lammersen (2004) take into account dike overflow along the upper and the lower Rhine. There is a clear relationship between the reduction of the peak flow and the magnitude of the peak flow but the strength of this relationship is not very great. This is because the effect of dike overflow depends on the origin and genesis of the flood wave: a flood wave coming from the upper Rhine will be affected by the floodings along the upper and the lower Rhine resulting in a relative wide flood wave entering the lower Rhine. A flood wave coming form the middle or lower Rhine only will be affected by flooding along the lower Rhine. 


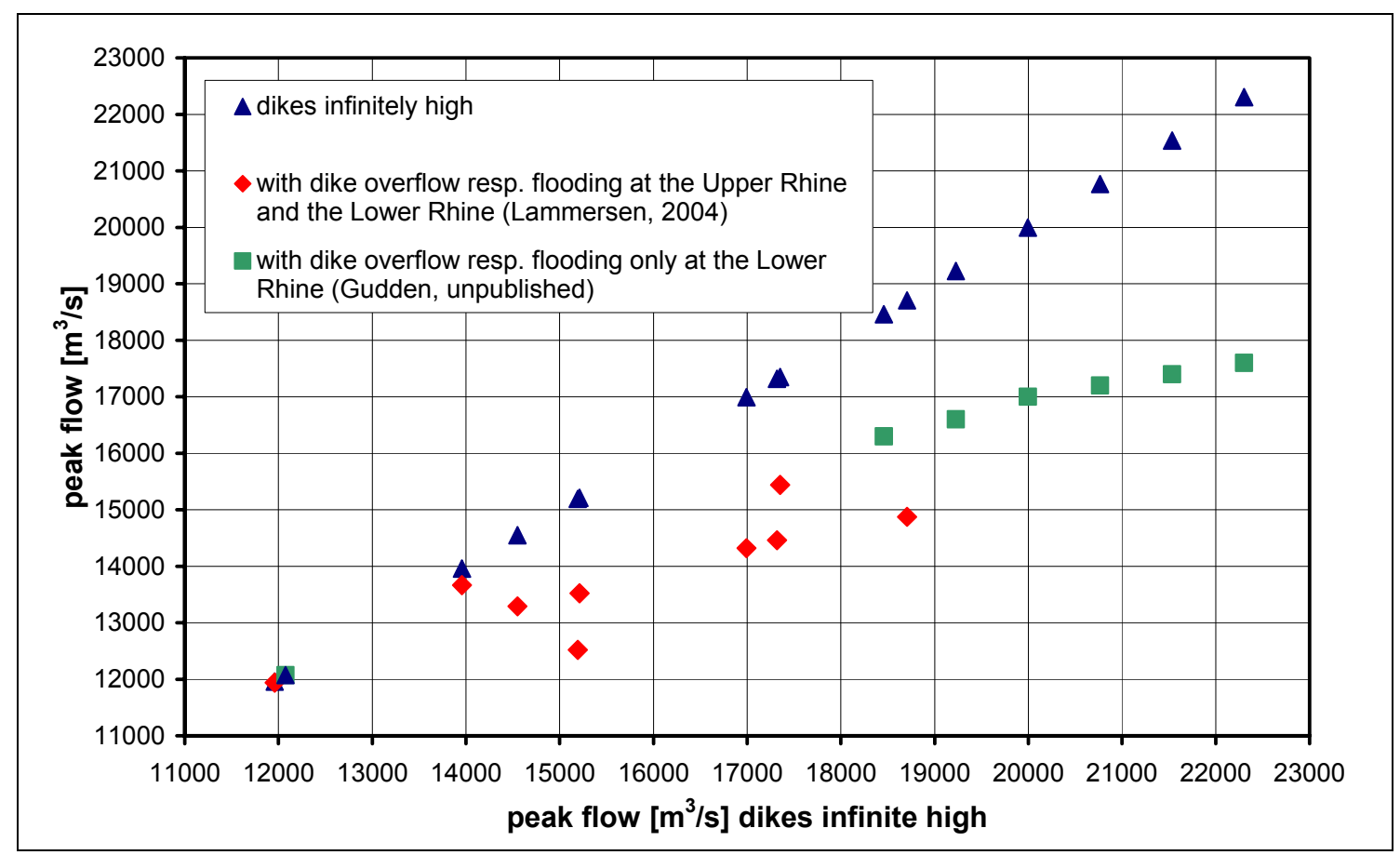

Figure B.7: Peak flows at Lobith with and without dike overflow along the upper and the lower Rhine in Germany, dike situation 2020 (after Lammersen, 2004) and with and without dike overflow along the Lower Rhine, dike situation 2020 (after Gudden, unpublished).

An estimation of the effect of flooding upon even bigger discharges has been done by Gudden (unpublished). He only took into account flooding along the lower Rhine, in order to get an estimate of the reduction of the discharge peak at Lobith under very extreme conditions. The results are also given in Figure B.7. The flood waves were generated by enlarging one particular flood wave by a certain percentage. The resulting flood waves thus do not differ in their origin or in their shape, therefore giving less variation in the resulting peak discharges at Lobith. In addition the estimate of the peak discharge at Lobith is rather rough, because a simulation without dike overflow (i.e. dikes are infinite high) is not possible with the model used by Gudden. Nevertheless, the resulting curve becomes more and more flat and does not exceed the level of approximately $17,500 \mathrm{~m}^{3} / \mathrm{s}$. However it does not give any insight in the variation which may occur due to flood waves with different genesis. The way of generating the higher discharges by Gudden (unpublished), where flooding along the upper Rhine is not taken into account and other uncertainties as the interaction of main river and tributaries under very extreme conditions etc. give an indications, that this level is rather an upper than a lower estimate.

Despite these uncertainties, both studies make clear that peak discharges at Lobith are considerably reduced due to flooding upstream of Lobith. From Figure 7 it can be concluded, that discharges of $16,500-19,000 \mathrm{~m}^{3} / \mathrm{s}$, i.e. the range of the 1250-year discharge projected for 2050 under the assumption that no flooding in Germany occurs (Beersma et al., 2008) will be reduced to approximately $15,500-17,000 \mathrm{~m}^{3} / \mathrm{s}$ and the projected 1250 -year discharges of $17,000-22,000 \mathrm{~m}^{3} / \mathrm{s}$ for 2100 will be reduced to approximately $16,000-$ $17,500 \mathrm{~m}^{3} / \mathrm{s}$ under the 2020 flood protection level in Germany. 
It should be noted that in the 2020 dike situation the flow capacity along most parts of the northern part of the lower Rhine is around $17,500 \mathrm{~m}^{3} / \mathrm{s}$. When, as a result of the combined effect of climate change and higher dikes upstream in Germany, peak flows larger than $17,500 \mathrm{~m}^{3} / \mathrm{s}$ would arrive at the northern lower Rhine, this will lead to uncontrolled flooding in this area and, as a result of transborder flooding through old river valleys, to uncontrolled flooding in the eastern part of the Netherlands as well.

\section{Conclusion}

KNMI concludes (Beersma et al, 2008), that as a result of climate change the 1250 -year discharge at Lobith of $16,000 \mathrm{~m}^{3} / \mathrm{s}$ (the design discharge) may increase to $16,500-19,000 \mathrm{~m}^{3} / \mathrm{s}$ in 2050 and to $17,000-22,000 \mathrm{~m}^{3} / \mathrm{s}$ in 2100 . However, due to the lower flood protection level in Germany compared with the Netherlands, flood waves of this magnitude will exceed the discharge capacity along the upper Rhine and the lower Rhine in Germany. This will cause flooding of areas usually protected against floods. This flooding in Germany will substantially reduce the peak discharge reaching the Netherlands at Lobith.

Under the current flood protection levels the peak discharges that can reach Lobith clearly will be lower than presented by KNMI (Beersma et al., 2008). Based on the hydrodynamic analysis it can be concluded that under the flood prevention situation in Germany in 2020 peak discharges at Lobith will be less than $17,500 \mathrm{~m}^{3} / \mathrm{s}$. Therefore, under 2020 flood protection conditions in Germany discharges of $16,500-19,000 \mathrm{~m}^{3} / \mathrm{s}$, i.e. the range of the 1250 -year discharge projected for 2050 under the assumption that no flooding in Germany occurs (Beersma et al., 2008) will be reduced to approximately $15,500-17,000 \mathrm{~m}^{3} / \mathrm{s}$ and the projected 1250 -year discharges of $17,000-22,000 \mathrm{~m}^{3} / \mathrm{s}$ for 2100 will be reduced to approximately $16,000-17,500 \mathrm{~m}^{3} / \mathrm{s}$.

From the flood studies in the lower Rhine area it is concluded that future peak discharges in the Netherlands are as much dependent on the activities in Germany as they are dependent on increasing discharge due to climate change. The future development of flood protection in Germany is unclear, but currently no plans are prepared to improve the flood protection to such an extend that floods above $17,500 \mathrm{~m}^{3} / \mathrm{s}$ can be expected. Increasing the flood protection level in Germany probably will result in peak discharges higher than $17,500 \mathrm{~m}^{3} / \mathrm{s}$. It must be emphasised however, that peak discharges as large as $22,000 \mathrm{~m}^{3} / \mathrm{s}$ can only reach the German-Dutch border, when flood protection levels in Germany generally will be enlarged to levels comparable with those practiced in the Netherlands. This would ask for a huge operation in Germany, both financially and technically and in some cases it will not be possible technically. In fact other strategies to adapt to floods rather than increasing flow capacity in the rivers are discussed in Germany intensively. Therefore it seems very unlikely, that Germany will rise its protection level to such an extend, that discharges of a magnitude of $22,000 \mathrm{~m}^{3} / \mathrm{s}$ will reach the Netherlands. For this reason and because it is very difficult to estimate the effects of partly enlarged protection levels in Germany, it is not possible to give a clear answer, what number then can be expected realistically. This is partly also due to other uncertainties such as 
the effect of (future) flood reduction measures, interaction of main river and tributaries under very extreme conditions etc.

Finally cooperation with Germany is very important; in order to be able to judge the consequences future German plans on the flood protection will have for the Netherlands. That is even more important, when dike improvement in Germany will result in an increase of peak discharges, which may cause trans-border flooding along the Northern part of the lower Rhine. 


\section{References}

Beersma, J.J., 2002, Rainfall Generator for the Rhine Basin - Description of 1000-year simulations. KNMI-publication 186-V, KNMI, De Bilt.

Beersma, J.J., A.M.R. Bakker, T.A. Buishand and A.M.G. Klein Tank, 2008. Future Rhine discharge as a result of climate change - review for the new Dutch Delta committee. KNMI, De Bilt.

Beersma, J.J., T.A. Buishand and H. Buiteveld, 2003, Droog, droger, droogst. KNMI/RIZA bijdrage aan de tweede fase van de Droogtestudie Nederland. KNMIpublicatie 199-II, KNMI, De Bilt.

Buishand, T.A. and Brandsma, T., 2001, Multi-site simulation of daily precipitation and temperature in the Rhine basin by nearest-neighbour resampling. Water Resources Research, 37, 2761-2776.

Buishand, T.A. and G. Lenderink, 2004. Estimation of future discharges of the River Rhine in the SWURVE project. KNMI Technical Report TR-273, KNMI, De Bilt.

Diermanse, F.L.M., 2004. HR2006-herberekening werklijn Rijn. Rapportage project Q3623 aan RIZA, WL | Delft Hydraulics, Delft.

Deltares, 2008. In preparation. Contact: J. Kwadijk, Deltares, Delft.

van Deursen, W.P.A., 1999, Impact of climate change on the River Rhine discharge regime, Scenario runs using Rhineflow-2. Report of the NRPproject: The impact of climate change on the river Rhine and implications for water management in the Netherlands. November 1999.

van Deursen, W., 2003, Klimaatveranderingen in de stroomgebieden van Rijn en Maas, Modelstudies met Rhineflow-3 en Meuseflow-2. Carthago Consultancy, Rotterdam, november 2002.

van Deursen, W., 2006, Rapportage Rhineflow/Meuseflow nieuwe KNMI scenario's. Carthago Consultancy, Rotterdam, mei 2006.

van Deursen, W., 2007, Concept Rapportage Rhineflow/Meuseflow Klimaatscenario's 2100 G, Gplus, W, Wplus. Carthago Consultancy, Rotterdam, november 2007.

Eberle, M.; Hammer, M.; Busch, N.; Engel, H.; Krahe, P. und Wilke, K., 2004, Effects of extreme floods along the Niederrhein (Lower Rhine), section Extreme floods from the River Rhine basin; (in German: ISBN 9036956501, in Dutch: ISBN 9036956684).

Gudden, J.J. , 2004, Effects of extreme floods along the Niederrhein (Lower Rhine), section Inundation in NRW and Gelderland; (in German: ISBN 9036956641, in Dutch: ISBN 9036956692). 
Gudden, J.J.: Results of 2-D Delft-FLS calculations of extreme discharges along the lower Rhine area (unpublished)

Van den Hurk, B. et al., 2006, KNMI Climate Change Scenarios 2006 for the Netherlands. Scientific report WR 2006-01, KNMI, De Bilt.

Kay, A.L., R.G. Jones and N.S. Reynard, 2005, RCM rainfall for UK flood frequency estimation. II. Climate change results. Journal of Hydrology, 318, 163 - 172, doi:10.1016/j.jhydrol.2005.06.013.

Klopstra, D., R. Versteeg and T. Kroon, 2005, Droogtestudie Nederland - Aard, ernst en omvang van watertekorten in Nederland (Eindrapport). RIZA-rapport 2005.016, Lelystad, september 2005.

Kors, A.G., F.A.M. Claessen, J.W. Wesseling en G.P. Können, 2000, Scenario's externe krachten voor WB21. RIZA, WL | Delft Hydraulics en KNMI.

Lammersen, R., 2004. Grensoverschrijdenden effecten van extreem hoogwater op de Niederrhein. Gezamenlijke uitgave van: Ministerium für Umwelt und Naturschutz, Landwirtschaft und verbraucherschutz des Landes NordrheinWestfalen, Provincie Gelderland, Ministerie van Verkeer en Waterstaat, Rijkswaterstaat Directie Oost-Nederland.

Lammersen, R., 2004, Effects of extreme floods along the Niederrhein (Lower Rhine), main report; (in German: ISBN 9036956382, in Dutch: ISBN 9036956390).

Lammersen, R., 2008. Effect of flooding in Germany upon the peak discharge at Lobith. Rijkswaterstaat Waterdienst, Lelystad.

Leander, R., T.A. Buishand, B.J.JM. van den Hurk and M.J.M de Wit, 2008, Estimated changes in flood quantiles of the river Meuse from resampling of regional climate model output. Journal of Hydrology, 351, 331 - 343, doi:10.1016/j.hydrol.2007.12.020.

Lenderink, G., A. Buishand and W. van Deursen, 2007, Estimation of future discharges of the river Rhine using two scenario methodologies: direct versus delta approach. Hydrol. Earth. Syst. Sci., 11, 1145 - 1159.

Te Linde, A., 2007. Effect of climate change on the rivers Rhine and Meuse Applying the KNMI 2006 scenarios using the HBV model. Report Q4286, WL I Delft hydraulics, Delft.

Mehlig, B., 2004, Effects of extreme floods along the Niederrhein (Lower Rhine), section Retention measures in NRW and in the Netherlands; (in German: ISBN 903695665, in Dutch: ISBN 9036956706).

Middelkoop, H., 1999, Estimating the impact of climate change on peak flows in the river Rhine. Report of the NRPproject: The impact of climate change on the river Rhine and implications for water management in the Netherlands. RIZA report 99.064, November 1999. 
Middelkoop, H. (Ed.), N.E.M. Asselman, H. Buiteveld, M. Haasnoot, F.J.P.M. Kwaad, J.C.J. Kwadijk, W.P.A. van Deursen, P.M. van Dijk, J.A.P.H. Vermulst and C. Wesseling, 2000, The impact of climate change on the river Rhine and implications for water management in the Netherlands, Summary report of the NRP project 952210. RIZA report 2000.010, June 2000.

Prudhomme, C., N. Reynard and S. Crooks, 2002, Downscaling of global climate models for flood frequency analysis: where are we now? Hydrological Processes, 16, 1137 - 1150, doi:10.1002/hyp.1054.

Räisänen, J., 2002, CO2-induced changes in interannual temperature and precipitation variability in 19 CMIP2 experiments. Journal of Climate, 15, 2395 2411.

Shabalova, M.V., W.P.A. van Deursen and T.A. Buishand, 2003, Assessing future discharge of the river Rhine using regional climate model integrations and a hydrological model. Climate Research, 23, 233 - 246.

Veen, R. van der; Lammersen, R.; Kroekenstoel, D.F. und Brinkmann, M., 2004a, Effects of extreme floods along the Niederrhein (Lower Rhine), section Input data for the DSS Lower Rhine and Rhine branches; (in German: ISBN 9036956668, in Dutch: ISBN 9036956714).

Veen, R. van der; Kroekenstoel, D.F. und Brinkmann, M., 2004b, Effects of extreme floods along the Niederrhein (Lower Rhine); section Results DSS Lower Rhine and Rhine branches; (in German: ISBN 9036956676, in Dutch: ISBN 9036956722).

de Wit, M. and A. Buishand, 2007, Generator of Rainfall And Discharge Extremes (GRADE) for the Rhine and Meuse basins. RIZA report 2007.027, KNMIpublication 218.

de Wit, M., H. Buiteveld and W. van Deursen, 2007. Klimaatverandering en de afvoer van Rijn en Maas. RIZA memo: WRR/2007-006, Arnhem, juni 2007. 


\section{Addendum - Sea level rise in foreign policy documents}

Local sea level and vulnerability to sea level change can differ significantly from the projected global average. That is why many countries publish their own projections to be used in the internal policy-making processes. In Table $\mathrm{C} 1$ there is a brief overview of some of these advised sea level rise values. Most of these documents use 1990 as a reference year.

Australia: In the latest Climate Change in Australia Technical Report (2007), the projections from the IPCC AR4 (Meehl et al., 2007) are cited. The report warns, however, that higher values are possible. Based on model studies, values $10 \mathrm{~cm}$ above the global average are given for the east coast in 2070.

Germany: The German Advisory Council on Global Change estimated that global sea-level rise may become as high as $3-5 \mathrm{~m}$ by the year 2300 . These estimates are based assumption of $3^{\circ} \mathrm{C}$ global warming. (WBGU, 2006, pp. 37)

Table C.1: Sea level rise, advised values of selected countries

\begin{tabular}{|l|l|l|l|l|}
\hline \multicolumn{1}{|c|}{ Country } & \multicolumn{3}{|c|}{ Sea level rise (m) } & \multicolumn{1}{c|}{ Source } \\
\hline & 2050 & 2100 & 2300 & \\
\hline Australia & & $\begin{array}{l}\text { IPCC 2007 } \\
\text { with } \\
\text { provision } \\
\text { for higher } \\
\text { values }\end{array}$ & & $\begin{array}{l}\text { Climate Change in Australia - } \\
\text { Technical Report 2007 }\end{array}$ \\
\hline Germany & & $3-5$ & WBGU, 2006 \\
\hline UK & 0.35 & 0.79 to & & DEFRA, 2006 \\
\hline $\begin{array}{l}\text { USA, along the } \\
\text { mid-Atlantic } \\
\text { coast }\end{array}$ & & 0.30 to 0.90 & & $\begin{array}{l}\text { Background Documents Supporting } \\
\text { Climate Change Science Program, } \\
\text { 2008 }\end{array}$ \\
\hline \begin{tabular}{l} 
USA, California \\
\hline
\end{tabular} & & 0.50 to 1.40 & & $\begin{array}{l}\text { Delta Vision "Blue Ribbon" Task Force, } \\
\text { 2008 }\end{array}$ \\
\hline
\end{tabular}

UK: DEFRA gives 'allowances', or methodology for the calculation of the rates of sea-level rise for different parts of the country up to 2115 . These allowances are used as a guidance for coastal defence planning. In its latest update from 2006 DEFRA replaces the simple linear interpolation used previously with exponential 
one. The highest projected levels are for eastern England: $35 \mathrm{~cm}$ for 2050 and 98 $\mathrm{cm}$ for 2100. Projections of storm surges and waves are not included. By the end of 2008, DEFRA is expected to come with new report and new projections for sea level rise. (DEFRA, 2006)

USA (California): Estimates for the full range of sea level rise in 2100 are in the range $50-140 \mathrm{~cm}$. The recommendation is given in March 2008 by Delta Vision "Blue Ribbon" Task Force, an independent unit appointed by the governor and responsible for recommending future actions to achieve a sustainable Delta and water resources for California. (personal communications)

\section{References}

Background Documents Supporting Climate Change Science Program Synthesis and Assessment Product 4.1: Coastal Elevations and Sensitivity to Sea Level Rise, J.G. Titus and E.M. Strange (eds.), 2008. EPA 430R07004. U.S. EPA, Washington, DC

Climate Change in Australia - Technical Report, 2007.

http://www.climatechangeinaustralia.gov.au/resources.php

DEFRA, 2006, Flood and Coastal Defence Appraisal Guidance, FCDPAG3 Economic Appraisal, Supplementary Note to Operating Authorities - Climate Change Impacts, October 2006, London.

Delta Vision "Blue Ribbon" Task Force, 2008 (personal communications)

WBGU, 2006, The Future Oceans - Warming Up, Rising High, Turning Sour, Berlin, ISBN 3-936191-14-X. http://www.wbgu.de/wbgu_sn2006_en.html 


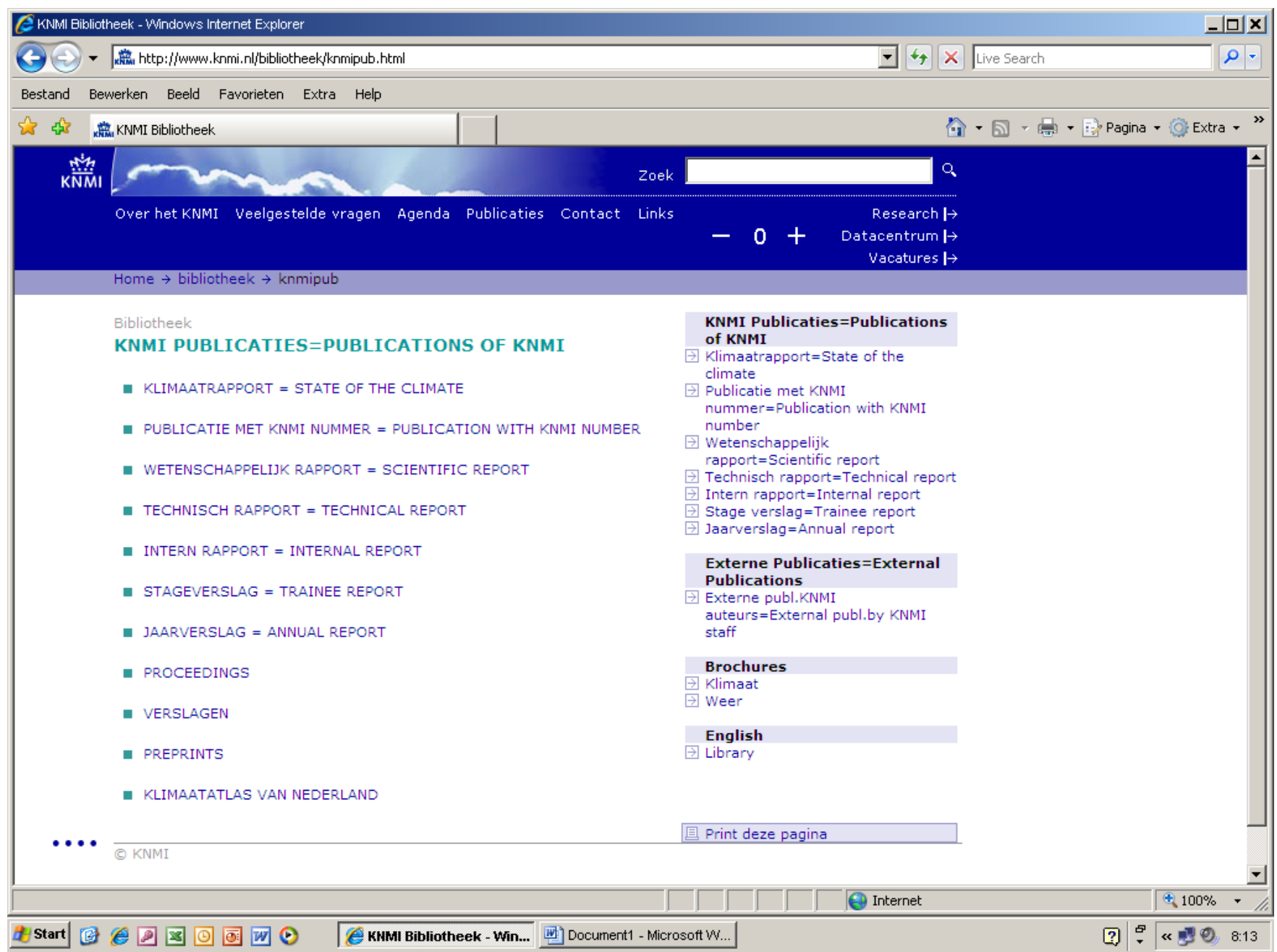

All titles of KNMI-publications (and a full text PDF for the most recent ones) can be found on

\section{http://www.knmi.nl/bibliotheek/knmipub.html}

If you have any questions, please contact us: bibliotheek@knmi.nI 


